\title{
A Methodology for Analyzing
}

Precursors to Earthquake-Initiated

and Fire-Initiated Accident

\section{Sequences}

Manuscript Completed: March 1998

Date Published: April 1998

Prepared by

R.J. Budnitza, H.E. Lambert ${ }^{2}$, G.Apostolakis ${ }^{b}$,

J.K. Salas ${ }^{b}, J-S ~ W u^{c}$, M.K. Ravindra ${ }^{d}$

${ }^{2}$ Future Resources Associates, Inc.

2039 Shattuck Avenue, Suite 402

Berkeley, CA 94704-1150

'Massachusetts Institute of Technology

Cambridge, MA 02139-4307

'Advanced System Concepts Associates

Rolling Hills Estates, CA 90274

DISTRIBUTION OF THIS DOCUMENT IS UNLIMITED

${ }^{`} \mathrm{EQE}$ International, Inc.

Newport Beach, CA 92660-2037

H.J. VanderMolen, NRC Project Manager

MASTER

\section{Prepared for}

Division of Systems Technology

Office of Nuclear Regulatory Research

U.S. Nuclear Regulatory Commission

NRC Job Code W6555

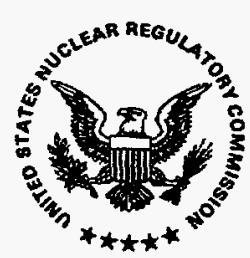




\section{DISCLAIMER}

This report was prepared as an account of work sponsored by an agency of the United States Government. Neither the United States Government nor any agency thereof, nor any of their employees, makes any warranty, express or implied, or assumes any legal liability or responsibility for the accuracy, completeness, or usefulness of any information, apparatus, product, or process disclosed, or represents that its use would not infringe privately owned rights. Reference herein to any specific commercial product, process, or service by trade name, trademark, manufacturer, or otherwise does not necessarily constitute or imply its endorsement, recommendation, or favoring by the United States Government or any agency thereof. The views and opinions of authors expressed herein do not necessarily state or reflect those of the United States Government or any agency thereof. 


\section{DISCLAIMER}

Portions of this document may be illegible electronic image products. Images are produced from the best available original document. 


\section{ABSTRACT}

This report covers work to develop a methodology for analyzing precursors to both earthquake-initiated and internal fire-initiated accidents at commercial nuclear power plants. Currently, the U.S. Nuclear Regulatory Commission sponsors a large ongoing project, the Accident Sequence Precursor project, to analyze the safety significance of other types of accident precursors, such as those arising from internally-initiated transients and pipe breaks, but earthquakes and fires are not within the current scope. The results of this project are that (i) an overall step-bystep methodology has been developed for precursors to both fire-initiated and seismic-initiated potential accidents; (ii) some stylized case-study examples are provided to demonstrate how the fully-developed methodology works in practice, and (iii) a generic seismic-fragility data base for equipment is provided for use in seismic-precursor analyses. 



\section{TABLE OF CONTENTS}

ABSTRACT $\ldots \ldots \ldots \ldots \ldots \ldots \ldots \ldots \ldots \ldots \ldots \ldots \ldots \ldots \ldots \ldots \ldots \ldots \ldots \ldots \ldots \ldots \ldots$

TABLE OF CONTENTS $\ldots \ldots \ldots \ldots \ldots \ldots \ldots \ldots \ldots \ldots \ldots \ldots \ldots \ldots \ldots \ldots \ldots$

EXECUTIVE SUMMARY $\ldots \ldots \ldots \ldots \ldots \ldots \ldots \ldots \ldots \ldots \ldots \ldots \ldots \ldots \ldots \ldots \ldots \ldots \ldots \ldots$

ACKNOWLEDGMENTS $\ldots \ldots \ldots \ldots \ldots \ldots \ldots \ldots \ldots \ldots \ldots \ldots \ldots \ldots \ldots \ldots \ldots \ldots$

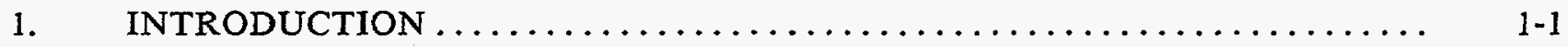

1.1 Objective of the Project.......................... 1-1

1.2 Identification of the Problem $\ldots \ldots \ldots \ldots \ldots \ldots \ldots \ldots \ldots \ldots \ldots, 1-1$

$1.3 \quad$ Significance of the Problem ...................... $1-2$

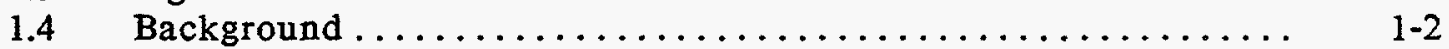

1.5 Technical Approach to the Project $\ldots \ldots \ldots \ldots \ldots \ldots \ldots \ldots \ldots \ldots$ 1-3

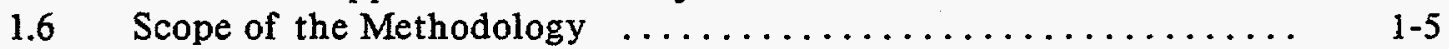

$1.7 \quad$ Specific Project Results ...................... 1-6

2. GENERAL DESCRIPTION OF THE ASP PROGRAM $\ldots \ldots \ldots \ldots \ldots \ldots \ldots \ldots . \ldots 2-1$

2.1 General Purpose of the ASP Program ................ $2-1$

2.2 Objectives of the ASP Program .................. $2-1$

$2.3 \quad$ ASP Methodology Approach ...................... $2-2$

$2.4 \quad$ Event Sequences Requiring Calculation. ............... 2-3

2.5 ASP Criteria for Documenting an Events as a Precursor ....... 2-4

3. STRUCTURE \& CRITERIA FOR SCREENING AND ANALYSIS $\ldots \ldots \ldots \ldots .3-1$

3.1 Objective of this Chapter ........................

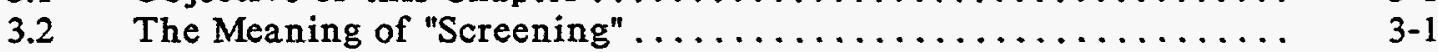

3.3 A Three-Step Process ........................... 3-1

3.4 Safety Insights vs. Designation as a "Precursor"............ 3-1

3.5 Considerations Applied in Developing the Screening Criteria .... 3-2

3.6 Screening and Analysis Guidance for Earthquake-Related LERs. . 3-3

3.6.1 A Seismic "Configuration-Compromise" LER ...... 3-3

3.6.2 Non-Seismic Failures that Could Affect Seismic-

Initiated Accident Sequences ........... 3-12

3.7 Screening and Analysis Guidance for Fire-Related LERs ..... 3-15

3.7.1 A Fire "Configuration-Compromise" LER ........ 3-15

3.7.2 An Actual Fire Reported in an LER ........... 3-24

Non-Fire Failures that Could Aff ect Fire-
Initiated Accident Sequences $\ldots \ldots \ldots \ldots \ldots \ldots \ldots . \ldots \ldots$

3.8 Back-Up Explanations for This Chapter $\ldots \ldots \ldots \ldots \ldots \ldots \ldots . . \ldots \ldots$ 3-44

3.8.1 Three-Step Screening . . . . . . . . . . . . . . . $3-44$

3.8.2 Seismic Margin Methodology $\ldots \ldots \ldots \ldots \ldots \ldots . . \ldots .44$ 
4. FIRE CASE STUDIES

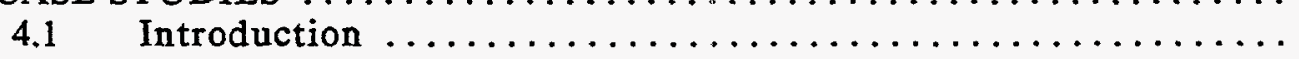

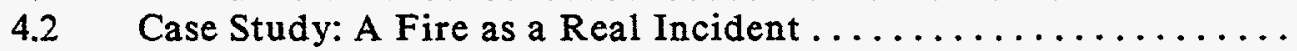

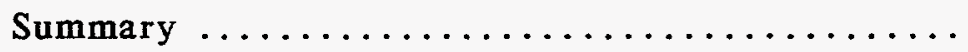

ASP Fire Review . . . . . . . . . . . . . . . . .

4.3 Case Study: A Fire Configuration Compromise LER .........

4.4 Case Study: A Non-Fire-Related Failure LER ...............

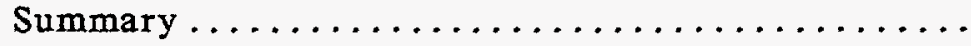

4.4 .3

Event Description

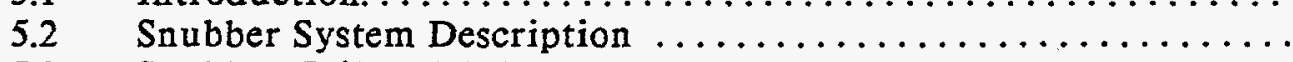

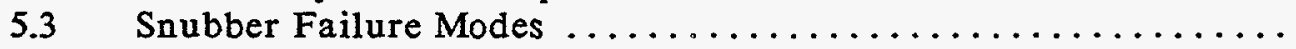

5.4 Failure to Lock Up . . . . . . . . . . . . . . . . . . .

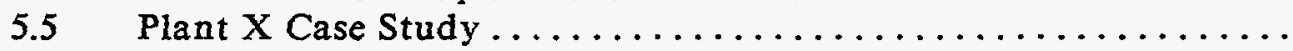

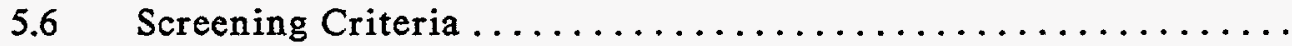

5.7 Back-Up Discussion for This Chapter

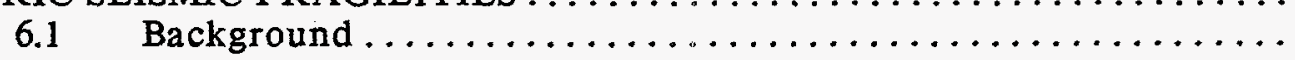


7. RECOMMENDATIONS CONCERNING NEEDED INFORMATION .......

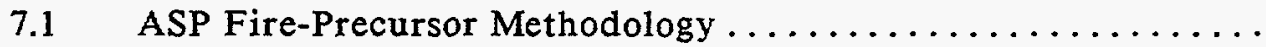

\section{LIST OF FIGURES}

Flow Diagram for Seismic Configuration LERs (4 sheets) ........... Flow Diagram for Non-Seismic-Failure LERs . . . . . . . . . . . . . Flow Diagram for Fire Configuration LERs (4 sheets). . . . . . . . . . Flow Diagram for Actual-Fire LERs (6 sheets) . . . . . . . . . . . . Flow Diagram for Non-Fire-Failure LERs $\ldots \ldots \ldots \ldots \ldots \ldots \ldots \ldots$

Schematic AC electrical distribution system of Plant $A \ldots \ldots \ldots \ldots \ldots$ Simplified P \& ID of the Residual Heat Removal System containing the involved interf acing system valves . . . . . . . . . . . . . . Interfacing System Loss of Coolant Accident event tree developed. . . . . . . Simplified sensitivity analysis for the failure probability for CLOSE vs. CCDP . . . . . . . . . . . . . . . . . . . . Schematic description of the postulated scenario in the

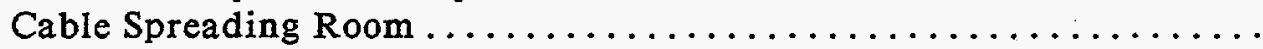
Results from uncertainty analysis for target $2-\mathrm{LHI}$ in the

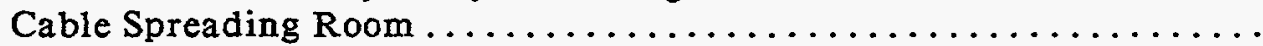
Results from uncertainty analysis for target 2-LMI in the

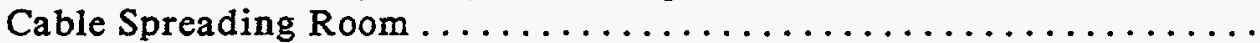
Impacted sequence in the Inadvertent Opening of a Safety Relief Valve

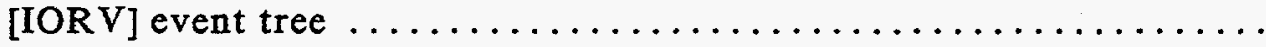

Paul Munroe/Enertech Hydraulic Snubber Schematic Diagram ..........

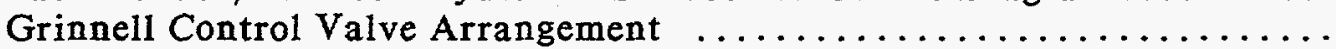
Characteristic Hydraulic Snubber Force and Velocity Time-History

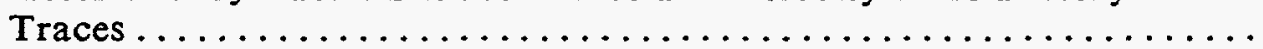

Comparison of the Best Estimate and Arithmetic Mean Seismic

Hazard Curves for the Plant-X Site . . . . . . . . . . . . . . . . .

Plant X, Safe Shutdown for Reactor Reactivity Control ..............

Plant X, Safe Shutdown for Reactor Coolant Inventory Control. .........

Plant X, Safe Shutdown for Decay Heat Removal. . . . . . . . . . . . . . . 


\section{LIST OF TABLES}

4.3.1 Input data for fire modeling of postulated scenario in the

Cable Spreading Room (15-page table) .................. 4-19

4.3.2 Definition and failure probabilities for basic events used on the quantification for the LER (2-page table)............... 4-34

4.3.3 Fire-related parameters used and results obtained in step $3(6 \mathrm{~A})$ Intermediate Screening ......................... $4-36$

4.3.4a Results from Montecarlo simulation using output data from

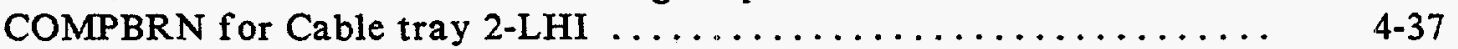

4.3.4b Results from Montecarlo simulation using output data from COMPBRN for Cable tray $2-\mathrm{LMI} \ldots \ldots \ldots \ldots \ldots \ldots \ldots \ldots \ldots \ldots$ 4-38

4.3.5 Fire-related parameters used and results obtained in step 3-C,

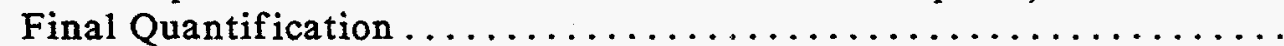

4.3.6 Quantification results for sequences of the Interfacing System

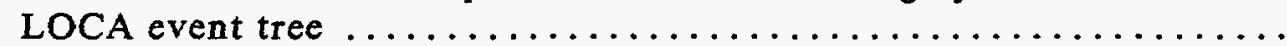

Sequence logic for dominant sequences identif ied for the LER .........

$4-40$

Conditional cut sets for higher probability sequences...............

4-41

Dominant sequence conditional probabilities and importance

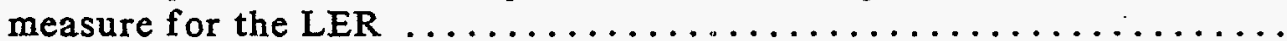

Definition and failure probabilities for basic events used on the quantification for the $\mathrm{LER} \ldots \ldots \ldots \ldots \ldots \ldots \ldots \ldots \ldots \ldots \ldots \ldots . \ldots \ldots$ 4.50

Higher probability cut sets for impacted sequence . . . . . . . . . . .

5-1 Snubber Failures for Plant X, Failure to Lock Up (8 page table) ......... 


\section{LIST OF ABBREVIATIONS}

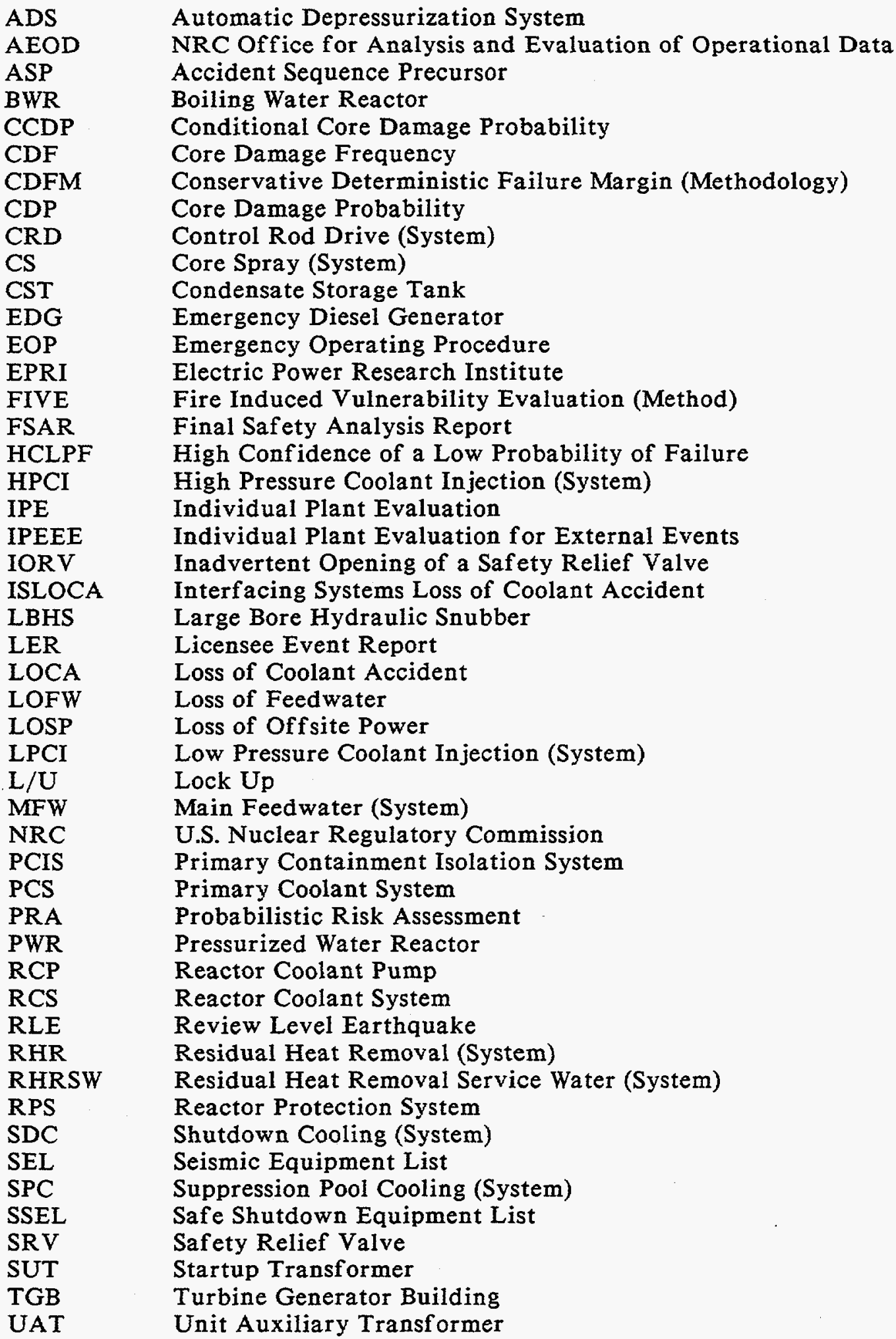





\section{EXECUTIVE SUMMARY}

\section{ES-1. Introduction}

The NRC Office for the Analysis and Evaluation of Operational Data (AEOD), established shortly after the TMI accident, has been the principal focus at NRC and indeed for the U.S. as a whole for analyzing operating data and operating events to understand their safety significance. One of AEOD's principal vehicles for performing their analysis has been the NRC-supported Accident Sequence Precursor (ASP) project. However, the current ASP methodology does not include precursors to earthquake-initiated or fire-initiated accident sequences, which is a significant gap in its coverage. Filling this gap is the subject of the work reported on here. Specifically, this project's purpose has been to develop a methodology for analyzing precursors to both earthquake-initiated and internal-fire-initiated accidents.

This gap in ASP's coverage is significant in light of the broadly accepted finding from the PRA literature that external events generally, and earthquakes and internal fires specifically, are of ten major contributors to the overall core-damage frequency and overall of fite risk from nuclear power plants. Obviously, there are numerous earthquake-related and fire-related "precursor events", both configuration-conpromise issues and some real fires, at our $100+$ operating power reactors, just as there are in other areas such as events initiated by LOCAs and internal-plant transients. However, the analysis of earthquake and fire precursors to obtain useful insights requires the development of different types of analytical tools and data-collection tools, tools specifically directed toward earthquake-initiated and fire-initiated accident sequences.

This project is especially timely now, because in earlier years, many nuclear power plants did not have a plant-specific PRA. Now, however, each plant has (or soon will have) a plant-specific PRA, many of them developed under the IPE program. This makes the application of our new methodology simpler and more effective, so that the potential for enhancing the benefits of the ASP insights will be great.

\section{ES-2. Categories of Precursors}

The methodology that we have structured, which relies on a PRA-type model, enables the ASP analyst to analyze the following different categories of precursors:

- $\quad$ fires: precursor fires as initiating events

- fires: precursor fire-configuration compromises

- fires: precursor non-fire failures

- earthquakes: precursor seismic-configuration compromises

o earthquakes: precursor non-seismic failures.

There have been almost no actual earthquakes that have affected nuclear power plants, nor are many expected, so we have not developed methods for evaluating the 
category "precursor earthquakes as initiating events". Rather, we anticipate that the "seismic" precursors will mostly be seismic-configuration compromises, such as inadequate anchorage issues or proximity issues.

\section{ES-3. Structure of the Methodology}

The methodology includes a pre-screening step, Step 1 (to screen out the unimportant precursor candidates prior to detailed analysis), followed by an intermediatescreening step, Step 2, requiring preliminary analysis, followed if necessary by a detailed-analysis step, Step 3. In this Executive Summary, only the structure of the methodology will be discussed: the details are in the full report. The three Steps are described as follows:

- Step 1 -- "Screening", whose aim is to sort out (eliminate from further evaluation) an LER that clearly will not ultimately be designated as a "precursor". Other LERs are passed on to Step 2. This step is envisioned as requiring no actual analysis but rather merely a comparison of the information in the LER to certain specific Step-1 criteria. Screening an LER in in Step 1 only implies that one cannot conclude without further evaluation whether or not it is worthy of ultimate designation as an "Accident Sequence Precursor."

Step 2 -- "Preliminary Analvsis", whose aim is to perform enough analysis to decide whether a given LER can be screened out (eliminated) based on comparison with specific Step-2 criteria, or requires additional analysis to ascertain whether or not it is an "Accident Sequence Precursor."

- Step 3 -. "Detailed Analvsis", whose aim is to subject a limited fraction of the LERs to detailed analysis if, based on specific Step-2 criteria, it is judged that Step-3 analysis is justified.

The NRC's ASP program, which currently studies only internal-initiated events, only documents Step-3-type "Precursors."

Our conception is that of the LERs that reach the Step-2 preliminary-analysis stage, we still only expect a modest fraction of them (rather than most or all of them) to be passed to the Step-3 stage. Specifically, of those that survive the Step-1 screening, the Step-2 "preliminary analysis" (i) may indicate that no new safety insights are obtainable from the LER; or (ii) may reveal those insights; or (iii) may indicate that the extensive analysis of Step 3 will be required to probe at a deeper level. In fact, some LERs that get to Step 3 will, upon in-depth analysis, be found not to meet the "Precursor" criteria. This situation is fully acceptable.

\section{ES-4. Considerations in Developing the Screening Criteria}

1) Conservative: --- During the Step-1 screening, LERs will be retained unless they can be affirmatively screened out, not the other way around. This is consistent with current ASP practice for internal faults.

2) Equivalence: We have tried to be roughly equivalent to the internal-faults ASP screening criteria where feasible. This criterion uses $10^{-6} /$ year conditional core damage frequency (CCDP), given the precursor, as a screening level. 
3) Ease of discrimination: The Step-1 screening criteria enables the analyst to discriminate easily between those LERs that are obviously not of much ASP interest and the others.

4) Rigor: The screening criteria cannot be rigorous and should not pretend to be. We have established a methodology so that considerable analyst judgment must be involved -- in fact, it is envisioned that no workable screening criterion can avoid such analyst iudgment in the fire and seismic areas!

\section{ES-5. Additional Information}

The full report also contains the following important sections:

- a multi-sheet block-diagram flow sheet for each of the individual methodologies to guide the analyst/user;

- several stylized case studies, derived from actual LERs, that illustrate how the methodological steps work in actual practice;

- a compilation of generic seismic fragilities for various categories of equipment, for use in applying the seismic-LER methodology; and

- recommendations concerning information that will be needed, but is not yet fully available, to implement the various methodological steps ef fectively. 


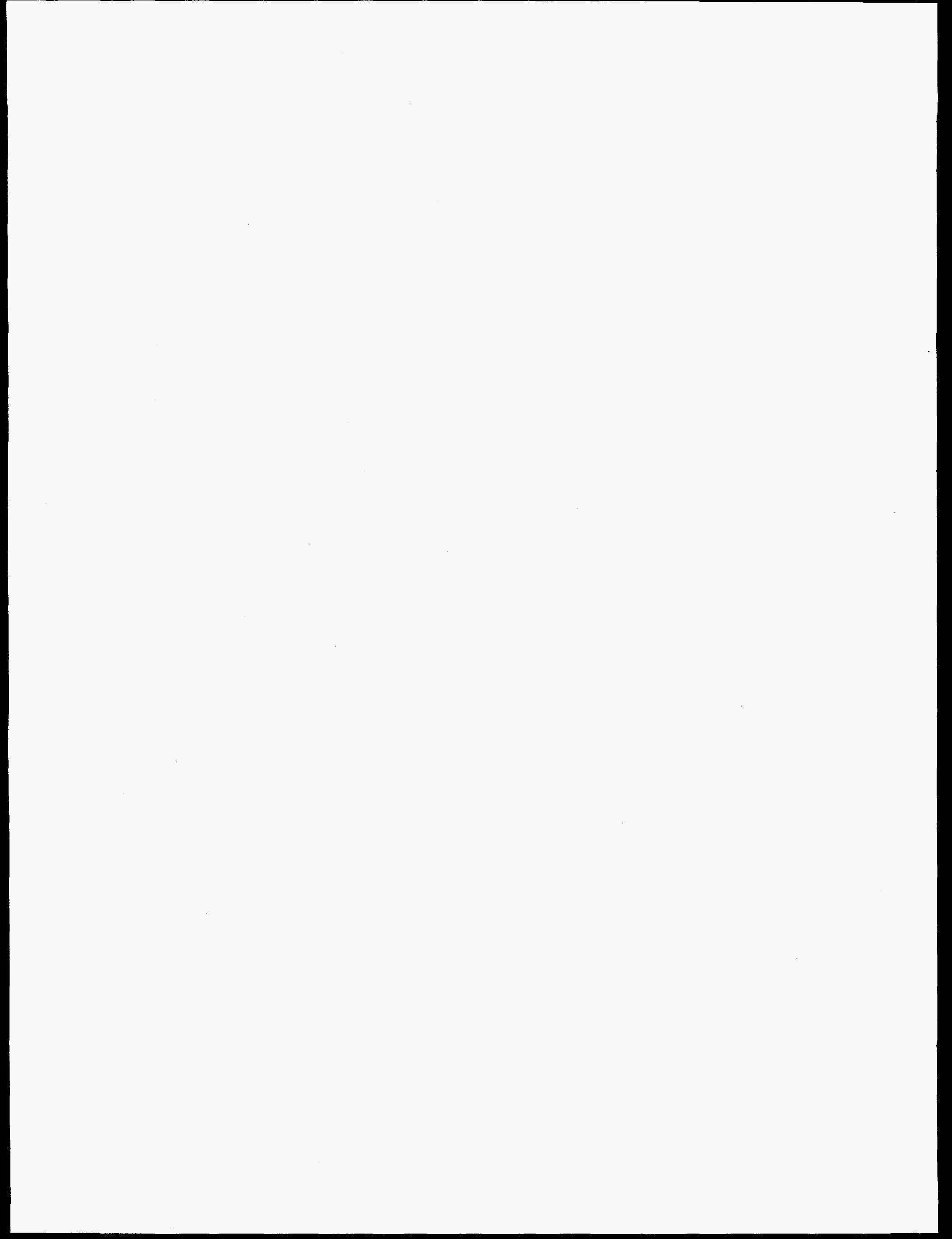




\section{ACKNOWLEDGMENTS}

This project has been supported by the U.S. Nuclear Regulatory Commission under contract NRC-04-95-037, "Development of a Methodology for Analyzing Precursors to Earthquake-Initiated and Fire-Initiated Accident Sequences", as a Phase-II project under the NRC's Small Business Innovation Research Program. J.S. Hyslop of NRC's Office of Nuclear Regulatory Research provided technical liaison with the project team.

The project could not have been effectively accomplished without the insights gained from the much larger Accident Sequence Precursor program that NRC has supported for more than 15 years. We wish to thank all the many participants in that project for their excellent work, and in particular Joseph Minarick of Science Applications International Corporation, who provided important advice to our team during our work. We also wish to thank Stanley $T$. Jones, whose work as one of the collaborators in the Phase-I project provided the groundwork for the successful completion of this Phase-II effort. 


\section{INTRODUCTION}

\subsection{Objective of the Project}

The broad objective of this project is to develop a methodology for analyzing precursors to both earthquake-initiated and internal fire-initiated accidents at commercial nuclear power plants. The project has been executed in two phases, of which this report covers the second phase; the first phase, whose final report was published in early 1995 (FRA, 1995), had the limited objective of demonstrating that developing such a precursor methodology for earthquakes and internal fires is fully feasible. The purpose of this second phase has been to carry out the development of the complete methodology and to document it. A key consideration has been to assure integration with the existing internal-events methodology for Accident Sequence Precursor (ASP) analysis (Minarick, 1990; ASP, 1994).

\subsection{Identification of the Problem}

The NRC Office for the Analysis and Evaluation of Operational Data (AEOD), established in 1979 shortly after the Three Mile Island accident, has been the principal focus at NRC and indeed for the U.S. as a whole for analyzing operating data and operating events at nuclear power plants to understand their safety significance. One of AEOD's principal vehicles for performing their analysis has been the Accident Sequence Precursor (ASP) Program (Minarick, 1990; ASP, 1994).

The ASP Program forms the basis and the backdrop for the work here. Specifically, this methodology-development effort is intended to provide supplementary tools so that the ASP Program can analyze earthquake- and fire-related operational precursor events. We will not discuss the ASP analysis methodology in detail here; a short discussion of its structure can be found in Chapter 2 below, where we will provide relevant details about those crucial aspects of the ASP methodology that interact with the methodological guidance presented here, including ASP's screening rules.

The ASP Program broadly defines a "precursor" as either an operational event or a configuration change at a nuclear power reactor that represents a significant potential to develop into a severe accident -.- had other failures occurred that in fact did not occur. Of course, the notion of a precursor is that no actual severe core-damage accident has actually occurred.

As we will discuss in more detail in Chapter 2 below, the ASP Program analyzes these precursors to develop insights into their safety significance. The principal vehicle for the ASP analysis is the development of a conditional core-damage probability (CCDP), given the events that actually did occur.

In January 1992, NRC sponsored a workshop in Annapolis entitled "NRC Workshop on the Use of PRA Methodology for the Analysis of Reactor Events and Operational Data" (NRC, 1992). At that workshop, one recommendation was that the ASP program should be extended to cover precursors to seismic-initiated and internal fire-initiated events, which are not presently covered within ASP's scope. 
The fact that precursors to neither earthquakes nor internal fires are currently within ASP's scope is a significant gap in its coverage. Filling that gap is the subject of this project.

\subsection{Significance of the Problem}

The gap in ASP's coverage is significant in light of the broadly accepted finding from the PRA literature that "external initiating events" generally, and earthquakes and internal fires specifically, are of ten major contributors to the overall core damage frequency and overall offsite risk from nuclear power plants. Obviously, there must be numerous "precursor events" at the U.S.'s $100+$ operating power reactors in the earthquake and fire areas, just as there are in other areas such as events initiated by pipe breaks, power interruptions, operator errors, and various other internal plant transients. However, the analysis of earthquake and fire precursors (including configuration-compromise problems) to obtain usef ul insights requires the development of different types of analytical tools and data collection tools: tools specifically directed toward earthquake-initiated and fire-initiated accident sequences.*

It is important to note here that today the analysis of accident precursors at U.S. nuclear power plants is not the sole province of NRC/AEOD and its contractors. Today, many of the utilities have or are developing in-house PRA expertise, and a few or them are now routinely analyzing operating data and events -- both from their own plants and more broadly. Therefore, the methodology being developed here should benefit both the NRC and the commercial nuclear power-plant industry.

\subsection{Background}

There is no doubt today that PRA methods are one of the most important ways to learn about the safety of nuclear power plants. The IPE (NRC, 1988) and IPEEE (NRC, 1991) efforts over the past few years at all U.S. nuclear power plants have resulted in PRA-type internal-initiator analyses for each operating plant, and in similar evaluations, although not always PRA-based, for the "external" initiators, of which earthquakes and internal fires are usually the most important. (Actually, although the IPE program has been completed, a few plants' IPEEE evaluations will not be completed until mid-1997.)

The ASP (Accident Sequence Precursor) program that NRC has supported for the past decade and a half has been one of the major beneficial applications of PRA methods. Now that each plant has a plant-specific internal-initiators PRA and corresponding earthquake and internal-fire evaluations, the potential for enhancing the benefits of the ASP insights will be great. However, as mentioned above, the

There are several other types of "external initiators", such as high winds, external floods, offsite explosions, and so on that may have potential safety significance at an individual plant but are not explicitly covered by the methodology here or elsewhere. However, the authors of this report believe that the methodology developed here for earthquake precursors can be readily adapted to any of these other offsite hazards if a specific operational event involving such a hazard were to arise. 
ASP methodology is incomplete in that it does not cover accidents initiated by earthquakes and internal fires.

With the improvements to the ASP methodology that will result from incorporating earthquakes and internal fires, several different types of insights will become available. The major new insights will be about initiating events; important components and systems; the role of human errors; common-cause failures; regulatory requirements; and possible new research topics.

The modeling and analysis of accidents initiated by external events such as fires and earthquakes are different than for accidents initiated by internal plant faults. External events can induce accident sequences that are not considered in an internal-events model and that may have unique common-cause failure effects. For example, passive failures are important in the analysis of earthquakes and fires. Typically, most passive failures are excluded from internal-events analysis due to their low probability of occurrence -- for example, the failure of multiple power cables would be very rare except from fires, and multiple failures of relays would be very rare except if they were to chatter in a large earthquake. In addition, external hazards may introduce new failure modes for active components, such as seismic-induced anchorage failures. Often, the externally-caused multiple failures involve losses of critical support systems such as ac (motive power) and/or dc (control power) to safety equipment that would not be considered in the same way in an internal-events analysis. It is for these reasons that the methodology for analyzing potential accident precursors from internal plant faults is not directly applicable for analyzing precursors of potential sequences initiated by fires and earthquakes.

\subsection{Technical Approach to the Project}

As mentioned above, the technical approach to this project was to begin with a first-phase scoping study, which was published in early 1995 (FRA, 1995), to demonstrate the feasibility of the larger methodology effort. The success of that scoping study led to the full-scale project reported on here.

Our technical approach -- our plan of attack -- has been to consider separately the different types of LERs that might involve safety compromises related to fires and earthquakes. Here by "types" we mean LERs sorted into those that report (i) firerelated or seismic-related failures, and then sorted into (ii) these failures as initiating events or as consequent failures. Our methodology guidance is structured separately for these different types of accident-sequence categories.*

The core of our work here is the methodological guidance that the ASP Program can use to examine potential earthquake-initiated and fire-initiated accident sequences. Certain modeling approaches turn out to be very useful, while others turn out not to be, based on whether the available information from the LERs (and other sources) is

It is important to note, as will be discussed below in greater detail, that the types of precursor data and events that are most interesting are less likely to be events initiated by precursor earthquakes and fires themselves (although actual precursor fires do, of course, occur) than precursor information involving configuration problems, or non-earthquake and non-fire failures, that can contribute to earthquake and fire sequences. 
or is not able to support a useful analysis. We have assumed that the existing analytical methods used by the various nuclear plants for the IPEEE program (NRC, 1991) are the points-of-departure for our modeling recommendations. For fires these have included both the fire PRA methodology (NRC, 1983; Apostolakis, 1993; LaSalle, 1993) and the FIVE (Fire Induced Vulnerability Evaluation) methodology (FIVE, 1993). For earthquakes these have included both the seismic PRA methodology (NRC, 1983; Brookhaven, 1985) and the seismic margin methodologies (NRC, 1985b; NRC, 1986; EPRI, 1988).

Our evaluation has included discussion of several case studies that demonstrate the principal issues covered. These case studies, which are based on actual LERs but are somewhat stylized for tutorial purposes, use existing information (from LERs) and one or more models suggested as ASP extensions to demonstrate how our recommended approaches can provide useful insights, and how our guidance can be applied in practice.

We believe it important to point out that the available precursor information that can cast light on potential earthquake-initiated accident sequences is quite different than for most other types of initiators. There have been no actual earthquake events of safety significance at any operating U.S. nuclear power plant (nor overseas either), and such earthquakes will never be frequent. The following discussion will show why. The PRAs reveal that the most seismically fragile aspect of the nuclear plants is their offsite power systems, because of the seismically weak ceramic switchyard insulators and of fsite transmission lines. At typical eastern-U.S. sites the recurrence rate for seismic-caused loss-of-offsite power (LOSP) is analyzed to be in the range of about or below 0.001 per year. Everything else of safety significance is generally found to be seismically stronger, requiring larger and hence rarer earthquakes to cause damage. This explains why damaging earthquake events per se, even earthquakes that would only cause LOSP but no other damage, are thought to be very rare.

However, one of the principal lessons from the seismic-PRA literature is that a large fraction (perhaps a majority, depending on how one counts) of the important seismic-initiated sequences involve a combination of seismic-caused failures plus non-seismic-caused failures or human errors (Budnitz, 1984; NRC, 1984a; Budnitz and Lambert, 1989; NRC, 1990). A significant fraction of the "precursor events" relevant to earthquakes may turn out to be non-seismic events that compromise various safety functions, such that the plant is vulnerable and its ability to withstand a major earthquake is significantly degraded.

The issues surrounding internal fires are quite different: fire-initiated accident sequences have specific characteristics different from those of sequences initiated by other internal plant faults (pipe breaks, transients, etc.). The most obvious characteristic is that fires damage collocated equipment, but there are other special characteristics as well. Because fires can damage front-line systems together with support systems (ac, dc, instrument air, service water, HVAC, etc.), their potential to cause sequences dominated by common-cause failures is greater than for sequences initiated by other internal plant faults. Especially for sequences involving some firecaused damage coupled with other equipment failures due to random (non-fire) problems and human errors, the combinations of potential vulnerabilities are very different. Furthermore, and crucially, even though the nuclear plants experience numerous small and some larger fires each year, it is likely that many of the 
"precursor events" of interest in the fire area may not be events involving fires at all, but rather (as with earthquakes) events involving other failures, or configuration problems, that can place the plant in a highly vulnerable status if a fire were to start.

As mentioned above, our technical approach has been to examine the PRA literature and the operating experience, derive insights from them, and build our guidance and recommendations on those insights.

\subsection{Scope of the Methodology}

Licensee Event Reports (LERs): The methodology discussed herein is intended for the review of Licensee Event Reports (LERs) that are reported by U.S. nuclear power plants to the U.S. Nuclear Regulatory Commission, under NRC rules in Title 10, Part 50.73 of the Code of Federal Regulations (see also [NRC, 1994]). LERs report operational situations that are out-of-the-ordinary and that have at least a modicum of safety significance. There are specific reporting rules, including thresholds below which the situation as discovered need not be reported; we will not discuss these here. Suffice it to say that over a thousand LERs are reported each year to the NRC, and that their analysis for precursor insights through NRC's ASP program is our subject here.

Throughout this report, we shall refer to LERs as the sole source of the reported abnormalities. However, we recognize that the ASP program also analyzes information from other sources. Nevertheless, for brevity's sake, we will write this report as if the LERs are the sole source of input to the ASP analysis, and will of ten refer to what an LER reports without due recognition that other sources of relevant information exist.

Categories of Seismic and Fire Precursor LERs: The methodology that we have structured enables the ASP analyst to analyze the following different categories of potential precursors. The groupings have been made for analytical convenience--specifically, the guidance in the body of this report will require different screening and analysis steps for these different categories:

o earthquakes: precursor seismic-configuration compromises (Section 3.6.1)

- earthquakes: precursor non-seismic failures (Section 3.6.2)

o fires: precursor fire-configuration compromises (Section 3.7.1)

- $\quad$ fires: precursor fires as initiating events (Section 3.7.2)

o fires: precursor non-fire failures (Section 3.7.3).

There have been almost no actual earthquakes that have affected nuclear power plants, nor are many expected, so we have not developed methods for evaluating the category "precursor earthquakes as initiating events". Rather, we anticipate that the "seismic" precursors will mostly be seismic-configuration compromises, such as inadequate anchorage issues or proximity issues.

It is important to observe here that sometimes an LER reports about an actual fire

$$
1-5
$$


that, upon review, has little to do with the main safety issue(s) involved with the LER, including having caused no important damage. In these cases, where the fire was not the cause of the event, but was caused by some undesired aspect of the event, the ASP analyst will sometimes realize upon review that the fire may really be a side-issue. For these cases, we have provided guidance to perform the A.SP analysis using the normal internal-plant-faults ASP methodology, with appropriate additional study of the fire as a potentially interesting side issue.

Availability of Plant-Specific Fire and Seismic Analyses as the Basis for the Methodology Here: The methodology here is structured to take advantage of the fact that all U.S. nuclear plants have recently performed a plant-specific PRA for internal-plant-fault initiators, as part of the IPE Program; and have also completed both seismic and fire evaluations as part of the IPEEE Program. The guidance provided here specifically requires using these internal-events PRA models and external-events IPEEE models (or their equivalent) and their supporting data.*

Unfortunately, as the guidance below will describe, some of the plants' IPEEE evaluations are not as useful for fire and seismic ASP precursor evaluations as they could be. Specifically, if a plant's IPEEE fire evaluation used other than the firePRA approach (for example, if it used only the FIVE methodology (FIVE, 1993) and especially if the plant found that everything is screened out), or if its seismic evaluation used the seismic-margin method (NRC, 1985b; NRC, 1986; EPRI, 1988) rather than the seismic-PRA method, the plant-specific models will not be as useful for the ASP reviews discussed here. The limitations, and the reasons for them, are discussed in detail below.

\subsection{Specific Project Results}

This project has produced four broad types of results, as follows:

(1) The overall step-by-step structure has been developed and is presented for a methodology for incorporating earthquake-initiated and internal-fire-initiated events into the analysis of accident sequence precursors. This includes both screening steps and analysis steps (Chapter 3). The methodological guidance includes the description, step-by-step, of how such a methodology is to be carried out, and also includes guidance as to the considerations, advantages, and limitations of the methodology as it is used in various different situations.

(2) Several case-study examples have been provided, for both fires (Chapter 4) and earthquakes (Chapter 5), to demonstrate how the fully-developed methodology

This means that the ASP analyst will require meaningful access to the plantspecific fire and seismic models and their supporting data. Both systems models and fire/seismic models are needed, in a form that allows the ASP analyst to manipulate them and to perform sensitivity studies with them. The analyst will also need access to the plant's internal-initiator PRA models and data. Fortunately, engineers at the Idaho National Engineering Laboratory under NRC support are in the process of "computerizing" these internalinitiator PRA models onto a user-friendly system (Sattison et al., 1995). This will help enormously in the screening and analysis work outlined here, even if no further "computerization" of the fire and seismic models is accomplished. 
works in practice.

(3) A compilation has been developed of generic seismic fragilities for equipment that can be used in ASP studies of earthquake-configuration precursors (Chapter 6).

(4) Some recommendations have been identified for the development of additional information and models that will enhance the ASP analyst's ability to carry out the methodological guidance herein (Chapter 7). 


\section{GENERAL DESCRIPTION OF THE ASP PROGRAM}

\subsection{General Purpose of the ASP program}

The methodology developed and used for the ASP program is intended to produce a reasonable estimate of the safety significance of operational events at nuclear power plants, including observed human and system interactions. The collection of operational events from a unique database of historical system failures, multiple losses of redundancy, and infrequent core damage initiators. These events are useful in identifying significant weaknesses in design and operation.

Thus, the primary focus of the ASP program is the development of risk-related information from operational events reported in the LERs.

\subsection{Objectives of the ASP program}

The following quotation from the NRC's 1994 "ASP Program Plan" (ASP Plan, 1994) provides a good overview of the current ASP Program objectives:

"Identify and Rank Risk Significance of Operational Events: Historically, this was the purpose of the ASP Program and it remains the primary objective. .."

"Determine Generic Implications of an Operational Event/Characterize Risk Insights: ASP events provide insight into potential problems at other plants and bring to light generic issues. This can be done by analyzing the trends and patterns of the ASP events as a whole, and it can be done on an eventby-event basis. Most importantly any risk insights need to be fed back to NRR, the Regions, and to the nuclear industry. (Sometimes these insights, either individual events or groups of events, result in issuance of generic communications.)

"Provide Supplemental Information on Plant Specific Performance: ASP data is often used along with other performance data to report on plants at the Senior Management Meeting and in various agency studies. Distribution of event analyses to a wider audience and conducting ASP seminars with the staff will increase the understanding and usage of ASP.

"Provide a Check on PRAs: ASP data and insights should be compared with expectations based on PRAs and IPEs. This will gauge some of the uncertainties and will help identify some modeling errors or areas with important completeness problems.

"Provide an Empirical Indication of Industry Risk and Associated Trends: ASP can be used as one input into trending of industry risk implications of operating reactor experience. The degree to which ASP can be used to support this objective is limited because of the limited models and data..." 


\subsection{ASP methodology approach}

The following discussion, adapted from NRC's annual ASP compilation (ASP, 1994), is a good introduction to the methodology:

Two types of events are analyzed in the current ASP program. The first type is a precursor that includes an initiating event, such as a small-break loss-of-coolant accident (LOCA) or a loss of offsite power (LOSP). The second type is a precursor that involves a failure condition over a period of time during which an initiating event could (but, in fact, did not) occur. The first type is referred to as an Initiating Event Assessment and the second one as a Condition Assessment.

The current ASP methodology for analyzing operational events is developed in two steps. The first step, the screening process, is performed in order to select the events that appear to deserve a detailed review and to eliminate those events that are clearly unimportant. In the second step, those events retained in the first step are subjected to a detailed analysis, which is intended to identify those considered to be precursors to potential severe core damage accidents.

Criteria utilized in the screening process: The NRC ASP compilation (ASP, 1994) states as follows:

"Events are identified for further consideration if they include:

- "All CD [core damage] initiators (LOOP, LOCA, steam pipe breaks \{PWR\})

- $\quad$ "All events where a trip was demanded

- "All failures in support systems (cooling water systems, instrument air, instrumentation and control, electric power systems).

- $\quad$ All events where two or more failures occur

- "Any event or operating condition different from that expected according to design

- "Any other that, according to reviewer's experience, could have resulted in or significantly affected a sequence of events leading to potential severe core damage.

"Events [are] eliminated from further consideration as precursors if they involved, at most, only one of the following:

- "a component failure with no loss of redundancy,

- "a loss of redundancy in only one system,

- "a seismic design or qualification error,

- "an environmental design or qualification error,

- "a structural degradation,

o "an event that occurred prior to initial criticality,

$2-2$ 


$$
\begin{aligned}
& \text { - "a design error discovered by reanalysis, } \\
& \text { o "an event impact bounded by a reactor trip or LOFW, } \\
& \text { o "an event with no appreciable impact on safety systems, or } \\
& \text { o "an event involving only post-core damage impacts." }
\end{aligned}
$$

Note that among the items in this long list that are "eliminated from further consideration as precursors" are configuration problems that might lead to vulnerabilities in large earthquakes and fires. It is precisely those potential safety concerns that are the subject of this project.

\subsection{Event sequences requiring calculation}

The NRC ASP compilation (ASP, 1994) provides the following guidance to the ASP analyst:

"If an initiating event occurs as part of a precursor (i.e., the precursor consists of an initiating event plus possible additional failures), then use the accident sequence model associated with the initiator; otherwise, use all accident sequence models impacted by the observed unavailability.

"Initiating event probability: If an initiating event occurs as part of a precursor, then the initiating event probability used in the calculation is 1.0. If an initiating event does not occur as part of the precursor, then the probability used for the initiating event is developed assuming a constant hazard rate. Event durations (the period of time which the failure existed) are based on information included in the event report, if provided. If the event is discovered during testing, then one-half of the test period is typically assumed, unless a specif ic failure duration is identified.

"Component failure probability estimation: For components that are observed failed during the precursor, the associated basic event is set to "true". Associated common-cause basic events are revised to reflect the type of failure that has occurred. For components that are observed to operate successfully, or are not challenged during the event, a failure probability equal to the nominal component failure probability is utilized.

"Nonrecovery probability: If an initiating event or a total system failure occurred as part of the precursor, the basic event representing the probability of not recovering from the failure is revised to reflect the potential for recovery of the specific failures observed during the event. For condition assessments, the probability of nonrecovery is estimated under the assumption that the initiating event has occurred.

"Failures in support systems: If the support system is not included in the ASP model, the impact of the failure is addressed by setting impacted components to failed. The modeling of a support system recognizes that as long as the failure remains unrecovered, all impacted components are unavailable, but if the support system failure is recovered, all impacted components are also recovered. This can be modeled through multiple calculations which address the impact of failure and success of the failed component. Calculated core damage probabilities for associated cut sets for each case are normalized based on the likelihood of not recovering the support system failure." 


\subsection{ASP criteria for documenting an event as a precursor}

The criteria for when the ASP analysis leads to actually reporting of certain events as "Accident Sequence Precursors" are discussed as follows (ASP, 1994):

"Events were selected and documented as precursors to potential severe core damage accidents (accident sequence precursors) if the conditional probability of subsequent core damage was at least $1.0 \times 10^{-6}$. Events of low significance are thus excluded, allowing attention to be focused on the more important events. . .

"Other events that provided insights into unusual failure modes with the potential to compromise continued core cooling but were determined not to be precursors were also identified. These are documented as 'interesting events'. .

Note that if the Conditional Core Damage Probability (CCDP) corresponding to the operational event does not exceed the screening value of $10^{-6}$ established for use in the ASP program, then the LER is screened out.

The methodology here for LERs related to seismic- and fire-initiated accidents uses the same criteria as above. The intent is that, if the criteria are met, these LERs will be treated and documented exactly as the LERs involving internal plant faults have been treated and documented over the years, such as in (ASP, 1994). 


\section{STRUCTURE AND CRITERIA FOR SCREENING AND ANALYSIS}

\subsection{Objective of this chapter}

This chapter establishes a structure for screening and analysis of LERs relevant to earthquakes and internal fires. The structure comprises a series of steps or levels of screening followed by analysis.

\subsection{The meaning of "screening"}

The notion of "screening" as used in Step 1 below is that a quick, non-laborintensive evaluation should be able to sort those LERs that require or merit further evaluation from those that do not. Screening an LER out means that it will not be designated as an "Accident Sequence Precursor" and that no important new safety insights can be gained from evaluating it further. Screening an LER in during either Step 1 or 2 only implies that one cannot conclude without further evaluation whether or not it will be designated as an "Accident Sequence Precursor."

\subsection{A three-step process}

The screening/analysis process is a three-step process: an initial screening step, followed by a second step that requires some analysis, followed by more detailed analysis only if appropriate. (See Section 3.8.1 for a more detailed discussion of the rationale for a three-step process.)

The three broad steps in the overall structure are follows:

- Step 1 .. "Initial Screening", whose aim is to sort out (eliminate from further evaluation) those LERs that require no further evaluation. Other LERs are passed on to Step 2. This step is envisioned as requiring no actual analysis but rather merely a comparison of the information in the LER to certain specific Step-1 criteria.

- Step 2 -- "Preliminary Analysis", whose aim is to perform enough analysis to decide whether a given LER is likely to be designated as an "Accident Sequence Precursor" or is otherwise likely to contain important new safety insights, or can be screened out (eliminated) based on a comparison with specific Step-2 criteria.

- Step 3 -- "Detailed Analysis", whose aim is to subject a limited number of LERs to detailed analysis if, based on specific Step-1 and Step-2 criteria, it is judged that Step-3 analysis is justified.

\subsection{Safety insights vs. designation as a "precursor"}

Designation as an "Accident Sequence Precursor" means that the LER meets the ASP criterion of CCDP $>10^{-6}$ (see below). Only a few LERs will meet this criterion and therefore will be so designated. However, in the guidance here the ASP fire/seismic

$$
3-1
$$


analyst is sometimes directed to develop and document a "safety insight" even for an LER that does not end up being designated as a "Precursor".

For some LERs, safety insights can be derived during the Step-2 phase, even if the event is screened out there, so that there is no need for further Step-3 precursor analysis. For some other LERs, Step-3 analysis will be required to ascertain if the LER is actually an "Accident Sequence Precursor", and separately if any other safety insights can be gained.*

Concerning "safety insights", analysts should understand that of the LERs that reach the Step-2 preliminary-analysis stage, only a fraction of them (rather than all of them) are expected to yield new safety insights. Specifically, of those that survive the Step-1 screening, the Step-2 "preliminary analysis" (i) may indicate that no new safety insights are obtainable from the LER; or (ii) may reveal certain safety insights; or (iii) may indicate that the detailed analysis of Step 3 will be required to probe at a deeper level. It is expected that some LERs that get to Step 3 will, upon in-depth analysis, be found not to yield important new safety insights. This situation is fully acceptable.

Also, the term "safety insight" applies not only to individual LERs, but to insights derived from studying a collection -- an ensemble -- of LERs.

\subsection{Considerations applied in developing the screening criteria}

1) Conservative: During both the Step-1 and Step-2 screening, LERs should be retained unless they can be affirmatively screened out, not the other way around. This is consistent with current ASP practice for internal faults.

2) Ease of discrimination: The Step-1 screening criteria are intended to enable the analyst to discriminate easily between those LERs that are obviously not of much ASP interest and the others.

3) Equivalence: The internal-faults ASP screening criterion uses a level of about $10^{-6}$ for CCDP (conditional core-damage probability). For Steps 2 and 3 below, the logic for earthquake- and fire-related LERs is structured to be consistent with that screening criterion.

4) Screening Using the Seismic-Margin Approach: About half of the U.S. nuclear plants performed the IPEEE seismic analysis using the seismic-margin method instead of the seismic-PRA method. For these plants, the IPEEE screening guidance in NUREG-1407 (NRC, 1991) requires that the plant-level seismic HCLPF capacity** be

* Note that for the existing ASP methodology that examines LERs related to internal plant faults, only Step-1 and Step-3 reviews are performed, with the primary aim of determining if an LER is an "Accident Sequence Precursor". Deriving other safety insights is secondary.

** The "HCLPF capacity" for any item is the seismic capacity for which there is a "High Confidence of Low Probability of Failure". It is defined in the seismic-margin literature (NRC, 1985b; NRC, 1986; EPRI, 1988) and is used in all seismic-margin reviews, as discussed in Chapter 6 . It corresponds to the

$3-2$ 
compared to the plant-specific review-level earthquake (RLE). The plant seismic capacity screens in or out depending on whether the RLE > HCLPF. The methodology guidance here assumes that the IPEEE screening threshold is roughly equivalent to screening of seismic-induced CDF at about $10^{-6} /$ year, and it therefore uses the same criterion.* (See Section 3.8.2 for a detailed discussion of why plants having only a seismic-margin review need separate treatment.)

5) Rigor: The screening criteria cannot be rigorous and there is no pretence that they are. As the criteria are applied, considerable analyst judgment is necessary: in fact, it is important to emphasize that no workable screening criterion can avoid such analyst judgment in the fire and seismic areas. (Of course, there is also considerable judgment necessary to apply the ASP approach to internal-plant-fault LERs.) It is important to point out that an element of conservatism, embedded in the ASP procedures here, compensates somewhat for this.

6) Models: It is assumed here that a plant-specific PRA or seismic-margin model exists and is available for both fire- and earthquake-initiated scenarios. The methodology here explicitly requires the analyst to use these models, and to adapt them as appropriate. (See Section 3.8.3 for a more extensive discussion of these issues.)

7) Configuration-compromise LERs: In the guidance below, we will refer of ten to socalled "configuration-compromise" situations. As we use this term here, it is intended to describe any deviation from the assumption of the existing "base-case" plant safety analysis. This is generally an "undetected condition": it could be a geometrical problem associated with the location of equipment or structures, or related to a seismic fragility or fire vulnerability, or involving a specific phenomenon such as the behavior of some item under earthquake or fire loads. A "configurationcompromise LER" is an LER that reports such a situation, which by our definition is inherently latent, so that no operational event has occurred, such as the tripping of any equipment.

\subsection{Screening and Analysis Guidance for Earthquake-Related LERs}

\subsubsection{A seismic "configuration-compromise" LER}

Scope: Under consideration here is an LER that reports a "configuration" abnormality that could affect risk of an earthquake-initiated accident. Note first that to be reported as an LER such an abnormality must be above a reporting threshold that should eliminate the completely trivial issues. Presumably, the reporting threshold is related to violations of the operating basis. A flow diagram in block form for analyzing these LERs is in Figure 3-1 (the flow diagram consists of 4 sheets.)

seismic capacity for which there is approximately a $95 \%$ confidence of only a $5 \%$ probability of failure.

For most eastern-U.S. nuclear plant sites, the RLE criterion (from NUREG1407, see [NRC, 1991]) actually corresponds to an earthquake with a mean frequency somewhat larger than $10^{-6}$ year, but for our purposes here using the standard seismic-margin RLE criterion nevertheless makes good sense because it is consistent with the standard seismic-margin-review practice as applied in essentially all of the eastern-U.S. seismic-margin IPEEE reviews.

$$
3-3
$$


Figure 3-1. Sheet 1 of 4

Seismic configuration LER

Methodology of analysis for a seismic configuration LER.

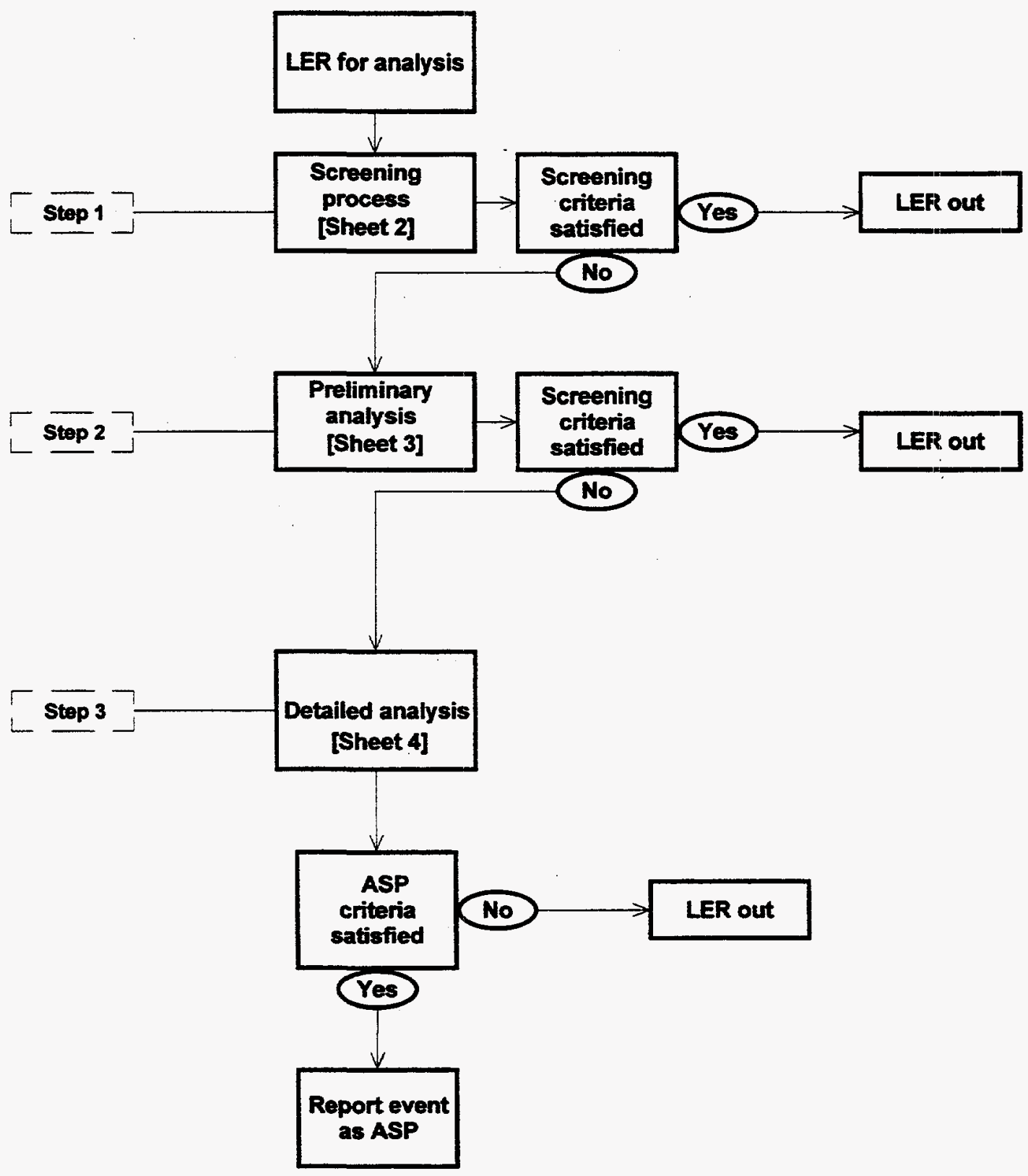


Figure 3-1. Sheet 2 of 4

Seismic configuration LER

STEP 1. Screening process for a seismic configuration LER.

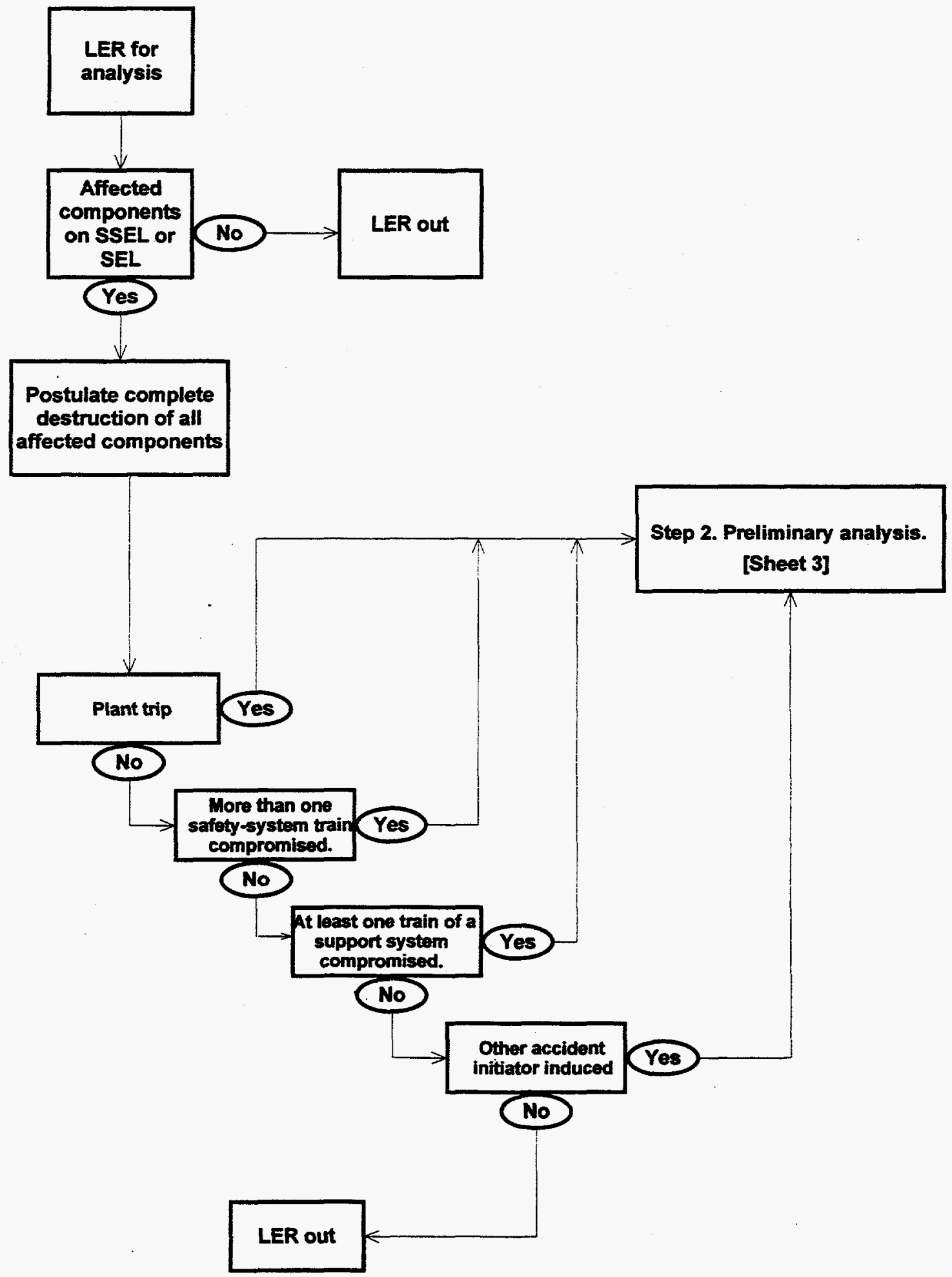

$3-5$ 
Figure 3-1. Sheet 3 of 4

Seismic configuration LER

STEP 2. Preliminary analysis for a seismic configuration LER.
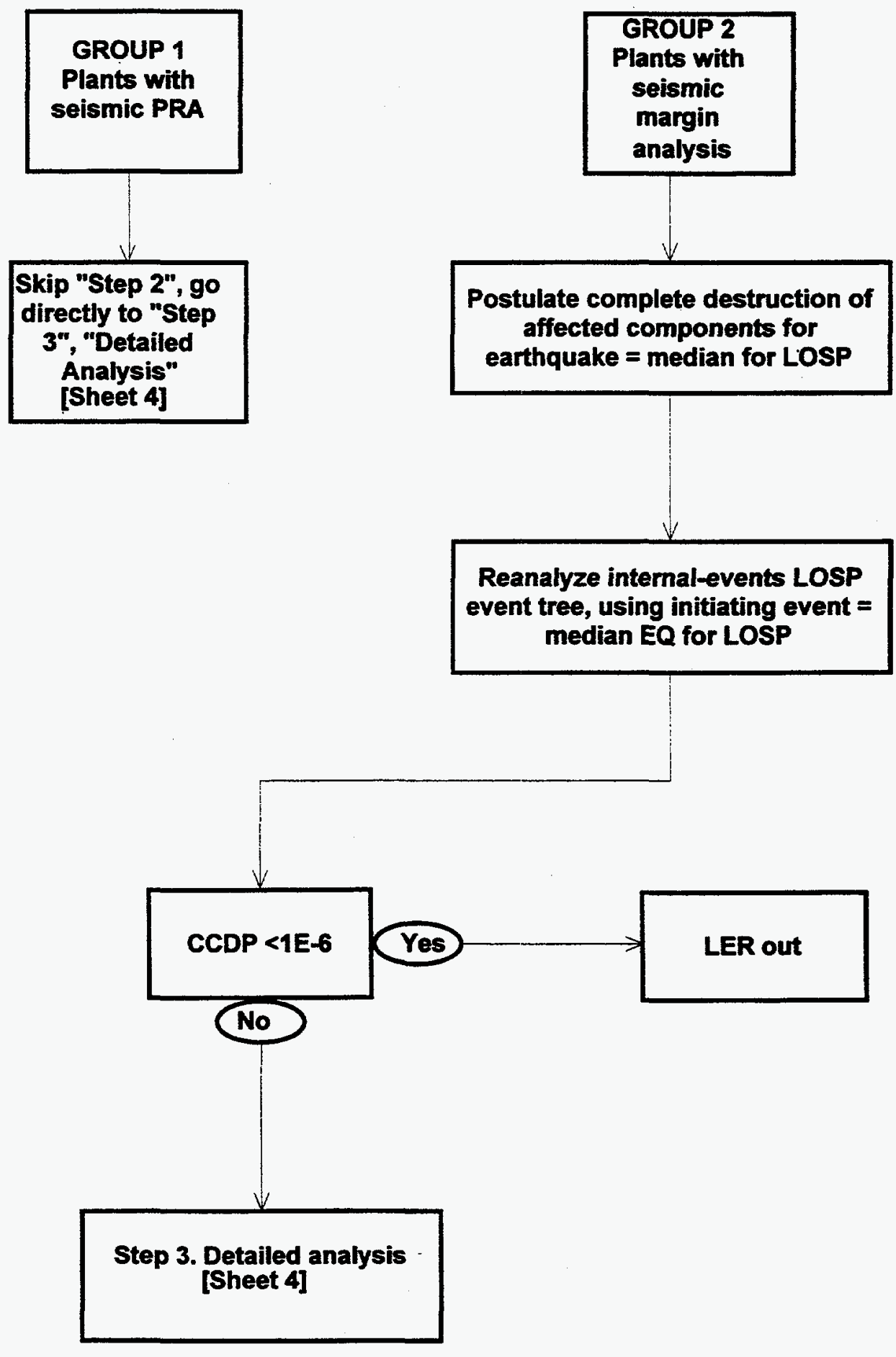
Figure 3-1. Sheet 4 of 4

Seismic configuration LER

STEP 3. Detailed analysis for a seismic configuration LER.

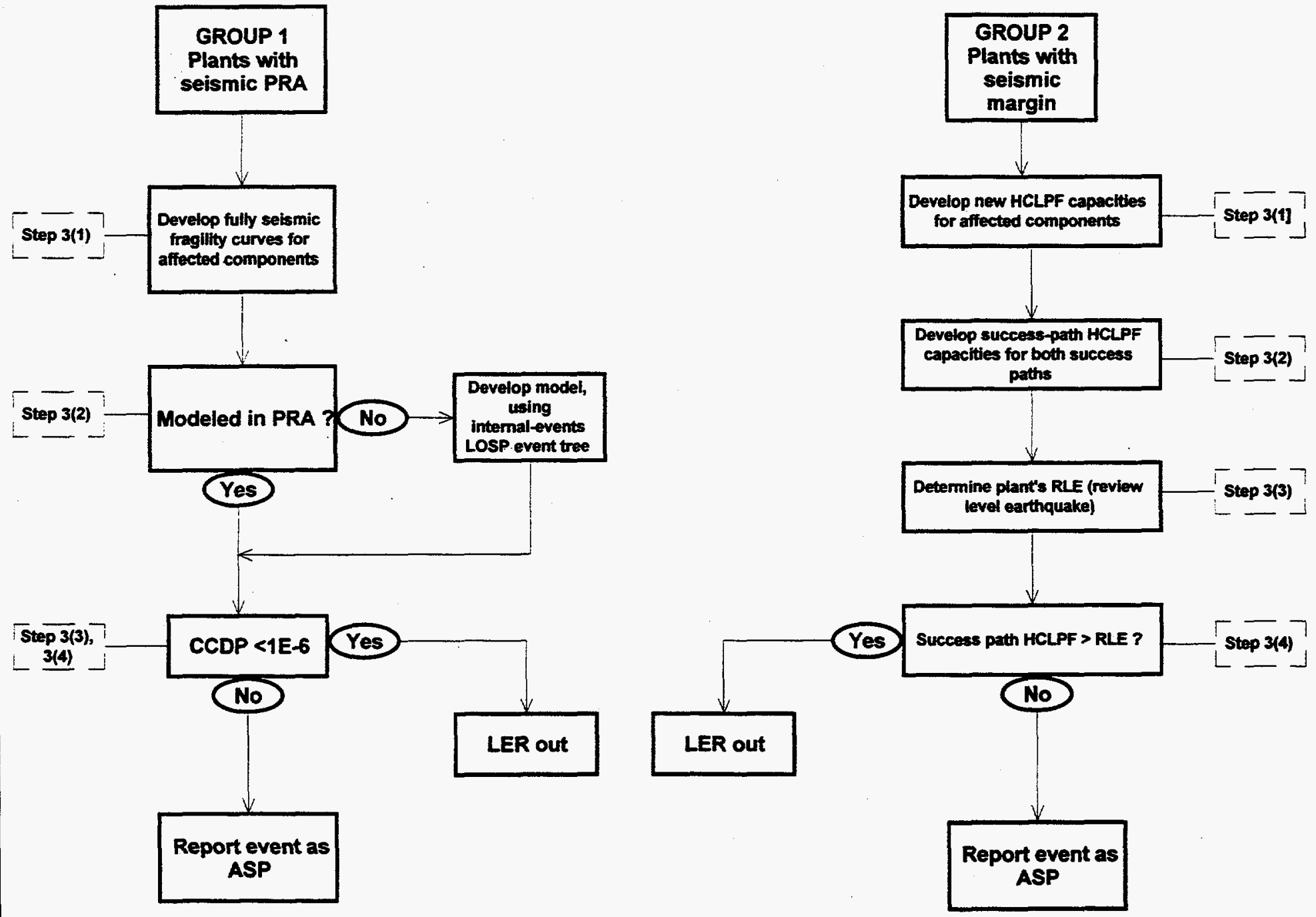


Step-1 Screening Criterion and Guidance:

(1) As the initial task, the analyst should determine all of the safety component(s) affected by the configuration compromise reported in the LER -- either affected directly or affected because the component would be indirectly damaged in an earthquake due to the degraded state of another structure or component reported in the LER. These will be called "affected components" below.

(2) The analyst should then ascertain whether any of the "affected components" from (1) are on the SEL (the Seismic Equipment List) for plants that have a seismic PRA, or on the SSEL (Safe Shutdown Equipment List) for plants that only have a seismic-margin review. The SEL covers all components whose seismic capacity was examined in the seismic PRA, and the SSEL contains a list of all components examined in the margin review because they belong to one of the two success paths used in that review.

If no "affected components" from (1) are on the SEL or SSEL, then the configuration compromise in the LER is assumed to be of little safety consequence and the LER can be screened out. Otherwise, continue with (3), as follows:

(3) In this task, the analyst should postulate that the equipment or structures identified in the LER as seismically weakened are very weak, such that an earthquake of even modest size will destroy those items and everything else that is potentially affected by secondary effects such as having heavy nearby items fall. The equipment here should include not only all "affected items" from (1) above, but all items identified as seismically weakened in the LER.

(4) The analyst should then evaluate the damage that would be caused by such an earthquake of even modest size.

(5) The LER can be screened out if all of the following four criteria are met. (See Section 3.8.4 for a discussion of the rationale for these four criteria.) Otherwise, the LER is screened in:

(i) if the damage would not have caused a plant trip;

(ii) if the damage would be limited to the net effect of compromising at most only a single train of a multi-train front-line safety system or function;

(iii) if the damage would not have compromised the functioning of any one train of a support system (cooling water, instrument air, electrical power, instrumentation and control, etc.) that supports a safety-relevant front-line system or function;

(iv) if the damage would not have caused one of the usual list of PRA accidentsequence initiators (LOCA, LOFW, loss of offsite power, turbine trip, etc.) used in the internal-faults ASP analysis methodology.

Step-2 Preliminary-Analysis Criterion and Guidance:

For this Step, the guidance will differ for plants with a full-scope seismic PRA (Group 1) and plants with only a seismic-margin review (Group 2). 


\section{Group 1 (those nuclear plants having a full-scope seismic PRA):}

For seismic-configuration-compromise LERs, there is no Step-2 analysis for these plants. The analyst should go directly to Step 3.

The reason is that for plants with a full-scope seismic PRA the Step-2 analysis that we have structured is very similar (although not identical) to that in Step 3, and not much additional benefit can be obtained from Step-2 screening. (For Group 2 plants -- see just below -- there is a substantial benefit from doing Step-2 preliminary analysis.)

Group 2 (those nuclear plants NOT having a full-scope seismic PRA -- it is assumed that these plants have done a recent seismic review using the EPRI-type seismicmargin methodology):

For LERs that have not been screened out during the Step-1 screening, the analyst should continue with the postulate that an earthquake has destroyed the equipment or structure(s) identified in the LER along with everything else that is potentially affected by secondary effects such as having heavy nearby items fall.

The guidance for this Step-2 analysis is as follows:

(1) Postulate that an earthquake has occurred that is of a size and character exactly equal to the median earthquake on the loss-of-of fsite-power (LOSP) seismic fragility curve, and that this earthquake has caused a LOSP event. (It is recognized that if only a seismic-margin review is available, there may not be a full plant-specific LOSP fragility curve; in this situation, one should either be developed or adapted from another plant.)

(2) Assume that the item (or items) whose seismic inadequacies are the cause of the seismic-configuration LER would fail with a seismic capacity equal to that of LOSP.

(3) Therefore, this item (or items) is assumed to have failed due to the earthquake postulated in (1), and this failure is assumed to be fully correlated with the assumed seismic-induced LOSP.

(4) From the plant-specific seismic analysis, ascertain if any other equipment or structure has a seismic HCLPF capacity lower than that of LOSP. If so (this would be very rare), postulate that it too has failed due to the earthquake postulated in (1).

(5) From the site-specific seismic hazard curves, determine the mean annual frequency of the earthquake in (1).

(6) Use this earthquake and its mean annual frequency as the initiating event in the plant-specific internal-events LOSP event tree. (See Section 3.8.5 for a discussion of the rationale for using this event tree.)

(7) Re-analyze the plant-specific internal-events LOSP event tree, assuming that the median-LOSP earthquake in (1) is the initiating event and that the item 
(or items) in (3) and (4) have failed with $100 \%$ probability due to the earthquake.

Work out the conditional core-damage probability (CCDP) for this postulated initiating event according to the usual ASP methods and using the appropriate assumptions for the plant-specific internal-events PRA under consideration.*

(9) If the CCDP from (8) is below about $10^{-6}$, the LER is screened out. If this criterion is exceeded, the LER is screened in and passed on to Step-3 (Detailed Analysis) for further evaluation.

\section{Step-3 Detailed-Analysis Criterion and Guidance:}

In this Step, the analyst must perform either full or partial, but detailed, probabilistic seismic modeling of the postulated event. The guidance for this modeling is as follows.

Before undertaking the remainder of the step-by-step analysis, the analyst must determine the failure mode of each "affected item" from Step 1 above. If the affected item's failure mode, given the configuration compromise reported in the LER, is a structural failure mode, then there is at least the possibility that a new seismic capacity can be determined by analysis. However, if the failure mode is a functional failure mode for a piece of active equipment, then this is not feasible (such equipment is qualified by testing and its seismic capacity in the weakened state cannot be determined feasibly in place.) In this latter case, the analyst should assign to such equipment the seismic capacity of LOSP (loss of of ssite power), because offsite power is generally the seismically weakest safety element in a nuclear power plant.

\section{Group 1 (those nuclear plants having a full-scope seismic PRA):}

(1) If feasible (see just above), develop a full seismic fragility curve for the affected component(s) whose seismic inadequacy is reflected in the seismicconfiguration LER. If this is not feasible, then assume that the seismic fragility is equal to that for seismic-caused LOSP. (See Section 3.8.6 for a more extensive discussion of the issue of developing new seismic fragility curves.)

(2) If the item is already modeled in the seismic PRA, proceed to (3). If not, the item must be modeled and then put into the seismic PRA model, by inserting it into the seismic-induced-LOSP event tree. (See Section 3.8.5 for a discussion of the rationale for using this event tree.) This is accomplished by taking the LOSP event tree from the internal-events PRA, inserting the

The idea embedded in the phrase "appropriate assumptions" here is to ensure that the analyst uses the same set of assumptions and data for the ASP analysis as were used for the base-case PRA and seismic-margin analyses that form the starting point for the ASP work. 
seismic failure of the item into that event tree (perhaps through subsidiary fault trees), and adapting this modified internal-events LOSP event tree to create the new seismic-induced-LOSP event tree that otherwise did not model the particular failure.

Adaptation usually will take the form of one or more new basic events at the fault-tree level to represent the previously unmodeled seismic failures. These fault trees will then become inputs to branches in the LOSP event tree. Note that some event-tree branches that are needed here may have been screened out in the base-case analysis in converting the internal-events LOSP event tree to the seismic LOSP event tree.

Sometimes, the ASP Step-3 analysis will incorporate entire new fault-tree and/or event-tree branches (see Section 3.8.5 for a more detailed discussion). Sometimes, these branches will involve some seismic failures of equipment or structures that have not been reported as weakened by the LER, but are nevertheless not otherwise modeled in the base-case seismic PRA. In this case, it is appropriate to use generic fragilities for these structures or equipment items, as a means of performing the ASP seismic analysis readily without performing seismic-fragility analysis on each such item.

Therefore, this project has developed from the literature a set of generic fragility curves for numerous classes of equipment, that can be used for this purpose (see Chapter 6 of this report.)

Using the plant-specific seismic-PRA model, work out the conditional coredamage probability (CCDP) for this event according to the usual ASP methods and using the appropriate assumptions for the plant-specif ic seismic PRA under consideration.* In this analysis, use the full earthquake spectrum based on the plant-specific hazard curves as in any seismic PRA.

(4) If the CCDP due to the weakened seismic condition in the LER is below about $10^{-6}$, the LER is screened out. If this criterion is exceeded, the LER is screened in and documented according to the ASP methodology.

Group 2 (those nuclear plants NOT having a full-scope seismic PRA -- it is assumed that these plants have done a recent seismic review using the EPRI-type seismicmargin methodologv):

(1) If feasible, work out the new seismic HCLPF capacity of each affected component (see discussion above.) If not feasible, assume that the component HCLPF is equal to that for seismic-caused LOSP.

(2) In the plant-specific seismic-margin review, two "success paths" were identified. Using the seismic-margins methodology, work out the success-

The idea embedded in the phrase "appropriate assumptions" here is to ensure that the analyst uses the same set of assumptions and data for the ASP analysis as were used for the base-case PRA analysis that forms the starting point for the ASP work. 
path-level HCLPF capacity for each success path, following the seismicmargins IPEEE guidance in NUREG-1407. This involves re-doing the plantspecific seismic-margins analysis with the introduction of the additional affected item (or items) whose seismic inadequacy is reflected in the seismic-configuration LER.*

Determine the plant's "review level earthquake" (RLE) based on NRC's IPEEE guidance in NUREG-1407 (NRC, 1991). (For most plants, the RLE is 0.30g, although it is $0.50 \mathrm{~g}$ for some plants. The margin methodology is not applicable for very-high-seismic sites such as in coastal California.)

(4) Compare the success-path-level HCLPF capacity from (2) above with the RLE value from (3). If the HCLPF capacity of both success paths exceeds the RLE level, the LER can be screened out. If the RLE exceeds the HCLPF capacity for either success path, the analyst should compare the new (compromised) HCLPF capacity with the success-path-level HCLPF capacity in the base case. If there is no change in that HCLPF capacity, the LER can be screened out. Otherwise, the LER should be screened in and documented according to the ASP methodology. The documentation should concentrate on the effect on whichever success path is affected (or both, if both are affected.)

\subsubsection{Non-seismic failures that could affect seismic-initiated accident sequences}

NOTE: For these LERs, there is no multi-level screening-followed-byanalysis. The evaluation is all done in one step, as the guidance below will indicate. However, the guidance is different for plants that have performed a seismic-PRA analysis (Group 1) than for those that have performed only a seismic-margin evaluation (Group 2).

A flow diagram in block form for analyzing these LERs is in Figure 3-2.

\section{A. Scope}

Here we consider an LER involving a so-called "random" failure (that is, a nonseismic failure, either a human error or a failure or unavailability of a piece of equipment.) (See Section 3.8.7 for a more extensive discussion of the rationale for the guidance below.) To select all such LERs for this analysis, however, could be very costly, so a criterion has been developed for selecting those few LERs likely to have most safety significance.

It is important to note that if the affected component(s) play no role in either of the two "sucesss paths" used in the EPRI-type margin review, then the weakened seismic capacity(ies) will not affect the overall plant HCLPF capacity. If only one success path is affected, then that path may have a smaller HCLPF capacity, but this may or may not affect the overall plantlevel HCLPF capacity. 
Figure 3-2. Sheet 1 of 1

Non-seismic failure LER

Methodology for analysis of non-seismic failures

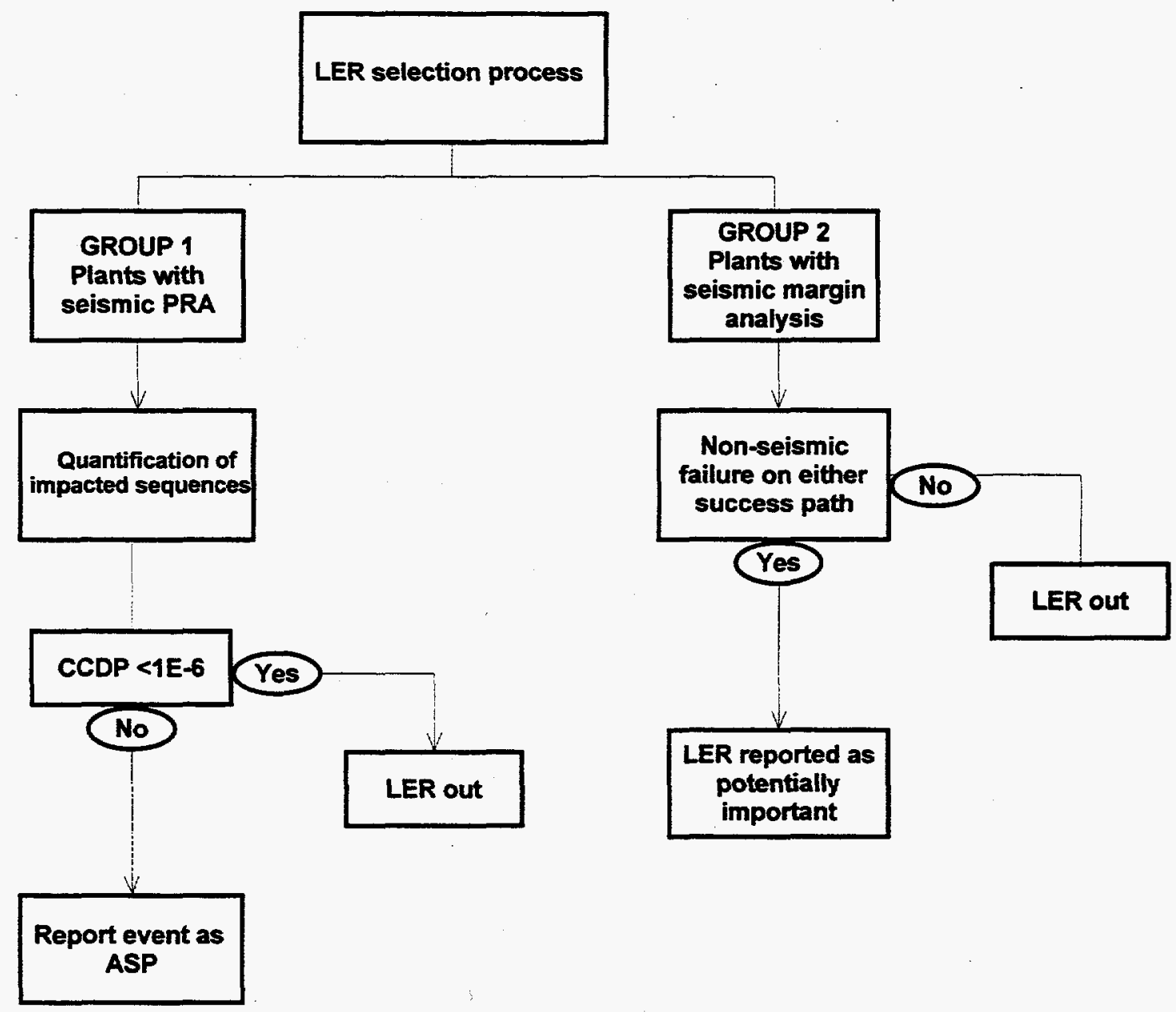




\section{B. Proposed criterion for selecting LERs for non-seismic-failure analysis}

The difficulty addressed here is as follows: if every LER reporting a non-seismic problem or failure -.- which would be over $99 \%$ of the LERs ... were to be examined for its potential to affect seismic-initiated accident sequences, the ASP analysis task would be enormous. Requiring every LER to be subjected to analysis of this kind would be very costly and undoubtedly not worth the effort in a costbenefit sense. Therefore, some selection criterion is needed, so that only a small fraction of the LERs are subjected to this analysis.

It is recommended here that the starting point for selecting LERs for this type of analysis should be the group of LERs that have already been analyzed by the internal-events ASP process, and have not been eliminated during its initial screening process, but have survived that initial screening and are subjected to detailed ASP analysis. (There are a few dozen of these LERs each year, only a fraction of which end up with CCDP $>10^{-6}$ so that they are designated as "Accident Sequence Precursors".) The set of safety issues raised in these LERs defines a group of events that clearly should be considered relevant in terms of safety significance.

It is recommended that the non-seismic failures in each such LER be subjected to the ASP analysis here. The rationale is that the various internal-plant-fault failures and unavailabilities that have survived the screening of the internal-events ASP process are a useful target group with the potential to affect the risk from seismicinitiated sequences.

Guidelines for selection: The following four factors should constitute the guidelines for the analyst in the selection of LERs to be examined in the seismic ASP for non-seismic failures:

(1) Select those LERs containing events or issues that have not been screened out in the initial phase of the internal-events ASP review. This is because the issues in these LERs have been identified as being the most significant in terms of risk among the whole family of LERs.

(2) Include only those LERs involving failures or unavailabilities considered in the seismic-initiated sequences developed by the plant. The information to perform this selection should be taken from the plant-specific seismic PRA, if available, or otherwise from the success-path structure of the seismic-margin review. This will narrow down the LER list selected in (1) above.

(3) Consider as a basic criterion the duration of the non-seismic failure or unavailability reported in the LER. Those safety issues or events for which the failure or the unavailability lasts for a "long" duration, as reported in the LER, should be selected preferentially. The phrase "long" should be interpreted, using expert judgment, by comparing the duration to the initiating event recurrence intervals (which are the inverse of the initiating-event frequencies) for the sequences at issue.

(4) Finally, an LER that reports only an initiating event should be eliminated from this aspect of the ASP analysis, because the interest here is in potential accident sequences that have their own (seismic) initiating event. For every LER being considered, the ASP analyst should calculate the probability that a relevant earthquake would occur in the reported duration of the failure or unavailability.

$$
3-14
$$




\section{Methodological Guidance}

Group 1 (plants with a seismic-PRA model):

Re-run the plant-specific seismic-PRA model with the additional random failure inserted into the model. [This is essentially identical to how the ASP program evaluates random failures today in its internal-faults precursor studies.]

(2) If the CCDP for the relevant accident sequence exceeds the CCDP criterion of $10^{-6}$, the sequence should be retained, studied, and documented. Otherwise, it is screened out.

Group 2 (those nuclear plants NOT having a full-scope seismic PRA -- it is assumed that these plants have done a recent seismic review using the EPRI seismic-margin methodology):

(1) Determine whether the random failure plays a role on either of the success paths used in the EPRI seismic-margin analysis.

(2) If not, the LER can be screened out. If so, the LER should be retained, studied, and documented.

NOTE: For plants in Group 2, the insights from the evaluation in terms of the importance of the random failure are likely to be mainly qualitative, because the EPRI seismic-margin method contains models whose structure is intrinsically incapable of providing quantitative analyses for these types of failures.

\subsection{Screening and Analysis Guidance for Fire-Related LERs}

\subsubsection{A fire "configuration-compromise" LER}

Scope: Under consideration here is an LER that reports a "configuration" abnormality that could affect risk of a fire-initiated accident. Note first that to be reported as an LER such an abnormality must cross a reporting threshold that should eliminate the completely trivial issues. Presumably, the reporting threshold is related to violations of the operating basis.

A flow diagram in block form for analyzing these LERs is in Figure 3-3 (the flow diagram consists of 4 sheets.)

Step-1 Screening Criterion: For this initial step, the analyst should postulate a fire that destroys everything within the fire zone where the configuration abnormality is reported to have occurred -- or the two or more zones if multiple zones are affected by the configuration abnormality. 
Figure 3-3. Sheet 1 of 4

Fire configuration LER

Methodology of analysis for a fire configuration LER.

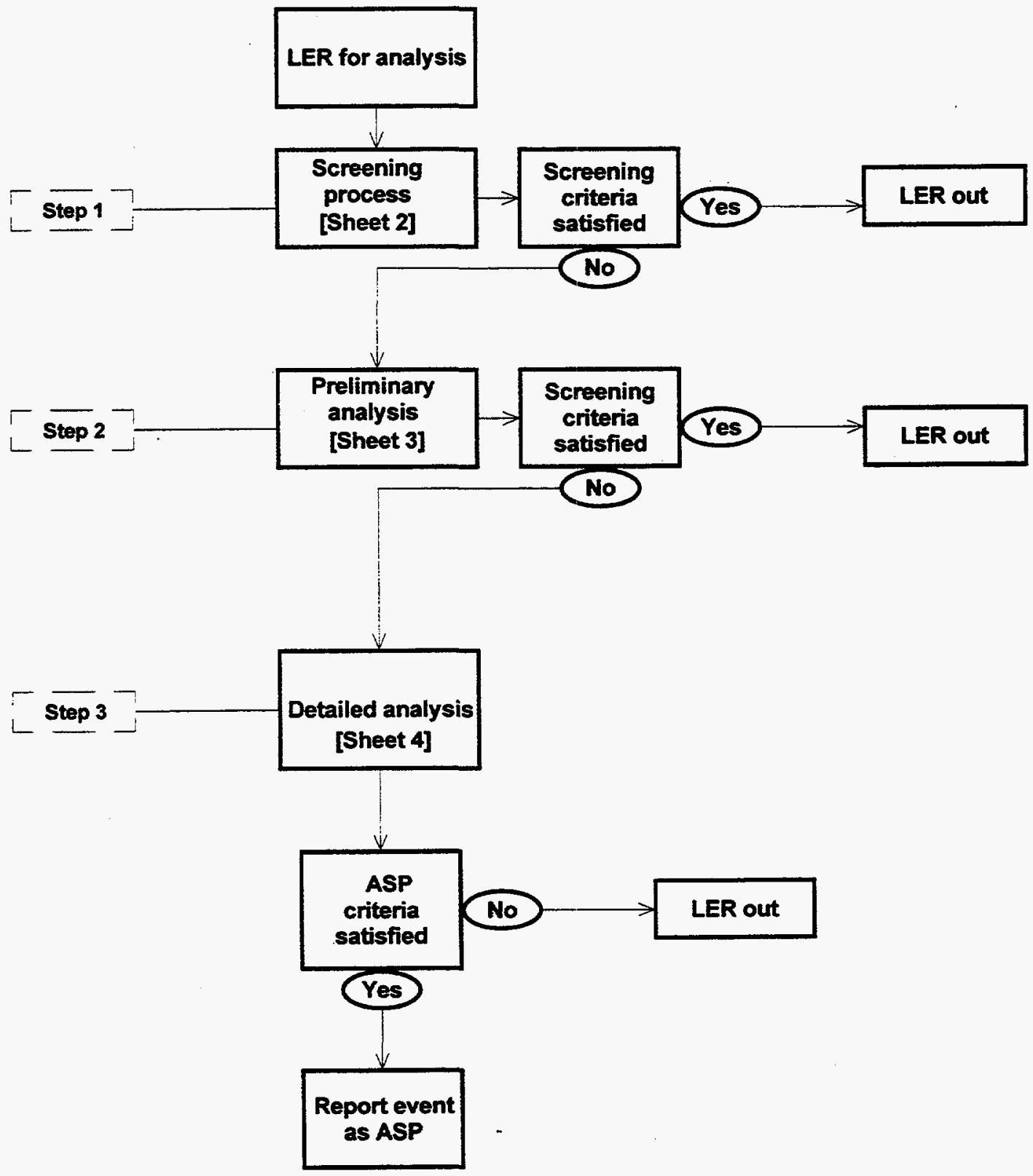


Figure 3-3. Sheet 2 of 4

Fire configuration LER

STEP 1. Screening process for a fire configuration LER

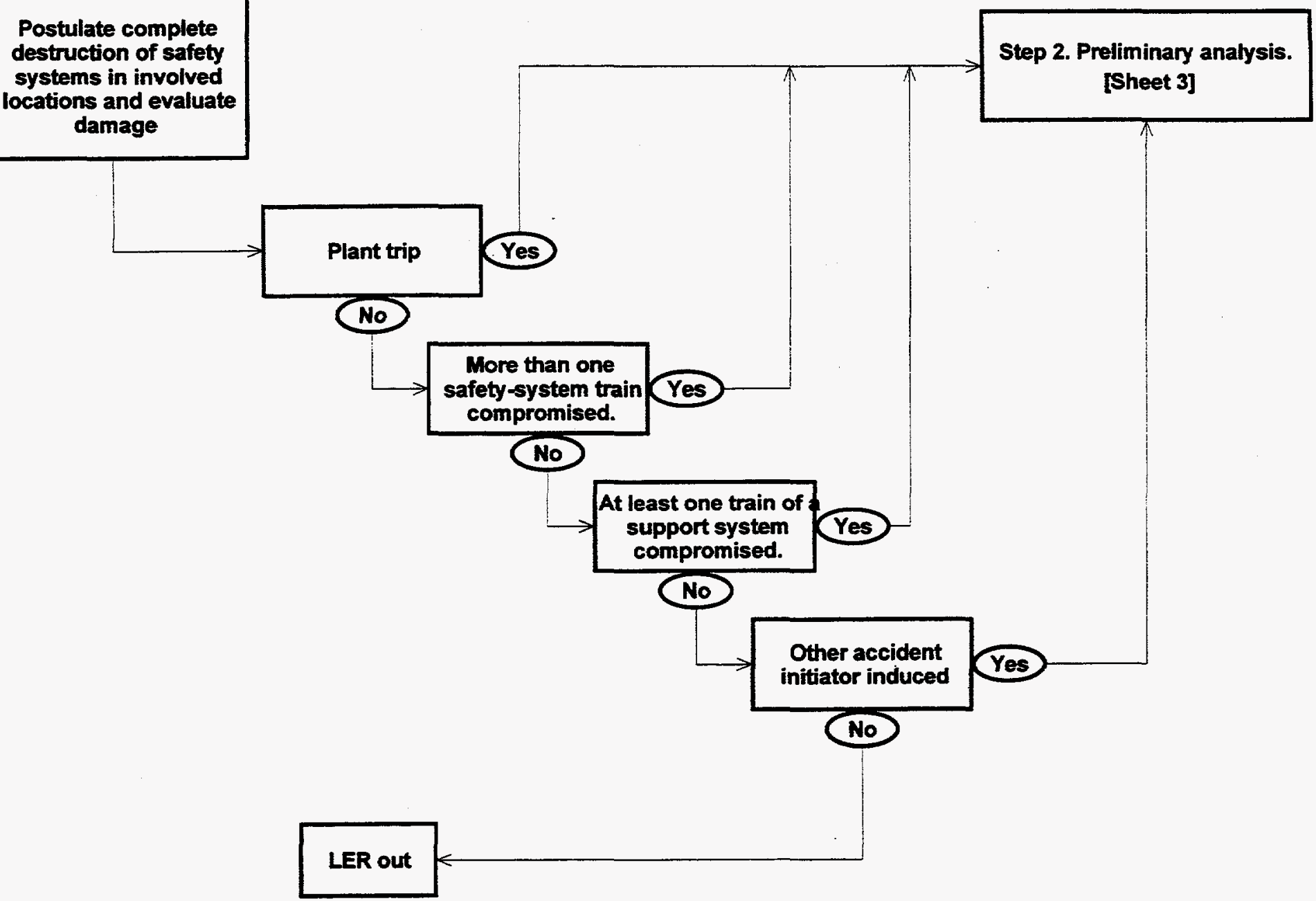


Figure 3-3. Sheet 3 of 4

Fire configuration LER

STEP 2. Preliminary analysis for a fire configuration LER

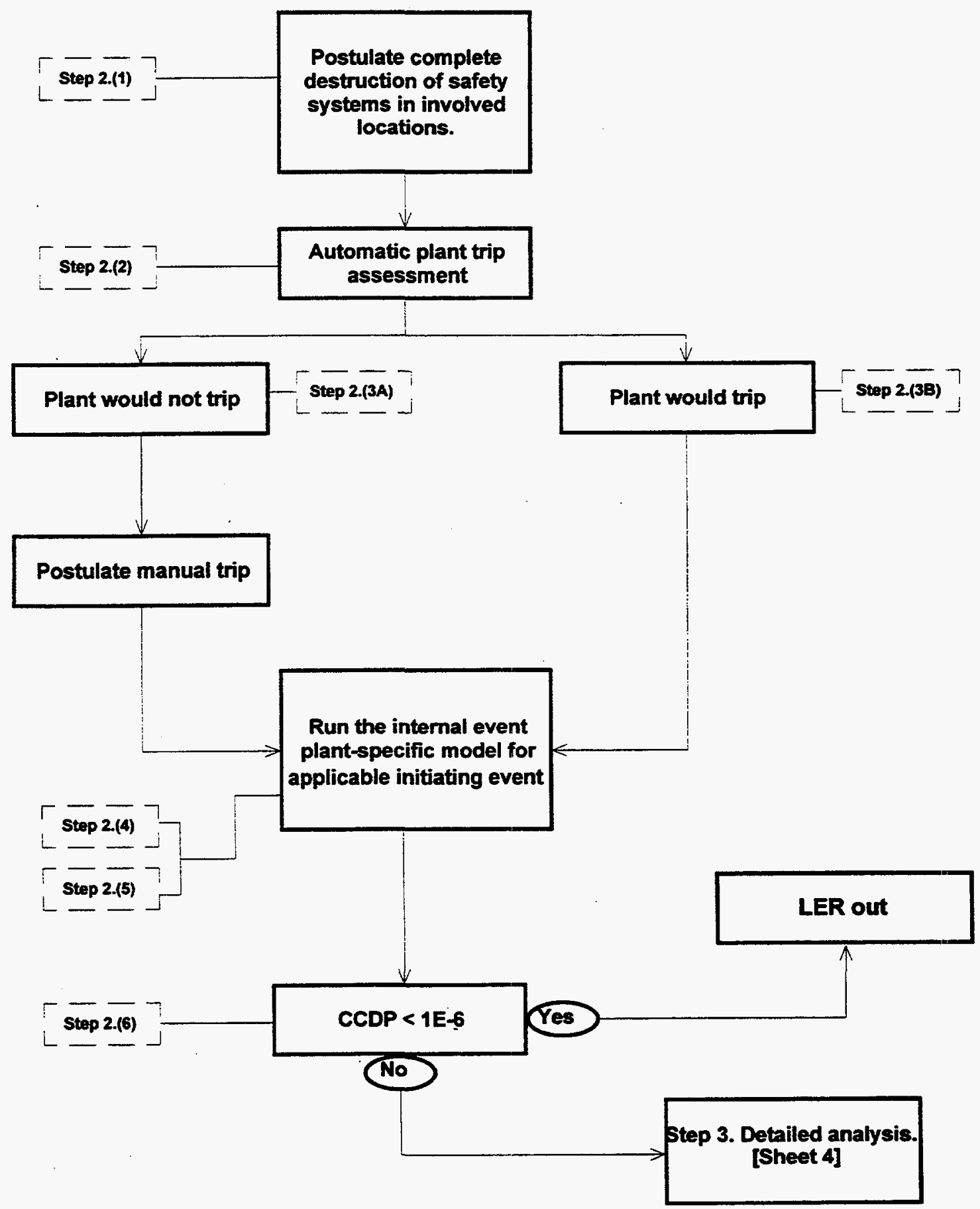


Figure 3-3. Sheet 4 of 4

Fire configuration LER

STEP 3. Detailed analysis for a fire configuration LER

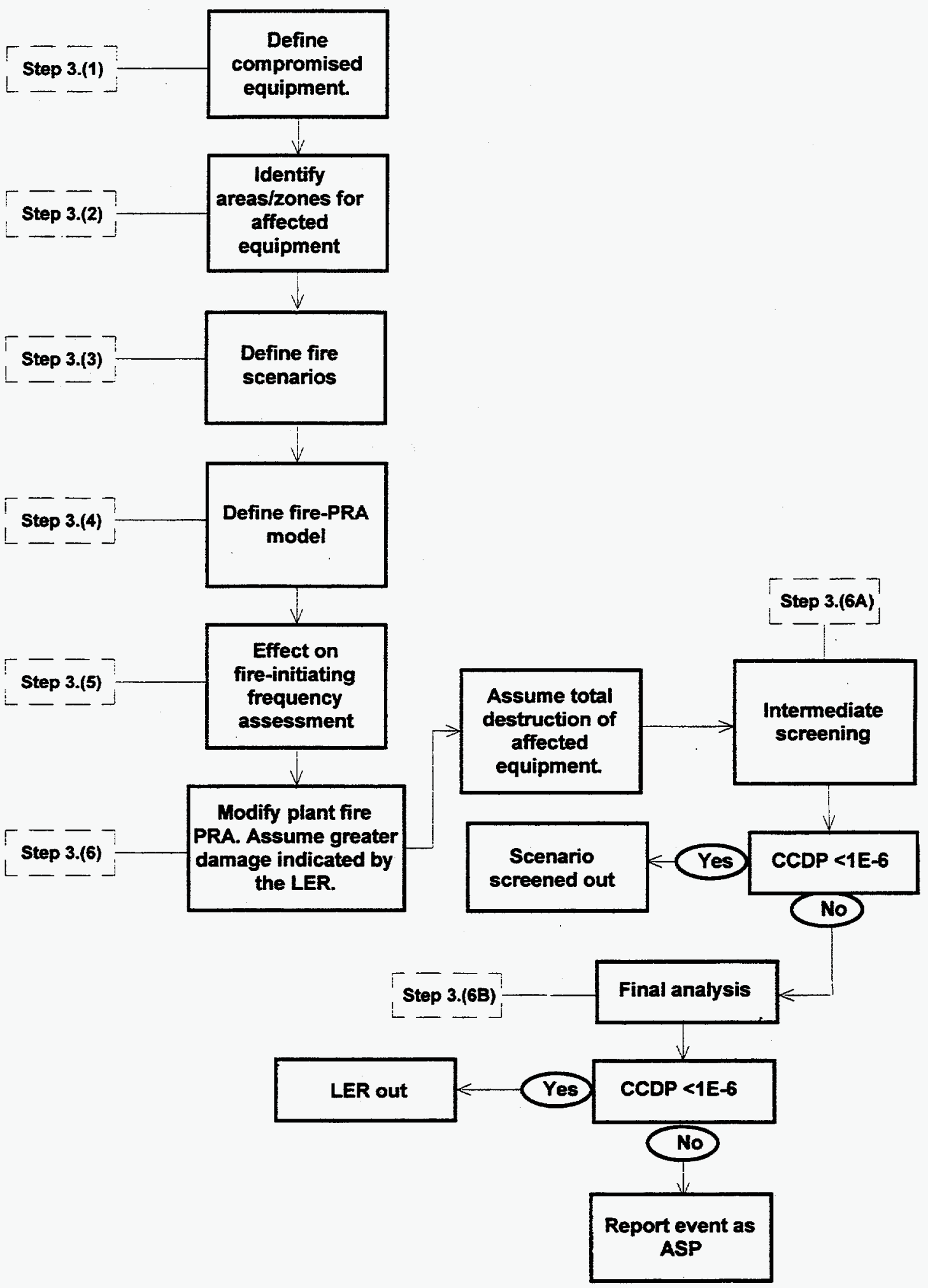


The LER can be screened out if all of the following four criteria are met. (See Section 3.8.4 for a discussion of the rationale for these four criteria.) Otherwise, the LER is screened in:

(i) if the fire damage would not have caused a plant trip;

(ii) if the fire damage would not have caused one of the usual list of PRA accidentsequence initiators (LOCA, LOFW, loss of offsite power, turbine trip, etc.) used in the internal-faults ASP analysis methodology;

(iii) if the fire damage would not have compromised the functioning of any one train of a support system (cooling water, instrument air, electrical power, instrumentation and control, etc.) that supports a safety-relevant front-line system or function;

(iv) if the fire damage would be limited to the net effect of compromising at most only a single train of a multi-train front-line safety system or function.

Notwithstanding the above four criteria, the LER should be retained for Step-2 analysis if an evaluation of the LER reveals an important compromise of the effectiveness of either the automatic suppression system or the ability of the fire brigade (or other manual suppression) to perform its function.

Step-2 Preliminary-Analysis Criterion and Guidance: For LERs that have not been screened out during the Step-1 screening, the analyst should continue with the postulate that everything in the entire fire zone in which the problem is located has been destroyed by a fire. In Step 2, a quasi-realistic analysis but based on a conservative scenario should be performed, the guidance for which is as follows:

(1) As mentioned, continue with the postulate that everything in the entire fire zone in which the configuration abnormality in the LER is located has been destroyed by a fire. (If more than one zone is a factor for this LER, for a reason such as a compromised fire barrier or a high wall temperature, then the analyst should postulate that all equipment in all involved zones has been destroyed.)

(2) Assess whether or not the loss of the equipment in (1) would cause an automatic plant trip. (See Section 3.8 .8 for a more extensive discussion of the rationale for the guidance below under (3A) and (3B).)

Case A -- Plant would not automatically trip:

(3A) Assume that the postulated fire damage in (1) above would cause the operators to initiate a manual trip. (See Section 3.8 .12 for a discussion of the rationale for assuming a manual trip.) For the PRA analysis in (4) below, use the appropriate internal-events PRA event tree for that manual trip. For the initiating event frequency, use the frequency, taken from either the plant-specific data base or, if necessary, a generic data base, of fires in the zone under consideration.

Case B --- Plant would automatically trip:

(3B) Assume that the frequency of the plant-trip initiating event, to be used in the PRA model in (4) below, is the frequency, taken from either the plant- 
specific data base or, if necessary, a generic data base, of fires in the zone under consideration. [This is the same frequency as in Case A.]

(4) Run the plant-specific internal-events PRA model, but with the failures from (1) put into the model, and with the plant-trip initiating event and its frequency taken from either (3A) or (3B).

(5) Work out the conditional core damage probability (CCDP) according to the usual PRA methods and using the appropriate assumptions for the plantspecific internal-events PRA under consideration.*

(6) If the CCDP is below about $10^{-6}$, the LER is screened out. If this criterion is exceeded, the LER is screened in and passed on to Step-3 (Detailed Analysis) for further evaluation.

Step-3 Detailed-Analysis Criterion and Guidance: In this Step, the analyst will perform either full or partial, but detailed, probabilistic modeling of the postulated event. The guidance for this modeling is as follows:

(1) Based on the information in the LER, the analyst should identify each of the specific equipment items whose fire capability has been compromised by the inadequate configuration.

(2) Earlier Step-1 screening or Step-2 preliminary analysis may have screened out some of the items in (1). The analyst should reduce the equipment list to only those items that have survived the earlier screening so that they require the detailed analysis in this Step 3. The fire area(s) or zone(s), from the PRA analysis, should be identified for all of the affected equipment on this reduced list.

(3) For each equipment item on the reduced list from (2), the analyst should define the fire scenario associated with that equipment in its actual location.** This includes the identification of the potential source of the postulated fire, the target for the fire, and other items that may be affected by the fire once it were to start.

The idea embedded in the phrase "appropriate assumptions" here is to ensure that the analyst uses the same set of assumptions and data for the ASP analysis as were used for the base-case PRA analysis that forms the starting point for the ASP work.

The phrase "fire scenario" has a particular meaning in the context of firePRA analysis. In this report, it will mean the combination of (i) a fire ignition source, (ii) one or more safety-related items of equipment that can be affected by that source, where the consequence of postulated fire damage has the potential to lead to a core-damage condition. Sometimes (but not necessarily always) the fire scenario leading to core-damage includes (iii) postulated non-fire failures and human errors that are necessary to lead to core damage. 
Note that it is possible that some of the equipment identified in (2) may represent the potential source of the fire; alternatively some or all of the equipment may be the fire's target -- the fire's source may be modeled as arising elsewhere such as due to transient fuels present in the vicinity.

The product of this substep is a list of fire scenarios involving safety-related equipment that can potentially be affected by the configuration-compromise change from the LER, such that a deeper analysis is necessary.

(4) For each scenario from (3), the analyst should define the fire-PRA model(s) that capture the accident sequence(s) in which the fire scenario may be involved. There are two different cases here, depending on whether or not each identified fire scenario and its associated accident sequence has or has not been included in the prior PRA analysis.

Case A - not included

(4A) If any of the fire scenario(s) is not modeled in the existing fire analysis (presumably because it was screened out of the base-case fire analysis on a valid basis), then it must be modeled before it can be analyzed. (See Section 3.8 .9 for a discussion of the rationale for the guidance here.)

This involves going back to the internal-events PRA model, identifying where the affected equipment enters into the PRA, and modifying the fire PRA model to account for the previously absent equipment. When this modification has been accomplished, go to (5).

This work may be difficult: the analyst must perform an in-depth review of the plant's fire-related documentation, so as to identify those fire scenarios that may have been examined by the earlier fire analysts as part of the development of the existing fire analysis, but were screened out for some valid reason. For these, the analyst here must determine if the conditions that allowed for the earlier screeningout are still applicable given the configuration-compromise situation from the L.ER. This work can reduce considerably the analyst's need for new modeling effort here.

Case B - included

(4B) Even if a fire scenario is already in the existing analysis model, it is necessary to assess whether that existing model adequately accounts for the affected equipment in its compromised state from the LER. If so, go to (5). If not, the analyst should modify the existing analysis to take account of the different situation from the LER. Then go to (5).

(5) Assess whether or not the configuration compromise from the LER would affect any of the fire initiation frequencies used in the base-case PRA fire analysis. (See Section 3.8.10 for a discussion of fire initiating-event-frequency issues.) If not, proceed. If so, modify the relevant fire-initiation frequencies before proceeding.

(6) Re-do the plant-specific fire analysis (fire PRA) using the fire scenarios (including the relevant fire initiating events and frequencies) from (4) and the frequency modifications from (5), but assuming that the postulated fire(s) cause the greater damage that is indicated by the LER, compared to the base-case situation. Use the earlier base-case-analysis assumptions and data, except if 
the base case should be modified to account for compromises as indicated in the LER.

This part of the analysis should be done in two stages: an "intermediate-screening" stage, that is followed, if necessary, by a "final-analysis" stage.

(6A) Perform an intermediate-screening analysis. This consists of the following sub-elements:

(i) Assume, for each scenario identified in (1) above, that all of the safety-related equipment identified in (1) above would be destroyed by the postulated fire, with $100 \%$ probability.

(ii) Using this assumption, re-run the plant-specific fire analysis.

(iii) Work out the conditional core-damage probability (CCDP) according to the usual ASP methods and using the appropriate assumptions for the plant-specific PRA under consideration.* In this analysis, use the full spectrum of fire initiating events and other internal-plant-fault initiating events.

(iv) If the CCDP due to the configuration compromise identified in the LER is below about $10^{-6}$, the LER is screened out. If this criterion is exceeded, proceed to the next stage, the "final-analysis" stage (6B).

If necessary, perform the final analysis. This consists of the following subelements:

(i) Perform a complete fire PRA modeling for each fire scenario. This will allow the development of a more realistic likelihood for fire-caused failure than the pessimistic assumption of $100 \%$ likelihood that was used in the intermediatescreening in $(6 \mathrm{~A})$.

In doing this modeling, the analyst should apply the procedures employed in a standard fire PRA, with the goal of producing a realistic quantification of the impact of the configuration compromise. Manual and automatic suppression, fire brigade actions, and so on should be included. For fire scenarios that were originally modeled, the analyst must perform the appropriate modifications to reflect the configuration compromise. For fire scenarios that were not originally modeled, a full model must be developed.

(ii) Using the model(s) from above, re-run the plant-specific fire analysis for each fire scenario.

(iii) Work out the conditional core-damage probability (CCDP) according to the usual ASP methods and using the appropriate assumptions for the plant-specific PRA

The idea embedded in the phrase "appropriate assumptions" here is to ensure that the analyst uses the same set of assumptions and data for the ASP analysis as were used for the base-case PRA analysis that forms the starting point for the ASP work. 
under consideration.* In this analysis, use the full spectrum of fire initiating events and other internal-plant-fault initiating events. If more than one fire scenario is involved, sum up the various scenario contributions for the purposes of CCDP analysis.

(iv) If the CCDP due to the configuration compromise identified in the LER is below about $10^{-6}$, the LER is screened out. If this criterion is exceeded, the LER is screened in and documented according to the ASP methodology.

\subsubsection{An actual fire reported in an LER}

Scope: Here we consider an LER that reports an actual fire. The evaluation described below will consider not only the location and size of the fire, but also the damage that it caused or that it might have caused (in a "near-miss" sense.) The evaluation will also consider the automatic response or the manual or fire-brigade response, if any, to the fire.

A flow diagram in block form for analyzing these LERs is in Figure 3-4 (the flow diagram consists of 6 sheets.)

General Guidance: In the screening and analysis, the methodology will concentrate principally on the fire-related events reported in the LER. Sometimes, an LER which reports an actual fire will also report about various internal faults not related to the fire, perhaps involving a plant trip or what is called a full "accident sequence initiating event" in the PRA literature.**

Step-1 Screening Criterion and Guidance: For an actual fire reported in an LER, the Step-1 screening criterion takes the following form:

Step 1-A: The LER is screened in and passed on for Step-2 analysis if the LER reports any one of the following. (See Section 3.8.4 for a discussion of the rationale for these four criteria.) Otherwise, move to Step 1-B:

(i) if the LER reports a plant trip;

(ii) if the LER reports any one of the usual list of PRA accident-sequence initiators (LOCA, LOFW, loss of offsite power, turbine trip, etc.) used in the internal-faults ASP analysis methodology;

The idea embedded in the clause "appropriate assumptions" here is to ensure that the analyst uses the same set of assumptions and data for the ASP analysis as were used for the base-case PRA analysis that forms the starting point for the ASP work.

In PRAs performed for light-water power reactors, there is a standard list of so-called "accident sequence initiating events", which are the entry points to the accident event trees that lie at the core of the systems analysis. These initiators include events such as loss of offsite power, loss of main feedwater, turbine trip, LOCA (loss-of-coolant-accident) breaks, and several others. 
Figure 3-4. Sheet 1 of 6

Actual fire LER

Methodology of analysis for a fire reported in an LER.

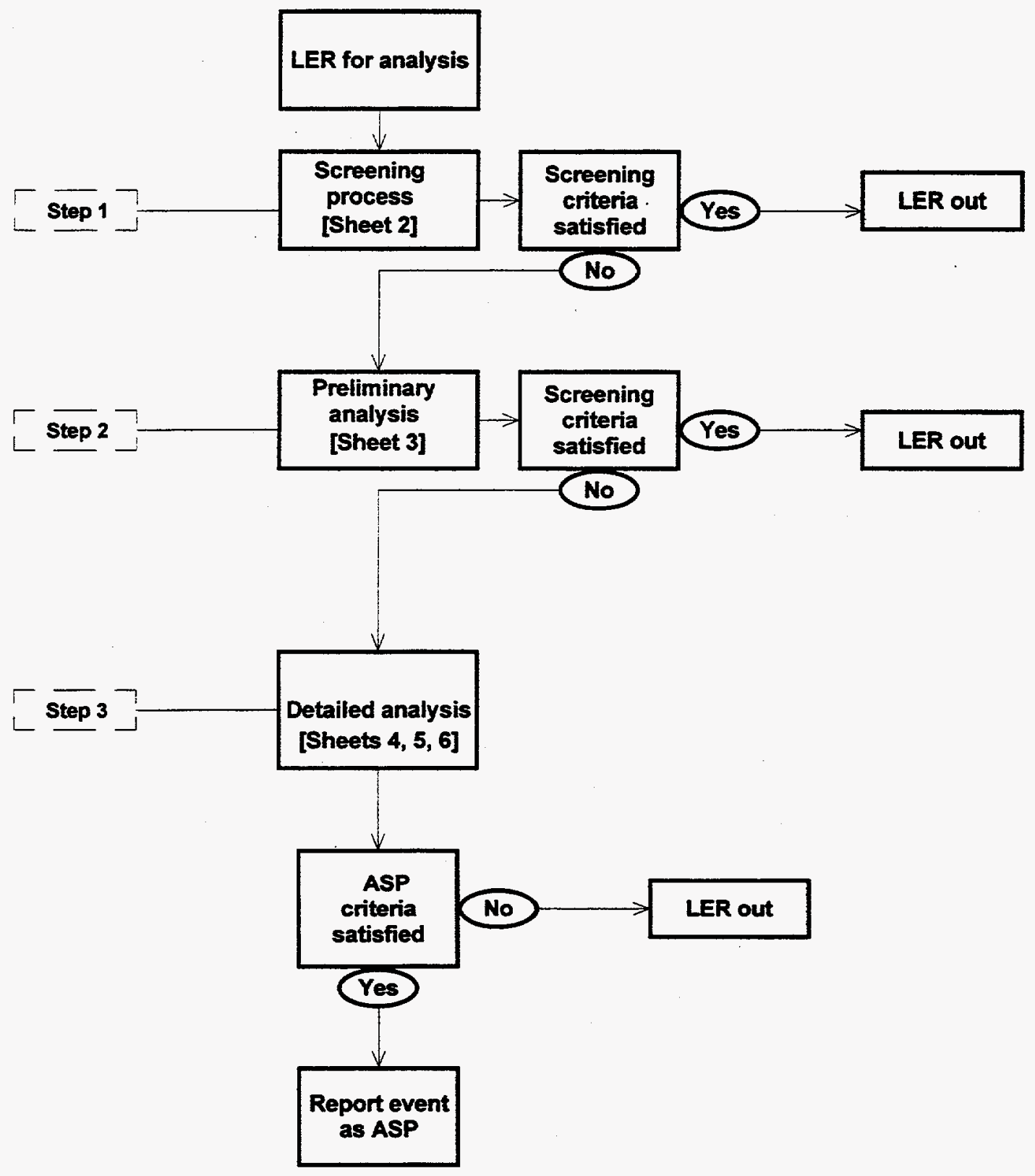


Figure 3-4. Sheet 2 of 6

\section{Actual fire LER}

STEP 1. Screening process for a fire reported in an LER.

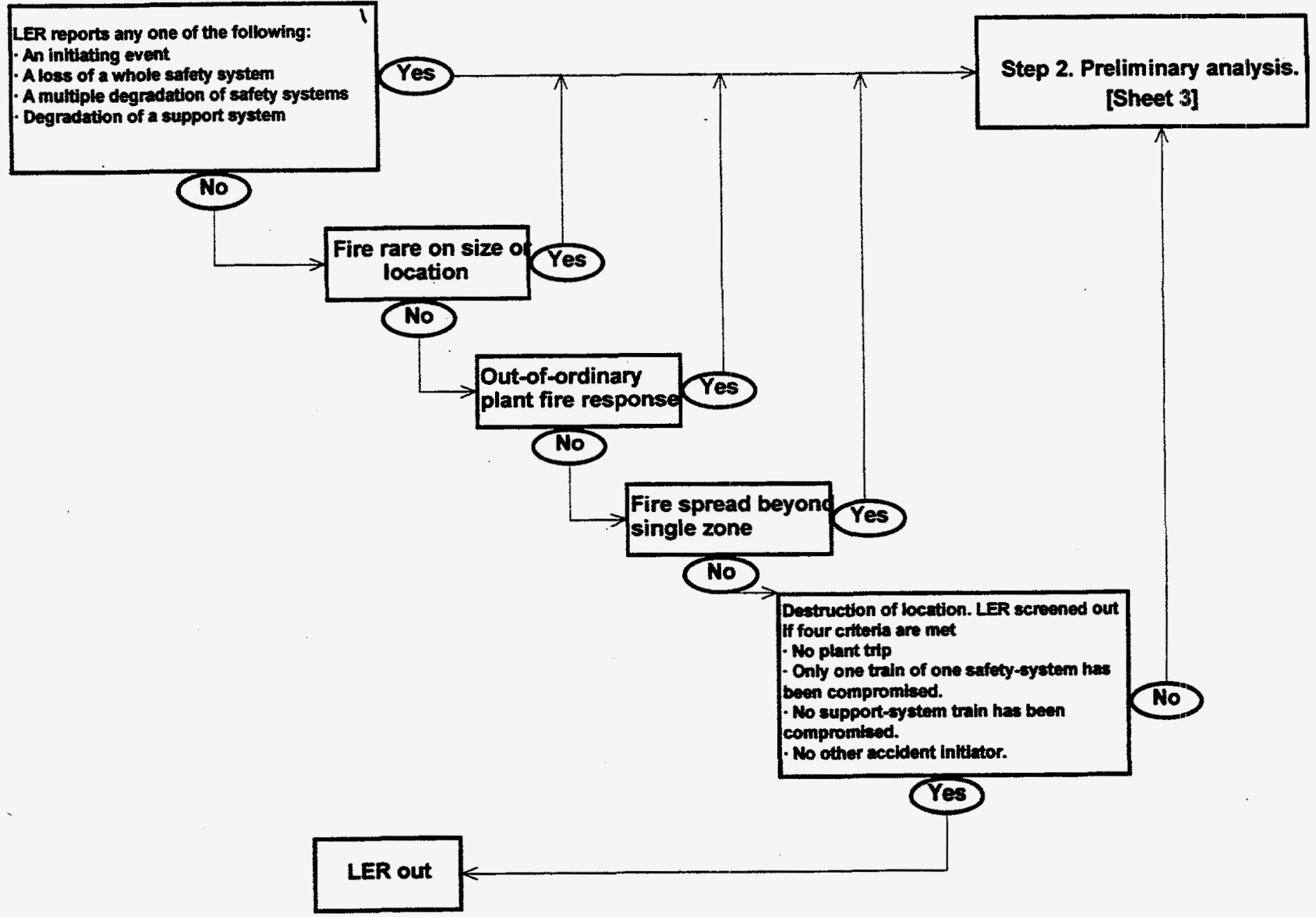


Figure 3-4. Sheet 3 of 6

Actual fire LER

STEP 2. Preliminary analysis for a fire reported in an LER.

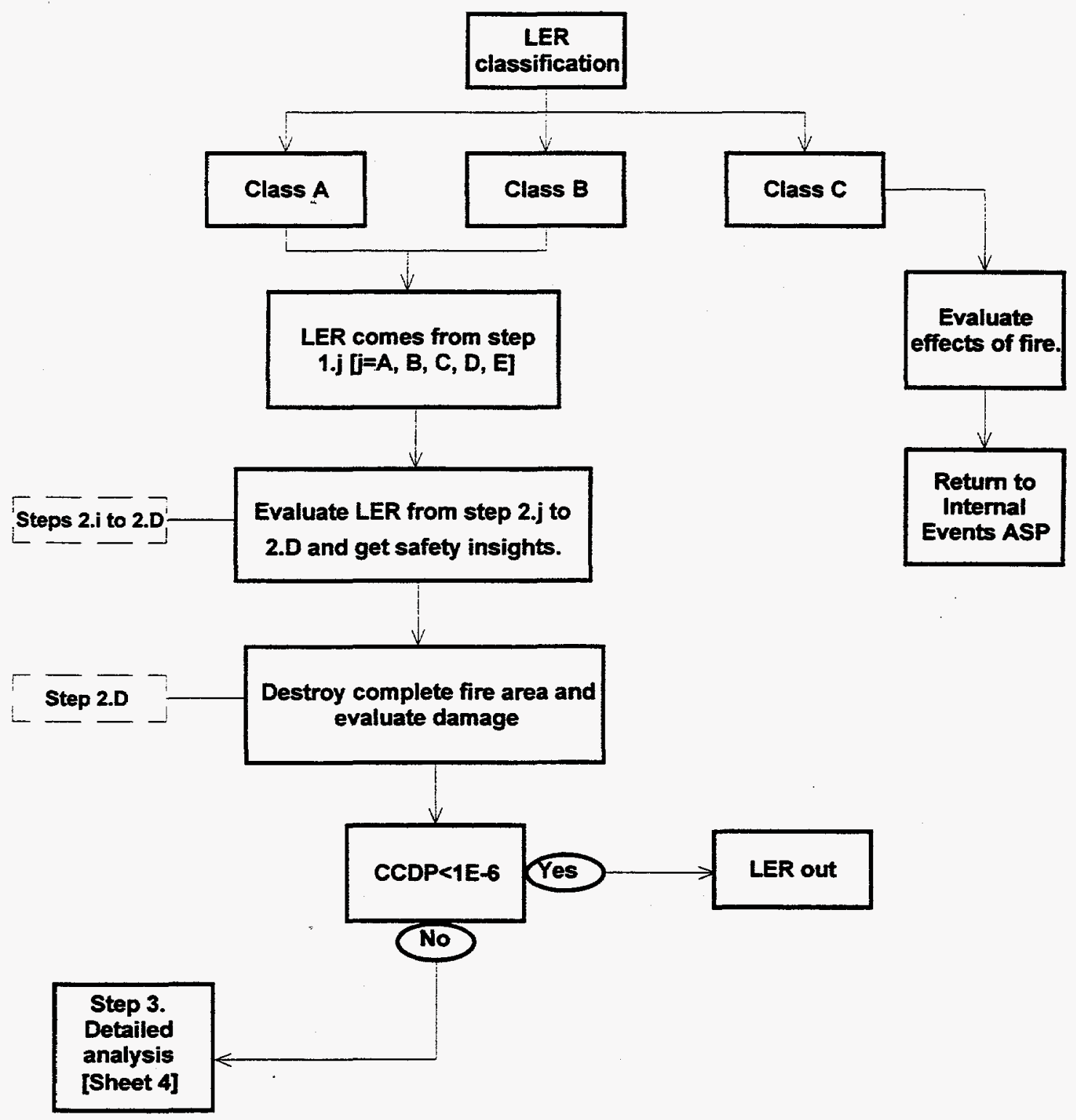


Figure 3-4. Sheet 4 of 6

Actual fire LER

STEP 3. Detailed analysis for a fire reported in an LER.

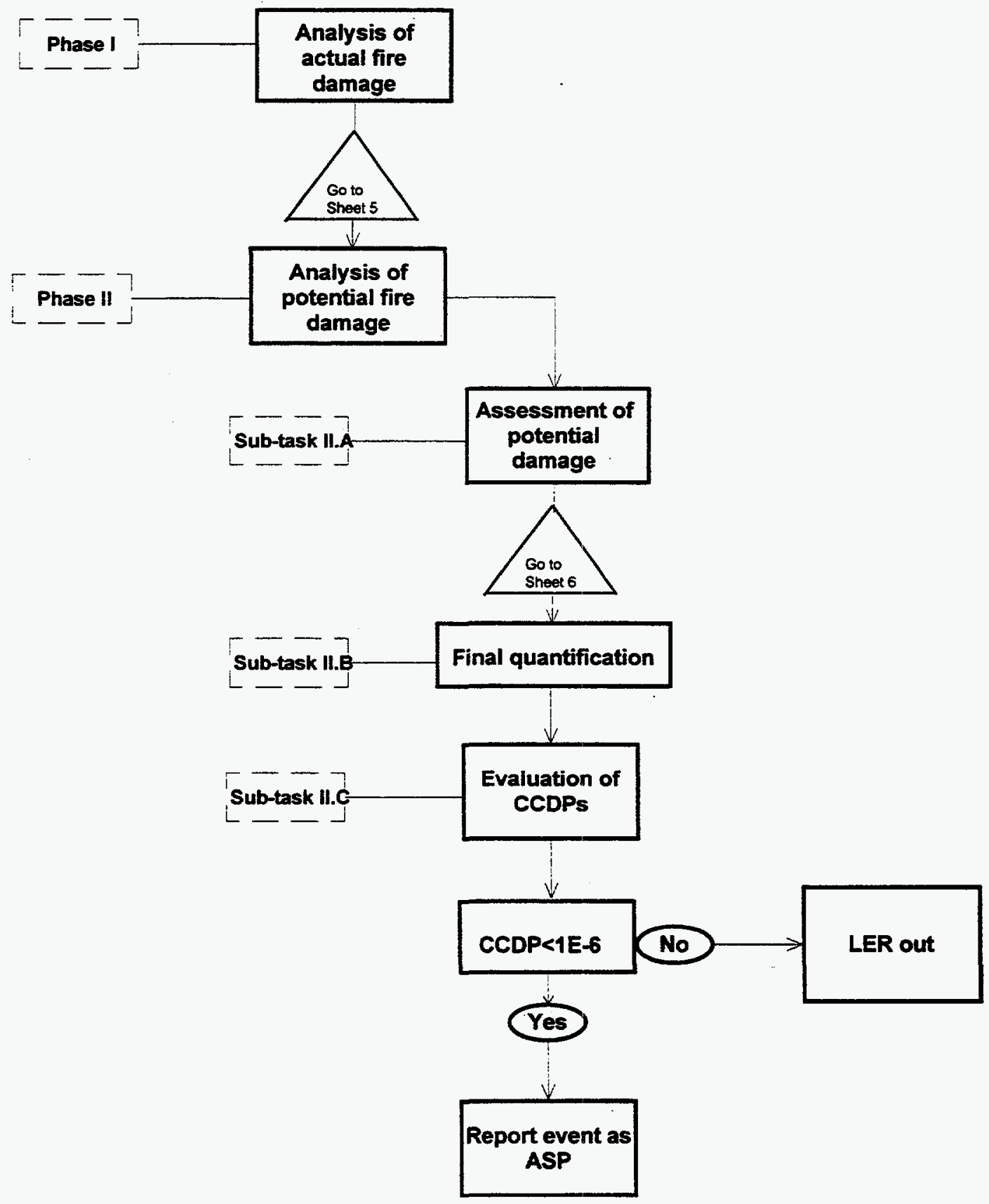


Figure 3-4. Sheet 5 of 6

Actual fire LER

STEP 3. Phase I. Analysis of actual fire damage.

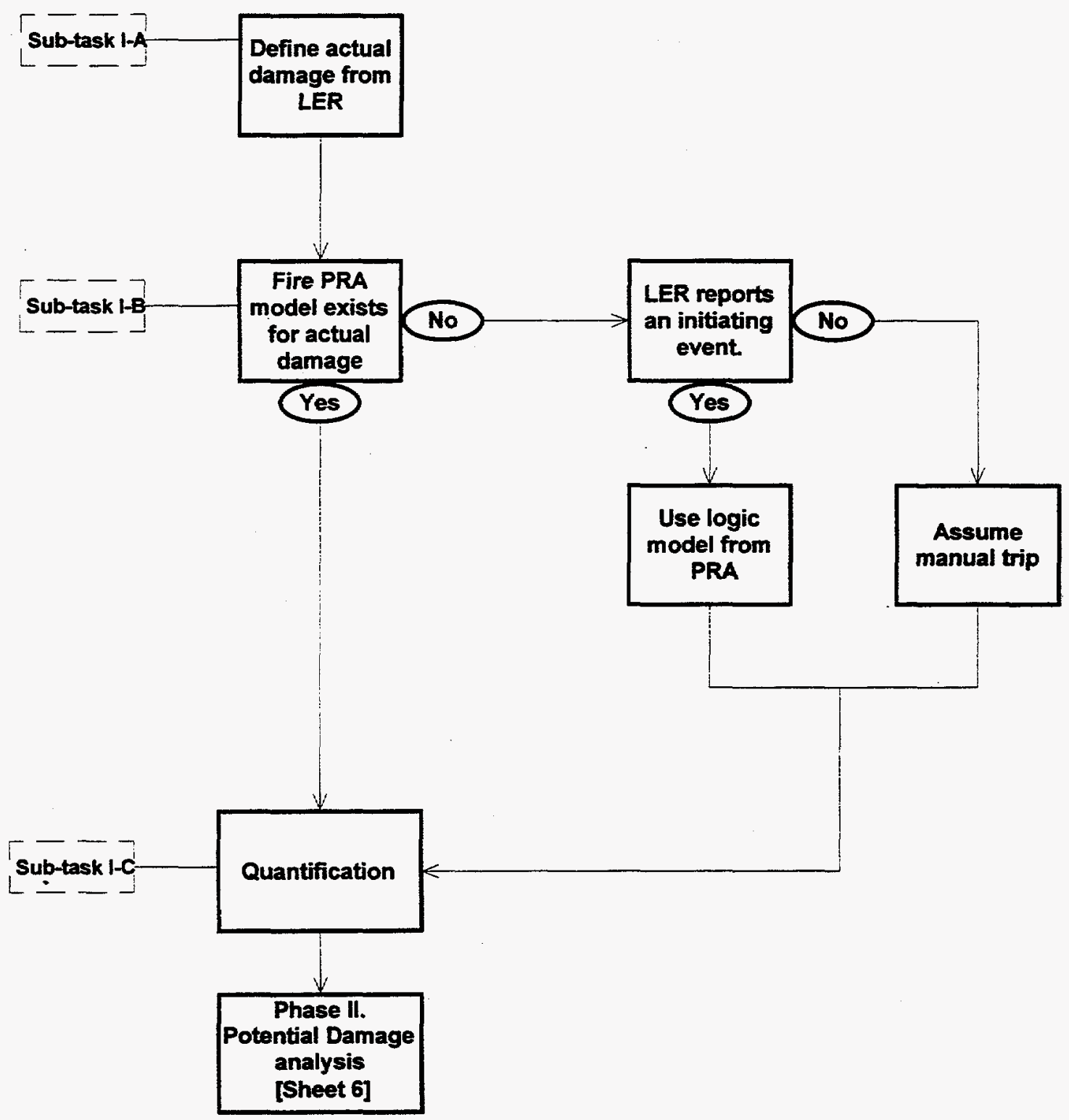


Figure 3-4. Sheet 6 of 6

Actual fire LER

STEP 3. Phase II. Sub-task II.A. Assessment of potential fire damage.

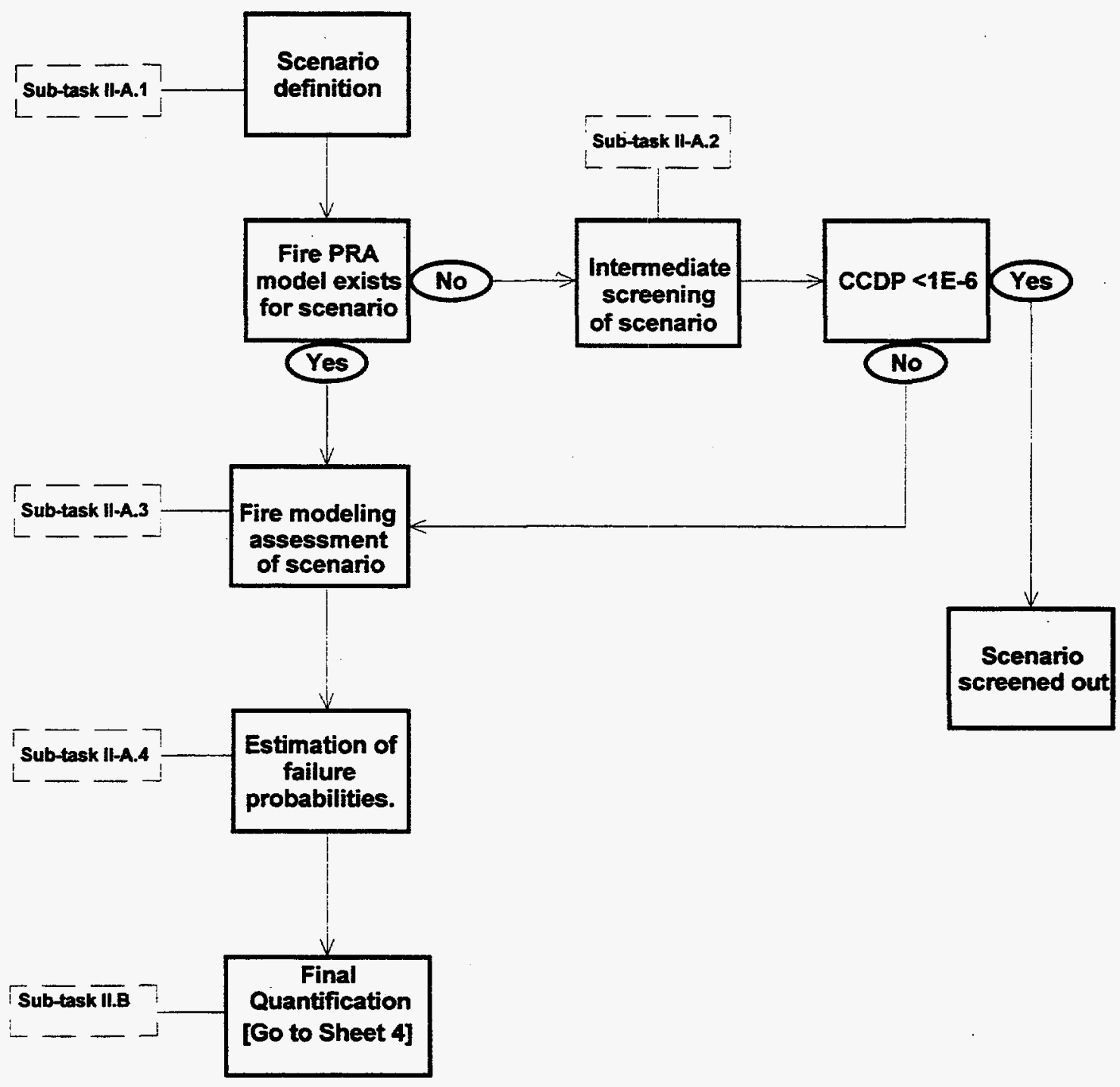


(iii) if the LER reports damage to more than a single train of a multi-train front-line safety system or function;

(iv) if the LER reports damage to the functioning of more than one train of a support system (cooling water, instrument air, electrical power, instrumentation and control, etc.) supporting a safety-relevant front-line system or function.

Step 1-B: Compare the individual fire's location and size with the generic fires data base. Expert judgment is necessary to accomplish this comparison. If this comparison reveals that fires in this type of location and of this size are absent or rare in the data base, then the event is screened in and the analyst should go to Step 2. (The opposite is when the fire is common in the fires data base.) Otherwise, go to Step 1-C.

Step 1-C: Evaluate the actual plant response to the fire, either the automatic response or the fire-brigade response. Expert judgment is necessary to accomplish this evaluation. If the evaluation reveals something out-of-the-ordinary about the response, then the event is screened in and the analyst should go to Step 2 . Otherwise, go to Step 1-D.

Step 1-D: If the fire actually spread beyond a single fire zone, or if in the analyst's expert judgment the fire had a reasonable likelihood of having spread beyond a single fire zone, then the event is screened in and the analyst should go to Step 2. Otherwise, go to Step 1-E.

Step 1-E: Postulate that everything in the entire fire zone (or zones) in which the fire occurred is destroyed by the fire. Evaluate the damage to safety-related equipment that would be caused by such a fire. The LER can be screened out if all of the following four criteria are met. (See Section 3.8.4 for a discussion of the rationale for these four criteria.) Otherwise, the LER is screened in and the analyst should go to Step 2:

(i) if the fire damage would not have caused a plant trip;

(ii) if the fire damage would not have caused one of the usual list of PRA accident-sequence initiators (LOCA, LOFW, loss of offsite power, turbine trip, etc.) used in the internal-faults ASP analysis methodology;

(iii) if the fire damage would be limited to the net effect of compromising at most only a single train of a multi-train front-line safety system or function;

(iv) if the fire damage would not have compromised the functioning of any one train of a support system (cooling water, instrument air, electrical power, instrumentation and control, etc.) supporting a safety-relevant front-line system or function.

LERs that do not survive any of the above screening evaluations are dropped from further consideration. All others are taken to Step 2. 
Step-2 Preliminary-Analysis Criterion and Guidance: This is the preliminary-analysis step, whose objective is to screen out through preliminary analysis those LERs that do not meet certain criteria, so that only a small fraction of the LERs get passed on to Step 3 for detailed analysis.

Before beginning the Step-2 analysis, it is necessary to differentiate three different classes of fire LERs that include an actual fire:

Class A: The LER reports neither a plant trip nor an "accident sequence initiating event" as usually defined in the PRA literature.

Class B: The LER reports a plant trip or a PRA "initiating event", and reports that the fire caused or was involved in the trip or initiating event.

Class C: The LER reports a plant trip or a PRA "initiating event", but reports that the fire did not cause and was not otherwise involved in the trip or initiating event.

Class $C$ will be dispensed with first, after which Classes $A$ and $B$ will be dealt with in much greater detail. Therefore, for Classes $A$ and $B$ the analyst should proceed to the rest of Step 2 below.

Class C: LERs that report a plant trip or PRA "initiating event" but report that the fire did not cause and was not otherwise involved in it. (See Section 3.8.11 for a more extensive discussion of Class C LERs.) For these LERs, because the plant trip/initiating event is unrelated to the fire, the LER should usually be returned for internal-events ASP analysis. However, before returning it, the fire ASP analyst should evaluate the effects of the fire. This evaluation will require considerable expert judgment. There are two qualitatively different cases here:

(i) In the first case, the fire did not induce any damage to safety equipment and/or did not have the potential to do so, in which case the internal-events ASP analyst can proceed without accounting for the fire in the ASP model, although there may be some lessons learned about what happened, from which recommendations can be developed.

It will require considerable expert judgment to conclude, one way or the other, whether or not the fire had the potential to damage any safety equipment. Specifically, in situation (i) the ASP analyst must evaluate all of the characteristics of the fire, concentrating on its potential for inducing other damage beyond what actually occurred; and should attempt to quantify, if possible, an approximate contingent probability that other fire-induced damage (that did not actually occur) might have occurred.* If this probability is truly negligible then the analyst can safely cate-

What this means in practice will depend on the particular situation in the LER. What is intended here is not a labor-intensive, detailed anlaysis in order to arrive at a well-defined numerical value for the contingent probability of other damage. Rather, what is intended is a very approximate estimate, if feasible, of that probability based on bounding estimates or other readily-available information that does not require a lot of "digging." The rationale for this is that, because this work is part of Step 2, it should not entail a large amount of detailed analysis: that should be left to Step 3 (but 
gorize the event into this subclass.

These LERs should be analyzed by the internal-events ASP methodology, not the fire ASP methodology. However, before returning them to the internal-events ASP, these LERs should be passed through Steps 2-B, 2-C, and 2-D (below), and any insights gained there should be documented.

(ii) In the second case, the fire in the LER did damage some safety equipment, or had an important potential to have done so. In this case, the analyst should carry the LER forward to the ASP fire analysis (continue with the full Step 2 below).

The main Step-2 analysis guidance begins here. LERs that have reached this stage in the methodology can be sorted into the following categories, depending on which sub-Step(s) in Step 1 caused the LER to be passed on to Step 2:

Step 2-A --- The fire caused a trip, an initiator, or damage (real or potential) that is judged to be potentially important as defined in Step 1: After evaluation, the analyst should document any "lessons-learned" concerning this fire as a safety insight. This requires considerable expert judgment. Following this evaluation, the event should then be passed back through the rest of the Step-1 screening: either it is passed on to the rest of Step 2 based on other criteria, or it is screened out so that it need not be subjected to further analysis.

In performing this evaluation, the analyst should consider the following points:

- The analyst should consider, if there has been a plant trip or an initiating event, the degree of participation of the fire in the incident (for example, whether the fire induced the initiating event, or the initiating event was due to other causes.)

- The analyst should determine the degree of participation of the fire in the reported events (for example, whether all of the failures reported in the LER were a result of the fire, or only some of them, and why.)

- The analyst should list and consider the human errors in the event and whether any of them were induced by the fire. Also, the analyst should consider various postulated sequences related to the actual sequence of events in the LER, and the impact of the fire on operator performance.

- If fire suppression was successful in limiting the fire, the analyst should evaluate the extent of potential damage that could have occurred had there been no or inadequate fire suppression.

- The analyst should identify the ignition source, the cause or mode of ignition, all damaged components (especially including cables), and other aspects that deserve attention.

only if appropriate, meaning only if the LER is not screened out before it arrives at Step 3.) 
Step 2-B -.- Fire location/size not common in the fires data base: After evaluation, the analyst should document any "lessons-learned" concerning this fire as a safety insight. This requires considerable expert judgment. The event should then be passed back through the rest of the Step-1 screening: either it is passed on to the rest of Step 2 based on other criteria, or it is screened out so that it need not be subjected to further analysis.

In performing this evaluation, the analyst should consider the following points:

- Reference to this type of fire in the data base

- Whether the plant has or has not considered this particular type of fire as an ignition source.

- Whether this fire ignited due to a violation of procedures regarding storage of potential fuel.

o Whether the fire occurred in a manned location

- Whether the fire occurred where separation criteria were not effective

o Whether materials ignited whose resistance to ignition was less than expected

o Whether the fire occurred in a location where ignition sources were expected to be absent

- Whether the fire location had been screened out as unimportant in the earlier fire analysis, and if so why

- If considered, how the fire location was considered: in which scenarios, and for which accident sequences.

Step 2-C--- Out-of-the-ordinary fire-brigade or automatic response: After evaluation, the analyst should document any "lessons-learned" from the plant-response aspect of this fire as a safety insight. This requires considerable expert judgment. The event should then be passed back through the rest of the Step-1 screening: either it is passed on to the rest of Step 2 based on other criteria, or it is screened out so that it need not be subjected to further analysis.

In performing this evaluation, the analyst should consider the following points:

\section{Detection:}

- Problems with actuation of detection devices

- Problems in performance of detection systems, either automatic or human such as a roving firewatch 


\section{Fire brigade response:}

o Timing of actuation

- External actuation for suppression; procedures

o Degradation of other plant functions for the benefit of the fire brigade

o Problems with the availability and/or the effectiveness of suppression materials

o Lack of clarity in procedures or responsibilities

o Duration required for fire suppression: comparison with "expected" time as used in safety basis for the plant

\section{Automatic suppression:}

o Problems with actuation of automatic devices

- Inadequate automatic-suppression devices in the location of the fire

o Properties of involved materials different than expected

o Problems with the elements considered in the fire safety system, as set down in the Safety Analysis Report.

Step 2-D --. Fire-spread beyond a single fire zone: After evaluation, the analyst should document any "lessons learned" from the fire-spread aspect of this fire as a safety insight. This requires considerable expert judgment. The event should then be passed back through the rest of the Step-1 screening: either it is passed on to the rest of Step 2 based on other criteria, or it is screened out so that it need not be subjected to further analysis.

In performing this evaluation, the analyst should consider the following points:

o Whether the zone(s) in the fire were considered in the plant's safety-basis fire analysis

o Whether the fire spread to multiple trains or functions beyond the separation criteria used in the plant's safety basis

- Existence of redundant trains without appropriate separation criteria, or without the proper materials (given that the normal separation criteria may not have been feasible for that location)

o Whether the fire spread to other fire areas or zones

o Whether any problems were observed regarding the resistance of fire barriers (walls, doors, seals, etc.) 
Step 2-E --- LER arriving at Step 2 because it has failed one or more of the systems-damage criteria: The guidance for this key part of the Step-2 analysis is as follows:

(1) The analyst should continue with the postulate that everything in the entire fire zone in which the fire occurred has been destroyed by the fire. (If fire-spread beyond the host zone is a factor for this LER, then the analyst should postulate that all equipment in all involved zones has been destroyed.)

(2) Assume no fire suppression.

(3) Determine whether the damage assumed in (1) would cause a plant trip (unless a fire-induced trip has already been reported in the LER itself.).

(4) If either a plant trip or one of the standard list of PRA initiating events was reported in the LER or would have been induced by the damage assumed in have occurred at the fire's location, use the event tree corresponding to that initiating event. Otherwise, conservatively assume that a manual plant trip would be produced by the fire, and use the event tree that captures the events that follow this manual trip. (This would normally correspond to the "transient" event tree within the plant-specific PRA.) (See Section 3.8 .12 for a discussion of the rationale for assuming a manual trip.)

(5) Work out the conditional core-damage probability (CCDP) as per the normal ASP analysis methodology, using the accident-sequence initiator from (4) and assuming the fire damage from (1). Use all of the appropriate assumptions for the plant-specific PRA under consideration.*

(6) If the ASP CCDP criterion of $10^{-6}$ is not exceeded, the event is screened out. If this criterion is exceeded, the event is screened in and passed on to Step-3 (Detailed Analysis) for further evaluation.

Step-3 Detailed-Analysis Criterion and Guidance: In this Step, the analyst will perform either full or partial, but detailed, probabilistic fire modeling of the event. This involves evaluating the events, failures and human errors reported in the LER, in two separate phases:

- Phase $I$ is designed to evaluate quantitatively the actual damage induced by the fire reported in the LER.

- Phase II is designed to evaluate the LER quantitatively in terms of the potential damage that the reported fire might have induced (but did not induce) in safetyrelated equipment in the involved locations.

In order to perform the detailed analysis, the analyst must make extensive use of all

The idea embedded in the phrase "appropriate assumptions" here is to ensure that the analyst uses the same set of assumptions and data for the ASP analysis as were used for the base-case PRA analysis that forms the starting point for the ASP work. 
prior plant-specific documentation covering earlier fire analyses that examined the relevant locations and the relevant ignition sources as reported in the LER. In addition, the analyst will require the information that can support developing either a partial or a complete fire model for each relevant fire scenario.*

\section{Phase I. Analysis of Actual Fire Damage}

In this phase the analyst should evaluate the LER, based on the actual damage induced to safety-related equipment, including direct fire damage itself; human errors that occurred as a consequence of the fire; non-fire-induced human errors; and internal or non-fire-induced (so-called "random") failures. For this actual-damage analysis, the evaluation should be limited to mapping the actual reported events onto the logic model and quantifying that model to obtain a conditional core damage probability.

In order to do the required evaluation, the analyst must perform a detailed analysis of the LER, to determine all of the actual failures and human errors that occurred as reported in the LER.

\section{Sub-Task I-A. Definition of Actual Damage}

In this sub-task, the analyst should perform a detailed analysis of the LER, in order to list all of the failures to safety-related equipment as reported in the LER, along with the human errors that occurred. The failures and human errors need to be expressed in terms of the basic events considered in the logic models, event trees, and fault trees, that have been structured for analyzing sequences and system failures (see the next sub-task). If a plant-specific fire-PRA model exists, it should be used as the basis for this work. Otherwise, it is likely that the analyst will need to rely in a major way on the plant-specific internal-events PRA model.

\section{Sub-Task I-B. Definition of the Logic Model}

The "sequence" is completely defined by the logic model along with the failures and human errors reported in the LER. In this sub-task, the analyst should define the logic model that will be used for calculating the conditional core damage probability.

If the sequence corresponding to the ignition source reported in the LER has been modeled by the plant in its earlier fire analyses, then the logic model should be that earlier model, using the same initiating event that was reported in the LER. If the LER reports that no initiating event occurred as a consequence of the events being reported, the analyst must estimate the most likely one that might have been produced. In many cases, this will be a manual trip, but might be a more serious initiator, depending on the circumstances.

The phrase "fire scenario" has a particular meaning in the context of firePRA analysis. In this report, it will mean the combination of (i) a fire ignition source, (ii) one or more safety-related items of equipment that can be affected by that source, where the consequence of postulated fire damage has the potential to lead to a core-damage condition. Sometimes (but not necessarily always) the fire scenario leading to core-damage also includes (iii) postulated non-fire failures and human errors that are necessary to lead to core damage. 
If the sequence corresponding to the ignition source reported in the LER has not been modeled by the plant, then the analyst should use the event tree from the internal-events PRA, corresponding to the initiating event reported in the LER. If the LER reports that no initiating event occurred as a consequence of the events being reported, the analyst must estimate the most likely one that might have been produced. In many cases, this will be a manual trip, but might be a more serious initiator, depending on the circumstances.

\section{Sub-Task I-C. Quantification}

In this sub-task, the analyst should calculate the conditional core damage probability (CCDP) corresponding to the actual events reported in the LER, based on the model developed in the sub-task described just above (Sub-Task I-B). For each reported failure or human error, the basic-event failure probability should be set to 1.0 and mapped onto the logic model. If a safety-related equipment failure or human error has not been included directly as a basic event in the logic model, the failure should be reflected by modifying those basic events that are impacted by the failure or human error.

The CCDP analyzed here will be used below when it is compared to the CCDP for the potential-fire-damage case.

\section{Phase II. Analysis of Potential Fire Damage}

In this second phase, the analyst should evaluate the LER, based on both the actual damage and the potential damage that might have been induced to safety-related equipment as a consequence of the reported fire. For this potential-damage analysis, the difficult part of the evaluation will involve (i) the determination of the potential losses to safety-related equipment, followed by (ii) the estimation of the probability that such losses might have occurred, given the information from the LER as well as other available information. Based on that analysis, an ASP quantification will be performed, making use of the logic model defined above as part of the Phase-I actual-damage analysis.

In order to screen out some LERs before performing a detailed fire modeling analysis, an intermediate quantitative screening step is recommended (see below), to eliminate those scenarios found to have negligible risk significance.

\section{Sub-Task II-A. Assessment of Potential Damage}

In this sub-task the analyst should assess all safety-related equipment that had the potential for being affected by the fire. This involves (i) definition of one or more "scenarios", (ii) an intermediate-screening evaluation, and then, if necessary, (iii) a full fire-modeling analysis.

\section{Sub-Task II-A.1. Scenario Definition}

In this sub-task, the analyst should define all safety-related equipment with the potential for being affected by the fire.

If the sequence corresponding to the ignition source reported in the LER has been modeled in the plant's earlier analyses, the safety-related equipment with the potential to be affected by the fire will already be defined from the scenario corresponding to the sequence. 
If the sequence corresponding to the ignition source reported in the LER has not already been modeled by the plant, the equipment with the potential to be affected by the fire must be defined from the scenario corresponding to the ignition source reported, based on the physical information and the plant documents regarding the relevant location.

Sub-Task II-A.2. Intermediate Screening of Each Scenario

This sub-task is performed separately for each scenario. In this sub-task, the analyst should:

1. Assume that all of the safety-related equipment defined in Sub-Task II-A.1 has been destroyed; this corresponds to setting the failure probabilities for each impacted basic event to 1.0 .

2. Map the real damage and the potential damage already defined, onto the logic model defined in Sub-Task I-B.1.

3. For each scenario, quantify the logic model. If the resulting conditional core damage probability (CCDF) exceeds the screening value of $10^{-6}$, the scenario should be passed on to Sub-Task II-A.3 for detailed fire modeling, so that a less conservative calculation of the probability of damage can be performed for each safetyrelated equipment item. Otherwise, the scenario can be screened out. If all scenarios are screened out, then the entire LER can be screened out.

\section{Sub-Task II-A.3. Fire Modeling Assessment for Each Scenario}

This sub-task is performed separately for each scenario. In this key sub-task, the analyst should perform a complete fire modeling for all of the safety-related equipment identified as the target(s) for the ignition source reported in the LER, in order to define fully those that had a potential for actual damage. The analyst must develop or obtain information regarding the time-to-damage for the safety-related equipment corresponding to the scenario, making use of a probabilistic fire model.

If the sequence corresponding to the scenario associated with the reported ignition source has already been modeled by the plant, then the information can be obtained from that existing modeling process.

If the sequence corresponding to the scenario has not been modeled previously by the plant, the analyst must perform a full fire modeling assessment of the scenario, using as the ignition source the actual fire reported in the LER, and using the target developed in Sub-Task II-A.1.

For each scenario, the product of the fire modeling assessment should be expressed as an estimate of the equipment damage resulting from the thermal effects of the fire [conductive, convective and radiative], in terms of a probabilistic curve of timeto-damage for each safety-related piece of equipment.

Sub-Task II-A.4. Estimation of Failure Probabilities for Each Scenario

This sub-task is performed separately for each scenario. In this sub-task, the analyst should estimate the probability that each item of safety-related equipment would have been lost due to the thermal effects from the ignition source reported in the LER. This estimation will require considerable expert judgment. 
The analyst should base his estimate for each safety-related piece of equipment on the following factors:

o A probabilistic distribution of the time-to-damage

- Information from the LER concerning the characteristics of the fire and the occurrence of events related to the induced damage

- Information in the LER concerning the time involved in the suppression of the actual fire, accounting for the actuation of the various suppression systems (both automatic and manual)

o Information provided by the plant, regarding the characteristics of the suppression systems and the procedures established for the actuation of the fire brigade in cases like that reported in the LER

- The analyst's own experience and judgment for the particular situation

- Opinions of fire experts, from inside and/or outside the plant.

\section{Sub-Task II.B. Final Ouantification*}

In this sub-task, the analyst should calculate the conditional core damage probability (CCDP) corresponding to both (i) the actual failures and human errors reported in the LER and (ii) those estimated to have the potential for having damaged safetyrelated equipment during the occurrence of the events reported in the LER.

For each actual failure or human error, the basic event probability should be set to 1.0. For each potential failure the basic event probability should be set to the value estimated in Sub-Task II-A.4.

Finally, such failures should be mapped onto the logic model determined in Sub-Task I-B.1. If a damaged or failed component has not been included as a basic event in the logic model, the failure will be reflected by modifying the basic event(s) impacted by the failures or human errors.

If the resulting total conditional core damage probability (CCDP) exceeds the screening value of $10^{-6}$, the LER should be reported and documented as an Accident Sequence Precursor. Otherwise, the LER should be screened out.

\section{Sub-Task II.C. Evaluation of CCDPs}

In this sub-task, the analyst should compare the CCDP determined in Phase I for the actual damage in the LER, with the CCDP determined in Phase II for the analysis of the actual damage plus the potential damage. Safety insights from this comparison should be documented.

In this sub-task, the analyst should first calculate the CCDP for each fire scenario, and then should sum up the CCDP values. 


\subsubsection{Non-fire failures that could affect fire-initiated accident sequences}

NOTE: For these LERs, there is no multi-level screening-followedby-analysis. The evaluation is all done in one step, as the guidance below will indicate. However, the guidance is different for plants that have performed a fire-PRA analysis (Group 1) than for those that have not performed such an analysis (Group 2).

A flow diagram in block form for analyzing these LERs is in Figure 3-5.

\section{A. Scope}

Here we consider an LER involving a so-called "random" failure (that is, a non-fire failure, either a human error or a failure or unavailability of a piece of equipment.) (See Section 3.8.7 for a more extensive discussion of the rationale for the guidance below.) To select all such LERs for this analysis, however, could be very costly, so a criterion has been developed for selecting those few LERs likely to have most safety significance.

\section{B. Proposed criterion for selecting LERs for non-fire-failure analysis}

The difficulty addressed here is as follows: if every LER reporting a non-fire problem or failure --- which would be over $99 \%$ of the LERs --- were to be examined for its potential to affect fire-initiated accident sequences, the ASP analysis task would be enormous. Requiring every LER to be subjected to analysis of this kind would be very costly and undoubtedly not worth the effort in a costbenefit sense. Therefore, some selection criterion is needed, so that only a small fraction of the LERs are subjected to this analysis.

It is recommended here that the starting point for selecting LERs for this type of analysis should be the group of LERs that have already been analyzed by the internal-events ASP process, and have not been eliminated during its initial screening process, but have survived that initial screening and are subjected to detailed ASP analysis. (There are a few dozen of these LERs each year, only a fraction of which end up with CCDP $>10^{-6}$ so that they are designated as "Accident Sequence Precursors".) The set of safety issues raised in these LERs defines a group of events that clearly should be considered relevant in terms of safety significance.

It is recommended that the non-fire failures in each such LER be subjected to the ASP analysis here. The rationale is that the various internal-plant-fault failures and unavailabilities that have survived the screening of the internal-events ASP process are a useful target group with the potential to affect the risk from fire-initiated sequences.

Guidelines for selection: The following four factors should constitute the guidelines for the analyst in the selection of LERs to be examined in the fire ASP analysis for non-fire failures:

(1) Select those LERs containing events or issues that have not been screened out in the initial phase of the internal-events ASP review. This is because the issues in these LERs have been identified as being the most significant in terms of risk among the whole family of LERs. 
Figure 3-5. Sheet 1 of 1

Non-fire failure LER

Methodology of analysis for non-fire failures.

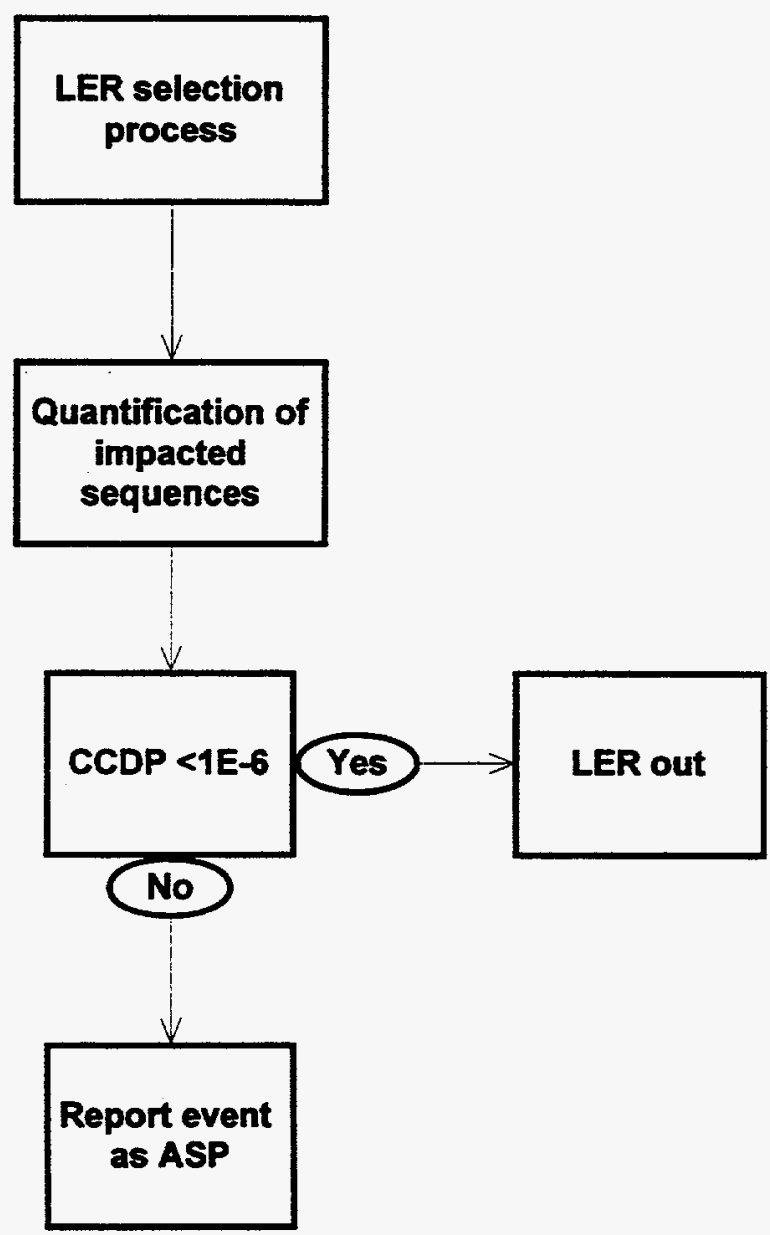


(2) Include only those LERs involving failures or unavailabilities considered in the fire-initiated sequences developed by the plant. The information to perform this selection should be taken from the plant-specific fire PRA, if available, or otherwise from whatever other system model exists. This will narrow down the LER list selected in (1) above.

(3) Consider as a basic criterion the duration of the non-fire failure or unavailability reported in the LER. Those safety issues or events for which the failure or the unavailability lasts for a "long" duration, as reported in the LER, should be selected preferentially. The phrase "long" should be interpreted, using expert judgment, by comparing the duration to the initiating event recurrence intervals (which are the inverse of the initiating-event frequencies) for the sequences at issue.

(4) Finally, an LER that reports only an initiating event should be eliminated from this aspect of the ASP analysis, because the interest here is in potential accident sequences that have their own (fire) initiating event. For every LER being considered, the ASP analyst should calculate the probability that a relevant fire would occur in the reported duration of the failure or unavailability.

\section{Methodological Guidance}

Group 1 (plants with a fire-PRA model):

Re-run the plant-specific fire-PRA model with the additional random failure inserted into the model. [This is essentially identical to how the ASP program evaluates random failures today in its internal-faults precursor studies.]

If the CDP for the relevant accident sequence exceeds the CCDP criterion of $10^{-6}$, the sequence should be retained, studied, and documented. Otherwise, it is screened out.

Group 2 (those nuclear plants that do NOT have a fire-PRA model):

For these plants, the absence of a fire-PRA model makes it impossible to analvze the safety significance of a random failure for fire sequences. The only guidance to offer is to admonish the ASP analyst to apply expert judgment to ascertain whether an important safety issue seems to emerge. While this is far short of an analysis, it can sometimes produce useful insights.

An example would be as follows: suppose that a particular random failure, as reported in an LER, had compromised the operation of one entire train of a twotrain safety system for a very long period of time (for example, for an entire year) before it was discovered. One can postulate a fire at a location that would compromise the entire other train, thereby disabling the entire two-train system. Expert judgment can be used to ascertain whether this situation is likely enough and/or serious enough to merit ASP-type analysis.

Such analysis would then require either adapting a generic fire-PRA model to the particular plant, or adapting the plant-specific internal-faults PRA to the fire situation. Neither task is easy or unambiguous except with much effort.

$$
3-43
$$




\subsection{Back-Up Explanations for this Chapter}

\subsubsection{Three-Step Screening: Rationale for the three-step screening/analysis}

process in Section 3.3

Careful thought was given to why a three-step screening/analysis process is best. The rationale is as follows:

The initial step (Step 1) in the screening, for both fires and earthquakes, has been structured so that it does not involve any analysis: rather, it involves only checking the information in the LER against a short list of easily determined facts. As such, it is intended to be quick, easy, and uncomplicated. Most LERs that involve fire or seismic issues will be screened out at this stage.

Because a full analysis of each remaining LER would be costly and complicated, it is not feasible to recommend such analysis before doing an intermediate step (Step 2, "preliminary analysis"), which involves a certain amount of conservative analysis but does not involve nearly the expense nor the specialized expertise that the full analysis would entail. The decision has therefore been made to perform preliminary Step-2 analysis, which it is expected will not only (i) screen out a significant fraction of the LERs that survive after Step 1, but will also (ii) provide some technical insights that can guide the ASP analyst to use resources for the Step-3 analysis better.

\subsubsection{Seismic margin methodology: Why plants having only an EPRI seismic-margin} analysis need separate treatment (supports Section 3.6)

The EPRI seismic-margin methodology (EPRI, 1988) was accepted by the NRC as a fully acceptable method for satisfying the requirements of the IPEEE seismic review required in Generic Letter 88-20 (NRC, 1991). However, the EPRI margin-review approach is not a seismic PRA, and cannot be used as easily as a PRA for A.SPtye seismic reviews. There are three principal reasons:

(i) First, the systems-analysis aspect uses "success paths" rather than a PRA's faultspace event trees and fault trees as its principal vehicle. Specifically, the analysis team is directed to select two different success paths that can be used by the operators to secure the plant in a safe condition after a large earthquake; all of the equipment on each of those success paths is identified for review. All of that equipment (but only that equipment) is studied for its seismic adequacy, along with any structures that could compromise that equipment.

This approach does not capture the full complexity of a plant's actual response after an earthquake the way a PRA does. For example, there is no way to capture correlations among responses. Also, there is no way to account for non-seismic failures or human errors, except by the general exhortation in the EPRI guidance (EPRI, 1988) to stay away from a success path that includes important human actions that might be prone to error, and also to stay away from equipment with relatively high non-seismic failure probabilities. For ASP-type reviews of LERs, this can be an important compromise, as is evidenced by the observation that, in seismic PRAs, a reasonable fraction of all of the important cut sets (accident sequences) contain both seismic failures and non-seismic failures or human errors, which together lead to the 
undesired outcome of core damage. These types of sequences are not captured explicitly by the EPRI margins approach, and to the extent that the ASP analysis of an LER might involve potential accident sequences of this type, they are difficult to analyze quantitatively using the ASP seismic approach here. Only qualitative judgments can be made.

(ii) Second, the margins approach allows the development of only so-called "HCLPF" seismic capacities ("High Confidence of Low Probability of Failure" capacities) for the important equipment and structures (NRC, 1985b; NRC, 1986; EPRI, 1988), rather than the full seismic fragility curves that are developed for a PRA. These HCLPF capacities are not directly useful in quantifying the core-damage frequency -- or the conditional core-damage probability -. without further information. While techniques have been developed for estimating a full seismic fragility curve from the HCLPF value (Ravindra, 1988), the methods are intrinsically very approximate and not very satisfactory.

(iii) Third, the seismic-margin method's central figure-of-merit for screening is to compare the plant-level HCLPF capacity with the so-called "Review Level Earthquake" (RLE), which for each plant was chosen for the IPEEE reviews by the NRC (NRC, 1991). For most U.S. plants, the RLE was chosen at $0.30 \mathrm{~g}$ (peak ground acceleration). The figure-of-merit is that if any given HCLPF capacity for an equipment item or structure is above the RLE, that item can be screened out as seismically adequately strong. Furthermore, if the plant-level HCLPF value is above the RLE, the entire plant is screened out, and the only statement that can be made is that "the plant-level HCLPF exceeds the RLE". While this is a very strong statement -- it seems to correspond, more-or-less, to a seismic core-damage frequency near about $10^{-6} /$ year -- it does not provide a very useful analytical basis for an ASP-type review of seismic-configuration LERs.

For these cases, about the best that can be done for an ASP review is to ascertain whether the plant-level HCLPF value in the compromised state is or is not above the RLE. [If HCLPF > RLE even for the compromised state represented by the LER, the plant should be judged as seismically adequately strong.] Whether this is the case or not, there is no straightforward method for quantifying the seismic-induced CDF or CCDP. The most useful statement that can be made is that the seismic-induced CDF is conservatively above, below, or perhaps near the annual recurrence frequency for the RLE. This is a weak statement compared to the likely actual seismic CDF, which for most plants is likely to be well below the annual frequency of the RLE.

There are two different seismic-margin methods, the so-called EPRI method (EPRI, 1988 ) and the so-called NRC method (NRC, 1985b; NRC, 1986). Most of the remarks above apply to both margin methods, but there is one key difference: The NRC method (which was used for the IPEEE by only a very few -- less than five -- U.S. nuclear power plants) employs a fault-space event-tree/fault-tree approach for the systems-analysis aspect, rather than the EPRI method's success-path systems approach. Thus the remarks above concerning the difficulties with the success-path approach do not apply. However, the other difficulties, concerning the availabilities of only HCLPF capacities and the use of the RLE figure-of-merit, certainly do apply for plants that used an NRC margin methodology rather than a PRA as the basis for their seismic IPEEE review. 
The interested reader who desires more information about the seismic-margin methodology should refer to the margin literature (NRC, 1985b; NRC, 1986; Ravindra et al., 1987; EPRI, 1988; Kennedy, 1989b; NRC, 1991).

\subsubsection{Existing Models: Use of existing PRA fire and seismic models}

The fire and seismic ASP methodology guidance here assumes that plant-specific seismic and fire PRA analyses or their equivalent exist for every plant. This assumption is based on the observation that all U.S. plants will have completed an IPEEE seismic and fire review by the middle of 1997. It is assumed that these models -- or their equivalent -- are available to the ASP analyst. In the guidance herein, it is explicitly assumed that these PRA-type models, and the data bases that were used to support them in the IPEEE reviews, can be employed by the ASP analyst himself/herself -- that they can be used directly, that certain of their inputs and structures can be altered/manipulated, and that sensitivity studies can be performed to obtain the ASP insights sought herein.

Especially for plants that did not perform a full-scope PRA --- for example, plants that used a seismic-margin method for reviewing earthquakes and/or a FIVE approach for reviewing fires ... the availability of the plant-specific models and their full supporting documentation is essential. Because both the seismic-margin and the FIVE approaches are essentially screening methods, the documentation as to what was screened out, and why, is central to their applicability for ASP-type reviews as discussed herein.

3.8.4 Systems Screening Criteria: Rationale for the systems screening criteria for Step-1 screening (suports Sections 3.6.1, 3.7.1, and 3.7.2)

The Step-1 systems screening for both seismic and fire LERs uses four criteria (see sections 3.6.1, 3.7.1, and 3.7.2). (To guide the reader, the first of them is "if the damage would not have caused a plant trip".) The rationale for choosing these four is that they are essentially the same criteria as are used by the traditional ASP methodology (Minarick, 1990; ASP, 1994) in the initial screening of LERs that report internal plant faults.

It is recognized that perhaps an LER containing a seismic or fire issue might have a CCDP above the $10^{-6}$ /year cutoff and still be screened out by these criteria. While this cannot be ruled out it is judged to be very unlikely.

\subsubsection{Using the LOSP Event Tree: Rationale for using the LOSP event tree for} seismic screening and analysis (supports Section 3.6.1)

In both the Step-2 and the Step-3 seismic-ASP guidance, the ASP analyst is directed to use the LOSP (loss-of-of fsite-power) event tree as the basis for the ASP analysis. The rationale for this is the observation that, in essentially all of the seismic PRAs currently available, the LOSP event tree is the principal (in fact, usually the only) event tree that appears in the seismic systems analysis (Budnitz, 1984; NRC, 1984; NRC, 1990).

The reason for this is that LOSP is generally seismically weaker than any other safety function in the plant. Specifically, the ceramic insulators in the plant electrical switchyard are almost invariably found to be the weakest seismic element 
in the plant. That is, they are found to fail at earthquake ground-shaking levels far smaller than the levels at which any other item of equipment would fail. Thus any earthquake that causes important plant damage will be significantly larger than needed to cause ceramic-insulator-caused loss of offsite power. This explains why the LOSP event is used as the initiating event for the seismic PRA analysis.

Very rarely, another item is found to have lower seismic capacity than LOSP, which is why sub-step (4) under seismic-ASP Step 2 asks that the analyst ascertain whether any components or structures weaker than LOSP exist.

Using the internal-events LOSP event tree for Step-2 "preliminary analysis": The logic that supports the methodology guidance for the Step-2 "preliminary analysis" is as follows: For the equipment reported in the LER as having a seismic configuration compromise, the analyst should first assign a low enough seismic capacity so that it will always fail for the "median earthquake" big enough to cause LOSP.* For an earthquake of this size, usually nothing else will fail. Thus according to the conservative assumptions made here, this postulated earthquake will cause (i) LOSP, (ii) failure of the weakened equipment from the LER, and (iii) nothing else.

For the preliminary-analysis work of Step 2, the guidance is to use the median-LOSP earthquake as the initiating event, with its appropriate annual frequency, but to run the internal-events LOSP event tree. For conservatism's sake, this earthquake has a pessimistically small amplitude of ground-motion and a correspondingly pessimistically large annual frequency. Thus the preliminary screening analysis done in Step 2 is conservative in terms of the initiating event frequency and the LER-reported damage, but otherwise realistic.

For Step 3 analysis of Group 1 plants (plants having a seismic PRA), the rationale for starting with the internal-events LOSP event tree, but analyzing with the seismic LOSP event tree, is as follows: The LOSP event tree for the internal-events PRA involves a very wide range of equipment, much of which is normally seismically rugged and therefore is normally screened out of a seismic PRA. If the equipment that the LER reports to have been seismically compromised is in this category (normally rugged, normally screened out by the seismic-PRA analysis), then it will not be found on the seismic-PRA LOSP event tree. However, if it plays any safety role after LOSP, it will be found on the internal-events LOSP event tree (or the numerous fault trees that support it.) Therefore, the appropriate procedure is (i) to start with the internal-events LOSP event tree and fault trees; (ii) to incorporate therein the equipment that the LER reports to be compromised; and then (iii) to go to the seismic LOSP event tree and adapt into it those new fault-tree and eventtree branches that have been identified from the internal-events LOSP tree.

This is shorthand for the earthquake corresponding to the median capacity on the LOSP seismic fragility curve. Specifically, this is the earthquake that is just large enough to have a $50 \%$ probability of causing LOSP.

$$
3-47
$$


3.8.6 Seismic Fragility Curves: Rationale for using the full seismic fragility curves for the weakened items where appropriate, and explanation as to why this is sometimes not feasible (supports Section 3.6.1)

When an LER reports that a seismic configuration compromise has been found, it is of ten, but not always, feasible to develop a full probabilistic seismic fragility curve for the equipment or structure in its weakened. state. Obviously, where it is feasible to develop such a fragility curve, it is desirable to do so. However, for some situations it is not feasible.

Examples of where it would be feasible include a large flat-bottomed yard tank found to have insufficient anchorage, or a concrete shear wall whose material properties are found to be different than previously thought. For these cases, a calculation of the seismic fragility curve is not only feasible, but can be done readily by any trained seismic-f ragility expert.

Examples of where such calculations are not feasible include a valve with a cantilevered motor operator whose mass is unsupported but normally should be supported; a cabinet found to contain relays that have never been tested but resemble a class of relays that are known to have very low seismic capacity; or an electric motor with a loose casing that is thought to be highly vulnerable even in small earthquakes. For these cases, the only realistic way to determine a seismic fragility would be by a shake-table test, because analysis is typically not feasible for much equipment. However, such a test cannot be performed without removing the item from the plant (which is seldom a real option.) In these cases, it is not feasible to develop a seismic fragility curve for the compromised state.

The methodology guidance, in such cases, directs the ASP analyst to use the seismic capacity of LOSP, as a default assumption. While it is recognized that this assumption may be pessimistic in many cases, there seems to be no other feasible assumption that can allow the ASP analyst to proceed. (Of course, if the analyst can develop a good rationale for any other fragility curve for the compromised item or structure, even an approximate one, it should be used.)

For plants whose recent IPEEE seismic review used the seismic margin method, and for which only HCLPF seismic capacities are available, the development of an itemspecific HCLPF capacity is needed. The default assumption would be that the compromised item has a HCLPF capacity equal to that of LOSP -- again, an assumption made because there seems to be no basis for any other assumption.

\subsubsection{Non-Seismic and Non-Fire Failures: Rationale for ASP Guidance (suports Sections 3.6.2 and 3.7.3)}

Plants with a seismic PRA or fire PRA: For plants with a seismic PRA (or fire PRA), the appropriate way to examine non-seismic (or non-fire) failures reported in an LER would be to re-run the plant-specific seismic (or fire) PRA with these failures included. Such an analysis would be in direct parallel with how the current ASP program evaluates such failures in the context of internally-initiated accident sequences. This is therefore the appropriate guidance.

One problem with this guidance is that most LERs that report safety-equipment problems involve what are called here "non-seismic" (or "non-fire") failures, namely 
failure modes or other problems with ordinary equipment! Thus the analysis of all of these LERs using the seismic and fire PRA models would pose a very large resource burden on the ASP program. While this is true, it is also worth recognizing that a reasonable fraction of all the plants with full-scope PRAs have cut-sets involving seismic and non-seismic failures, as well as cut sets involving fire and non-fire failures, among the important cut sets. To ignore the potential contribution of such cut sets would not be correct. Therefore, their analysis is included here.

Plants that have only an EPRI-type seismic-margin analysis: For these plants, even in principle the ASP approach can do only a much less useful piece of analysis. Specifically, either the compromised item is found to be necessary for one of the seismic-margin success paths (in which case it is "important"), or it is not. Any statement beyond this would be strictly qualitative, based on the ASP analyst's expert judgment.

Plants without a fire-PRA model: For these plants, as the text indicates in Section 3.7.3, there is no feasible way to do an analysis of the significance of a non-fire failure as it might interact with sequences involving a real fire.

3.8.8 Plant-Trip vs. Non-Trip Issue: LERs with a fire configuration compromise, Step-2 analysis -- the plant-trip vs. non-trip distinction, and rationale for initiating-event frequencies (supports Section 3.7.1)

The case under discussion involves an LER with a fire-related configuration compromise, that has not been screened out using the Step-1 systems criteria. The Step-2 analysis begins by postulating that everything in the entire co-located fire zone(s) has been destroyed by a fire. The guidance is that one should re-run the plant-specific internal-events PRA model, but with all of this equipment lost. The issue under discussion here is what to use for the initiating-event(s), and with what frequency.

There are two cases, depending on whether the postulated loss of all of this colocated equipment would or would not cause a plant trip. For cases where no plant trip would occur, the guidance is to assume a manual trip as the initiating event (see Section 3.8.12 for a detailed discussion of this point); for cases where a plant trip would occur, the analyst should use that automatic trip as the initiating event. Either way, the guidance is to use the data-base frequency of fires in the zone under consideration as the frequency of the initiating event for purposes of the Step-2 analysis.

The rationale for this guidance on the frequency is as follows: the sequence of events being postulated is that a fire occurs in the zone, causing total damage in that zone. Clearly, the best indicator of fire frequency in that specific zone ought to be that zone's data-base fire frequency, taken from either the plant-specific fireinitiator data base or, if necessary, from a generic data base. This is what the guidance calls for.

There may be reasons why the data-base frequency is not appropriate, such as when the configuration compromise under review would seriously affect the data-base frequency. However, that type of consideration is too detailed for Step-2 preliminary analysis, and it is left for consideration if the LER survives to undergo detailed review under Step 3 (detailed analysis). Substep (5) under Step 3 for configuration-

$$
3-49
$$


compromise LERs is where this review is to be done, and Subsection 3.8 .10 contains a more detailed discussion of the data-base-frequency issue.

3.8.9 Rationale for Starting with the Internal-Events PRA: For Step 3 analysis of Case-A plant situations (LER with fire-configuration compromise, but the affected "fire scenario" is not currently in the fire model): the rationale for starting with the internal-events PRA model, but analyzing with the fire model (supports Section 3.7.1)

The internal-events PRA involves a very wide range of equipment, some of which will have been screened out of the fire analysis because fire "scenarios" involving its loss in a fire would normally not be of much safety significance. If the fire scenario under review (based on what the LER reports to have been compromised by a fire-configuration problem) is in this category, then that scenario will not be found in the fire model. However, the fire problem identified in the LER may still be important, even if not modeled earlier. If so -- if there is any safety role for the "scenario" involving this equipment -- it will be found in the internal-events PRA model, either in certain of the event trees or in some of the numerous fault trees that support them. Therefore, the appropriate procedure is (i) to start with the internal-events PRA model; (ii) to identify therein the equipment that the LER reports to be potentially compromised, thereby understanding the safety role of this equipment in various accident situations; and then (iii) to go to the fire model and adapt into that model the "fire scenario", including the insights from (ii).

\subsubsection{Fire-Initiation Data Base Modifications: LERs with a fire configuration compromise, Step-3 - modifications to the plant-specific fire-initiation data- base frequencies (supports Section 3.7.1)}

In Step 3 for fire-configuration LERs, the fif th analysis task is to assess whether the fire configuration compromise would affect any of the fire initiation frequencies used in the base-case fire analysis, and if so, to modify the relevant frequencies. In order to accomplish this step, it is necessary to obtain the plant-specific fireinitiation frequencies, and to determine how the LER information might affect them, and by how much. To do this, considerable expert judgment is needed.

Most fire LERs probably would not have a configuration compromise that would affect the fire-initiation frequency for the fire zone at issue, but it could happen, for example, if the initiation frequency (either the plant-specific frequency or a frequency taken from a generic data base) depends on the amount of transient fuel, and the LER reports a very different amount of transient fuel than assumed in the data base. Another example is if the base-case fire-initiation frequency assumes certain spatial separations that are entirely different as reported in the LER.

The starting point for this reassessment could be either the plant-specific data base used in the plant's PRA, or one or another of the generic data bases currently available, including perhaps that developed under NRC support (Wheelis, 1986), or the EPRI data base (FIVE, 1993), where available to an individual utility. 
3.8.11 Class-C Fire LERs: LERs that report an actual fire -- discussion of the "Class-C" LERs that report a plant trip but the fire was not involved in it (supports Section 3.7.2)

An actual example of this type of LER is the Plant-A actual-fire LER that is discussed in more detail in the case study elsewhere in this report (Section 4.2), in which the actual fire was only ancillary to the main safety issues in the event. The guidance here is that if the fire did not induce any damage to safety equipment and/or did not have the potential to do so (ascertaining this latter potential requires considerable expert judgment), such LERs should be returned for ASP internal-events analysis. The reason for this is that in these cases there is no apparent basis for further fire-related accident analysis. The fire is, as in the Plant-A LER (Section 4.2), simply and entirely a side issue of little safety significance.

However, it is helpful to the internal-events ASP analyst to develop certain information here, and some qualitative guidance is provided on this subject. The guidance in the main text is self-explanatory; its rationale is that the fire-ASP analyst is in a better position than the internal-events ASP analyst to develop this information.

3.8.12 Manual Trip Assumption: discussion of the Step-2 manual-trip assumption (configuration-compromise fire LERs, Section 3.7.1) and of the Step 2-E manual-trip assumption (LERs that report an actual fire, Section 3.7.2)

This case here is where an LER reporting an actual fire is being subjected to Step2-E analysis (subtask (4)), or a configuration-compromise LER is being subjected to Step-2 analysis (subtask (3A)). In either case, the analysis has reached a stage where the analyst finds that (i) for a real-fire LER, a plant trip did not occur, and the analysts have determined that one would not have occurred assuming that everything in the entire fire zone in which the actual fire occurred were destroyed; or (ii) for a configuration-compromise LER, a plant trip would not have occurred under the postulated total-damage-in-the-affected-zone conditions.

The guidance is to assume a manual plant trip, and then to proceed with the ASP analysis of CCDP for that plant trip. The rationale for this manual-trip assumption is that given the damage by fire of everything in the zone, and given that, with the assumption of this damage, the LER was not screened out using the Step-1 criteria, it is hard to understand why the operators would not find it appropriate to trip the plant. 


\section{FIRE CASE STUDIES}

\subsection{Introduction}

This chapter will introduce and then discuss three "case studies" to illuminate how precursors to fire-initiated accidents, as reported in an LER, can be analyzed using the ASP methodology presented in Chapter 3 of this report.

The three case studies cover different aspects of the ASP fire-precursor methodology, and are keyed to the three separate discussions of fire-LER guidance in Sections 3.7.1 (guidance for a fire-configuration-compromise LER), 3.7.2 (guidance for a real-fire LER), and 3.7 .3 (guidance for a non-fire-failure LER).

The case study involving a real fire is taken from a 1995 LER reported by a PWR (see Section 4.2 below), in which a fire was caused by a defective automatic fast power transfer.

The case study involving a fire configuration compromise is taken from a 1989 LER reported by a BWR (see Section 4.3 below), involving a potential for a fire in the cable-spreading room to produce a spurious opening of certain valves leading to possible overpressurization of the low-pressure piping.

The case study involving a non-fire failure is taken from a 1994 LER reported by a BWR (see Section 4.4 below), involving the long-term unavailability of the HPCI (high pressure coolant injection) system, which unavailability could make the plant more susceptible to fire-initiated accidents than would otherwise be the case.

It is important to recognize up-front that the actual safety issues reported in these LERs have long since been resolved: no safety issues exist today. These LERs were chosen because they provide useful tutorial examples for our case-study purposes here. The selection of these LERs was done solely to fulfill this tutorial objective.

Note that, in order to keep the focus of the case studies on the methodological guidance, we have chosen to keep the actual nuclear-plant names anonymous. Four plants are involved, which we call Plants $A, B, C$, and D. (The nuclear plant studied in the seismic case study in Chapter 5 is called Plant X.)

\subsection{Case study: A fire as a real incident}

\subsubsection{Summary}

Plant $A$ is a Westinghouse pressurized water reactor (PWR) with a large dry containment. In late 1995, there was an electrical grid transient in a switchyard near the Plant A nuclear power plant. The actuation of an oversensitive relay resulted in a generator lockout and an automatic fast transfer of power from the main generator to offsite power.

The transfer was deficient and caused a reactor trip and a fire. A fire resulted due

$$
4-1
$$


to large currents on bus $3 \mathrm{~A} 2$ that was fed simultaneously by the main generator and offsite power. These power sources were out of phase. Under normal conditions the unjustified signal of transfer should not have caused an incident. The root of the problem was a deficiency in the fast transfer.

Given that the LER reports an initiating event (a trip), the LER was screened in during the initial screening process and was selected for further analysis. In the preliminary analysis, it was concluded that the fire reported in the LER neither induced damage nor had the potential to affect safety-related equipment in the location involved. Therefore, the LER was finally screened out from further evaluation. However, given that the LER reports several out-of-the-ordinary situations regarding the suppression activities and the presence of smoke, this analysis evaluated the event anyway from the fire point-of-view and some recommendations have been developed.

\subsubsection{Event Description}

\section{A. The transfer from onsite to of fsite power}

According to the simplified AC system scheme shown in Figure 4.2.1, the following transfers were expected:

- Train A: From UAT 3A to SUT 3A for buses 3A1 and 3A2.

- Train B: From UAT 3B to SUT 3B for buses 3B1 and $3 B 2$.

The expected action for the transfer is the following: each Unit Auxiliary Transformer [UAT] feeder breaker opens and simultaneously the corresponding Startup Transformer [SUT] feeder breaker closes, transferring power from onsite to offsite. The transfer was deficient for the A train, for both buses.

a) Bus 3Al: In the $3 \mathrm{Al}$ bus [6.9 $\mathrm{kV}$, the UAT feeder breaker [henceforth UA1] opened as expected and the SUT feeder breaker [henceforth SA1] failed to close, due to a random failure. As a result, bus $3 \mathrm{Al}$ was lost, with the subsequent loss of the Reactor Coolant Pumps [RCPs] $1 \mathrm{~A}$ and $1 \mathrm{~B}$, leading to a reactor trip due to RCP low flow. In addition, losses of the condensate pumps $A$ and $C$ and circulating pumps $A$ and $C$ occurred. Also, an auxiliary-relay random failure resulted in a false indication, preventing the operating staff from knowing about the loss of the $3 \mathrm{Al}$ bus.

b) Bus 3A2: In the $3 \mathrm{~A} 2$ bus [4.16 kV], the UAT feeder breaker [henceforth UA2] opened too slowly, while the SUT feeder breaker [henceforth SA2] closed as expected. During a fraction of a second [0.3 sec.] both feeder breakers remained closed, in overcurrent condition. As a consequence of the overcurrent, the breaker UA2 was destroyed and the breaker SA2 was open. The ultimate consequence was the loss of the $3 \mathrm{~A} 2$ bus, a partial loss of offsite power and the start and run of the electrical diesel generator [EDG] A. The destruction of the breaker UA2 produced a fire and subsequent smoke in the Turbine Generator Building [TGB] Switchgear Room. 
Figure 4.2.1. Schematic AC electrical distribution system of Plant A

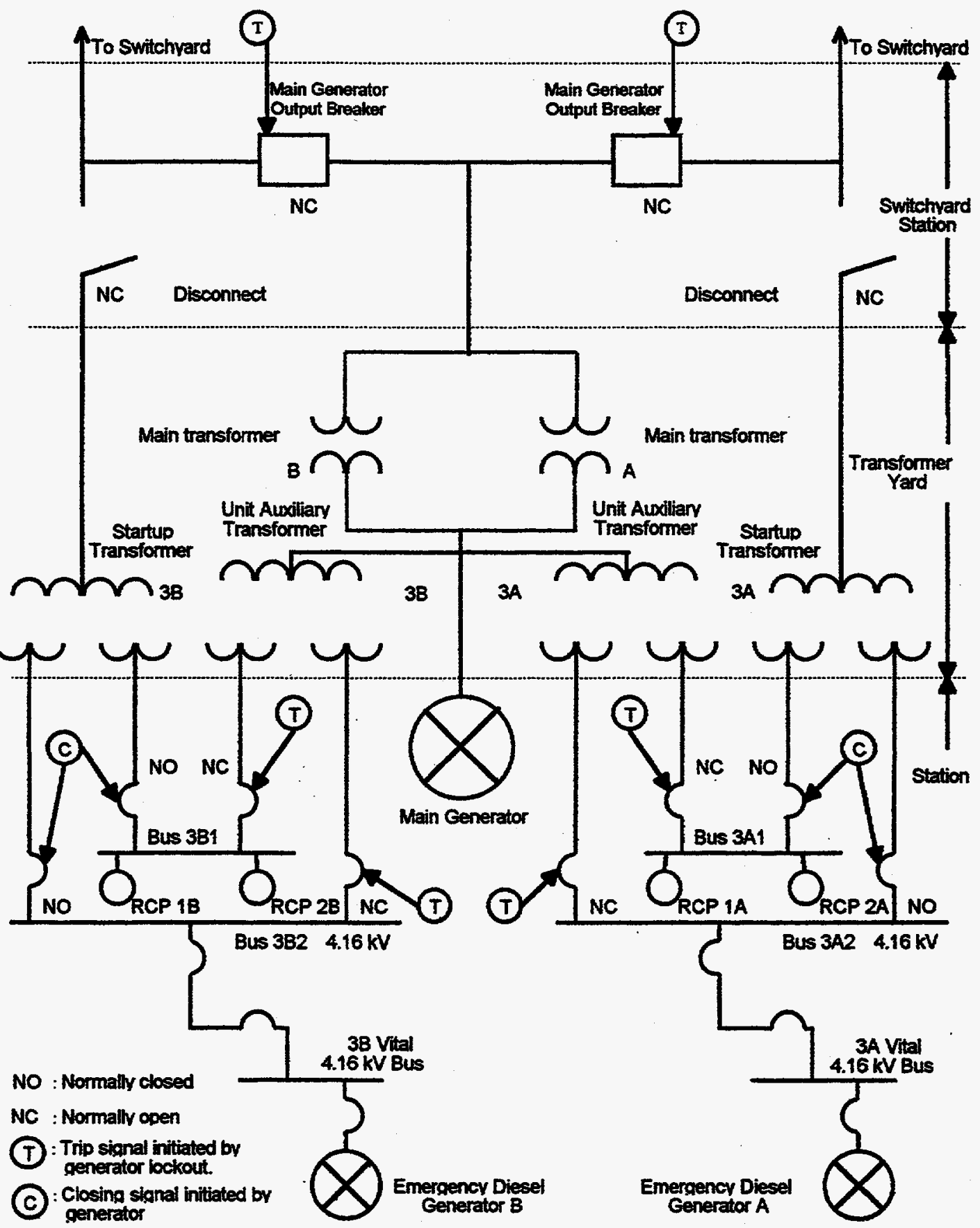


Chronological description of the fire

(all times below are in minutes)

$t=0$ : Lighting arrester electrical fault on nearby $230-\mathrm{kV} / 345-\mathrm{kV}$ substation; reactor trip.

$\mathrm{t}=1: \quad$ Fire and smoke are automatically detected by a group of system detectors located in the TGB switchgear room.

$t=8: \quad$ Smoke coming from the TGB switchgear is reported by a TGB operator. Two auxiliary operators are sent to verify the problem.

$t=37: \quad$ Fire is reported as occurring above the $3 \mathrm{~A} 2$ switchgear and declared.

$t=37: \quad$ Suppression activities are initiated by the plant fire brigade.

$t=47: \quad$ An "unusual event" is declared because the fire was not extinguished within 10 minutes.

$t=60: \quad$ The local fire brigade arrives on site. Portable dry chemical extinguishers are not effective in combating the fire.

$t=84: \quad$ Following water application with a nozzle, the fire is apparently extinguished. A forced entry into the interior of the affected switchgear is initiated. A reflash occurs, requiring additional water application.

$t=135: \quad$ The fire is officially extinguished. The time from detection to total suppression was about 134 min., i.e., about eleven times longer than the 12 minutes estimated by the plant in its fire analysis.

\section{Other relevant operational events}

a) Detection of fire/smoke: The control room operators received a notification of fire/smoke at $t=1$ from the automatic detection system. Simultaneously, alarms for the scram were received. In addition, a verbal notification about smoke was given at $t=8$ and a phone notification occurred at the same time, from different personnel.

b) Fire declaration delay: In spite of the alarm notifications for fire/smoke and the reports of smoke, the control-room operators did not declare a fire until the visualization of flames. The firefighting procedures and station policies did not specify when a fire should be declared. Therefore, the fire declaration was left to the judgment of the control-room supervisor. Based on previous experience, the operators estimated that a fire resulting from an electrical fault would rapidly burn out and produce the smoke being observed.

c) Delay in entering EOP "Loss-of-offsite-power recovery" after the verification of electrical bus status: At $t=0$, due to the scram, the operators entered emergency operating procedure OP-902-000, "Emergency Entry Procedure", consisting of some immediate steps and some diagnostic steps. One of the immediate steps is the verification of safety-related buses [3A3-S, 3B3-S, 3AB3-S], and one of the diagnostic steps is the verification of non-safety-related buses [3A1, 3A2, 3B1, 3B2].

$$
4-4
$$


Regarding the verification of the status of the electrical buses, the immediate steps were completed. During the diagnostic steps, the verification of the $3 \mathrm{Al}$ bus loss, source of the trip, was not correctly performed and the deenergization status of the bus was not detected. Given the failure of the auxiliary relay on the $3 \mathrm{Al}$ bus, described earlier, the indications for the loads of the bus, RCPs $1 \mathrm{~A}$ and $2 \mathrm{~A}$, condensate pumps $A$ and $C$ and circulating pumps $A$ and $C$ remained lighted. During that step the following errors were committed with the results that the status of the $3 \mathrm{Al}$ bus and the subsequently decreased coolant flow were not detected:

- The "open" indication light for SUT 3A1 feeder breaker was missed.

- The backup indications for RCP status [loop differential pressure and RCP amperage] were not used. These would have allowed the operating crew to acknowledge the status of some RCPs and to relate it to the loss of the $3 \mathrm{~A} 1$ bus.

d) Failure to complete an immediate step of the EOP: The Closure of the Moisture Separator Reheater control valves to a required post-trip position is one of the immediate steps in the EOP. The operator in charge of the step was directed to the TGB switchgear room to investigate the smoke. The operator judged that it was unnecessary to notify the control room that the step had not been completed. On the other hand, the control room personnel judged the investigation of the fire to be a high priority and did not send another operator to complete this immediate step. In this case, the out-of-position valves had no effect on reactor operation.

\subsubsection{Additional information regarding the incident}

\section{A. Effects of the fire}

The fire damage was limited mainly to the UAT feeder breaker supplying the $3 A 2$ non-safety-related bus and the adjoining meter cabinet. The root cause of the fire in the 3A2 switchgear was the improper automatic bus transfer from the UAT to the SUT.

Two switchgear cabinets were heavily damaged by the fire. The insulation on the bus duct from the UAT to bus $3 \mathrm{~A} 2$ was completely consumed by fire over the approximately 10-foot vertical run where the cables entered the switchgear cabinet. Damage to the horizontal run of the cables appeared to be confined to the plume: that is, there did not seem to be any horizontal propagation.

The cable bus duct for the SUT feed to bus $3 \mathrm{~A} 2$ [the of fsite power feed] is stacked above the UAT to $3 A 2$ bus duct. Damage to the SUT to $3 A 2$ cables was limited to external heat damage to the insulation. Subsequent testing of these cables verified that continuity and insulation were intact. No other significant damage was found. Therefore, the fire damage was limited to the UAT to $3 A 2$ feeder breaker [fire source] and the surrounding cables. The UAT to $3 \mathrm{~A} 2$ feeder breaker had already been destroyed by the overcurrent, and the fire did not cause damage which could compromise other components or cables.

\section{B. Effects of the smoke}

In general, smoke may have two effects: a physical and a psychological effect. The

$$
4-5
$$


physical effect is preventing some action from being performed in the affected location. This refers to situations when smoke obscures some location, affecting actions involving components or elements. The psychological effect is the inducing of human errors or actions not related to smoke-affected locations. This refers, for example, to changes in priorities that could allow or force a procedure to be delayed, dismissed or not completed.

The following are the conclusions about the effects of smoke on the incident, after the reactor trip and partial loss of offsite power were produced -- that is, on the significant events identified.

a) Fire declaration delay: Even though the smoke hid the presence of flames, it is judged that the delay should not be attributed to that fact. The operators had the fire notification from the automatic detection system, and even though the policies of the plant regarding a fire declaration did not provide adequate guidelines, the human error was the predominant factor in the delay. Basing the non-declaration on past experience was, in this case, an incorrect decision.

b) Delay on entering EOP "LOOP recoverv": According to the description of the event given earlier, the crew did not verify correctly the electrical bus status and did not make use of the backup indicators for the loss of RCPs. The delay in that diagnostic step (verification of non-safety electrical buses) is judged not to be related to the presence of smoke.

c) Failure to complete an immediate step of the EOP "emergency entry procedure": This event, according to the Plant $A$ event report, was the consequence of the change of priorities made by the Control Room personnel due to the presence of smoke. Therefore, it is judged that the smoke played a psychological role in this event. However, the fact that an operator was not sent to perform this immediate step but did not complete it is judged to be a human error.

4.2.4

ASP Fire Review of the Case Study

4.2.4.1 Step 1 screening process

The LER should be initially screened in, because it reports an "initiating event" (reactor trip) among the events involved during the operational event. Therefore, step 1-A indicates that the LER should be passed on to step 2 (preliminary analysis), specifically to step 2-A.

\subsubsection{Step 2 preliminary analysis}

1. Step 2-A. LER screened in, because it reports an initiating event

Given the availability of more detailed information from the plant and the events reported in the LER, the ASP analyst should evaluate the role of the fire in the whole situation, considering the possibility that the fire could have been incidental to the simultaneous occurrence of the other events and also the fire's potential to induce damage in safety-related equipment. If the analyst were to demonstrate that the fire was, in fact, incidental and did not have the potential to affect safety-related equipment, the LER may be screened out in this step. 
If it were screened out, the LER should nevertheless be passed back through the rest of the steps of the screening process and the analyst should evaluate the events from a fire-analysis point of view and document the lessons learned.

a) Analysis of the LOSP: During the time that the UA2 and the SA2 feeder breakers were closed, the overcurrent caused the former to fail and the latter to open. Once the UA2 feeder breaker was destroyed, the fire was initiated. According to the evaluation of damage in the TGB switchgear room, the fire did not affect the SA2 feeder breaker or cables.

For this reason, it is concluded that the partial LOSP was caused by the destruction of the UA2 feeder breaker and not by the resulting fire.

b) Analysis of the trip: The cause of the trip was the loss of the $6.9 \mathrm{kV}$ bus $3 \mathrm{~A} 1$. The loss of this bus causes reactor trip on low RCP speed. Since safety-related equipment is powered by a separate $4.16 \mathrm{kV}$ line, the failure of the bus $3 \mathrm{Al}$ does not affect other safety-related equipment. The low RCP speed, caused by RCP speed sensed at less than $96.5 \%$ of rated flow, induces a signal of Departure from Nucleate Boiling Ratio, which trips the reactor. In the present case, 2 out of $4 \mathrm{RCP}$ pumps were lost.

From the analysis performed, it is apparent that the fire was incidental to the simultaneous occurrence of the other reported events. That is, the reactor trip as the initiating event and the partial LOSP were not related to the existence of the fire in the plant. Both the initiating event and the partial LOSP are internally-induced events and therefore they should be evaluated accordingly. The fire was a conseguence of these events and did not either induce damage or have the potential to induce damage that could have increased the risk from the loss of safety-related equipment.

However, given that the LER also reported problems related to fire detection and suppression, and also given the presence of smoke, and considering that such out-of-the-ordinary situations should be considered for further analysis, the LER should be analyzed in order to obtain safety insights and recommendations from the point of view of fire analysis.

\subsubsection{Analysis of problems related to fire}

\section{Detection}

a) Declaration of fire incident: Suppression activities depend strongly on adequate detection. In the present incident, the automatic detection system worked as expected, but the human response was inadequate, so that the fire detection was ignored. Even though the volume of the sound alarms was decreased by the presence of a tape layer over some alarm annunciators, a light signal for fire was available in the control room and was not used by the operators.

The non-declaration of a fire incident, in spite of alarm actuations, a report of smoke from the TGB operator, and a phone report of smoke from the Generation Service Building is considered a human error. The personnel in charge based their decision on previous experience. The operator placed inappropriate emphasis on the visual observation of flames. This turned out to be incorrect.

$$
4-7
$$




\section{Suppression}

One of the most important deviations from the plant's IPEEE fire analysis is the effective duration time of the fire. As discussed above, the suppression activities took almost eleven times as long as the time duration considered by the IPEEE (134 minutes compared to 12 minutes).

Even though this particular event demonstrated that the extensive time did not cause damage to other components or cables beyond the immediate area of the source, it is judged that the assumed 12 minutes may not be realistic and it should be revisited.

According to the analysis of the report, there was evidence of the following fire brigade training problems during the incident:

- Lack of adequate training on what to do before the leader arrives, which complicated the tasks of ventilation.

0

Insufficient training, or lack of training, for fighting fires in areas such as a run of cables, where it was difficult to apply the extinguishing agent and the residual heat was concentrated.

\subsubsection{Results}

A key conclusion is that the LER event should be screened out from the fire-ASP analysis based on the fact that the fire was a consequence of another event that tripped the plant, and that the fire did not cause any other safety concern to the plant. However, various lessons-learned from this incident are important to discuss, as follows:

First, as mentioned, the fire was not a cause but a consequence of the events at Plant $A$ and did not have any relationship to the partial loss of of site power. The damage from the fire was limited to the already-failed UAT to $3 A 2$ feeder breaker and associated cables to the $3 \mathrm{~A} 2$ bus. No other damage was induced.

The presence of smoke in the plant made the incident more confusing to the crew and caused it to change priorities and act erroneously. However, all of the problems caused by the fire (fire-declaration delay, delay in entering the EOP, and failure to complete one step) depended strongly on human error, but not on the presence of smoke.

The unexpectedly slow response of the fire brigade probably contributed to more extensive switchgear damage that would have otherwise occurred. However, the damage was limited to the $3 A 2$ UAT and surrounding cables, and other already-failed components [3A2 UAT feeder breaker].

It is estimated that in this incident, the fire did not contribute significantly to the sequence of events. First, the fire did not cause any direct impact on the safety of the plant during the development of the incident. The problem reported is completely attributable to other non-fire events. However, the event demonstrated the problems associated with fire-detection and fire-fighting procedures and the negative effects of smoke on the operators. 
The present LER should be interesting from the point of view of internal-events ASP, because the following situations occurred during the incident:

- A new type of initiating event, a reactor trip due to loss of the $3 \mathrm{Al}$ bus, was produced. This initiator had not been previously considered by the plant among the possible initiating events.

- Problems occurred in the transfer from onsite to offsite power, due to an internal failure of an oversensitive relay, thus initiating the incident.

This event should be returned to the internal-events ASP for analysis. The internalevents ASP analysts should consider the fact that the effect of smoke on various human actions may lead to higher values of human error probabilities.

\subsection{Case Study: a fire configuration compromise}

\subsubsection{Summary}

Plant B is a General Electric boiling water reactor (BWR) in a Mark II containment. One day in 1989, personnel at Plant $\mathrm{C}$ determined that a fire in the Cable Spreading Room could result in the spurious opening of two high/low pressure interface shutdown cooling valves, which could result in a possible overpressurization of the low pressure piping. The root cause of this condition was determined to be the lack of detailed procedures used in performing the original safe-shutdown analysis. The reported condition was classified as a configuration compromise and analyzed in detail. The Conditional Core Damage Probability associated with the condition is calculated to be $5.5 \times 10^{-6}$. Therefore, the detected condition meets the criteria to be designated as an "Accident Sequence Precursor."

\subsubsection{Event description}

As a result of a Safe Shutdown Analysis, Plant B personnel determined that a fire in the Cable Spreading Room could result in the spurious opening of the high/low pressure interface Residual Heat Removal [RHR] shutdown cooling valves (designated HV-51-1F008 and HV-51-1F009), which could result in the possible overpressurization of the low pressure piping. As a result, if both of the valves in the RHR system were to open due to fire damage, a Loss of Coolant Accident [LOCA] could occur due to the ruptured piping. Figure 4.3.1 shows a simplified diagram of the Residual Heat Removal System containing the interfacing system valves involved.

The reported condition was present for a long time, four years and nine months, from late 1984 to mid-1989.

Corrective actions: As a compensatory measure, some corrective actions were implemented. The power supply breaker for the RHR shutdown cooling section, outboard containment isolation valve HV-51-1F008 was to be locked open, de-energizing the valve in the closed position whenever the reactor coolant pressure was greater than $75 \mathrm{psig}$, so that a fire in any one fire area could not cause both the inboard and outboard containment isolation valves to open spuriously and result in overpressurizing the low pressure piping. 


\subsubsection{Analysis}

\subsubsection{Logic model for quantification}

In the compilation of accident sequences developed by Plant $B$ through their Individual Plant Examination [IPE], the frequency of an interfacing system LOCA was found to be far below the dominant core-damage-frequency contributors. Therefore, based on the low probability of occurrence of the sequence, an event tree was not developed originally. Given that the LER has been screened in for further analysis, the development of the logic model for quantification will be required.

Interfacing-system LOCA event tree development: The interfacing-system LOCA [ISLOCA] event tree is based on the mitigation features of the plant for a large LOCA and the approach for analyzing interfacing-system LOCAs for PWRs in WASH 1400 (NRC, 1975). The ISLOCA event tree that was developed is shown in Figure 4.3.2.

The systems available at plants like Plant B to mitigate the consequences of a LOCA are (LaSalle, 1993):

- High pressure coolant injection.

- Low pressure core spray.

o Low pressure coolant injection/Residual Heat Removal mode.

- Reactor core isolation cooling.

- Automatic depressurization system.

- Control rod drive.

Assumptions: The following are the assumptions made in the definition of the event tree with an ISLOCA as the initiating event:

1) It is possible to mitigate an ISLOCA. That is, it is assumed that an ISLOCA does not lead directly to core damage.

2) It is possible to close the path from the high pressure to the low pressure systems before core damage. That is, there is enough time between the ISLOCA initiator and core damage, so that an operator corrective action is possible. The path from the high-pressure side to the low-pressure side can be closed when a certain level of depressurization is reached, by isolating the damaged piping by closing at least one of the compromised RHR shutdown cooling valves.

3) The emergency coolant systems are capable of providing coolant makeup to prevent core damage. That is, it is possible to maintain the core covered before the closing of the path. If this assumption is not correct, then the LOCA leads to core damage immediately. For large LOCAs, the low-pressure systems are designed to provide enough coolant makeup and they will be used for this LOCA model.

4) The event tree for an ISLOCA, under the conditions mentioned, can be based on a large-LOCA event tree, assumed for this case to be the worst condition, considering that for this condition the volume of lost coolant is maximal. 
5) It is judged that the most likely action to be performed by the operators would be the manual closing of at least one of the reported valves. A calculation was performed based on expert judgment to work out the "likelihood of failure to close the path opened by the rupture of the low pressure piping". A conservative value of 0.1 will be used as the failure probability to close the path before water depletion.

The following factors were considered in the above estimate:

- Assumptions in analyses of similar plants (LaSalle, 1993) that this type of sequence would lead directly to core damage.

The fact that it has been assumed that the probability of closing [F-CLOSE] the path exists.

- By performing a sensitivity analysis for that probability, it is found that a value equal to or less than 0.01 causes the reported condition to be screened out as being less than the ASP screening value for the CCDP of $1.0 \times 10^{-6}$. A more exact calculation may be performed, but the result will not significantly affect the value. A simplified sensitivity analysis for the "failure probability to CLOSEn $^{n}$ vs. CCDP is shown in Figure 4.3.3.

\subsubsection{ISLOCA event tree definition}

The interfacing-system-LOCA event tree (Figure 4.3.2) uses the following definitions:

\section{1) Initiating event: Interfacing system LOCA [ISLOCA]}

The initiating event is the opening of the upstream and downstream RHR shutdown cooling valves in the Cable Spreading Room, creating a path from the reactor vessel to the reactor enclosure.

\section{2) Reactor Protection System [RPS]}

This system performs the subcriticality function. A sufficient number of control rods must be inserted to terminate power production.

\section{3) Low pressure coolant in jection [LCI, LCS]}

Given the assumption that the large loss of coolant through the valves and the damaged low pressure pipes causes depressurization, the safety relief valves are not used and there is a need for coolant makeup from the low pressure systems, i.e., the Core Spray System [CS] and the Low Pressure Coolant Injection System [LPCI], an operating mode of the RHR system. Coolant makeup is provided by the low-pressure systems by using the water located in the Condensate Storage Tank, the suppression pool and the RHR service water [RHRSW].

Even with the low-pressure systems operable, it is still necessary to keep the core covered during the time that the coolant is escaping through the open path. The low-pressure systems may be able to provide the necessary flow rate to keep the core covered, but it is still necessary to close the path before the water sources deplete. 


\section{4) Close path before water depletion. [CLOSE]}

This function consists of the necessary steps for closing at least one of the valves, assuming that it is possible to isolate the reactor vessel. It is assumed that the most likely action would be performed by plant operators, i.e., manually closing one of the valves.

If it is assumed that the path is closed before core damage, then the following functions are designed to remove the residual heat from the core and the containment:

\section{5) Containment heat removal [CHR]}

This function preserves primary containment integrity and transfers fission-product decay heat to the environment. It is performed by the RHR and the RHRSW systems.

\section{6) Containment venting $[\mathrm{CV}]$}

For LOCAS [large, medium or small], the function "venting success" is included, considering the fact that coolant has been blown down into the containment and therefore the containment pressure has increased. Thus, containment venting is necessary when the containment heat removal fails.

\section{7) Injection systems available}

The event "injection systems available" is considered in the event tree because a failure to vent the containment may produce a failure in those systems. The systems considered are: Control Rod Drive [CRD] and RHRSW in jection.

The factors that contribute to the consideration of this branch are:

Failure of the containment heat removal: Without decay-heat removal from the containment, the suppression pool will eventually heat up and steam will be generated in the wetwell. Pressure in the containment will continue to increase. The failure of the containment would lead to two potential phenomena that would compromise the ability to keep the core covered:

(i) The suppression pool may have a substantial portion of the inventory flash to steam, leading to:

o Possible cavitation causing damage to the pumps during the postulated containment blowdown phase.

- Potential piping or valve damage due to the large steam generation rate during the blowdown of the containment.

- Venting of steam into the reactor enclosure, adversely affecting the switchgear, motor control centers or instrumentation for the injection systems located in the reactor enclosure.

(ii) The failure of the containment may also lead to failure of the coolant-

$$
4-12
$$


injection piping supplying water to the vessel from the hotwell, the condensate storage tank and the suppression pool due to structural damage in the reactor enclosure.

\subsubsection{Scenario involving reported cables as targets for a fire ignition source}

For the development of the present case study, not all the required information about the location and the physical scenario containing the reported cables was available. For our pedagogical purposes, that information was assumed known, based on the use of limited sources from the plant and other alternatives -- of course, in a real case the analyst will have or must obtain the necessary information to develop the correct analysis of the reported event. Alternatively, information from generic databases and that from similar plants can be used.

In this case study, the following information was assumed known:

- The contents of the physical scenario in the Cable Spreading Room, containing the reported cables for the interfacing system valves, along with other safety-related cables, all of them potentially affected by a postulated fire.

o Characteristics of the involved location. That is, components and cables of safety-related equipment in the Cable Spreading Room, including their spatial distribution, physical properties and parameters of fuel, materials and room required for fire modeling. Table 4.3.1 lists the input data for the scenario in the Cable Spreading Room --- these input data are necesary for the detailed analysis to be discussed below.

- Necessary information for the definition of parameters concerning the fire initiating frequency and the geometric, severity and non-suppression factors, developed according to standard fire-PRA procedures.

Cable Spreading Room scenario modeling: According to the available information from the plant, the Cable Spreading Room contains cables that are associated with shutdown methods $A, B, C$ and $D$ of the plant. In addition, the Cable Spreading Room does not contain cabinets and the self-ignition of cables is considered very unlikely. If a potential fire is to be considered, the most likely possibility would be from a transient ignition source.

As a result, for the scenario involving the reported interfacing system valve cables, the existence of a transient source was postulated, with the potential to affect the trays containing the cables involved with power/control for the following safety-related systems:

Trav LHI

- Train B of the Residual Heat Removal Service Water system.

Tray LMI

o Train A of the Control Rod Drive.

- Residual Heat Removal shutdown cooling valve

HV-51-1F008, components of RHR train A. 
Tray LLO

o Train B of the Low Pressure Coolant System.

Tray RHI

- Train A of the High Pressure Coolant In jection System.

- Residual Heat Removal shutdown cooling valve HV-51-1F009, components of RHR train A.

\subsubsection{Quantification procedure}

According to standard fire-PRA procedures (Apostolakis, 1993), the expression to be used for quantification is the following product:

$$
C D F=\lambda_{f} \times f_{2} \times f_{s} \times f_{n s} \times Q
$$

where:

$$
\begin{aligned}
& C D F=\text { Core Damage Frequency (per year) } \\
& \lambda_{\mathrm{f}}=\text { Initiating event frequency (fires/year) } \\
& \mathrm{f}_{\mathrm{a}}=\text { Geometric factor } \\
& \mathrm{f}_{\mathrm{s}}=\text { Severity factor } \\
& \mathrm{f}_{\mathrm{ns}}=\text { Non-suppression factor } \\
& \mathrm{Q}=\text { Logic model value, involving fire-induced failures and random failures. }
\end{aligned}
$$

The quantification process was performed by using the IRRAS computer code (IRRAS, 1995) and the ASP electronic files for the plant, containing the fault trees for all the safety-related systems included in the event tree corresponding to the ISLOCA as the initiating event. In each case where a quantification was performed, either in the preliminary analysis, the intermediate screening or the final quantification, the procedure was the following:

1. Identify the basic events in the fault trees affected by the reported condition (in this case, the trains or components affected by fire damage). Set the failure probability of identified basic events equal to 1.0. In addition, assume a value of 1.0 for the initiating event for the event tree.

2. The unimpacted basic events maintain their failure probabilities equal to the random failure values established in the fault tree models, from generic and/or plant-specific data.

3. With the information from 1 and 2 , quantify the integrated event tree to get the value of $Q$.

4. Estimate, as required, the parameters involved in the fire initiating frequency and its modifying factors, the geometric factor, the severity factor, the nonsuppression factor and any other applicable factor, by using standard firePRA procedures.

$$
4-14
$$


5. The probability, $P$, that a fire-induced initiating event could occur during the period of the failure or unavailability is calculated by multiplying the value of the modified fire initiating-event frequency by the duration of that period.

6. Finally, the Conditional Core Damage Probability is calculated by multiplying the value of $Q$ by the value of $P$.

7. In addition, the importance measure is determined by calculating the value of the Core Damage Probability [CDP] for the period of the unavailability or failure, with all the failure probabilities for the basic events in the quantification model equal to their random failure values. The importance measure is then the value that results from the subtraction of the CDP from the CCDP determined above, for the same period.

\subsubsection{ASP Fire Review}

\subsubsection{Step 1 -- Initial screening}

It is deemed that the reported condition represents a potentially important safety issue and therefore it is of interest to the present ASP methodology, because it involves a potential Interfacing System LOCA as the initiating event. Therefore, if the involved location is destroyed, at least one of the consequences would be an ISLOCA. and a plant trip would be caused. As a result, the LER is screened in and passed on to Step 2, "preliminary analysis", for further analysis.

\subsubsection{Step 2 -- Preliminary analysis}

For the preliminary analysis, it is assumed (i) that the entire zone in which the configuration compromise has been detected is destroyed by fire; and (ii) that no fire suppression is available or performed. For every basic event contained in the plant-specific internal-event model that is affected by the destruction of components or cables in the Cable Spreading Room, the failure probability is set equal to 1.0 .

Running the internal-event plant-specific model for the interfacing system LOCA as the initiating event, the LER is screened in for the following reason:

The value of the Conditional Core Damage Probability using a modified-IPE internalevents PRA model, even considering only the scenario containing the reported cables for the interfacing system valves, is $1.04 \times 10^{-4}$ which significantly exceeds the screening value of $1.0 \times 10^{-6}$. That is the necessary and sufficient condition for the LER to be passed on to Step 3 for detailed analysis. Definition and failure probabilities for selected basic events used in this quantification are presented in Table 4.3.2.

\subsubsection{Step 3 -- Detailed analysis}

\section{Substeps (1) and (2)}

The equipment items affected by the inadequate configuration were identified and listed earlier in the Cable Spreading Room scenario.

$$
4-15
$$


Substep (3)

The scenario corresponding to the configuration compromise was defined earlier according to the items in Substeps (1) and (2), with a postulated transient ignition source in the Cable Spreading Room.

\section{Substeps (4) and (5)}

In the present case, the consequence of the reported condition (a configuration compromise) has been explicitly defined in the LER as the possibility of an interfacing system LOCA as the initiating event for a fire-initiated sequence.

Analyzing the information from the plant, it has been concluded that no fire PRA model exists for the scenario containing the interfacing system valve cables (for BWRs). Therefore, the condition corresponds to substep (4A), Case A, "not included". Thus, in order to evaluate the risk significance of the reported condition, a PRA model must be created and the LER will be passed on to substep (5) and then to substep (6). However, to reduce unnecessary effort for fire modeling, an intermediate quantitative screening analysis must be performed. Therefore, the reported condition will be passed on to Step (6A) for intermediate screening.

\section{Substep (6A), Intermediate screening}

To perform this analysis, the parameters associated with the fire initiating frequency, geometric factor and severity factor corresponding to the defined scenario were estimated using standard fire-PRA procedures.

All of the safety-related equipment involved in the scenario containing the interfacing system valve cables was assumed lost. The failure probabilities for the impacted basic events associated with each loss were set to 1.0. Then, the interfacing system LOCA event-tree model was quantified for the period that the detected condition lasted, assuming no fire suppression.

The CCDP resulting from the quantification process is $1.45 \times 10^{-4}$. Consequently, the intermediate screening value has been exceeded and the reported condition is passed on to Step (6B) for "final analysis". Definitions and failure probabilities for basic events used in the intermediate screening are presented in Table 4.3.2. Table 4.3.3 summarizes the values for the parameters indicated above and shows the results. According to (6B.i), a fire model must be developed, so that a less conservative calculation of the probability of damage for each safety-related equipment can be performed.

\section{Substeps (6B.i) and (6B.ii), Fire model}

In order to determine more realistically the consequences of a postulated fire in the Cable Spreading Room for the reported valves and the safety-related systems, the COMPBRN IIIe (Ho, Chien, and Apostolakis, 1990) fire growth code was used to calculate fire propagation and equipment damage. The code calculates the time to equipment damage given that a fire has started. Input parameters were obtained from the COMPBRN IIIe database and generic case studies (Apostolakis, 1993), as detailed in Table 4.3.1. The description of the scenario is presented in Figure 4.3.4. According to the requirements of COMPBRN IIIe for the development of the model,

$$
4-16
$$


each tray was subdivided into three parts (for example, for tray LHI parts LHIl, LHI2 and LHI3 were created).

In addition to providing the time-to-damage for each target involved in the scenario, COMPBRN IIIe has the capability of performing uncertainty analysis, using simulation techniques, based on the probability distribution of the parameters involved in the model for fuel, targets and room. The uncertainty analysis performed by the code was complemented by the use of an analytic risk-analysis software program, in order to get a probabilistic distribution for the time-to-damage for each component involved in the modeled scenario. The results from the uncertainty analysis for two of the targets are presented in Figures $4.3 .5 \mathrm{a}$ and $4.3 .5 \mathrm{~b}$, based on data from COMPBRN IIIe in Tables 4.3.4a and 4.3.4b. The following are the mean values for the time-to-damage for the involved targets:

- Tray LHI. Cable 2-LHI, Train B of the Residual Heat Removal Service Water system is damaged in 8 minutes.

- Tray LMI. Cable 2-LMI, Train A of the Control Rod Drive and Residual Heat Removal shutdown cooling valve HV-51-1F008 are damaged in 7 minutes.

- Tray LOL. Cable 2-LLO, Train B of the Low Pressure Coolant System. is damaged in 7 minutes.

- Tray RHI. Cable 2-RHI, Train A of the High Pressure Coolant Injection System and Residual Heat Removal shutdown cooling valve HV-51-1F009 are damaged in 7 minutes.

According to standard fire-PRA procedures, the damage time is then used in conjunction with plant-specific information regarding fire suppression to obtain the probability that the fire will cause equipment damage before being suppressed. The reported condition is now passed on to Step 3-C for final quantification.

\section{Substeps (6B.iii) and (6B.iv), Final quantification}

All of the safety-related equipment involved in the scenario containing the interfacing-system-valve cables is assumed lost, according to the results from fire modeling. The failure probabilities for the impacted basic events associated with each loss were set to 1.0 and the interfacing-system-LOCA event-tree model quantified according to quantification procedures established in Section 4.3.3 ("Analysis").

Definitions and failure probabilities for the basic events used on the final quantification are presented in Table 4.3.2. Table 4.3.5 summarizes the values for the parameters indicated above and shows the results.

\subsubsection{Results}

Table 4.3.6 shows the values of $Q$ for the quantification of the core-damage sequences of the interfacing system LOCA event tree, assuming the loss of the cable trays and associated failures to interfacing-system valves and safety-related systems. Dominant sequences are sequence 12 and sequence 9. Table 4.3.7 shows the sequence logic for dominant sequences identified for the LER. 
Dominant cut sets and associated basic events for higher probability sequences are shown in Table 4.3.8.

Finally, Table 4.3.9 shows the final results for the evaluation of the reported condition, in terms of the Conditional Core Damage Probability and the importance measure.

The Conditional Core Damage Probability for the detected condition is $5.47 \times 10^{-6}$. The importance measure for the period of four years and nine months is $5.47 \times 10^{-6}$. Based on the Conditional Core Damage Probability value, the risk significance of the LER exceeds the established ASP screening value and therefore the detected condition should be reported as an "Accident Sequence Precursor." 
Table 4.3.1. Input data for fire modeling of postulated scenario in the Cable Spreading Room I. OVERALL JOB PARAMETERS

\begin{tabular}{|l|l|}
\hline Time increment: & 60.0 seconds \\
\hline Number of time steps: & 60 \\
\hline Total time of simulation: & 60.0 minutes \\
\hline
\end{tabular}

\section{VARIABILITY FACTORS FOR FIRE MODELS}

\begin{tabular}{|l|l|}
\hline Ventilation controlled burning rate & 1.00 \\
\hline Fuel-surface controlled burning rate & 1.00 \\
\hline Flame height for horizontal fuel & 1.00 \\
\hline Flame height for vertical fuel & 1.00 \\
\hline Radiative heat flux interchange & 1.00 \\
\hline Buoyant plume temperature & 1.00 \\
\hline Convective heat transfer coefficient for vertical objects in plume & 1.00 \\
\hline Convective heat transfer coefficient for horizontal objects in plume & 1.00 \\
\hline Gas layer local temperature & 1.00 \\
\hline Heat transfer to self for vertical fuel & 1.00 \\
\hline Heat transfer to adjacent fuel & 1.00 \\
\hline Heat flux from ceiling hot gas layer & 1.00 \\
\hline Heat flux from reflections off walls and barriers & 1.00 \\
\hline Mass burnout fraction & 1.00 \\
\hline
\end{tabular}


Table 4.3.1 (continued)

\section{PHYSICAL FUEL PARAMETERS}

NUMBER OF FUEL TYPES INCLUDED: 4

1. CEILING

2. WALL

3. CABLE

4. SOLVENT

FUEL TYPE No. 1 - CEILING

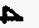

\begin{tabular}{|l|l|l|l|l|}
\hline \multicolumn{1}{|c|}{ Parameter } & Distrilhution & Point value & Low value & Hilgh value \\
\hline Thermal conductivity $[\mathrm{W} / \mathrm{mK}]$ & Normal & 1.06 & .4200 & 1.700 \\
\hline Thermal diffusivity $\left[\mathrm{m}^{2} / \mathrm{s}\right]$ & Point value & $0.537 \mathrm{E}-06$ & & \\
\hline Reflectivity [dimensionless] & Lognormal & $0.950 \mathrm{E}-01$ & $.5000 \mathrm{E}-01$ & .3500 \\
\hline
\end{tabular}

FUEL TYPE No. 2 - WALL

\begin{tabular}{|l|l|l|l|l|}
\hline \multicolumn{1}{|c|}{ Paramoter } & Disiriluution & Point value & Low value & High value \\
\hline Thermal conductivity [W/mK] & Normal & 1.06 & .4200 & 1.700 \\
\hline Thermal diffusivity [m2/s] & Point value & $0.537 \mathrm{E}-06$ & & \\
\hline Reflectivity [dimensionless] & Lognormal & $0.920 \mathrm{E}-01$ & $.5000 \mathrm{E}-01$ & .3500 \\
\hline
\end{tabular}


Table 4.3.1 (continued)

FUEL TYPE No. 3 - CABLE

\begin{tabular}{|c|c|c|c|c|}
\hline Parameter & Distribution & Polnt value & Low value & Highvalue \\
\hline Density [kg/m3]: & Uniform & 950. & 900.0 & 1000. \\
\hline Specific heat [j/kgk] & Neg-log & $0.225 E+04$ & 1823. & 2350. \\
\hline Thermal conductivity [W/mK] & Lognormal & 0.100 & $.8000 E-01$ & .4200 \\
\hline Heating value $[\mathrm{J} / \mathrm{kg}]$ & Point value & $0.231 E+08$ & $.7100 E+07$ & $.3500 E+08$ \\
\hline Pilot ignition temperature [K] & Point value & 800. & 576.0 & 1029. \\
\hline Spontaneous ignition temp. [K] & Point value & 840 & 750 & 850.0 \\
\hline Damage temperature $[\mathrm{K}]$ & Shift-log & 573 & 400 & 700.0 \\
\hline Vent. control burning rate constant [dimensionless] & Point value & 0.110 & 1.000 & 1.000 \\
\hline Specific burning rate constant $\left[\mathrm{kg} / \mathrm{m}^{2} \mathrm{~s}\right]$ & Point value & $0.187 E-01$ & $.1060 \mathrm{E}-01$ & $.3300 E-01$ \\
\hline Surface control burning rate constant $[\mathrm{kg} / \mathrm{J}]$ & Point value & $0.360 \mathrm{E}-06$ & $.9500 \mathrm{E}-07$ & $.1020 E-05$ \\
\hline Combustion efficiency [dimensionless] & Point value & 0.265 & .2000 & .3500 \\
\hline Fraction of flame heat released as radiation [dimensionless] & Point value & 0.450 & $.2700 \mathrm{E}-01$ & .7000 \\
\hline Absorption coefficient for flame gases $\left[\mathrm{m}^{-1}\right]$ & Point value & 1.40 & 1.000 & 1.000 \\
\hline Reflectivity [dimensionless] & Lognormal & 0.120 & $.8000 E-01$ & .3000 \\
\hline
\end{tabular}


Table 4.3.1 (continued)

FUEL TYPE NO. 4 - SOLVENT

\begin{tabular}{|c|c|c|c|c|}
\hline Parameler & Distrilbution & Point value & Lowvalue & Hilgh value \\
\hline Density [kg/m3]: & Point value & 679 & 679.5 & 888.2 \\
\hline Specific heat $[/ \mathrm{kgk}]$ & Point value & $0.224 E+04$ & 1880 & 2364. \\
\hline Thermal conductivity [W/mK] & Point value & 0.128 & .1280 & .1780 \\
\hline Heating value $[\mathrm{J} / \mathrm{kg}]$ & Point value & $0.467 E+08$ & $.4330 \mathrm{E}+08$ & $.5000 \mathrm{E}+09$ \\
\hline Pilot ignition temperature $[\mathrm{K}]$ & Point value & 269 & 228.0 & 494.0 \\
\hline Spontaneous ignition temp. [K] & Point value & 486. & 477.0 & 644.0 \\
\hline Damage temperature $[\mathrm{K}]$ & Point value & 1.00 & 1.000 & 1.000 \\
\hline Ventilation control burning rate constant [dimensionless] & Point value & 0.110 & 1.000 & 1.000 \\
\hline Specific burning rate constant $\left[\mathrm{kg} / \mathrm{m}^{2} \mathrm{~s}\right]$ & Normal & $0.610 \mathrm{E}-01$ & $.5500 \mathrm{E}-01$ & $.7500 \mathrm{E}-01$ \\
\hline Surface control burning rate constant $[\mathrm{kg} / \mathrm{J}]$ & Point value & $0.200 \mathrm{E}-06$ & 1.000 & 1.000 \\
\hline Combustion efficiency [dimensionless] & Uniform & 0.925 & .8500 & .9500 \\
\hline Fraction of flame heat released as radiation [dimensionless] & Point value & 0.507 & .4000 & .5000 \\
\hline Absorption coefficient for flame gases $\left[\mathrm{m}^{-1}\right]$ & Point value & 1.40 & 1.000 & 1.000 \\
\hline Reflectivity [dimensionless] & Point value & 0.100 & $.8000 \mathrm{E}-01$ & .3500 \\
\hline
\end{tabular}

\section{COMPARTMENT OBJECT DEFINITION}

NUMBER OF OBJECTS DEFINED: 18

\begin{tabular}{|l|l|l|l|l|l|l|l|l|}
\hline 1. CEILING & 3. F-WALL & 5. R. WALL & 7. C.1LHI & 9. C. 3LHI & 11. C. 2 LMI & 13. C.1LLO & 15. C.-3LLO & 17. C.-2RHI \\
\hline 2. L. WALL & 4. B. WALL & 6. Solvent & 8. C. 2 LHI & 10. C.-1LMI & 12. C.-3LMI & 14. C.-2LLO & 16. C.-1RHI & 18.C.-3RHI \\
\hline
\end{tabular}


Table 4.3.1 (continued)

\section{OBJECT 1 - CEILING}

\begin{tabular}{|l|l|l|l|}
\hline \multicolumn{2}{|c|}{ Parameter } & \multicolumn{2}{l}{} \\
\hline Object midpoint coordinates [X-Y-Z]: & 8.54 & 7.32 & 4.27 \\
\hline Dimensions [length, width, depth] [m]: & 17.1 & 14.6 & 1.00 \\
\hline Number of subdivided elements: & 1 & & \\
\hline First element midpoint coordinates [X-Y-Z]: & 8.54 & 7.32 & 4.27 \\
\hline Direction of logitudinal and normal axes: & $X$ & $Z$ & \\
\hline Total mass [kg]: & $0.100 \mathrm{E}+04$ & & \\
\hline Mass per element [kg]: & $0.100 \mathrm{E}+04$ & & \\
\hline Porosity factor [dimensionless] & 1.00 & & \\
\hline
\end{tabular}

OBJECT 2 - LEFT-WALL

\begin{tabular}{|l|l|l|l|}
\hline \multicolumn{1}{|c|}{ Parameter } & \multicolumn{2}{l|}{} \\
\hline Object midpoint coordinates [X-Y-Z]: & $0.000 \mathrm{E}+00$ & 7.32 & 2.13 \\
\hline Dimensions [length,width, depth] [m]: & 14.6 & 4.27 & 1.00 \\
\hline Number of subdivided elements: & 3 & & \\
\hline First element midpoint coordinates [X-Y-Z]: & $0.000 \mathrm{E}+00$ & 2.45 & 2.13 \\
\hline Direction of logitudinal and normal axes: & $Y$ & $X$ & \\
\hline Total mass [kg]: & $0.100 \mathrm{E}+04$ & & \\
\hline Mass per element [kg]: & 333. & & \\
\hline Porosity factor [dimensionless] & 1.00 & & \\
\hline
\end{tabular}


Table 4.3.1 (continued)

\section{OBJECT 3 - FRONT-WALL}

\begin{tabular}{|l|l|l|l|}
\hline \multicolumn{1}{|c|}{ Parameter } & \multicolumn{3}{l|}{} \\
\hline Object midpoint coordinates [X-Y-Z]: & 8.34 & $0.000 \mathrm{E}+00$ & 2.09 \\
\hline Dimensions [length, width,depth] [m]: & 17.0 & 4.24 & 1.00 \\
\hline Number of subdivided elements: & 4 & & \\
\hline First element midpoint coordinates [X-Y-Z]: & 1.97 & $0.000 \mathrm{E}+00$ & 2.09 \\
\hline Direction of logitudinal and normal axes: & $X$ & $Y$ & \\
\hline Total mass [kg]: & $0.100 \mathrm{E}+04$ & & \\
\hline Mass per element [kg]: & 250. & & \\
\hline Porosity factor [dimensionless] & 1.00 & & \\
\hline
\end{tabular}

OBJECT 4 - BACK-WALL

\begin{tabular}{|c|c|c|c|}
\hline Parameter & & & \\
\hline Object midpoint coordinates [X-Y-Z]: & 8.54 & 7.32 & 2.13 \\
\hline Dimensions [length, width, depth] [m]: & 17.1 & 4.27 & 1.00 \\
\hline Number of subdivided elements: & 4 & & \\
\hline First element midpoint coordinates [X-Y-Z]: & 2.13 & 7.32 & 2.13 \\
\hline Direction of logitudinal and normal axes: & $x$ & $Y$ & \\
\hline Total mass [kg]: & $0.100 \mathrm{E}+04$ & & \\
\hline \multicolumn{4}{|l|}{ Mass per element [kg]: } \\
\hline Porosity factor [dimensioniess] & 1.00 & & \\
\hline
\end{tabular}


Table 4.3.1 (continued)

OBJECT 5 - RIGHT-WALL

\begin{tabular}{|l|l|l|l|}
\hline \multicolumn{2}{|c|}{ Parameter } & \multicolumn{3}{l|}{} \\
\hline Object midpoint coordinates [X-Y-Z]: & 17.1 & 7.32 & 2.13 \\
\hline Dimensions [length, width, depth] [m]: & 14.6 & 4.27 & 1.00 \\
\hline Number of subdivided elements: & 3 & & \\
\hline First element midpoint coordinates [X-Y-Z]: & 17.1 & 2.45 & 2.13 \\
\hline Direction of logitudinal and normal axes: & $Y$ & $X$ & \\
\hline Total mass [kg]: & $0.100 E+04$ & & \\
\hline Mass per element [kg]: & 333. & & \\
\hline Porosity factor [dimensionless] & 1.00 & & \\
\hline
\end{tabular}

$+$

OBJECT 6 - HEPTANE-POOL

\begin{tabular}{|l|l|l|l|}
\hline \multicolumn{2}{|c|}{ Parameter } & \multicolumn{2}{l|}{} \\
\hline Object midpoint coordinates [X-Y-Z]: & 2.20 & 7.32 & 0.153 \\
\hline Dimensions [length, width,depth] [m]: & 0.610 & 0.305 & 0.305 \\
\hline Number of subdivided elements: & 1 & & \\
\hline First element midpoint coordinates [X-Y-Z]: & 2.20 & 7.32 & 0.153 \\
\hline Direction of logitudinal and normal axes: & $Y$ & $Z$ & \\
\hline Total mass [kg]: & 37.5 & & \\
\hline Mass per element [kg]: & 37.5 & & \\
\hline Porosity factor [dimensionless] & 1.00 & & \\
\hline
\end{tabular}


Table 4.3.1 (continued)

OBJECT 7 - CABLE-1LHI

\begin{tabular}{|l|l|l|l|}
\hline \multicolumn{2}{|c|}{ Parameler } & \multicolumn{2}{l|}{} \\
\hline Object midpoint coordinates [X-Y-Z]: & 0.473 & 2.44 & 3.92 \\
\hline Dimensions [length, width,depth] [m]: & 4.88 & 0.458 & $0.915 \mathrm{E}-01$ \\
\hline Number of subdivided elements: & 10 & & \\
\hline First element midpoint coordinates [X-Y-Z]: & 0.473 & 0.244 & 3.92 \\
\hline Direction of logitudinal and normal axes: & $\mathrm{Y}$ & $\mathrm{Z}$ & \\
\hline Total mass [kg]: & 2.57 & & \\
\hline Mass per element [kg]: & 0.257 & & \\
\hline Porosity factor [dimensionless] & 3.14 & & \\
\hline
\end{tabular}

$A$

\section{OBJECT 8 - CABLE-2LHI}

\begin{tabular}{|l|l|l|l|}
\hline \multicolumn{1}{|c|}{ Parameter } & \multicolumn{3}{l}{} \\
\cline { 1 - 2 } Object midpoint coordinates [X-Y-Z]: & 0.473 & 7.32 & 3.92 \\
\hline Dimensions [length, width,depth] [m]: & 4.88 & 0.458 & $0.915 \mathrm{E}-01$ \\
\hline Number of subdivided elements: & 10 & & \\
\hline First element midpoint coordinates [X-Y-Z]: & 0.473 & 5.12 & 3.92 \\
\hline Direction of logitudinal and normal axes: & $Y$ & $Z$ & \\
\hline Total mass [kg]: & 2.57 & & \\
\hline Mass per element [kg]: & 0.257 & & \\
\hline Porosity factor [dimensionless] & 3.14 & & \\
\hline
\end{tabular}


Table 4.3.1 (continued)

OBJECT 9 - CABLE-3LHI

\begin{tabular}{|l|l|l|l|}
\hline \multicolumn{2}{|c|}{ Parameter } & \multicolumn{3}{l|}{} \\
\hline Object midpoint coordinates [X-Y-Z]: & 0.473 & 12.2 & 3.92 \\
\hline Dimensions [length, width,depth] [m]: & 4.88 & 0.458 & $0.915 E-01$ \\
\hline Number of subdivided elements: & 10 & & \\
\hline First element midpoint coordinates [X-Y-Z]: & 0.473 & 10.0 & 3.92 \\
\hline Direction of logitudinal and normal axes: & $Y$ & $Z$ & \\
\hline Total mass [kg]: & 2.57 & & \\
\hline Mass per element [kg]: & 0.257 & & \\
\hline Porosity factor [dimensionless] & 3.14 & & \\
\hline
\end{tabular}

\section{OBJECT 10 - CABLE-1LMI}

\begin{tabular}{|l|l|l|l|}
\hline \multicolumn{2}{|c|}{ Parameter } & \multicolumn{2}{l}{} \\
\cline { 1 - 2 } Object midpoint coordinates [X-Y-Z]: & 0.473 & 2.44 & 2.30 \\
\hline Dimensions [length, width,depth] [m]: & 4.88 & 0.458 & $0.915 \mathrm{E}-01$ \\
\hline Number of subdivided elements: & 10 & & \\
\hline First element midpoint coordinates [X-Y-Z]: & 0.473 & 0.244 & 2.30 \\
\hline Direction of logitudinal and normal axes: & $Y$ & $Z$ & \\
\hline Total mass [kg]: & 2.57 & & \\
\hline Mass per element [kg]: & 0.257 & & \\
\hline Porosity factor [dimensionless] & 3.14 & & \\
\hline
\end{tabular}


Table 4.3.1 (continued)

\section{OBJECT 11 - CABLE-2LMI}

\begin{tabular}{|l|l|l|l|}
\cline { 1 - 2 } Parameler & \multicolumn{3}{l|}{} \\
\cline { 1 - 2 } Object midpoint coordinates [X-Y-Z]: & 0.473 & 7.32 & 2.30 \\
\hline Dimensions [length,width,depth] [m]: & 4.88 & 0.458 & $0.915 \mathrm{E}-01$ \\
\hline Number of subdivided elements: & 10 & & \\
\hline First element midpoint coordinates [X-Y-Z]: & 0.473 & 5.12 & 2.30 \\
\hline Direction of logitudinal and normal axes: & $Y$ & $Z$ & \\
\hline Total mass [kg]: & 2.57 & & \\
\hline Mass per element [kg]: & 0.257 & & \\
\hline Porosity factor [dimensionless] & 3.14 & & \\
\hline
\end{tabular}

\section{OBJECT 12 - CABLE-3LMI}

\begin{tabular}{|c|c|c|c|}
\hline Parameter & & & \\
\hline Object midpoint coordinates [X-Y-Z]: & 0.473 & 12.2 & 2.30 \\
\hline Dimensions [length, width, depth] [m]: & 4.88 & 0.473 & $0.915 E-01$ \\
\hline Number of subdivided elements: & 10 & & \\
\hline First element midpoint coordinates $[X-Y-Z]$ : & 0.473 & 10.0 & 2.30 \\
\hline Direction of logitudinal and normal axes: & $\underline{Y}$ & $z$ & \\
\hline Total mass [kg]: & 2.57 & & \\
\hline Mass per element [kg]: & 0.257 & & \\
\hline Porosity factor [dimensionless] & 3.14 & & \\
\hline
\end{tabular}


Table 4.3.1 (continued)

OBJECT 13 - CABLE-1LLO

\begin{tabular}{|l|l|l|l|}
\hline \multicolumn{2}{|c|}{ Parameter } & \multicolumn{2}{l}{} \\
\hline Object midpoint coordinates [X-Y-Z]: & 0.473 & 2.44 & 0.686 \\
\hline Dimensions [length, width,depth] [m]: & 4.88 & 0.458 & $0.915 \mathrm{E}-01$ \\
\hline Number of subdivided elements: & 0 & & \\
\hline First element midpoint coordinates [X-Y-Z]: & 0.473 & 0.244 & 0.686 \\
\hline Direction of logitudinal and normal axes: & $Y$ & $Z$ & \\
\hline Total mass [kg]: & 2.57 & & \\
\hline Mass per element [kg]: & 0.257 & & \\
\hline Porosity factor [dimensionless] & 3.14 & & \\
\hline
\end{tabular}

\section{OBJECT 14 - CABLE-2LLO}

\begin{tabular}{|l|l|l|l|}
\hline \multicolumn{2}{|c|}{ Parameler } & \multicolumn{2}{l}{} \\
\hline Object midpoint coordinates [X-Y-Z]: & 0.473 & 7.32 & 0.686 \\
\hline Dimensions [length, width,depth] [m]: & 4.88 & 0.458 & $0.915 \mathrm{E}-01$ \\
\hline Number of subdivided elements: & 10 & & \\
\hline First element midpoint coordinates [X-Y-Z]: & 0.473 & 5.12 & 0.686 \\
\hline Direction of logitudinal and normal axes: & $\mathrm{Y}$ & \\
\hline Total mass [kg]: & 2.57 & $\mathrm{Z}$ & \\
\hline Mass per element [kg]: & 0.257 & & \\
\hline Porosity factor [dimensionless] & 3.14 & & \\
\hline
\end{tabular}


Table 4.3.1 (continued)

OBJECT 15 - CABLE-3LLO

\begin{tabular}{|l|l|l|l|}
\hline \multicolumn{2}{|c|}{ Parameter } & \multicolumn{2}{l}{} \\
\cline { 1 - 3 } Object midpoint coordinates [X-Y-Z]: & 0.473 & 12.2 & 0.686 \\
\hline Dimensions [length, width, depth] [m]: & 4.88 & 0.458 & $0.915 \mathrm{E}-01$ \\
\hline Number of subdivided elements: & 10 & & \\
\hline First element midpoint coordinates [X-Y-Z]: & 0.473 & 10.0 & 0.686 \\
\hline Direction of logitudinal and normal axes: & $Y$ & $Z$ & \\
\hline Total mass [kg]: & 2.57 & & \\
\hline Mass per element [kg]: & 0.257 & & \\
\hline Porosity factor [dimensionless] & 3.14 & & \\
\hline
\end{tabular}

OBJECT 16 - CABLE-1RHI

\begin{tabular}{|l|l|l|l|}
\hline \multicolumn{2}{|c|}{ Parameter } & \multicolumn{2}{l|}{} \\
\hline Object midpoint coordinates [X-Y-Z]: & 1.85 & 2.44 & 3.92 \\
\hline Dimensions [length, width,depth] [m]: & 4.88 & 0.458 & $0.915 \mathrm{E}-01$ \\
\hline Number of subdivided elements: & 10 & & \\
\hline First element midpoint coordinates [X-Y-Z]: & 1.85 & 0.244 & 3.92 \\
\hline Direction of logitudinal and normal axes: & $\mathrm{Y}$ & \\
\hline Total mass [kg]: & 2.57 & $\mathrm{Z}$ & \\
\hline Mass per element [kg]: & 0.257 & & \\
\hline Porosity factor [dimensionless] & 3.14 & & \\
\hline
\end{tabular}


Table 4.3.1 (continued)

\section{OBJECT 17 - CABLE-2RHI}

\begin{tabular}{|l|l|l|l|}
\hline \multicolumn{1}{|c|}{ Parameter } & \multicolumn{3}{l|}{} \\
\hline Object midpoint coordinates [X-Y-Z]: & 1.85 & 7.32 & 3.92 \\
\hline Dimensions [length, width,depth] [m]: & 4.88 & 0.458 & $0.915 \mathrm{E}-01$ \\
\hline Number of subdivided elements: & 10 & & \\
\hline First element midpoint coordinates [X-Y-Z]: & 1.85 & 5.12 & 3.92 \\
\hline Direction of logitudinal and normal axes: & $\mathrm{Y}$ & $\mathrm{Z}$ & \\
\hline Total mass [kg]: & 2.57 & & \\
\hline Mass per element [kg]: & 0.257 & & \\
\hline Porosity factor [dimensionless] & 3.14 & & \\
\hline
\end{tabular}

OBJECT 18 - CABLE-3RHI

\begin{tabular}{|l|l|l|l|}
\hline \multicolumn{2}{|c|}{ Parameter } & \multicolumn{2}{l}{} \\
\cline { 1 - 2 } Object midpoint coordinates [X-Y-Z]: & 1.85 & 12.2 & 3.92 \\
\hline Dimensions [length, width, depth] [m]: & 4.88 & 0.458 & $0.915 \mathrm{E}-01$ \\
\hline Number of subdivided elements: & 10 & & \\
\hline First element midpoint coordinates [X-Y-Z]: & 1.85 & 10.0 & 3.92 \\
\hline Direction of logitudinal and normal axes: & $Y$ & $Z$ & \\
\hline Total mass [kg]: & 2.57 & & \\
\hline Mass per element [kg]: & 0.257 & & \\
\hline Porosity factor [dimensionless] & 3.14 & & \\
\hline
\end{tabular}


Table 4.3.1 (continued)

V. PILOT-FIRE PARAMETERS:

\begin{tabular}{|l|l|}
\hline \multicolumn{1}{|c|}{ Parameter } & \\
\hline LOCATION OF PILOT FIRE [OBJECT, ELEMENT]: & 6,1 \\
\hline FUEL TYPE: & SOLVENT [No. 4] \\
\hline PILOT MASS [KG]: & 1.00 \\
\hline
\end{tabular}

\section{ROOM DATA AND MISCELLANEOUS PARAMETERS}

\begin{tabular}{|c|c|c|c|}
\hline \multirow[b]{2}{*}{ Room temperature [k]: } & & & \\
\hline & 298. & & \\
\hline Calorimeter temperature $[\mathrm{K}]$ : & 298. & & \\
\hline Flame heat transfer coef. W/m $\mathrm{m}^{2} \mathrm{~K}$ & 23.0 & & \\
\hline Conv. Heat tran. Coef. Outside & 10.0 & & \\
\hline Ceiling length, width, height [m]: & 17.1 & 14.6 & 4.27 \\
\hline Forced ventilation constants [fh and fc]: & 1.00 & 1.00 & \\
\hline Door height, width [m]: & 2.13 & 1.22 & \\
\hline Door inflow coefficient & 0.600 & & \\
\hline Door outflow coefficient & 0.700 & & \\
\hline Hot gas absorption coefficient & 1.30 & & \\
\hline Ceil. Heat transfer coef. W/m $/ \mathrm{m}^{2} \mathrm{~K}$ & 10.0 & & \\
\hline Plume entrainment coefficient & 1.50 & & \\
\hline
\end{tabular}


Table 4.3.1 (continued)

Values for uncertainty analysis

\begin{tabular}{|c|l|l|l|l|}
\hline \multicolumn{1}{|c|}{ Parameter } & Distribution & Polnt value & Low value & High value \\
\hline Flame heat transfer coef. $W / \mathrm{m}^{2} \mathrm{~K}$ & Shift-log & 23.00 & 15.00 & 50.00 \\
\hline Conv. Heat tran. Coef. Outside hot gas layer $\mathrm{W} / \mathrm{m}^{2} \mathrm{~K}$ & Normal & 10.00 & 5.000 & 15.00 \\
\hline
\end{tabular}

$\therefore$ 
Table 4.3.2. Definition and failure probabilities for basic events used in the quantification of the LER.

\begin{tabular}{|c|c|c|c|c|c|}
\hline Event name & Description & $\begin{array}{c}\text { Base } \\
\text { prohability }\end{array}$ & $\begin{array}{c}\text { Eurrent } \\
\text { Probability }\end{array}$ & Type & $\begin{array}{c}\text { Illodiffied } \\
\text { for this } \\
\text { cvent }\end{array}$ \\
\hline ILOCA & $\begin{array}{l}\text { Interfacing System } \\
\text { LOCA initiator }\end{array}$ & 1.00E-05 & $1.00 E+01$ & TRUE & $\mathbf{Y}$ \\
\hline CR1-XHE-XE-ERROR & $\begin{array}{l}\text { Operator fails to } \\
\text { align CRD (After } \\
\text { venting) }\end{array}$ & 5.00E-02 & 5.00E-02 & & $\mathbf{N}$ \\
\hline CR1-XHE-XE-NOREC & $\begin{array}{l}\text { Operator fails to } \\
\text { recover CRD }\end{array}$ & $1.00 \mathrm{E}+01$ & $1.00 \mathrm{E}+01$ & & $\mathbf{N}$ \\
\hline CDS-TNK-HW-CST & $\begin{array}{l}\text { Condensate } \\
\text { storage tank fails }\end{array}$ & $1.00 \mathrm{E}-04$ & $1.00 \mathrm{E}-04$ & & $\mathbf{N}$ \\
\hline CRD-AOV-CC-FCTRL & $\begin{array}{l}\text { CRD flow control } \\
\text { station valves fail } \\
\text { to open fully }\end{array}$ & $1.00 \mathrm{E}-02$ & $1.00 \mathrm{E}-02$ & & $\mathbf{N}$ \\
\hline CRD-CKV-CC-INJEC & $\begin{array}{l}\text { CRD injection } \\
\text { check valve fails }\end{array}$ & $1.00 \mathrm{E}-03$ & $1.00 E-03$ & & $\mathbf{N}$ \\
\hline CRD-MDP-CF-PUMPS & $\begin{array}{l}\text { CRD pumps fail } \\
\text { from CC. }\end{array}$ & $7.20 \mathrm{E}-04$ & $7.20 \mathrm{E}-04$ & & $\mathbf{N}$ \\
\hline CRD-MOV-CC-MV2O & $\begin{array}{l}\text { Flow control valve } \\
\text { fails to open fully }\end{array}$ & $3.00 \mathrm{E}-02$ & $3.00 \mathrm{E}-02$ & & $\mathbf{N}$ \\
\hline CRD-XVM-CC-FILTR & \begin{tabular}{|l|} 
CRD suction filter \\
valve fails to open
\end{tabular} & $5.00 \mathrm{E}-03$ & $5.00 \mathrm{E}-03$ & & $\mathbf{N}$ \\
\hline CRD-MDP-FC-TRNA & Train A failures & $7.20 \mathrm{E}-03$ & $1.00 E+01$ & TRUE & $Y$ \\
\hline CRD-MDP-FC-TRNB & Train B failures & $4.70 \mathrm{E}-02$ & 4.70E-02 & & $\mathbf{N}$ \\
\hline$A C P-B A C-L P-D I$ & $\begin{array}{l}\text { Division I AC } \\
\text { power buses fail }\end{array}$ & $9.00 \mathrm{E}-04$ & $9.00 E-04$ & & $\mathbf{N}$ \\
\hline$A C P-B A C-L P-D I I$ & $\begin{array}{l}\text { Division II } A C \\
\text { power buses fail }\end{array}$ & $9.00 \mathrm{E}-04$ & $9.00 \mathrm{E}-04$ & & $\mathbf{N}$ \\
\hline SSW-XHE-XE-ERROR & $\begin{array}{l}\text { Operator fails to } \\
\text { recover RHRSW }\end{array}$ & $5.00 \mathrm{E}-02$ & 5.00E-02 & & $\mathbf{N}$ \\
\hline SSW-XHE-XE-NOREC & $\begin{array}{l}\text { Operator fails to } \\
\text { align RHRSW }\end{array}$ & $1.00 \mathrm{E}+01$ & $1.00 E+01$ & & $\mathbf{N}$ \\
\hline
\end{tabular}


Table 4.3.2. Definition and failure probabilities for basic events used in the quantification of the LER. (Cont.)

\begin{tabular}{|l|l|c|c|c|c|}
\hline \multicolumn{1}{|c|}{ Event name } & \multicolumn{1}{|c|}{ Description } & $\begin{array}{c}\text { Base } \\
\text { prohahility }\end{array}$ & $\begin{array}{c}\text { Gurrent } \\
\text { Prohahility }\end{array}$ & Type & $\begin{array}{c}\text { Wodtifed for } \\
\text { this event }\end{array}$ \\
\hline SSW-MDP-CF-MDPS & $\begin{array}{l}\text { Common cause } \\
\text { failure of RHRSW } \\
\text { pumps. }\end{array}$ & $3.70 \mathrm{E}-03$ & $3.70 \mathrm{E}-03$ & $\mathrm{~N}$ \\
\hline SSW-MOV-CC-FLOOD & Valves fail to open & $6.10 \mathrm{E}-02$ & $6.10 \mathrm{E}-02$ & & $\mathrm{~N}$ \\
\hline SSW-MDP-FC-TRNB & $\begin{array}{l}\text { Train D component } \\
\text { failures }\end{array}$ & $3.80 \mathrm{E}-02$ & $1.00 \mathrm{E}+01$ & TRUE & $\mathrm{Y}$ \\
\hline SSW-MDP-FC-TRND & $\begin{array}{l}\text { Train B component } \\
\text { failures }\end{array}$ & $3.80 \mathrm{E}-02$ & $3.80 \mathrm{E}-02$ & $\mathrm{~N}$ & $\mathrm{~N}$ \\
\hline CLOSE & Close open path & $1.00 \mathrm{E}-07$ & $1.00 \mathrm{E}+01$ & TRUE & $\mathrm{N}$ \\
\hline IE-LOOP & $\begin{array}{l}\text { Loss of offsite } \\
\text { power initiator }\end{array}$ & $1.70 \mathrm{E}-04$ & $0.00 \mathrm{E}+00$ & IGNORE & $\mathrm{y}$ \\
\hline IE-SLOCA & $\begin{array}{l}\text { Small LOCA } \\
\text { initiator }\end{array}$ & $4.80 \mathrm{E}-06$ & $0.00 \mathrm{E}+00$ & IGNORE & $\mathrm{y}$ \\
\hline IE-TRAN & Transient initiator & $1.10 \mathrm{E}-02$ & $0.00 \mathrm{E}+00$ & IGNORE & $\mathrm{y}$ \\
\hline
\end{tabular}


Table 4.3.3. Fire-related parameters used and results obtained in step $3(6 \mathrm{~A})$, Intermediate Screening.

\begin{tabular}{|l|c|c|}
\hline \multicolumn{1}{|c|}{ factor } & & Value \\
\hline Initiating event frequency $\left[\mathrm{yr}^{-1}\right]$ & $\lambda_{\mathbf{f}}$ & $6.48 \mathrm{E}-03$ \\
\hline Geometric factor & $\mathbf{f}_{\mathbf{a}}$ & $1.50 \mathrm{E}-01$ \\
\hline Severity factor & $\mathbf{f}_{\mathbf{s}}$ & $3.00 \mathrm{E}-01$ \\
\hline Non suppression factor & $\mathrm{n} / \mathbf{a}$ & \\
\hline Logic model value & $\mathbf{Q}$ & $1.04 \mathrm{E}-01$ \\
\hline Time of duration detected condition $[\mathrm{Yr}]$. & $\mathbf{t}$ & 4.75 \\
\hline Probability of a fire in $\mathbf{t}=\lambda_{\mathbf{f}} \times \mathbf{f}_{\mathbf{a}} \times \mathbf{f}_{\mathbf{s}} \times \mathbf{t}$ & $\mathbf{P}$ & $1.39 \mathrm{E}-0.3$ \\
\hline Conditional Core Damage Probability $=\mathbf{P Q}$ & $\mathbf{C C D P}$ & $1.45 \mathrm{E}-04$ \\
\hline
\end{tabular}

(*) Value from Table 4.3.6 
Table 4.3.4a. Results from Montecarlo simulation using output data from COMPBRN for Cable tray 2-LHI.

\begin{tabular}{|l|c|}
\hline \multicolumn{1}{|c|}{ Stamsties } & UaluE \\
\hline Trials & 500 \\
\hline Mean & 451.19 \\
\hline Median (approx.) & 447.34 \\
\hline Mode (approx.) & 427.88 \\
\hline Standard Deviation & 58.67 \\
\hline Variance & $3,442.05$ \\
\hline Skewness & 1.01 \\
\hline Kurtosis & 6.37 \\
\hline Coeff. of Variability & 0.13 \\
\hline Range Minimum & 313.70 \\
\hline Range Maximum & 821.18 \\
\hline Range Width & 507.48 \\
\hline Mean Std. Error & 2.62 \\
\hline
\end{tabular}

\begin{tabular}{|c|c|}
\hline PERGEMTILE & TME TO DAMAGE [s] \\
\hline $0 \%$ & 313.70 \\
\hline $10 \%$ & 380.35 \\
\hline $20 \%$ & 400.82 \\
\hline $30 \%$ & 422.38 \\
\hline $40 \%$ & 432.49 \\
\hline $50 \%$ & 447.34 \\
\hline $60 \%$ & 461.08 \\
\hline $70 \%$ & 473.43 \\
\hline $80 \%$ & 490.89 \\
\hline $90 \%$ & 525.15 \\
\hline $100 \%$ & 821.18 \\
\hline
\end{tabular}


Table 4.3.4b. Results from Montecarlo simulation using output data from COMPBRN for Cable tray 2-LMI.

\begin{tabular}{|l|c|}
\hline \multicolumn{1}{|c|}{ STamsnes } & UALU \\
\hline Trials & 500 \\
\hline Mean & 464.69 \\
\hline Median (approx.) & 457.46 \\
\hline Mode (approx.) & 439.92 \\
\hline Standard Deviation & 56.06 \\
\hline Variance & $3,143.05$ \\
\hline Skewness & 0.55 \\
\hline Kurtosis & 4.16 \\
\hline Coeff. of Variability & 0.12 \\
\hline Range Minimum & 300.88 \\
\hline Range Maximum & 728.69 \\
\hline Range Width & 427.81 \\
\hline Mean Std. Error & 2.51 \\
\hline
\end{tabular}

\begin{tabular}{|c|c|}
\hline PEREEMIII & THE TO DAMAGE ISI \\
\hline $0 \%$ & 300.88 \\
\hline $10 \%$ & 396.90 \\
\hline $20 \%$ & 423.34 \\
\hline $30 \%$ & 436.35 \\
\hline $40 \%$ & 446.95 \\
\hline $50 \%$ & 457.46 \\
\hline $60 \%$ & 471.53 \\
\hline $70 \%$ & 488.76 \\
\hline $80 \%$ & 510.10 \\
\hline $90 \%$ & 534.39 \\
\hline $100 \%$ & 728.69 \\
\hline
\end{tabular}


Table 4.3.5. Fire-related parameters used and results obtained in Step 3-C, Final Quantification.

\begin{tabular}{|c|l|l|l|l|}
\hline Facter & \multicolumn{1}{|c|}{ Dlstribution } & Best estimate & Lower hound & Uppor hound \\
\hline$\lambda_{\mathbf{f}}\left[\mathrm{yr}^{-1}\right]$ & Gamma & $6.48 \mathrm{E}-03$ & $1 \mathrm{E}-08$ & 0.027 \\
\hline $\mathbf{f}_{\mathbf{a}}$ & $\begin{array}{l}\text { Maximum } \\
\text { Entropy }\end{array}$ & 0.15 & 0.03 & 0.75 \\
\hline $\mathbf{f}_{\mathbf{s}}$ & $\begin{array}{l}\text { Maximum } \\
\text { Entropy }\end{array}$ & 0.3 & 0.19 & 0.67 \\
\hline $\mathbf{f}_{\mathbf{n s}}$ & $\begin{array}{l}\text { Maximum } \\
\text { Entropy }\end{array}$ & 0.038 & $6 \mathrm{E}-03$ & 0.047 \\
\hline $\mathbf{Q}$ & Point value (*) & $1.04 \mathrm{E}-01$ & & \\
\hline
\end{tabular}

\begin{tabular}{|l|c|l|}
\hline Time of duration detected condition $[\mathrm{Yr}]$. & $\mathbf{t}$ & 4.75 \\
\hline Probability of a fire in $\mathbf{t}=\lambda_{\mathbf{f}} \times \mathbf{f}_{\mathbf{a}} \times \mathbf{f}_{\mathbf{s}} \times \mathbf{f}_{\mathrm{ns}} \times \mathbf{t}$ & $\mathbf{P}$ & $5.26 \mathrm{E}-05$ \\
\hline Conditional Core Damage Probability $=\mathbf{P Q}$ & $\mathbf{C C D P}$ & $5.47 E-06$ \\
\hline
\end{tabular}

(*) Value from Table 4.3.6 
Table 4.3.6. Quantification results for sequences of the Interfacing System LOCA event tree.

\begin{tabular}{|c|c|c|}
\hline Impacted sequence \# & Q for sequence & \%eonurilumion to totale \\
\hline 4 & $3.69 \mathrm{E}-08$ & $3.55 \mathrm{E}-05$ \\
\hline 7 & $3.73 \mathrm{E}-10$ & $3.58 \mathrm{E}-07$ \\
\hline 9 & $4.01 \mathrm{E}-03$ & 3.85 \\
\hline 11 & $4.05 \mathrm{E}-05$ & $3.91 \mathrm{E}-02$ \\
\hline 12 & $1.00 \mathrm{E}-01$ & 96.10 \\
\hline 16 & $4.60 \mathrm{E}-12$ & $4.42 \mathrm{E}-09$ \\
\hline 19 & $4.64 \mathrm{E}-14$ & $4.46 \mathrm{E}-11$ \\
\hline 21 & $4.99 \mathrm{E}-07$ & $4.80 \mathrm{E}-04$ \\
\hline 23 & $5.04 \mathrm{E}-09$ & $4.84 \mathrm{E}-06$ \\
\hline 24 & $1.25 \mathrm{E}-05$ & $1.20 \mathrm{E}-02$ \\
\hline 25 & $4.97 \mathrm{E}-07$ & $4.78 \mathrm{E}-04$ \\
\hline $\mathbf{Q}$ total & $1.04 \mathrm{E}-1$ & \\
\hline
\end{tabular}

Table 4.3.7. Sequence logic for dominant sequences identified for the LER.

\begin{tabular}{|c|c|l|}
\hline $\begin{array}{c}\text { Event tree } \\
\text { name }\end{array}$ & $\begin{array}{c}\text { Sequence } \\
\text { name }\end{array}$ & \multicolumn{1}{|c|}{ Logic } \\
\hline ILOCA & 9 & /RPS, /LCl, /CLOSE, RHRSW, /CVS, CR1 \\
\hline ILOCA & 12 & /RPS, /LCI, CLOSE \\
\hline
\end{tabular}


Table 4.3.8. Conditional cut sets for higher probability sequences

\begin{tabular}{|c|c|c|c|}
\hline Gut set\# & \% Gentribution & Frequency & Gat sets \\
\hline \multicolumn{3}{|c|}{ Sequence \# 12} & \\
\hline 1 & 100 & $1.0 \mathrm{E}-1$ & CLOSE \\
\hline \multicolumn{2}{|c|}{ Total [all eut sets] } & $1.0 \mathrm{E}-1$ & \\
\hline \multicolumn{3}{|c|}{ Sequence \# 9} & \\
\hline 1 & 77.3 & $2.5 \mathrm{E}-3$ & SSW-XHE-XE-ERROR, CR1-XHE-XE-ERROR \\
\hline 3 & 7.3 & $2.4 \mathrm{E}-4$ & $\begin{array}{l}\text { SSW-XHE-XE-ERROR, CR1-XHE-XE-NOREC, } \\
\text { CRD-MDP-FC-TRNB, CRD-MDP-FC-TRNA }\end{array}$ \\
\hline 5 & 4.6 & $1.5 \mathrm{E}-4$ & $\begin{array}{l}\text { SSW-XHE-XE-ERROR, CR1-XHE-XE-NOREC, } \\
\text { CRD-MOV-CC-MV20 }\end{array}$ \\
\hline 2 & 1.9 & $6.1 \mathrm{E}-5$ & $\begin{array}{l}\text { SSW-XHE-XE-NOREC, SSW-MOV-CC-FLOOD, } \\
\text { CR1-XHE-XE-ERROR }\end{array}$ \\
\hline 7 & 1.6 & $5.0 \mathrm{E}-5$ & $\begin{array}{l}\text { CR1-XHE-XE-NOREC, CRD-AOV-CC-FCTRL, } \\
\text { SSW-XHE-XE-ERROR }\end{array}$ \\
\hline \multicolumn{2}{|c|}{ Total [all cut sets] } & 4.0 E-3 & \\
\hline
\end{tabular}

Table 4.3.9. Dominant sequence conditional probabilities and importance measure for the LER.

\begin{tabular}{|c|c|c|c|c|c|}
\hline $\begin{array}{c}\text { Event tree } \\
\text { name }\end{array}$ & $\begin{array}{c}\text { Sequence } \\
\text { name }\end{array}$ & eGDP & EDP & $\begin{array}{c}\text { Importance } \\
\text { [CEDP-GDP] }\end{array}$ & \% Conturibution \\
\hline ILOCA & 9 & $2.09 \mathrm{E}-07$ & $1.97 \mathrm{E}-12$ & $2.09 \mathrm{E}-07$ & 3.7 \\
\hline ILOCA & 12 & $5.26 \mathrm{E}-06$ & $5.26 \mathrm{E}-11$ & $5.26 \mathrm{E}-06$ & 96.2 \\
\hline Total [all sequences] & $5.47 \mathrm{E}-06$ & $5.47 \mathrm{E}-11$ & $5.47 \mathrm{E}-06$ & \\
\hline
\end{tabular}


Figure 4.3.1. Simplified P \& ID of the Residual Heat Removal System containing the involved interfacing system valves.

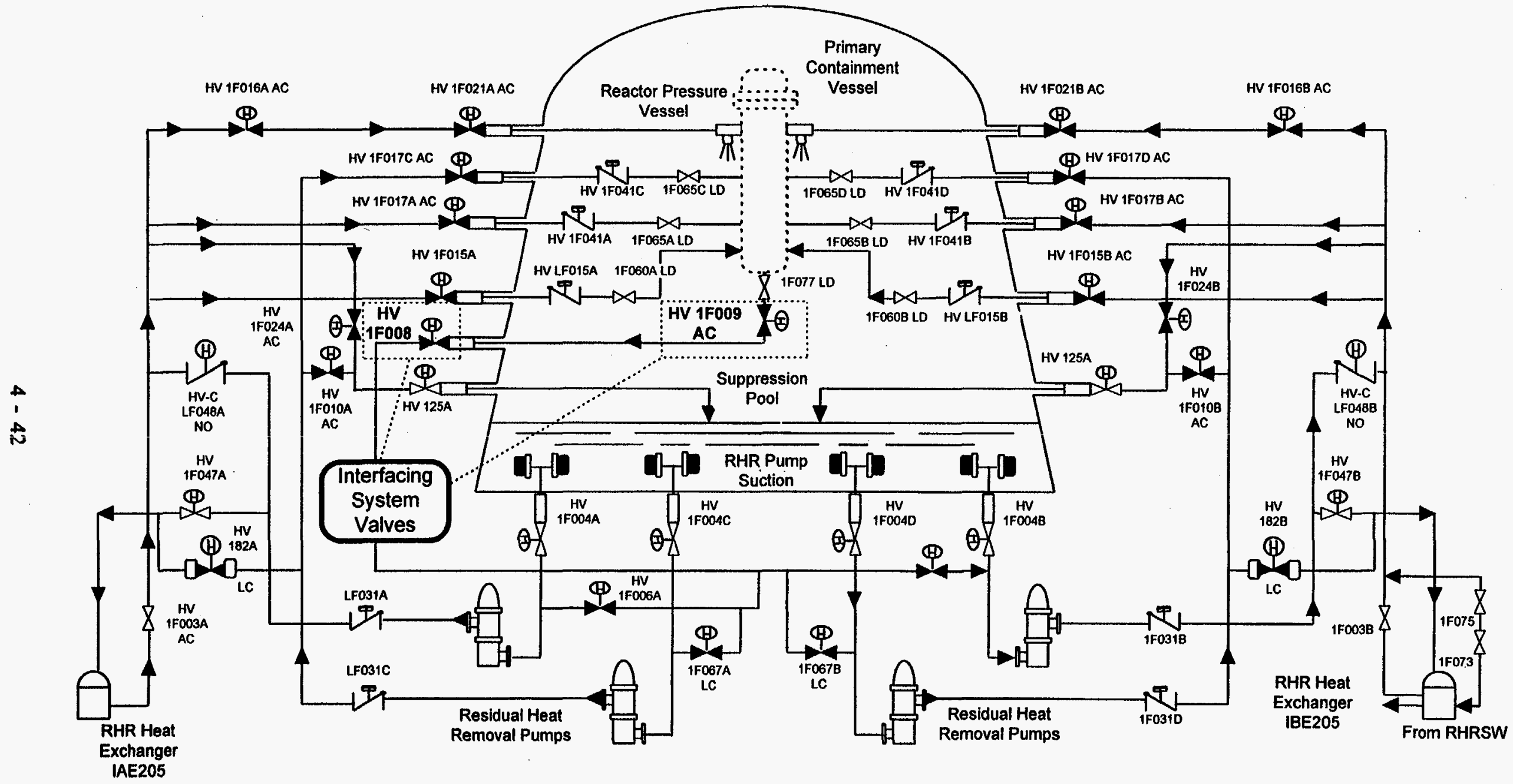


Figure 4.3.2. Interfacing System Loss of Coolant Accident event tree developed.

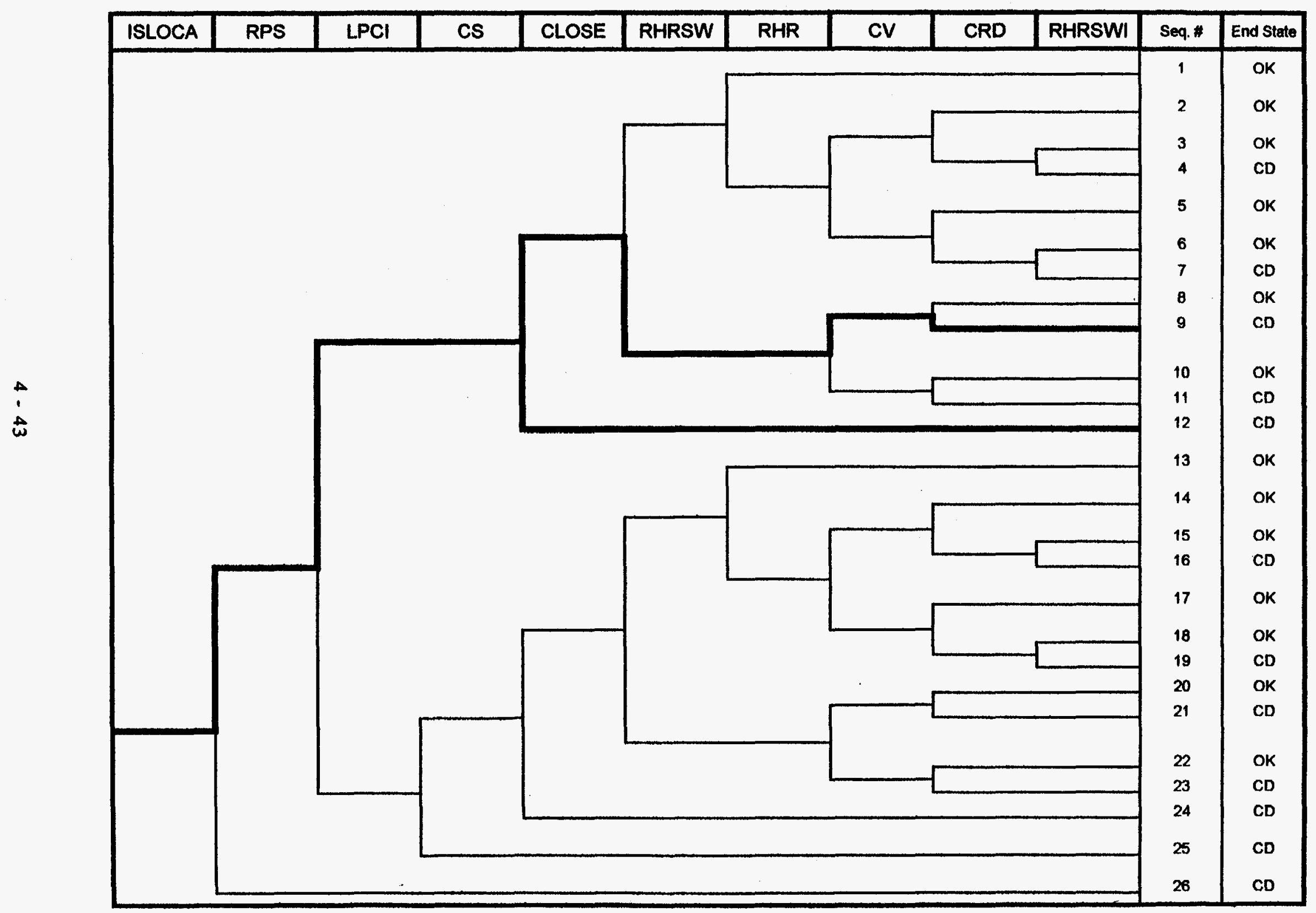


Figure 4.3.3. Simplified sensitivity analysis for the failure probability for CLOSE vs. CCDP.

\begin{tabular}{|c|c|c|c|}
\hline cIOSE failure probability & etotal & EEDP & AsP Erttorioa \\
\hline $1.00 \mathrm{E}-01$ & $1.00 \mathrm{E}-01$ & $5.47 \mathrm{E}-06$ & LER In \\
$1.00 \mathrm{E}-02$ & $1.00 \mathrm{E}-02$ & $5.47 \mathrm{E}-07$ & LER Out \\
$1.00 \mathrm{E}-03$ & $1.40 \mathrm{E}-03$ & $7.66 \mathrm{E}-08$ & LER Out \\
$1.00 \mathrm{E}-04$ & $5.50 \mathrm{E}-04$ & $3.01 \mathrm{E}-08$ & LER Out \\
$1.00 \mathrm{E}-05$ & $4.60 \mathrm{E}-04$ & $2.52 \mathrm{E}-08$ & LER Out \\
$1.00 \mathrm{E}-06$ & $4.50 \mathrm{E}-04$ & $2.46 \mathrm{E}-08$ & LER Out \\
$1.00 \mathrm{E}-07$ & $4.50 \mathrm{E}-04$ & $2.46 \mathrm{E}-08$ & LER Out \\
\hline
\end{tabular}

CCDP

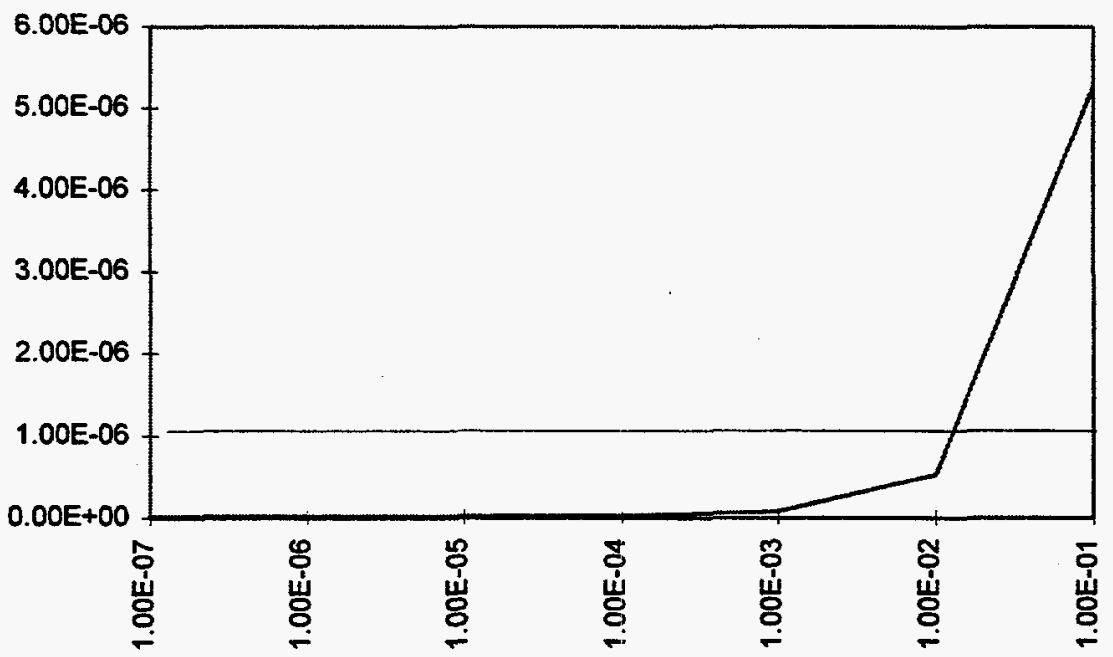

CLOSE failure probability 
Figure 4.3.4. Schematic description of the postulated scenario in the Cable Spreading Room.

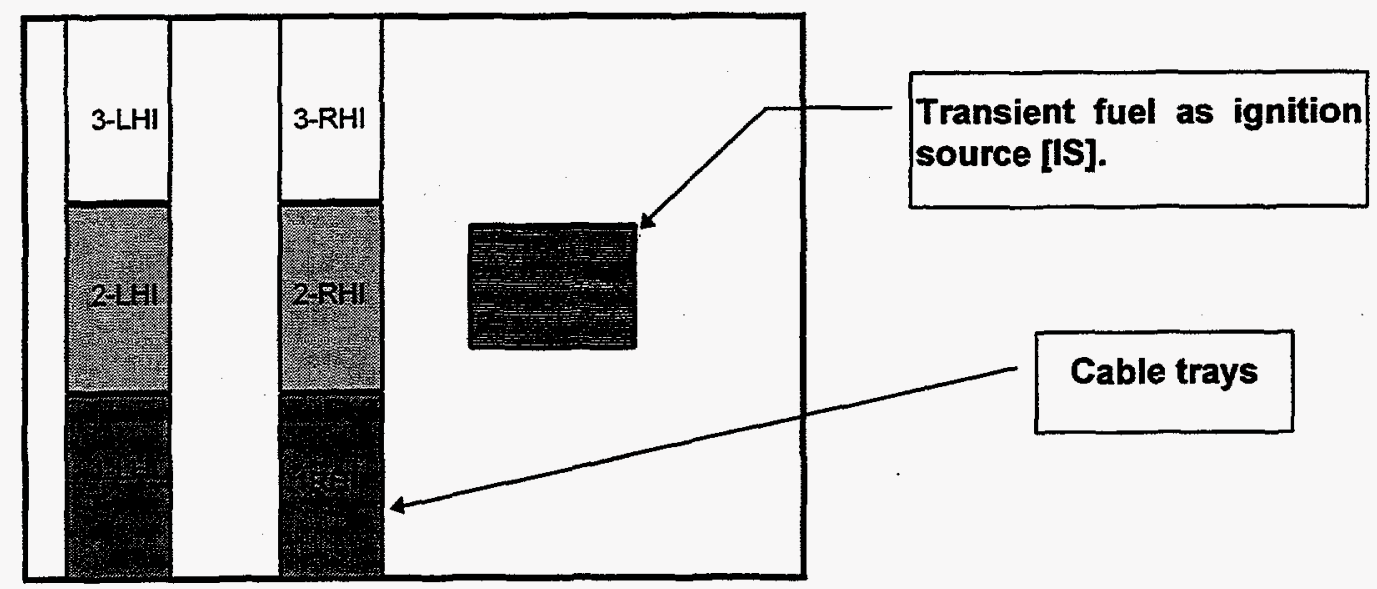

Overhead View

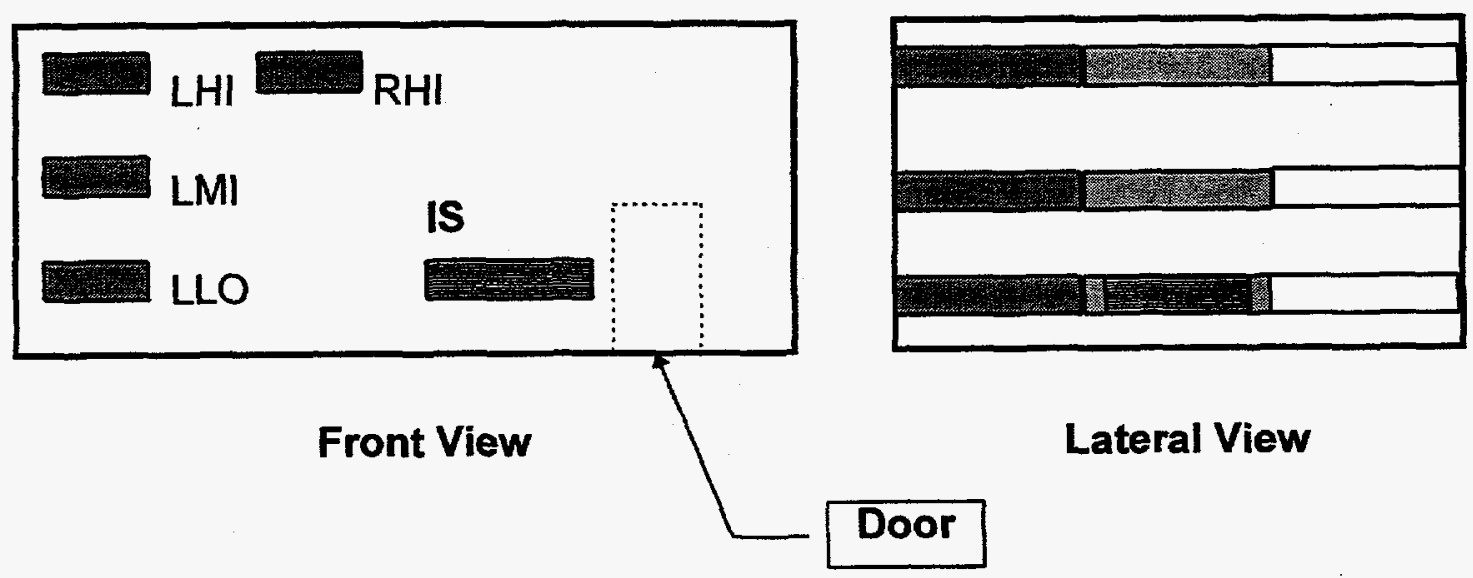


Figure 4.3.5a. Results from uncertainty analysis for target 2-LHI in the Cable Spreading Rooom.

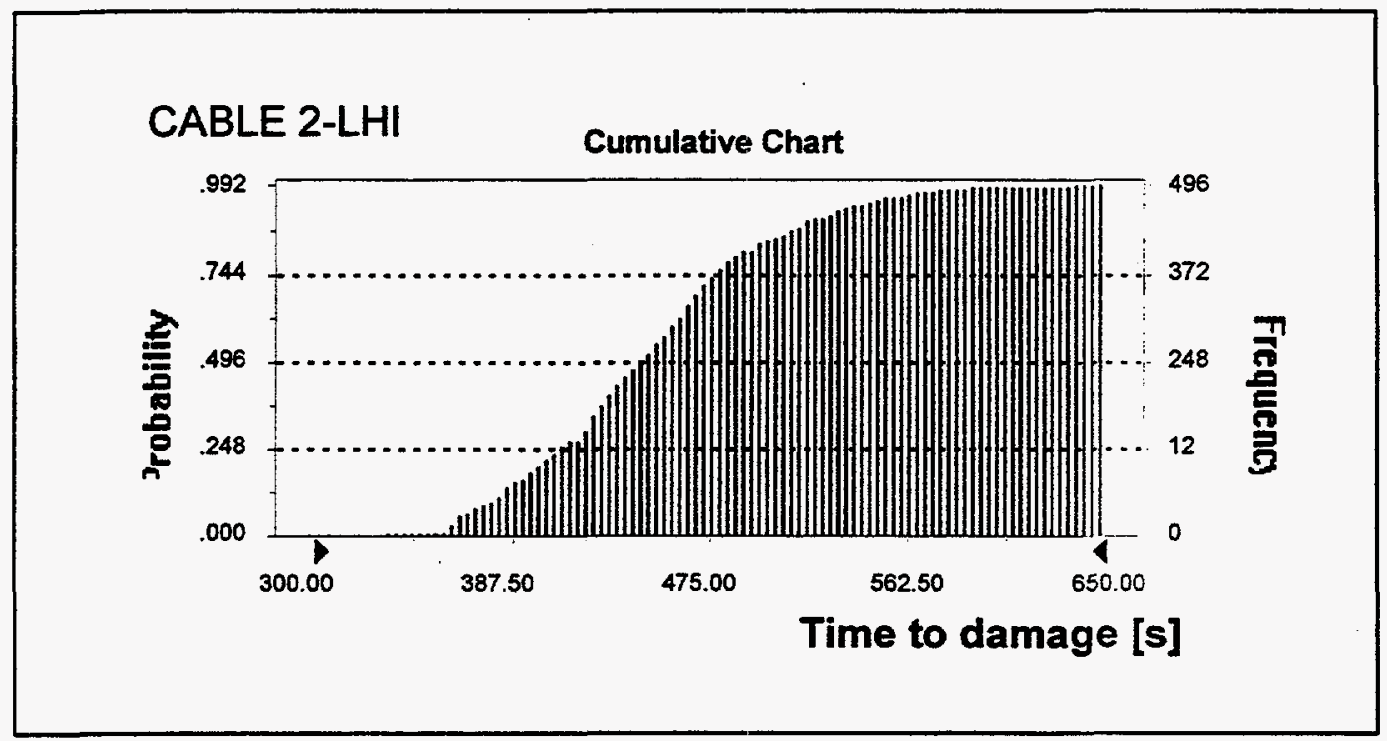

Figure 4.3.5b. Results from uncertainty analysis for target 2-LMI in the Cable Spreading Rooom.

Cable 2-LMI

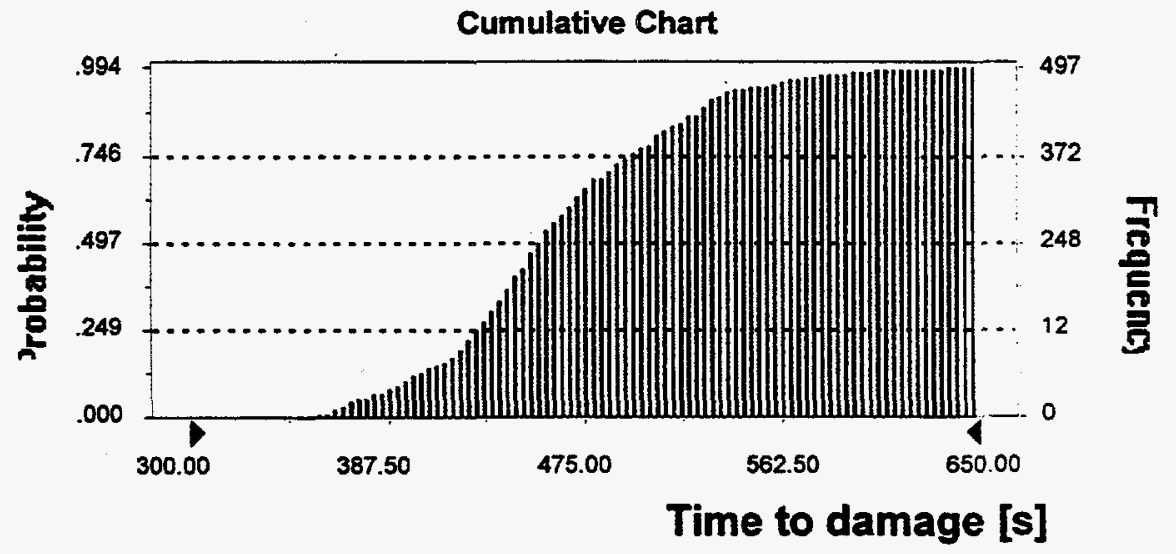




\subsection{Case study: a non-fire-related-failure LER}

\subsubsection{Summary}

This case study involves an LER that was reported in 1994 by a General Electric boiling water reactor (BWR) with a Mark I containment. We will call this plant "Plant C". However, because some of the systems information from Plant C was not available, this case study has used the systems information from another BWR plant, which we will call "Plant D", for parts of this case study. Because this case study is being written for tutorial purposes, we do not consider it important that the events described in our analysis are not fully realistic (that is, faithful in detail) compared to the actual events described in the LER.

The LER reported that with the plant at $99 \%$ power, the high-pressure-coolantinjection turbine tripped due to high exhaust pressure during a monthly surveillance test. The LER was analyzed by the internal events ASP and modeled as a long-term unavailability of the High Pressure Coolant Injection System [HPCI]. The period of unavailability was established to be one month ( 720 hours). The conditional core damage probability (CCDP) estimated for that event was $3.1 \times 10^{-6}$ and therefore it was reported as an "Accident Sequence Precursor".

According to the requirements established for setting up the fire ASP methodology, the plant has defined the most important fire-initiated sequences. One of the insights is that a fire with enough severity, produced in location A of the Essential Switchgear Room, would induce an inadvertent opening of a safety relief valve [IORV] and the unavailability of the Main Feedwater system.

An accident sequence initiated by an IORV transient was considered by the plant as one of the most risk-important. The HPCI system is one of the important ways to mitigate such events.

The LER was analyzed and the Conditional Core Damage Probability related to fires was estimated at $2.7 \times 10^{-7}$. Therefore, the relevant accident sequence does not exceed the CCDP criterion of $1.0 \times 10^{-6}$ and, as a result, the LER was screened out from a fire-ASP point of view.

\subsubsection{Event description}

\section{A. Internal event description}

With Plant C plant at $99 \%$ power, the high pressure coolant injection [HPCI] turbine tripped due to high exhaust pressure during a monthly surveillance test. The cause of the exhaust pressure was determined to be a failed check valve. The failure mechanism indicated that, in the period since the last monthly surveillance test, the HPCI turbine would have tripped shortly after starting if the HPCI system had been called upon to perform its safety function.

The event was modeled as a long-term unavailability of the HPCI system. The difficulty encountered in identifying the root case of the pump failure indicates that the failure would not have been recovered easily during an actual demand. Therefore, the failure was modeled as unrecoverable. The HPCI was considered unavailable for one period of surveillance (one month, or 720 hours.) It was assumed that any 
demand for the HPCI turbine, subsequent to the last successful monthly surveillance, would have resulted in several minutes of high pressure injection followed by a HPCI turbine trip.

The event was modeled as a failed HPCI train [Basic event HCI-TDP-FC-TRAIN set to TRUE] and considered as unrecoverable [Basic event HCI-XHE-XE-NOREC set to TRUE].

The event in the LER was analyzed by the internal-events ASP methodology and reported as an "Accident Sequence Precursor", with an associated Conditional Core Damage Probability of $3.1 \times 10^{-6}$.

\section{B. Fire-initiated sequences impacted}

The HPCI has been considered in the plant's fire analysis as a mitigating system in a transient sequence initiated by the inadvertent opening of a safety relief valve [IORV]. Therefore, the unavailability of this system to perform its safety function in a situation in which a fire occurred would degrade the response of the plant.

1. Characteristics of the scenario linked to impacted sequence: If a fire with enough severity were to occur in location A of the Essential Switchgear Room, it would cause the following consequences in safety-related equipment associated with the location:

i) A fire-induced spurious opening of a safety relief valve, producing an IORV initiating event.

ii) Unavailability of the Main Feedwater system due to damage to control circuits in the location and a subsequent common-cause failure.

2. Description of sequences: The sequence impacted by the unavailability of the HPCI system is composed of the following events. Figure 4.4.1 shows the impacted sequence from the IORV event tree.

\section{IORV. Initiating event}

Inadvertent opening of a safety relief valve, an initiating event arising from a spurious signal due to a fire in location $A$ of the Essential Switchgear Room Fire Area.

\section{S1. Reactor trip}

There may be no trip signal generated by the reactor protection system [RPS] during the initial stages of an IORV event sequence. The operator will be alerted to an IORV by observing generator load reduction, the Safety Relief Valve [SRV] position indicators, the SRV tailpipe temperatures, the annunciators associated with open SRVs or the suppression pool temperature.

Failure to trip (S1) implies failure of the operator to scram the reactor prior to the suppression pool reaching a temperature requiring prompt RHR system operation.

\section{RPS. Mechanical portion of the Reactor Protection System}

The Reactor Protection System performs the subcriticality function. number of control rods must be inserted to terminate power production.

$$
4-48
$$


MFW. Main Feedwater System [MFW] available for in iection

According to operating experience, the IORV event is not expected to cause a Main Steam Isolation Valve closure. Therefore, the MFW system is available to perform its function with the Power Conversion System [PCS] and it is considered as a mitigating system.

HPCI. High Pressure Coolant In jection [HPCI] system available

In case of a MFW system failure, the coolant-makeup function can be provided by the HPCI system.

\section{ADS. Automatic depressurization system}

In case of unavailability of the HPCI system, the coolant makeup can be provided by the low-pressure systems. To operate any of these, it is necessary to depressurize the reactor, which is performed by the ADS. Failure to depressurize would lead to core damage.

\subsubsection{ASP fire review}

Step 1-C. Quantification: In the logic model corresponding to the IORV-initiated sequence developed by the plant, failure probabilities for each basic event impacted by the postulated fire in the indicated location were set equal to unity. The failure probability for the HPCI system was also set equal to 1.0 and an unavailability period of 720 hours was assumed. Basic events that were unimpacted were assigned the corresponding random-failure values. The fire-PRA model corresponding to the sequence was quantified using the data from above. A Conditional Core Damage Probability of $2.7 \times 10^{-7}$ was obtained.

Definitions and failure probabilities for the basic events used in the final quantification are presented in Table 4.4.1.

\subsubsection{Results}

Table 4.4.2 shows the higher-probability cut sets for the impacted sequence. Table 4.4.3 presents the quantification results, in terms of the CCDP (Conditional Core Damage Probability) estimated for the period of the HPCI unavailability, 720 hours. Data for the quantification were taken from the IORV-initiated sequence analysis developed by the plant, considering the fire initiating frequency, the geometric factor, the severity factor and the non-suppression factor.

Given that the CCDP value does not exceed the criterion of $1.0 \times 10^{-6}$, the LER, from the fire ASP point of view, is screened out. 
Table 4.4.1. Definition and failure probabilities for basic events used on the quantification for the LER.

\begin{tabular}{|c|c|c|c|c|c|}
\hline Event name & Description & $\begin{array}{c}\text { Base } \\
\text { mrohability }\end{array}$ & $\begin{array}{l}\text { Eurrent } \\
\text { Probability }\end{array}$ & Type & $\begin{array}{l}\text { Itodified } \\
\text { for this } \\
\text { ovent }\end{array}$ \\
\hline IE-IORV & $\begin{array}{l}\text { Inadvertent SRV } \\
\text { opening. }\end{array}$ & 7.00E-03 & $1.00 \mathrm{E}+01$ & TRUE & $Y$ \\
\hline RPS-SYS-FC-MECH & $\begin{array}{l}\text { Mechanical failure of } \\
\text { the RPS }\end{array}$ & $1.00 \mathrm{E}-05$ & $1.00 E-05$ & & $\mathbf{N}$ \\
\hline MFW-XHE-XE-NOREC & $\begin{array}{l}\text { Operator fails to } \\
\text { recover Condensate. }\end{array}$ & $1.00 \mathrm{E}+00$ & $1.00 E+00$ & & $\mathbf{N}$ \\
\hline MFW-TDP-CF-PUMPS & $\begin{array}{l}\text { Feedwater pump fail } \\
\text { from common cause. }\end{array}$ & $8.60 \mathrm{E}-04$ & $1.00 \mathrm{E}+00$ & TRUE & $Y$ \\
\hline HCl-XHE-XE-NOREC & $\begin{array}{l}\text { Operator fails to } \\
\text { recover } \mathrm{HCl} .\end{array}$ & 7.00E-01 & $1.00 E+00$ & TRUE & $Y$ \\
\hline HCI-TDP-FC-TRAIN & \begin{tabular}{|lll}
$\mathrm{HCl}$ train level \\
failures.
\end{tabular} & $3.80 \mathrm{E}-02$ & $1.00 E+00$ & TRUE & $Y$ \\
\hline ADS-XHE-XE-ERROR & $\begin{array}{l}\text { Operator fails to } \\
\text { depressurize (ADS) }\end{array}$ & $1.00 \mathrm{E}-02$ & $1.00 E-02$ & & $\mathbf{N}$ \\
\hline ADS-XHE-XE-NOREC & $\begin{array}{l}\text { Operator fails to } \\
\text { recover ADS. }\end{array}$ & $7.10 \mathrm{E}-01$ & 7.10E-01 & & $\mathbf{N}$ \\
\hline ADS-SYS-CF-VALVS & 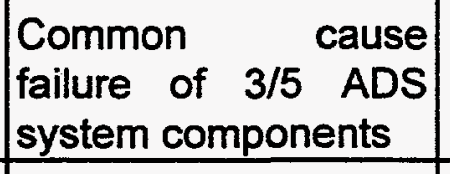 & $7.20 \mathrm{E}-05$ & 7.20E-05 & & $\mathbf{N}$ \\
\hline ADS-XHE-XE-MDEPR & $\begin{array}{l}\begin{array}{l}\text { Operator fails to } \\
\text { depressurize } \\
\text { reactor. }\end{array} \\
\text { the } \\
\end{array}$ & $1.00 \mathrm{E}-02$ & $1.00 \mathrm{E}-02$ & & $\mathbf{N}$ \\
\hline ADS-SRV-CC-VALVS & $\begin{array}{l}\text { ADS valves fail to } \\
\text { open. }\end{array}$ & 3.70E-03 & 3.70E-03 & & $\mathbf{N}$ \\
\hline
\end{tabular}


Table 4.4.2. Higher probability cut sets for impacted sequence.

\begin{tabular}{|c|c|c|l|}
\hline Cut set \# & \% Contribution & Frequency & \multicolumn{1}{|c|}{ Gut sets } \\
\hline 1 & 88.3 & $6.80 E-03$ & $\begin{array}{l}\text { IE-IORV, MFW-XHE-XE-NOREC,MFW-TDP-CF- } \\
\text { PUMPS, HCI-XHE-XE-NOREC,HCI-TDP-FC-TRAIN, } \\
\text { (ADS-XHE-XE-ERROR or ADS-XHE-XE-MDEPR) }\end{array}$ \\
\hline 3 & 11.7 & $9.01 E-04$ & $\begin{array}{l}\text { IE-IORV, MFW-XHE-XE-NOREC,MFW-TDP-CF- } \\
\text { MPS,HCI-XHE-XE-NOREC,HCI-TDP-FC-TRAIN, } \\
\text { (ADS-XHE-XE-ERROR or ADS-SRV-CC-VALVS, } \\
\text { ADS-XHE-XE-NOREC) }\end{array}$ \\
\hline \multicolumn{2}{|c|}{ Total call cut setsI } & $\mathbf{7 . 7 2 E - 0 3}$ & \multicolumn{1}{l}{} \\
\hline
\end{tabular}

Table 4.4.3. Data for fire-induced sequences for the LER.

\begin{tabular}{|l|l|l|l|l|}
\hline \multicolumn{1}{|c|}{ Factor } & \multicolumn{1}{|c|}{ Distribution } & Best estimate & Lower hound & Upper hound \\
\hline$\lambda_{\mathbf{f}\left[y \mathbf{r}^{-1}\right]}$ & Gamma & $7.97 \mathrm{E}-03$ & $7.37 \mathrm{E}-06$ & 0.084 \\
\hline $\mathbf{f}_{\mathbf{a}}$ & $\begin{array}{l}\text { Maximum } \\
\text { Entropy }\end{array}$ & 0.18 & 0.036 & 0.90 \\
\hline $\mathbf{f}_{\mathbf{s}}$ & $\begin{array}{l}\text { Maximum } \\
\text { Entropy }\end{array}$ & 0.3 & 0.19 & 0.67 \\
\hline $\mathbf{f}_{\mathbf{n s}}$ & $\begin{array}{l}\text { Maximum } \\
\text { Entropy }\end{array}$ & 0.98 & 0.42 & 1.0 \\
\hline $\mathbf{Q}\left(^{*}\right)$ & Point value & $7.72 \mathrm{E}-03$ & & \\
\hline
\end{tabular}

\begin{tabular}{|l|c|l|}
\hline Time of duration detected condition $[\mathrm{Yr}]$. & $\mathbf{t}$ & $1 / 12$ \\
\hline Probability of a fire in $\mathbf{t}=\lambda_{\mathrm{f}} \times \mathbf{f}_{\mathrm{a}} \times \mathbf{f}_{\mathrm{s}} \times \mathbf{f}_{\mathrm{ns}} \times \mathbf{t}$ & $\mathbf{P}$ & $3.51 \mathrm{E}-05$ \\
\hline Conditional Core Damage Probability $=\mathbf{P Q}$ & $\mathbf{C C D P}$ & $2.71 \mathrm{E}-07$ \\
\hline
\end{tabular}

(*) Value from Table 4.4.2 


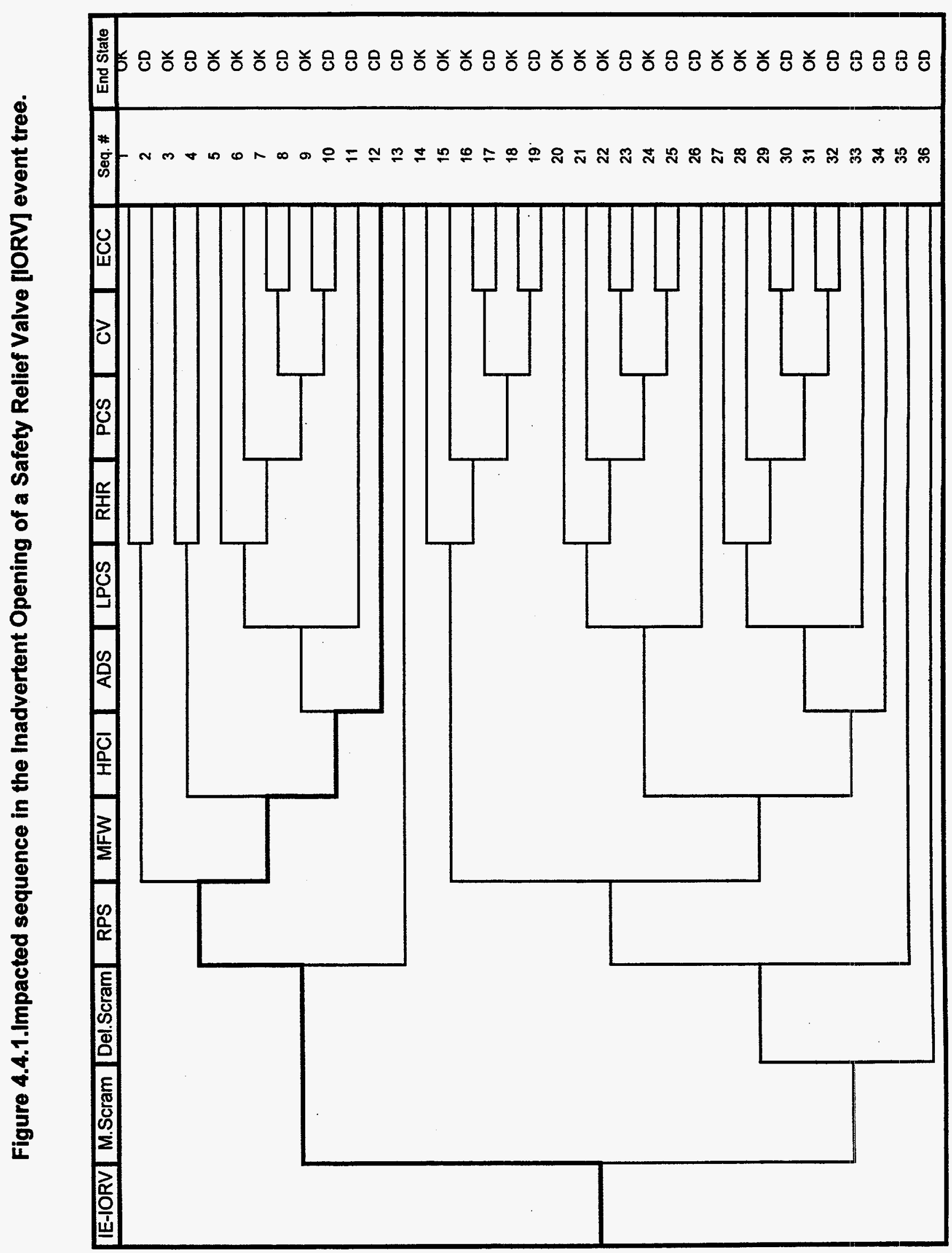

$4-52$ 


\section{SEISMIC CASE STUDY}

\subsection{Introduction}

This chapter will introduce and then discuss a "case study" to illuminate how a seismic configuration compromise reported in an LER can be analyzed using the ASP methodology presented in Chapter 3 of this report, specifically in Section 3.6.1 (LERs with a seismic configuration compromise).

The case study involves a very old LER -- from 1981 -- generated at a General Electric BWR-4 boiling water reactor (BWR) with a steel-lined concrete Mark I containment, that we will call "Plant $X^{\prime \prime}$ here. It is important to recognize up-front that the actual problem reported in the 1981 LER has long since been remedied: no safety issue exists today. This LER has been chosen solely because it provides a useful tutorial example for our case-study purposes here.

The LER reports snubber problems. However, Plant $X$ was not the only plant to report snubber problems during that period: numerous failures with snubbers were discovered at many plants during the late 1970s and early 1980s (NRC, 1982; NRC, 1984b; Nitzel et al., 1992), and a large number of LERs were generated. In the intervening years, these failures have been corrected by a combination of better engineering design, manufacturing, installation, maintenance and surveillance testing. For our purposes here, we are interested in snubber failure modes that could place significant additional stress on safety grade equipment or piping if a large earthquake were to occur. These failures represent potential configuration compromises, that could be precursors to an earthquake-initiated accident.

The topics discussed as part of this case study are:

o snubber system description

- snubber failure modes

- specific failure mode "failure to lock up"

- the Plant $X$ case study

- Application of the screening criteria to the Plant $\mathrm{X}$ case study.

To satisfy the IPEEE seismic review requirement (NRC, 1991), Plant X conducted an EPRI seismic-margins review (EPRI, 1988). The Plant X IPEEE report has been the source of our system descriptions. Relevant aspects of the Plant $X$ systems are summarized below (Section 5.7).

\subsection{Snubber System Description}

Hydraulic snubbers are devices in which the load is transferred through a hydraulic fluid. Large bore hydraulic snubbers (LBHSs) are defined as those units with rated load capacities of 50 kips or greater. LBHSs prevent unrestrained pipe motion during seismic or severe transients while allowing thermal movement during normal 
operation.

Most LBHSs are on safety-related systems. For PWRs the majority of LBHSs are on reactor coolant systems and steam generators. For BWRs the majority of LBHSs are on main steam systems, feedwater lines and recirculation systems with a few on feedwater, residual heat-removal systems and safety-in jection lines.

Hydraulic snubbers consist of a cylinder containing fluid, a piston internal to the cylinder, control valves and a fluid reservoir. Figure 5-1 shows a schematic of a Paul Munroe/Enertech assembly. Figure 5-2 shows a Grinell assembly with adjustable poppet valve and bleed settings.

For either snubber, the piston is free to move in either direction with no restrictions up to the lock-up velocity. At the lock-up velocity the poppet valve internal to the snubber closes. Closure of the poppet in either tension or compression greatly reduces the fluid flow through the control valve, increasing the pressure on the operating side of the cylinder and generating a resistance force. A small bleed orifice is supplied that allows the hydraulic snubber to translate slowly under a sustained load after locking. When the applied velocity of the snubber becomes zero, the poppet valve opens once again, allowing free piston movement. The bleed orifice opening is fixed in Figure 5-1 but is adjustable in Figure 5-2.

Figure 5-3 shows the characteristic applied load and velocity time-histories for a hydraulic snubber during a dynamic event. The snubber must overcome a breakaway force before it can move. The breakaway force is the force required to overcome the snubber static friction and initiate snubber piston motion. Drag force is the force required to sustain piston motion (that is, overcome dynamic friction). Lockup velocity is the piston velocity required to activate the snubber control valves, causing the snubber to become rigid (that is, to lock up). Bleed rate refers to the rate of relaxation of the snubber once lock-up is achieved. Bleed rate is a combination of fluid flow through the orifices designed into the control valve mechanism and leakage past the seals.

\subsection{Snubber Failure Modes}

A snubber could fail to lock up (L/U) or could have a high lock-up velocity. After lock-up, a snubber could have either a high or a low bleed-rate velocity. A snubber could remain locked up if there is no bleed rate. In addition, the snubber could be locked up prior to motion.

A high or low bleed rate does not affect seismic capability. Failure to lock up indicates that the snubber will not restrain the equipment or piping during strong motion and is a failure mode that will be considered in this case study. In addition, it is conceivable that a locked up snubber fully retracted or extended could place additional stress on equipment.

\section{$5.4 \quad$ Failure to Lock Up}

Failure to lock up means that the hydraulic fluid does not develop a resistance force sufficient to retard piston movement. Snubber failure modes for this failure naode include: 
o control valve fails to close due to a broken spring or spring capture

o piston seals allow leakage past pistons

o miscellaneous seal failures

- contaminated hydraulic fluid or wrong hydraulic fluid used.

\subsection{Plant $X$ Case Study}

As mentioned above, the case study below is based on a 1981 LER. In that year, Plant $X$ began testing hydraulic snubbers according to technical specifications. As mentioned, Plant $X$ is a General Electric BWR-4 boiling water reactor with a steellined concrete Mark I containment. A total of 640 snubbers were removed from service and functionally tested. Of this number, 130 failed the tests and thus required rebuilding. An additional 80 snubbers were rebuilt for preventive maintenance, raising the total needing rebuilding to 210 . A program was established to inspect and evaluate each snubber that was rebuilt. A large percentage of the rebuilt snubbers were found to be degraded with worn poppets, and deformed poppet retaining springs.

We will concentrate here, for purposes of our case study, on 33 snubbers that reported lock-up failures. These are listed in Table 5-1. The information contained in Table 5-1 includes:

Column 1 -- Entry number

Column 2 -- Snubber diameter size in inches

Column 3 -- System location

Column 4 -- $\quad$ Possible effect of snubber failure given a seismic event

Column 5 -- Whether the snubber failure can cause an Engineered Safeguard Front Line System failure or Support System failure

Column 6 -- Number of trains involved

Column 7 -- $\quad$ Whether the snubber failure could fail either a primary or alternate shutdown path. These paths were identified for the EPRI seismic margins study conducted for the plant's IPEEE described in Section 5.7.

We assume in Table 5-1 that a snubber lock-up failure could result in any of numerous failure modes, two examples of which are piping failure (rupture or plugging), and loss of pump function.*

* A few system failures such as the air off-gas system and fuel-pool cooling are not considered further here because their safety significance is only minor.

$$
5-3
$$




\subsection{Screening Criteria}

We now apply the seismic-ASP screening criteria from Chapter 3 to the snubber failure modes listed in Table 5-1. We collectively consider the entire set of snubber failure modes.

Step 1 --- Initial Screening

As Table 5-1 shows, the potential exists for the failure of numerous front-line safety systems and support systems. These failures are listed below (entry numbers are from Table 5-1):

\section{Reactor Coolant System Inventory Control}

High Pressure Coolant Injection (HPCI) (entries 2, 3, 7, 8, 10, 11 and 20)

Reactor Core Isolation Cooling system ( $\mathrm{RCIC)}$ (entries 6, 12, 13, 14, 19 and 21)

Low Pressure Injection (RHR) (entries 9, 17 and 32)

Core Spray (entry 24)

Decay Heat Removal

Suppression Cooling Mode (RHR) (entries 9, 17, 32, 28, 29 and 33)

\section{Support Systems}

Service Water System (entries 5, 16, 22 and 23)

Reactor Building Component Cooling Water System (entries 18 and 23).

When the Step-1 screening criteria from Chapter 3 are applied to the above group of systems, we observe that the number of affected safety systems and functions is very large. Hence, LER is screened in at this step.

It is important to note that there is one train of Core Spray (Low Pressure Injection) that is unaffected -- that is, none of the snubber failures reported in the LER involve this train. Containment venting used for decay heat removal is also unaffected.

\section{Step 2 --- Preliminary Analysis}

In this step, following the methodology guidance in Chapter 3, we assume that all of the systems listed in Table 5-1 will fail.

Assuming a loss of offsite power, a core-damage accident would occur if either one of the following two additional failures were to occur, assuming that all of the systems in Table 5-1 have also failed: 
1) one train of core spray fails (resulting in total failure of reactor inventory control)

OR

2) containment venting fails (resulting in total loss of decay heat removal).

For this preliminary analysis, we conservatively assume a median seismic capacity for LOSP (loss of offsite power) of $0.2 \mathrm{~g}$.

Figure 5-4 shows the site-specific seismic hazard curve for the Plant $X$ site (Savy et al., 1993). At a ground acceleration of $0.2 \mathrm{~g}$ (approximately $200 \mathrm{~cm} / \mathrm{sec}^{2}$ ), the mean exceedance probability is about $1.6 \times 10^{-3}$ per year.

Because venting of the containment is a manual operation, it is reasonable to assume that the human error probability is greater than $1.0 \times 10^{-3}$, and this does not even account for the observation that a large earthquake can impose additional stress on the operators. This means that we would expect an unconditional core melt frequency of greater than $1.0 \times 10^{-6}$ per year for a $0.2 \mathrm{~g}$ earthquake, assuming all of the failures above. Hence, the LER is still screened in at this point, and passed forward to Step 3 ("Detailed Analysis").

As an additional check, we can refine our preliminary analysis slightly, and perform some rough calculations for core-damage frequency under the assumption that the seismic risk is dominated by a single element. For our simplified situation, this would be a single snubber failure (or a large number of $100 \%$-correlated snubber failures). We will do the approximate calculation twice, for two assumed values for the median seismic capacity of a snubber:

(a) $0.2 \mathrm{~g}$ (median capacity of of fite power)

(b) $0.5 \mathrm{~g}$.

We also assume that for the snubber seismic fragility the composite standard deviation of the seismic capacity, so-called "beta-c", equals 0.40 . (This is not typical of most equipment --- see Table 6-1 in Chapter 6 -- but we make this assumption for the purposes of this stylized case study.)

At $0.5 \mathrm{~g}$, the mean exceedance probability from the seismic hazard curve is about $2.4 \times 10^{-4}$ per year. It is a simple matter to perform the convolution of the Plant $\mathrm{X}$ site-specific seismic hazard curve with the assumed snubber fragility curve. We obtain the following point-value estimated core-damage frequencies for the median capacities given above:
(a) $2.0 \times 10^{-3}$ per year $(0.2 \mathrm{~g}$ case $)$
(b) $3.3 \times 10^{-4}$ per year ( $0.5 \mathrm{~g}$ case).

These frequencies are unconditional, which means that they include the earthquake initiating frequency, and also the assumed snubber failure(s). Such a core-damagefrequency calculation is slightly different from the way our recommended ASP methodology approaches the problem here, but we are only doing this brief analysis

$$
5-5
$$


as an additional check. Clearly, these frequency estimates, although very approximate, are too high to allow the LER to be screened out at this stage. Therefore, we have confirmed that we should pass the LER on to Step 3 ("Detailed Analysis").

Step 3 --- Detailed Analysis

NOTE: To understand the systems details in this next part of the text, the reader should become familiar with the Plant $X$ systems discussions in back-up Section 5.7 below.

The Step-3 Detailed-Analysis work will follow the Group-2 guidance under seismicASP Step 3, because Plant $X$ has only a seismic-margin review, not a full-scope seismic PRA.

To begin our detailed analysis, we examine the two success paths used in the Plant $X$ seismic-margin analysis. The full Plant $X$ success-path structure is shown in Figure 5-9, and the four subsidiary functional success paths are shown in Figures 5-5 through 5-8. (A detailed discussion of the systems and functions is provided below in Section 5.7).

Our task here is to examine the various system failures that would be caused by the various seismic-induced snubber failures. We do this by examining the snubber failures in Table 5-1 in conjunction with the system logic on the success paths.

When we do this, we observe (Figure 5-8) that if both trains of RHR fail, successful decay-heat removal cannot be accomplished and both success paths will fail. From Table 5-1, we note (Entries 17 and 32) that both RHR trains are affected by snubber failures. In addition, Figure 5-7 indicates that the primary path (but not the alternate path) for reactor coolant inventory control will also fail due to the assumed snubber failures (see Entries 2, 3, 7, 8, 10, 11, and 20 on Table 5-1.)

To understand the significance of these success-path failures, we must conduct a detailed snubber seismic-capacity analysis, so as to determine the weakest element in each success path. However, because Plant $X$ only has a seismic-margin review, our task is simplified: we need only determine the snubber HCLPF capacities. In an actual LER seismic review, there would be significant effort required at this point to determine the snubbers' seismic HCLPF capacities in their compromised states. We have not done that work -- instead we will postulate certain snubber capacities, in order to get on with the tutorial case-study example.

For the purposes of our case-study tutorial here, let us consider four different cases (all of these cases are merely postulated, not actual -- that is, none of these cases is actually reflected in the Plant $X$ LER under consideration):

Case A: Assume that the snubbers governing RHR [Figure 5-8] (Entries 17 and 32 on Table 5-1) have HCLPF capacities of $0.12 \mathrm{~g}$. All other snubbers are seismically very strong.

Case B: Assume that the snubbers governing RHR [Figure 5-8] (Entries 17 and 32 on Table 5-1) have HCLPF capacities of $0.25 \mathrm{~g}$. All other snubbers are seismically very strong. 
Case C: Assume that the snubbers governing RHR [Figure 5-8] (Entries 17 and 32 on Table 5-1) have HCLPF capacities of $0.40 \mathrm{~g}$. All other snubbers are seismically very strong.

Case D: Assume that the snubbers governing reactor coolant inventory control [Figure 5-7] (Entries 2, 3, 7, 8, 10, 11, and 20 on Table 5-1) have HCLPF capacities of $0.12 \mathrm{~g}$. All other snubbers are seismically very strong.

Case A: Assume that the snubbers governing RHR [Figure 5-8] (Entries 17 and 32 on Table 5-1) have HCLPF capacities of $0.12 \mathrm{~g}$. All other snubbers are seismically very strong. If this situation were true, then both of Plant $X$ 's seismic-margin success paths would be significantly compromised in an earthquake: both would have HCLPF capacities of $0.12 \mathrm{~g}$ (which is very low), because the RHR failures represented by Entries 17 and 32 are present in series in both success paths.

The ASP analyst should note this result, document the conclusions, and designate this LER as an "Accident Sequence Precursor", worthy of significant attention.

Case B: Assume that the snubbers governing RHR [Figure 5-8] (Entries 17 and 32 on Table 5-1) have HCLPF capacities of $0.25 \mathrm{~g}$. All other snubbers are seismically very strong. If this situation were true, then both of Plant X's seismic-margin success paths would be compromised: both would have HCLPF capacities of $0.25 \mathrm{~g}$, because the RHR failures represented by Entries 17 and 32 are present in series in both success paths.

The HCLPF capacities of 0.25 are not "very strong", but they are not "very weak" either .- so the LER here would represent an intermediate case. If the base-case HCLPF capacity of either Plant $X$ success path (in the uncompromised state) is higher than $0.25 \mathrm{~g}$, then that success path would now have the lower HCLPF-capacity value of $0.25 \mathrm{~g}$ (this decrease could be true for either or perhaps for both of the base-case success paths.)

The ASP analyst should note this result, and document the conclusions. Whether the LER would be designated as an "Accident Sequence Precursor", worthy of significant attention, depends on applying some expert judgment. However, for Case B this LER should definitely be documented, rather than merely screened out.

Case C: Assume that the snubbers governing RHR [Figure 5-8] (Entries 17 and 32 on Table 5-1) have HCLPF capacities of $0.40 \mathrm{~g}$. All other snubbers are seismically very strong. If this situation were true, then neither of Plant $X$ 's seismic-margin success paths would be compromised. This is because the "rules" of the seismic-margin analysis methodology allow any component to be screened out if its HCLPF capacity exceeds $0.3 \mathrm{~g}$ (the Review Level Earthquake for Plant $X$ ) --- so for Case $C$ the snubber problem would not affect the HCLPF capacity of either success path.

The ASP analyst should note this result, and document the conclusions, but this LER would be screened out, and would definitely not be designated as an "Accident Sequence Precursor".

Case D: Assume that the snubbers governing reactor coolant inventory control [Figure 5-7] (Entries 2,3,7,8,10,11, and 20 on Table 5-1) have HCLPF capacities 
of $0.12 \mathrm{~g}$. All other snubbers are seismically very strong. If this situation were true, then only one of Plant X's two seismic-margin success paths would be compromised, because only one train of Core Spray system would be affected by snubber failure (see Figure 5-7). The other success path would remain strong. Therefore, the plant-level HCLPF capacity would be unchanged, but the HCLPF capacity of the one affected success path would be $0.12 \mathrm{~g}$, which is quite low.

The ASP analyst should note this result and document the conclusions. The write-up should note that in an important earthquake one of the two success paths would be significantly compromised by the snubber failure as reported in the LER. However, this LER would not be designated as an "Accident Sequence Precursor".

Summary: The four postulated. Cases (A, B, C, D) have very different outcomes. This tutorial is intended to demonstrate how the ASP seismic analyst would deal with each of these situations.

Of course, whether snubber failures actually represent a real plant safety issue is another question, and one that we have not addressed directly here. We wish to point out, though, that another nuclear plant, Surry, conducted a stress analysis to determine the effect of snubber failures discovered at their plant (VEPCO, 1984; NRC, 1984b). They found that the seismic capacities of their vital equipment vrere adequate even with these snubber failures. However, here we have been assuming that the snubber failures reported in the LER would lead to equipment failures. This assumption has been made strictly for the tutorial purposes of our case studies here.

\subsection{Back-up Discussion for This Chapter}

As mentioned above, Plant $X$ conducted an EPRI seismic margin review to fulfill the seismic part of their IPEEE requirement (NRC, 1991). The EPRI SMA methodology is based on a system "success path" approach. The approach defines and evaluates the seismic capacities of the components required to bring the plant to a stable condition for at least 72 hours. Four safety functions must be successfully maintained to reach this stable condition: reactor reactivity control, reactor coolant pressure control, reactor coolant inventory control, and decay heat removal.

The following steps were conducted to identify the systems required to maintain a safe-shutdown condition following the postulated $0.3 \mathrm{~g}$ RLE (Review Level Earthquake) that is the starting point for the seismic-margin analysis:

o Develop plant-specific safety function models (Success Path Logic Diagrams.)

- Identify systems that can accomplish these success paths.

- Identify preferred and alternate success paths based on operational and system considerations.

- Identify important components within these systems.

The two full detailed safe-shutdown success paths are shown in Figure 5-9; the four supporting figures (Figures 5-5 through 5-8) show specific pieces of the success-path structure. The discussion just below will cover the specific systems considerations 
for these success-path elements.

The selection of the IPEEE safe-shutdown paths was governed by the conditions and assumptions summarized below (see EPRI, 1988; NRC, 1991):

- Offsite power is assumed to be lost following the seismic event.

- Each success path must be able to maintain a stable cold or hot shutdown condition for 72 hours following the postulated review-level earthquake (RLE).

- The seismic-margin review should address only seismically-induced transient events and seismically-induced one-inch LOCA events.

- Safety-function success is measured at the system level, not at the train level. If one train is found to be seismically rugged, the other train is assumed to possess similar seismic capacity (although it must be confirmed during the walkdown).

- Non-seismic component or system unavailabilities are not addressed for multiple or redundant trained systems, but must be considered for single-train systems.

- Only systems whose function is to prevent severe core damage are evaluated.

- Non-seismic failures and human actions should be considered in accordance with the guidance provided in NUREG-1407 (NRC, 1991).

- Containment isolation and mitigation systems should be examined as discussed in NUREG-1407. The focus is to identify vulnerabilities that involve potential early failures of containment functions.

As part of the selection of IPEEE safe-shutdown systems, the IPEEE analysts considered components that could challenge the integrity of the shutdown path (i.e., the pressure boundary). This evaluation included the effects of spurious actuation of safety signals which could cause inadvertent component actuation/operation. Additionally, the unavailabilities of the systems selected were reviewed in the internal-events Probabilistic Safety Assessment and verified by plant engineering to ensure that the systems chosen did not have an unusually high unavailability.

\section{Reactor Reactivity Control}

The first plant challenge in response to a seismic event is to control reactivity, thus reducing core power to decay-heat levels. This function is accomplished by the rapid insertion of the control rods into the core. This is the normal method for reactor shutdown and occurs automatically when a reactor trip signal is generated. As a backup action, the operators can execute a manual reactor trip from the main control board. The control rods provide adequate shutdown margin to allow for the control rod of the highest worth to fail to insert. The inherent redundancy of this system provides protection against a single active failure. The Standby Liquid Control system was not selected as a backup means for reactivity control because it does not rapidly shut down the reactor and its operation is somewhat stressful for the operator. 
The function of reactivity control is achieved by interaction between the Reactor Protection System (RPS) and the Control Rod Drive Hydraulic Control Unit (CRD/HCU) System. The RPS contains the actuation circuitry, alarms, active equipment, and passive equipment required to trip the reactor. It also contains the equipment used to confirm and monitor the trip status. The CRD system provides the passive, mechanical means to insert the control rods. Interaction between these two systems will provide for reactivity control. Figure 5-5 shows the success path diagram for reactivity control. The bold lines in Figure 5-5 represent the primary success path and the thin lines represent the success alternate path.

\section{Reactor Coolant System Pressure Control}

Following a loss of of fsite power and subsequent plant trip, the main steam isolation valves will automatically close and an increase in the RCS pressure will occur requiring RCS pressure relief and control. The plant response to control RCS pressure is the lifting of the safety relief valves (SRVs) at their respective setpoints. An automatic depressurization system (ADS) exists, but is inhibited by the controlroom operators in accordance with the Emergency Operating Procedures (EOPs) and no credit is taken for ADS in this analysis. The SRVs are, however, manually operated by the control room operators to lower reactor pressure and allow low pressure injection, if needed, in accordance with EOPs. The redundancy against a single active failure is provided by the divisional separation and multiple numbers of SRVs, and the redundancy of the Nitrogen Backup system. The system is comprised of eleven valves which are dependent on the Nitrogen Backup system for their pneumatic motive force. Success is defined by the proper functioning of at least two SRVs and their support systems. Additionally, use of this means places a high burden on the operator. Figure 5-6 shows the success path diagram for reactor pressure control. The bold lines in Figure 5-6 represent the primary success path and the thin lines represent the alternate success path.

\section{Reactor Coolant System Inventory Control}

This section describes the safe shutdown equipment required for accomplishing the reactor coolant inventory control function. The inventory of the reactor coolant system (RCS) is controlled by injecting water into the RCS and by minimizing the loss of water from the various openings in the system. Note that the alternatives for reactor coolant inventory control are closely related to some of the alternatives for reactor coolant pressure control.

RCS Inventory Supply: RCS inventory can be supplied by one of the following systems depending on the RCS pressure:

(i) High Pressure Coolant Injection (HPCI): The normal makeup function is provided by taking suction from the Condensate Storage Tank (CST) to the HPCI pump and discharging through the normal charging paths to the $R C S$ through the main feedwater line $A$. However, the alternate suction path from the Suppression Pool (SP) has been chosen due to its greater seismic capacity and larger margin of success over the 72-hour mission time. HPCI is capable of maintaining reactor coolant inventory during the expected transients and a small LOCA.

(ii) Core Spray (CS) [for pressure < 410 psig pressure]: An option for providing makeup to the RCS is to use one train of the Core Spray system (in

$$
5-10
$$


conjunction with manual depressurization to $<410$ psig). Either train can be chosen to be very reliable. Each CS pump takes suction from the Suppression Pool and in jects into the RCS.

RCS Inventory Discharge: The discharge from the RCS is controlled by minimizing the loss of inventory through various paths. Significant paths are:

(i) Safety Relief Valves (SRVs): The SRVs are included on the success path to ensure that they close af ter demand.

(ii) Primary Containment Isolation System (PCIS): The PCIS system is included to provide containment isolation for a small LOCA. The primary purpose of this aspect of the seismic evaluation is to identify any vulnerabilities that involve early containment failure functions. The PCIS valves were used to determine the scope of valves for the containment isolation evaluation. Figure 5-7 shows the success-path diagram for reactor coolant inventory control. The bold lines in Figure 5-7 represent the primary success path, the thin lines represent the alternate path, and the dashed lines represents an optional path.

\section{Decay Heat Removal}

The final function required to meet safe shutdown is decay heat removal. Decay heat removal can be accomplished at either hot or cold shutdown conditions. Plant $X$ 's procedures direct the operators to go to cold shutdown following a seismic event. During the early stages of the plant shutdown procedure, decay heat removal is achieved by placing one loop of the Residual Heat Removal (RHR) system in the Suppression Pool Cooling (SPC) mode with the second RHR loop available as a backup path. In the latter stages of the plant shutdown procedure, decay heat removal is achieved by placing one loop of RHR in the Shutdown Cooling (SDC) mode with the second loop providing the backup function.

The suction and discharge paths are dependent on the mode of operation. During the SPC mode, the RHR system takes suction from and discharges to the Suppression Pool via the RHR Heat Exchangers. During the SDC mode, the system takes suction from and discharges to the reactor vessel via the RHR Heat Exchangers. The Suppression Pool inventory is sufficient for the designated 72-hour mission time. Figure 5-8 shows the success-path diagram for decay heat removal. The bold lines in Figure 5-8 represent the primary success path and the thin lines represent the alternate path.

The complete success path for the combined transient and LOCA case is shown in Figure 5-9.

\section{Required Support Systems}

In addition to the front-line systems assigned to the success paths, the support systems required to maintain front-line functions must be identified. A dependency matrix is provided in Table 5-2. The table identifies only the direct dependencies of the front-line systems on the support systems. It indicates the support systems which must be assessed since each provides an important function which must be met following a seismic event. Therefore, important components in these support systems must be included in the seismic-margin analysis.

$$
5-11
$$


Table 5 - 1

Snubber Failures for Plant X, Failure to Lock Up

\begin{tabular}{|c|c|c|c|c|c|c|}
\hline $\begin{array}{l}\text { ENTRY } \\
\text { NO }\end{array}$ & $\begin{array}{c}\text { SNUBBER } \\
\text { DIAMETER } \\
\text { SIZE } \\
\text { IN } \\
\text { INCHES }\end{array}$ & $\begin{array}{l}\text { SYSTEM } \\
\text { LOCATION }\end{array}$ & $\begin{array}{l}\text { POSSIBLE } \\
\text { EFFECT OF } \\
\text { SNUBBER } \\
\text { FAILURE GIVEN } \\
\text { SEISMIC EVENT }\end{array}$ & $\begin{array}{l}\text { ESF FRONT } \\
\text { LINE OR } \\
\text { SUPPORT } \\
\text { SYSTEM } \\
\text { FAILURE? }\end{array}$ & $\begin{array}{c}\text { NUMBER } \\
\text { OF } \\
\text { TRAINS } \\
\text { INVOLVED }\end{array}$ & $\begin{array}{l}\text { FAILURE OF } \\
\text { PRIMARY OR } \\
\text { ALTERNATE } \\
\text { SHUTDOWN } \\
\text { PATH? }\end{array}$ \\
\hline 1 & 5 & $\begin{array}{l}\text { 2B REACTOR } \\
\text { RECIRC PUMP }\end{array}$ & $\begin{array}{l}\text { 1. PARTIIAL } \\
\text { LOSS OF } \\
\text { PRIMARY } \\
\text { COOLANT } \\
\text { RECIRCULATION } \\
\text { 2. POSSIBLE } \\
\text { PIPE RUPTURE } \\
\text { CAUSES LARGE } \\
\text { LOCA } \\
\end{array}$ & No & $\mathrm{N} / \mathrm{A}$ & NO \\
\hline 2 & $\begin{array}{c}10 \\
\text { "SNUBBER A" }\end{array}$ & $\begin{array}{l}\text { HPCI PUMP } \\
\text { DISCHARGE }\end{array}$ & $\begin{array}{l}\text { HPCI PUMP } \\
\text { FAILS TO } \\
\text { START OR RUN }\end{array}$ & $\begin{array}{l}\text { YES - - FRONT } \\
\text { LINE -- LOSS } \\
\text { OF A SINGLE } \\
\text { TRAIN OF HIGH } \\
\text { PRESSURE } \\
\text { MAKEUP }\end{array}$ & 1 & $\begin{array}{l}\text { YES -- FAILS } \\
\text { PRIMARY PATH } \\
\text {-- REACTOR } \\
\text { COOLANT } \\
\text { INVENTORY } \\
\text { CONTROL } \\
\end{array}$ \\
\hline 3 & $\begin{array}{c}10 \\
\text { "SNUBBER B" }\end{array}$ & $\begin{array}{l}\text { HPCI PUMP } \\
\text { DISCHARGE }\end{array}$ & $\begin{array}{l}\text { HPCI PUMP } \\
\text { FAILS TO } \\
\text { START OR RUN }\end{array}$ & $\begin{array}{l}\text { YES -- FRONT } \\
\text { LINE-- LOSS } \\
\text { OF A SINGLE } \\
\text { TRAIN OF HIGH } \\
\text { PRESSURE } \\
\text { MAKEUP }\end{array}$ & 1 & $\begin{array}{l}\text { YES -- FAILS } \\
\text { PRIMARY PATH } \\
\text { - REACTOR } \\
\text { COOLANT } \\
\text { INVENTORY } \\
\text { CONTROL }\end{array}$ \\
\hline
\end{tabular}


Table 5 - 1 (continued)

\begin{tabular}{|c|c|c|c|c|c|c|}
\hline $\begin{array}{l}\text { ENTRY } \\
\text { NO }\end{array}$ & $\begin{array}{c}\text { SNUBBER } \\
\text { DIAMETER } \\
\text { SIZE } \\
\text { IN } \\
\text { INCHES }\end{array}$ & $\begin{array}{l}\text { SYSTEM } \\
\text { LOCATION }\end{array}$ & $\begin{array}{l}\text { POSSIBLE } \\
\text { EFFECT OF } \\
\text { SNUBBER } \\
\text { FAILURE GIVEN } \\
\text { SEISMIC EVENT }\end{array}$ & $\begin{array}{l}\text { ESF FRONT } \\
\text { LINE OR } \\
\text { SUPPORT } \\
\text { SYSTEM } \\
\text { FAILURE? }\end{array}$ & $\begin{array}{c}\text { NUMBER } \\
\text { OF } \\
\text { TRAINS } \\
\text { INVOLVED }\end{array}$ & $\begin{array}{l}\text { FAILURE OF } \\
\text { PRIMARY OR } \\
\text { ALTERNATE } \\
\text { SHUTDOWN } \\
\text { PATH? }\end{array}$ \\
\hline 4 & 3 & $\begin{array}{l}\text { RHR HEAD } \\
\text { SPRAY }\end{array}$ & $\begin{array}{l}\text { SPRAY HEAD } \\
\text { RESTRICTED } \\
\text { FLOW }\end{array}$ & $\begin{array}{l}\text { YES FRONT } \\
\text { LINE - LOSS } \\
\text { OF A SINGLE } \\
\text { TRAIN OF } \\
\text { CONTAINMENT } \\
\text { SPRAY COOLING } \\
\end{array}$ & 1 & No \\
\hline 5 & 10 & $\begin{array}{l}\text { SW SUPPLY TO } \\
\text { RHR BOOSTER } \\
\text { PUMPS }\end{array}$ & $\begin{array}{l}\text { ALTERNATE } \\
\text { SUPPLY OF } \\
\text { COOLANT } \\
\text { UNAVAILABLE }\end{array}$ & $\begin{array}{l}\text { YES FRONT } \\
\text { LINE-- } \\
\text { PARTIAL LOSS } \\
\text { OF LOW } \\
\text { PRESSURE } \\
\text { INJECTION }\end{array}$ & 1 & NO \\
\hline 6 & 3 & $\begin{array}{l}\text { RCIC PUMP } \\
\text { SUPPLY }\end{array}$ & $\begin{array}{l}\text { RCIC PUMP } \\
\text { FAILS TO } \\
\text { START OR RUN }\end{array}$ & $\begin{array}{l}\text { YES FRONT } \\
\text { LINE-- LOSS } \\
\text { OF ONE TRAIN } \\
\text { HIGH PRESSURE } \\
\text { INJECTION }\end{array}$ & 1 & No \\
\hline 7 & 3 & $\begin{array}{l}\text { HPCI STEAM } \\
\text { SUPPLY }\end{array}$ & $\begin{array}{l}\text { HPCI PUMP } \\
\text { FAILS TO } \\
\text { START OR RUN }\end{array}$ & $\begin{array}{l}\text { YES FRONT } \\
\text { LINE - - LOSS } \\
\text { OF A SINGLE } \\
\text { TRAIN OF HIGH } \\
\text { PRESSURE } \\
\text { INJECTION }\end{array}$ & 1 & $\begin{array}{l}\text { YES --FAILS } \\
\text { PRIMARY PATH } \\
\text {-- REACTOR } \\
\text { COOLANT } \\
\text { INVENTORY } \\
\text { CONTROL }\end{array}$ \\
\hline
\end{tabular}


Table 5 - 1 (continued)

\begin{tabular}{|c|c|c|c|c|c|c|}
\hline $\begin{array}{c}\text { ENTRY } \\
\text { NO }\end{array}$ & $\begin{array}{c}\text { SNUBBER } \\
\text { DIAMETER } \\
\text { SIZE } \\
\text { IN } \\
\text { INCHES }\end{array}$ & $\begin{array}{l}\text { SYSTEM } \\
\text { LOCATION }\end{array}$ & $\begin{array}{l}\text { POSSIBLE } \\
\text { EFFECT OF } \\
\text { SNUBBER } \\
\text { FAILURE GIVEN } \\
\text { SEISMIC EVENT }\end{array}$ & $\begin{array}{l}\text { ESF FRONT } \\
\text { LINE OR } \\
\text { SUPPORT } \\
\text { SYSTEM } \\
\text { FAILURE? }\end{array}$ & $\begin{array}{l}\text { NUMBER } \\
\text { OF } \\
\text { TRAINS } \\
\text { INVOLVED }\end{array}$ & $\begin{array}{l}\text { FAILURE OF } \\
\text { PRIMARY OR } \\
\text { ALTERNATE } \\
\text { SHUTDOWN } \\
\text { PATH? }\end{array}$ \\
\hline 8 & 3 & $\begin{array}{l}\text { HPCI PUMP } \\
\text { DISCHARGE }\end{array}$ & $\begin{array}{l}\text { HPCI PUMP } \\
\text { FAILS TO } \\
\text { START OR RUN }\end{array}$ & $\begin{array}{l}\text { YES FRONT } \\
\text { LINE-- LOSS } \\
\text { OF A SINGLE } \\
\text { TRAIN OF HIGH } \\
\text { PRESSURE } \\
\text { INJECTION }\end{array}$ & 1 & $\begin{array}{l}\text { YES - -FAILS } \\
\text { PRIMARY PATH } \\
\text {-- REACTOR } \\
\text { COOLANT } \\
\text { INVENTORY } \\
\text { CONTROL }\end{array}$ \\
\hline 9 & 10 & $\begin{array}{l}\text { RHR LPCI } \\
\text { INJECTION }\end{array}$ & $\begin{array}{l}\text { LPCI LOOP A } \\
\text { PUMPS FAIL TO } \\
\text { START OR RUN }\end{array}$ & $\begin{array}{l}\text { YES FRONT } \\
\text { LINE-- LOSS } \\
\text { OF A SINGLE } \\
\text { TRAIN OF LOW } \\
\text { PRESSURE } \\
\text { INJECTION }\end{array}$ & 1 & No \\
\hline 10 & 3 & $\begin{array}{l}\text { HPCI STEAM } \\
\text { EXHAUST }\end{array}$ & $\begin{array}{l}\text { HPCI PUMP } \\
\text { FAILS TO } \\
\text { START OR RUN }\end{array}$ & $\begin{array}{l}\text { YES FRONT } \\
\text { LINE-- LOSS } \\
\text { OF A SINGLE } \\
\text { TRAIN HIGH } \\
\text { PRESSURE } \\
\text { INJECTION } \\
\end{array}$ & 1 & $\begin{array}{l}\text { YES -- FAILS } \\
\text { PRIMARY PATH } \\
-- \text { REACTOR } \\
\text { COOLANT } \\
\text { INVENTORY } \\
\text { CONTROL } \\
\end{array}$ \\
\hline 11 & 3 & $\begin{array}{l}\text { HPCI STEAM } \\
\text { EXHAUST }\end{array}$ & $\begin{array}{l}\text { HPCI PUMP } \\
\text { FAILS TO } \\
\text { START OR RUN }\end{array}$ & $\begin{array}{l}\text { YES FRONT } \\
\text { LINE--LOSS OF } \\
\text { A SINGLE } \\
\text { TRAIN OF HIGH } \\
\text { PRESSURE } \\
\text { INJECTION }\end{array}$ & 1 & $\begin{array}{l}\text { YES --FAILS } \\
\text { PRIMARY PATH } \\
-- \text { REACTOR } \\
\text { COOLANT } \\
\text { INVENTORY } \\
\text { CONTROL }\end{array}$ \\
\hline
\end{tabular}


Table 5 - 1 (continued)

\begin{tabular}{|c|c|c|c|c|c|c|}
\hline $\begin{array}{c}\text { ENTRY } \\
\text { NO }\end{array}$ & $\begin{array}{c}\text { SNUBBER } \\
\text { DIAMETER } \\
\text { SIZE } \\
\text { IN } \\
\text { INCHES }\end{array}$ & $\begin{array}{l}\text { SYSTEM } \\
\text { LOCATION }\end{array}$ & $\begin{array}{l}\text { POSSIBLE } \\
\text { EFFECT OF } \\
\text { SNUBBER } \\
\text { FAILURE GIVEN } \\
\text { SEISMIC EVENT }\end{array}$ & $\begin{array}{l}\text { ESF FRONT } \\
\text { LINE OR } \\
\text { SUPPORT } \\
\text { SYSTEM } \\
\text { FAILURE? }\end{array}$ & $\begin{array}{c}\text { NUMBER } \\
\text { OF } \\
\text { TRAINS } \\
\text { INVOLVED }\end{array}$ & $\begin{array}{l}\text { FAILURE OF } \\
\text { PRIMARY OR } \\
\text { ALTERNATE } \\
\text { SHUTDOWN } \\
\text { PATH? }\end{array}$ \\
\hline 12 & 3 & $\begin{array}{l}\text { RCIC STEAM } \\
\text { SUPPLY }\end{array}$ & $\begin{array}{l}\text { RCIC PUMP } \\
\text { FAILS TO } \\
\text { START OR RUN }\end{array}$ & $\begin{array}{l}\text { YES FRONT } \\
\text { LINE--LOSS OF } \\
\text { A SINGLE } \\
\text { TRAIN OF HIGH } \\
\text { PRESSURE } \\
\text { INJECTION }\end{array}$ & 1 & No \\
\hline 13 & 3 & $\begin{array}{l}\text { RCIC TURBINE } \\
\text { INLET DRAIN }\end{array}$ & $\begin{array}{l}\text { RCIC PUMP } \\
\text { FAILS TO } \\
\text { START OR RUN }\end{array}$ & $\begin{array}{l}\text { YES FRONT } \\
\text { LINE--LOSS OF } \\
\text { A SINGLE } \\
\text { TRAIN OF HIGH } \\
\text { PRESSURE } \\
\text { INJECTION }\end{array}$ & 1 & No \\
\hline 14 & 3 & $\begin{array}{l}\text { RCIC PUMP } \\
\text { SUPPLY }\end{array}$ & $\begin{array}{l}\text { RCIC PUMP } \\
\text { FAILS TO } \\
\text { START OR RUN }\end{array}$ & $\begin{array}{l}\text { YES FRONT } \\
\text { LINE--LOSS OF } \\
\text { A SINGLE } \\
\text { TRAIN OF HIGH } \\
\text { PRESSURE } \\
\text { INJECTION }\end{array}$ & 1 & No \\
\hline 15 & 3 & $\begin{array}{l}\text { FUEL POOL } \\
\text { COOLING FROM } \\
\text { RHR }\end{array}$ & $\begin{array}{l}\text { NOT } \\
\text { CONSIDERED } \\
\text { FURTHER }\end{array}$ & & & \\
\hline
\end{tabular}


Table 5 - 1 (continued)

\begin{tabular}{|c|c|c|c|c|c|c|}
\hline $\begin{array}{l}\text { ENTRY } \\
\text { NO }\end{array}$ & $\begin{array}{c}\text { SNUBBER } \\
\text { DIAMETER } \\
\text { SIZE } \\
\text { IN } \\
\text { INCHES }\end{array}$ & $\begin{array}{l}\text { SYSTEM } \\
\text { LOCATION }\end{array}$ & $\begin{array}{l}\text { POSSIBLE } \\
\text { EFFECT OF } \\
\text { SNUBBER } \\
\text { FAILURE GIVEN } \\
\text { SEISMIC EVENT }\end{array}$ & $\begin{array}{l}\text { ESF FRONT } \\
\text { LINE OR } \\
\text { SUPPORT } \\
\text { SYSTEM } \\
\text { FAILURE? }\end{array}$ & $\begin{array}{c}\text { NUMBER } \\
\text { OF } \\
\text { TRAINS } \\
\text { INVOLVED }\end{array}$ & $\begin{array}{l}\text { FAILURE OF } \\
\text { PRIMARY OR } \\
\text { ALTERNATE } \\
\text { SHUTDOWN } \\
\text { PATH? }\end{array}$ \\
\hline 16 & 3 & SW RETURN & $\begin{array}{l}1 \text { OUT OF } 4 \text { SW } \\
\text { LINES } \\
\text { DISABLED }\end{array}$ & SUPPORT & 1 & $\begin{array}{l}\text { YES -- } \\
\text { PARTIAL LOSS } \\
\text { OF } 1 \text { ONE } \\
\text { TRAIN OF } \\
\text { DECAY HEAT } \\
\text { REMOVAL }\end{array}$ \\
\hline 17 & 10 & $\begin{array}{l}\text { RHR PUMP B\&D } \\
\text { DISCHARGE }\end{array}$ & $\begin{array}{l}\text { B LOOP } \\
\text { UNAVAILABLE - } \\
\text { INJECTION AND } \\
\text { DECAY HEAT } \\
\text { REMOVAL }\end{array}$ & $\begin{array}{l}\text { PARTIAL } \\
\text { FRONT/SUPPORT } \\
\text { SYSTEM } \\
\text { FAILURE }\end{array}$ & 1 & $\begin{array}{l}\text { PRIMARY } \\
\text { SHUTDOWN } \\
\text { PATH }\end{array}$ \\
\hline 18 & 3 & $\begin{array}{l}\text { REACTOR BLDG } \\
\text { CLOSED } \\
\text { COOLING } \\
\text { WATER } \\
\text { SYSTEM, } \\
\text { RBCCWS, PUMP } \\
\text { DISCHARGE } \\
\end{array}$ & $\begin{array}{l}\text { FAILS } 1 \text { OUT } \\
\text { OF } 3 \text { RBCCW } \\
\text { PUMPS }\end{array}$ & $\begin{array}{l}\text { PARTIAL } \\
\text { SUPPORT } \\
\text { SYSTEM } \\
\text { FAILURE }\end{array}$ & 1 & No \\
\hline 19 & 3 & $\begin{array}{l}\text { RCIC TURBINE } \\
\text { INLET DRAIN }\end{array}$ & $\begin{array}{l}\text { RCIC PUMP } \\
\text { FAILS TO } \\
\text { START OR RUN }\end{array}$ & $\begin{array}{l}\text { YES FRONT } \\
\text { LINE--LOSS OF } \\
\text { A SINGLE } \\
\text { TRAIN OF HIGH } \\
\text { PRESSURE } \\
\text { INJECTION }\end{array}$ & 1 & No \\
\hline
\end{tabular}


Table 5 - 1 (continued)

\begin{tabular}{|c|c|c|c|c|c|c|}
\hline $\begin{array}{l}\text { ENTRY } \\
\text { NO }\end{array}$ & $\begin{array}{l}\text { SNUBBER } \\
\text { DIAMETER } \\
\text { SIZE } \\
\text { IN } \\
\text { INCHES }\end{array}$ & $\begin{array}{l}\text { SYSTEM } \\
\text { LOCATION }\end{array}$ & $\begin{array}{l}\text { POSSIBLE } \\
\text { EFFECT OF } \\
\text { SNUBBER } \\
\text { FAILURE GIVEN } \\
\text { SEISMIC EVENT }\end{array}$ & $\begin{array}{l}\text { ESF FRONT } \\
\text { LINE OR } \\
\text { SUPPORT } \\
\text { SYSTEM } \\
\text { FAILURE? }\end{array}$ & $\begin{array}{c}\text { NUMBER } \\
\text { OF } \\
\text { TRAINS } \\
\text { INVOLVED }\end{array}$ & $\begin{array}{l}\text { FAILURE OF } \\
\text { PRIMARY OR } \\
\text { ALTERNATE } \\
\text { SHUTDOWN } \\
\text { PATH? }\end{array}$ \\
\hline 20 & 3 & $\begin{array}{l}\text { HPCI VACUUM } \\
\text { PUMP TO VENT }\end{array}$ & $\begin{array}{l}\text { HPCI PUMP } \\
\text { FAILS TO } \\
\text { START } \\
\text { OR RUN }\end{array}$ & $\begin{array}{l}\text { YES FRONT } \\
\text { LINE--LOSS OF } \\
\text { A SINGLE } \\
\text { TRAIN OF HIGH } \\
\text { PRESSURE } \\
\text { INJECTION } \\
\end{array}$ & 1 & $\begin{array}{l}\text { YES -- FAILS } \\
\text { PRIMARY PATH } \\
\text {-- REACTOR } \\
\text { COOLANT } \\
\text { INVENTORY } \\
\text { CONTROL } \\
\end{array}$ \\
\hline 21 & 3 & $\begin{array}{l}\text { RCIC STEAM } \\
\text { SUPPLY }\end{array}$ & $\begin{array}{l}\text { RCIC PUMP } \\
\text { FAILS TO } \\
\text { START OR RUN }\end{array}$ & $\begin{array}{l}\text { YES FRONT } \\
\text { LINE--LOSS OF } \\
\text { A SINGLE } \\
\text { TRAIN OF HIGH } \\
\text { PRESSURE } \\
\text { INJECTION }\end{array}$ & 1 & No \\
\hline 22 & 3 & $\begin{array}{l}\text { SW RETURN } \\
\text { LINE }\end{array}$ & $\begin{array}{l}1 \text { OUT OF } 4 \\
\text { SERVICE WATER } \\
\text { LINES } \\
\text { DISABLED }\end{array}$ & $\begin{array}{l}\text { PARTIAL } \\
\text { SUPPORT } \\
\text { SYSTEM } \\
\text { FAILURE }\end{array}$ & 1 & $\begin{array}{l}\text { YES -- } \\
\text { PARTIAL } \\
\text { FAILURE OF } \\
\text { PRIMARY PATH } \\
\text { - LOSS OF } 1 \\
\text { TRAIN OF } \\
\text { DECAY HEAT } \\
\text { REMOVAL } \\
\end{array}$ \\
\hline 23 & 3 & $\begin{array}{l}\text { SW RBCCW HX } \\
\text { OUTLET }\end{array}$ & $\begin{array}{l}1 \text { OUT OF } 3 \\
\text { CRD PUMPS } \\
\text { COULD FAIL }\end{array}$ & $\begin{array}{l}\text { YES--SUPPORT } \\
\text { SYSTEM } \\
\text { FAILURE } \\
\text { PARTIAL } \\
\text { CAUSES } \\
\text { FAILURE OF } \\
\text { CRD INJECTION }\end{array}$ & 1 & No \\
\hline
\end{tabular}


Table 5 - 1 (continued)

\begin{tabular}{|c|c|c|c|c|c|c|}
\hline $\begin{array}{l}\text { ENTRY } \\
\text { NO }\end{array}$ & $\begin{array}{c}\text { SNUBBER } \\
\text { DIAMETER } \\
\text { SIZE } \\
\text { IN } \\
\text { INCHES }\end{array}$ & $\begin{array}{l}\text { SYSTEM } \\
\text { LOCATION }\end{array}$ & $\begin{array}{l}\text { POSSIBLE } \\
\text { EFFECT OF } \\
\text { SNUBBER } \\
\text { FAILURE GIVEN } \\
\text { SEISMIC EVENT }\end{array}$ & $\begin{array}{l}\text { ESF FRONT } \\
\text { LINE OR } \\
\text { SUPPORT } \\
\text { SYSTEM } \\
\text { FAILURE? }\end{array}$ & $\begin{array}{c}\text { NUMBER } \\
\text { OF } \\
\text { TRAINS } \\
\text { INVOLVED }\end{array}$ & $\begin{array}{l}\text { FAILURE OF } \\
\text { PRIMARY OR } \\
\text { ALTERNATE } \\
\text { SHUTDOWN } \\
\text { PATH? }\end{array}$ \\
\hline 24 & 3 & $\begin{array}{l}\text { CORE } \\
\text { SPRAY, CS, } \\
\text { PUMP } \\
\text { DISCHARGE }\end{array}$ & $\begin{array}{l}1 \text { OUT OF } 2 \text { CS } \\
\text { PUMPS FAIL }\end{array}$ & $\begin{array}{l}\text { YES FRONT } \\
\text { LINE--LOSS OF } \\
1 \text { OUT OF } 2 \\
\text { TRAINS OF CS }\end{array}$ & 1 & $\begin{array}{l}\text { YES--PARTIAL } \\
\text { FAILURE OF } \\
\text { ALTERNATE } \\
\text { PATH FOR } \\
\text { REACTOR } \\
\text { COOLANT } \\
\text { INVENTORY } \\
\text { CONTROL }\end{array}$ \\
\hline 25 & 3 & $\begin{array}{l}\text { AOG -- AIR } \\
\text { OFF GAS } \\
\text { SYSTEM }\end{array}$ & $\begin{array}{l}\text { NOT } \\
\text { CONSIDERED } \\
\text { FURTHER }\end{array}$ & & & \\
\hline 27 & 3 & AOG & $\begin{array}{l}\text { NOT } \\
\text { CONSIDERED } \\
\text { FURTHER }\end{array}$ & & & \\
\hline 28 & 3 & $\begin{array}{l}\text { RHR HEAT } \\
\text { EXCHANGE } \\
\text { RELIEF LINE }\end{array}$ & $\begin{array}{l}\text { RUPTURE OR } \\
\text { FLOW } \\
\text { RESTRICTION } \\
\text { OF RHR SPC } \\
\text { LOOP A }\end{array}$ & $\begin{array}{l}\text { YES FRONT } \\
\text { LINE-- } \\
\text { PARTIAL LOSS } \\
\text { OF RHR SPC } \\
\text { DECAY HEAT } \\
\text { REMOVAL }\end{array}$ & 1 & $\begin{array}{l}\text { YES PARTIAL } \\
\text { FAILURE OF } \\
\text { ALTERNATE } \\
\text { HEAT } \\
\text { REMOVAL-- }\end{array}$ \\
\hline
\end{tabular}


Table 5 - 1 (continued)

\begin{tabular}{|c|c|c|c|c|c|c|}
\hline $\begin{array}{l}\text { ENTRY } \\
\text { NO }\end{array}$ & $\begin{array}{c}\text { SNUBBER } \\
\text { DIAMETER } \\
\text { SIZE } \\
\text { IN } \\
\text { INCHES }\end{array}$ & $\begin{array}{l}\text { SYSTEM } \\
\text { LOCATION }\end{array}$ & $\begin{array}{l}\text { POSSIBLE } \\
\text { EFFECT OF } \\
\text { SNUBBER } \\
\text { FAILURE GIVEN } \\
\text { SEISMIC EVENT }\end{array}$ & $\begin{array}{l}\text { ESF FRONT } \\
\text { LINE OR } \\
\text { SUPPORT } \\
\text { SYSTEM } \\
\text { FAILURE? }\end{array}$ & $\begin{array}{c}\text { NUMBER } \\
\text { OF } \\
\text { TRAINS } \\
\text { INVOLVED }\end{array}$ & $\begin{array}{l}\text { FAILURE OF } \\
\text { PRIMARY OR } \\
\text { ALTERNATE } \\
\text { SHUTDOWN } \\
\text { PATH? }\end{array}$ \\
\hline 29 & 3 & $\begin{array}{l}\text { COOLING FOR } \\
\text { RHR HX } 2 A\end{array}$ & $\begin{array}{l}\text { RUPTURE OR } \\
\text { FLOW } \\
\text { RESTRICTION } \\
\text { OF RHR SPC } \\
\text { LOOP A } \\
\end{array}$ & $\begin{array}{l}\text { YES - } \\
\text { PARTIAL LOSS } \\
\text { OF RHR SPC } \\
\text { DECAY HEAT } \\
\text { REMOVAL } \\
\end{array}$ & 1 & $\begin{array}{l}\text { YES --FAILS } \\
\text { ALTERNATE } \\
\text { PATH OF } \\
\text { DECAY HEAT } \\
\text { REMOVAL } \\
\end{array}$ \\
\hline 30 & 3 & $\begin{array}{l}\text { RHR DRAIN TO } \\
\text { REDWASTE }\end{array}$ & $\begin{array}{l}\text { NOT } \\
\text { CONSIDERED } \\
\text { FURTHER }\end{array}$ & & & \\
\hline 31 & 3 & AOG & $\begin{array}{l}\text { NOT } \\
\text { CONSIDERED } \\
\text { FURTHER }\end{array}$ & & & \\
\hline 33 & 3 & $\begin{array}{l}\text { COOLING FOR } \\
\text { RHR HX 2A }\end{array}$ & $\begin{array}{l}\text { RUPTURE OR } \\
\text { FLOW } \\
\text { RESTRICTION } \\
\text { OF RHR SPC } \\
\text { LOOP A } \\
\end{array}$ & $\begin{array}{l}\text { YES - } \\
\text { PARTIAL LOSS } \\
\text { OF RHR SPC } \\
\text { DECAY HEAT } \\
\text { REMOVAL } \\
\end{array}$ & 1 & $\begin{array}{l}\text { YES - FAILS } \\
\text { ALTERNATE } \\
\text { PATH OF } \\
\text { DECAY HEAT } \\
\text { REMOVAL }\end{array}$ \\
\hline
\end{tabular}


Table 5-2

\section{Matrix of Front-Line System Direct Dependencies on Support Systems}

\begin{tabular}{|c|c|c|c|c|c|c|}
\hline \multirow{2}{*}{$\begin{array}{l}\text { FRONT LINE } \\
\text { SYSTEM }\end{array}$} & \multicolumn{6}{|c|}{ DEPENDENCY } \\
\hline & $\mathbf{A C P}$ & DCP & SW & HVAC & ECCS & $\begin{array}{l}\text { N2 } \\
\text { BACIKUP }\end{array}$ \\
\hline RPS & $\mathbf{x}$ & & & & & \\
\hline \multicolumn{7}{|l|}{ CRD/HCU } \\
\hline HPCI & $\mathbf{x}$ & $\mathbf{x}$ & & $\mathbf{x}$ & $x$ & \\
\hline SRVs & $x$ & $x$ & & & & $x$ \\
\hline RHR & $x$ & $\mathbf{x}$ & $x$ & $x$ & $x$ & \\
\hline $\mathrm{cs}$ & $\mathrm{x}$ & $x$ & & & & \\
\hline SSDM & $\mathrm{x}$ & $\mathrm{x}$ & & & & \\
\hline PCIS & $\mathbf{x}$ & $\mathrm{x}$ & & & & \\
\hline
\end{tabular}

RPS

CRD/HCU

HPCI

SRVS

RHR

SSDM

PCIS

ACP

DCP

SW

HVAC

ECCS
Reactor Protection System

Control Rod Drive/Hydaulic Control Unit

High Pressure Coolant Injection

Safety Relief Valves

Residual Heat Removal

Primary Containment Isolation System

AC Power

DC Power

Service Water

Heating, Ventilation, and Air Conditioning

Emergeny Core cooling System

Nitrogen Backup 
Figure 5 - 1

\section{Paul Monroe/Enertech Hydraulic Snubber Schematic Diagram}

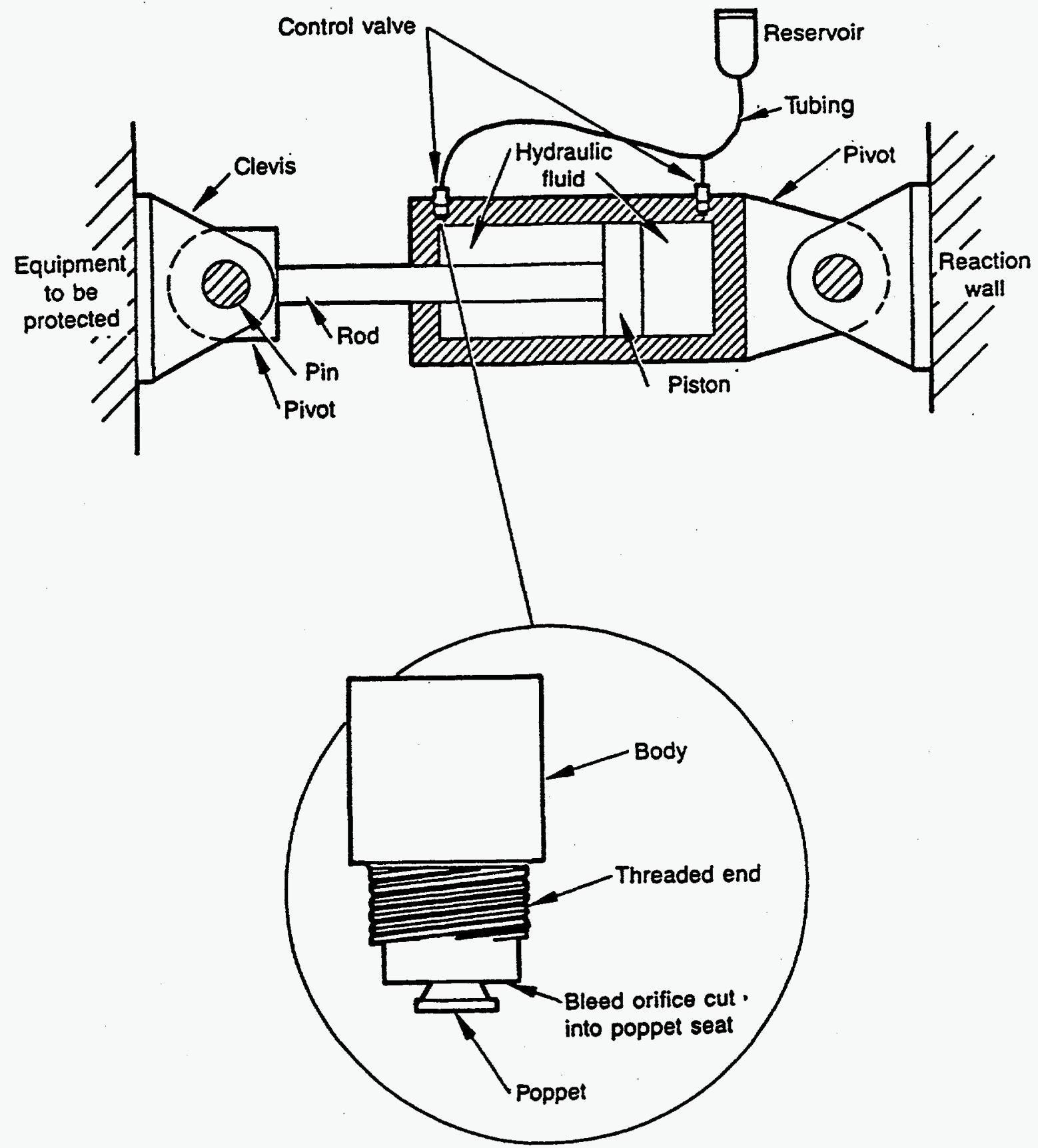




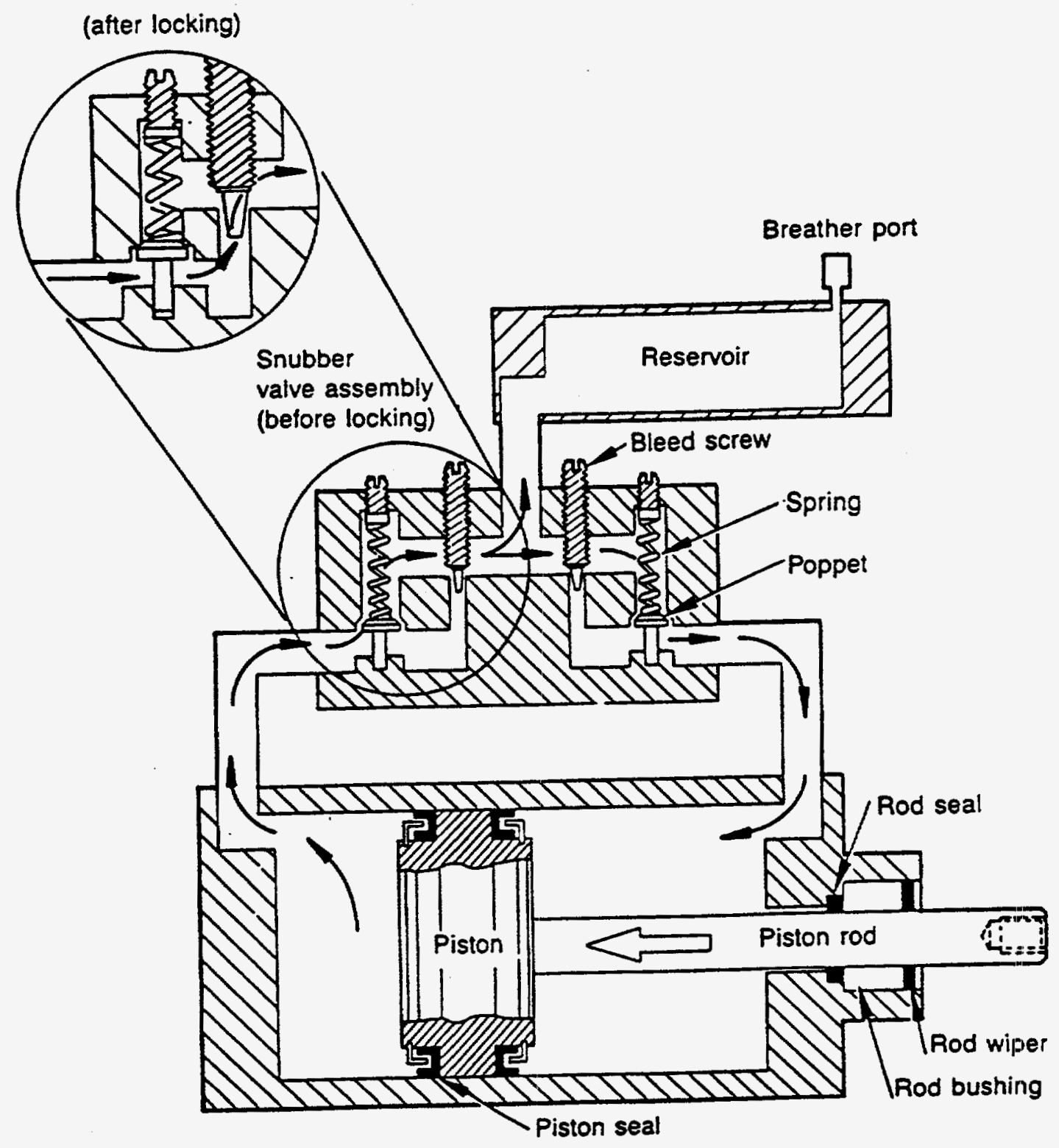

Figure 5 - 2

Grinnell Control Valve Arrangement 


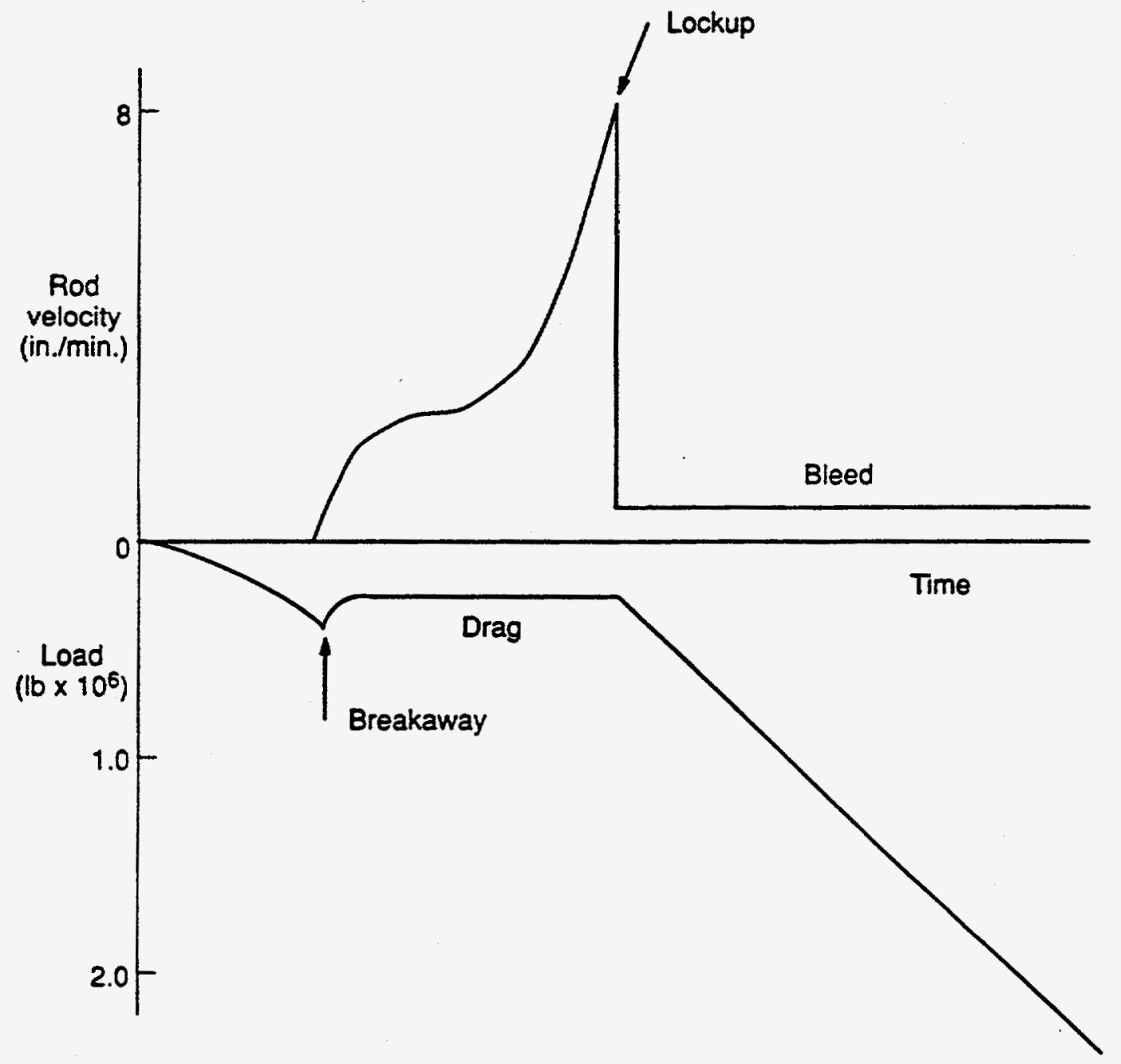

Figure 5 - 3

Characteristic Hydraulic Snubber Force and Velocity Time-History Traces 


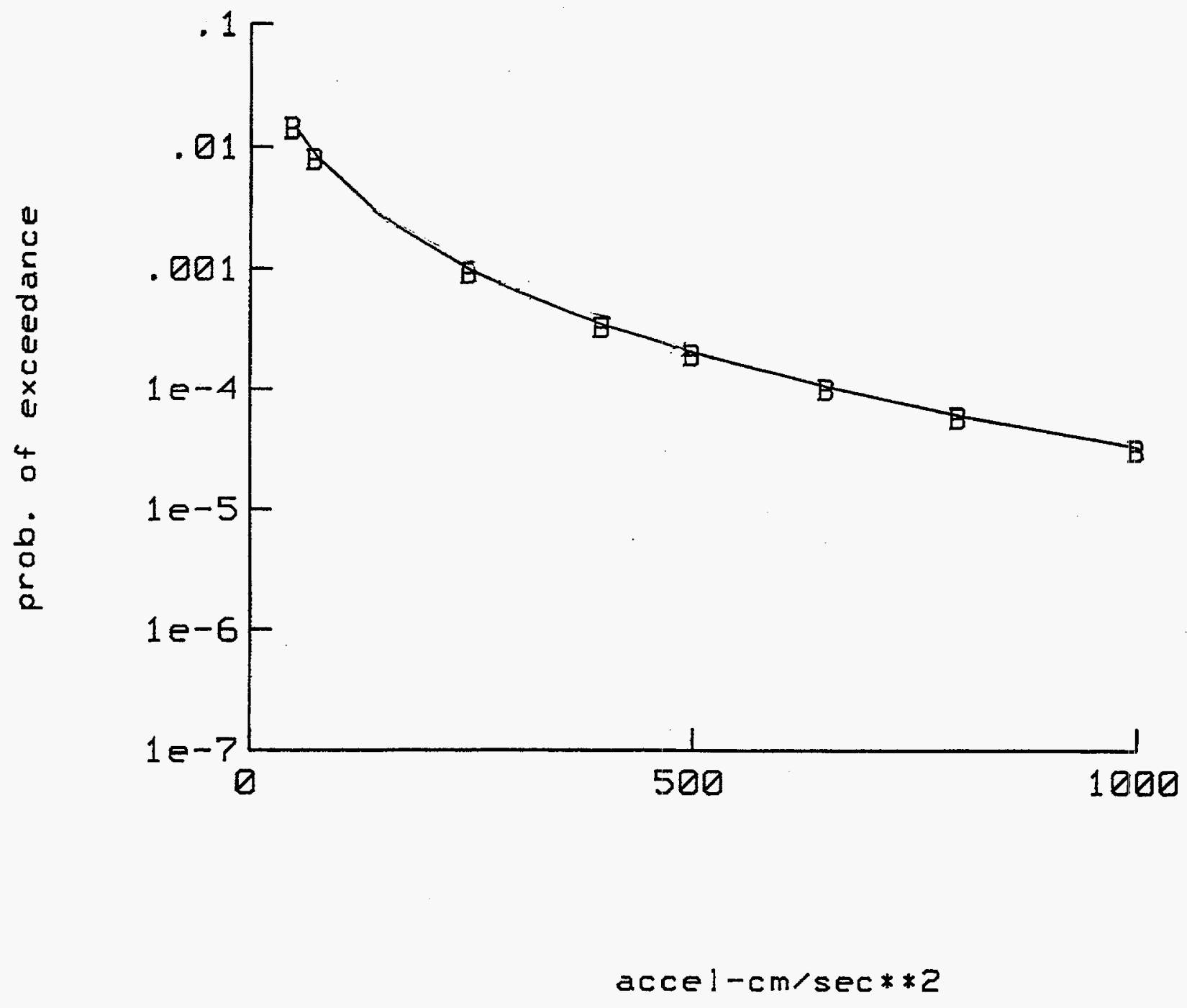

Figure 5 - 4

Mean Seismic Hazard Curve for the Plant-X Site (from Savy et al., Lawrence Livermore Laboratory, 1993) 


\section{Reactor Reactivity \\ Control}

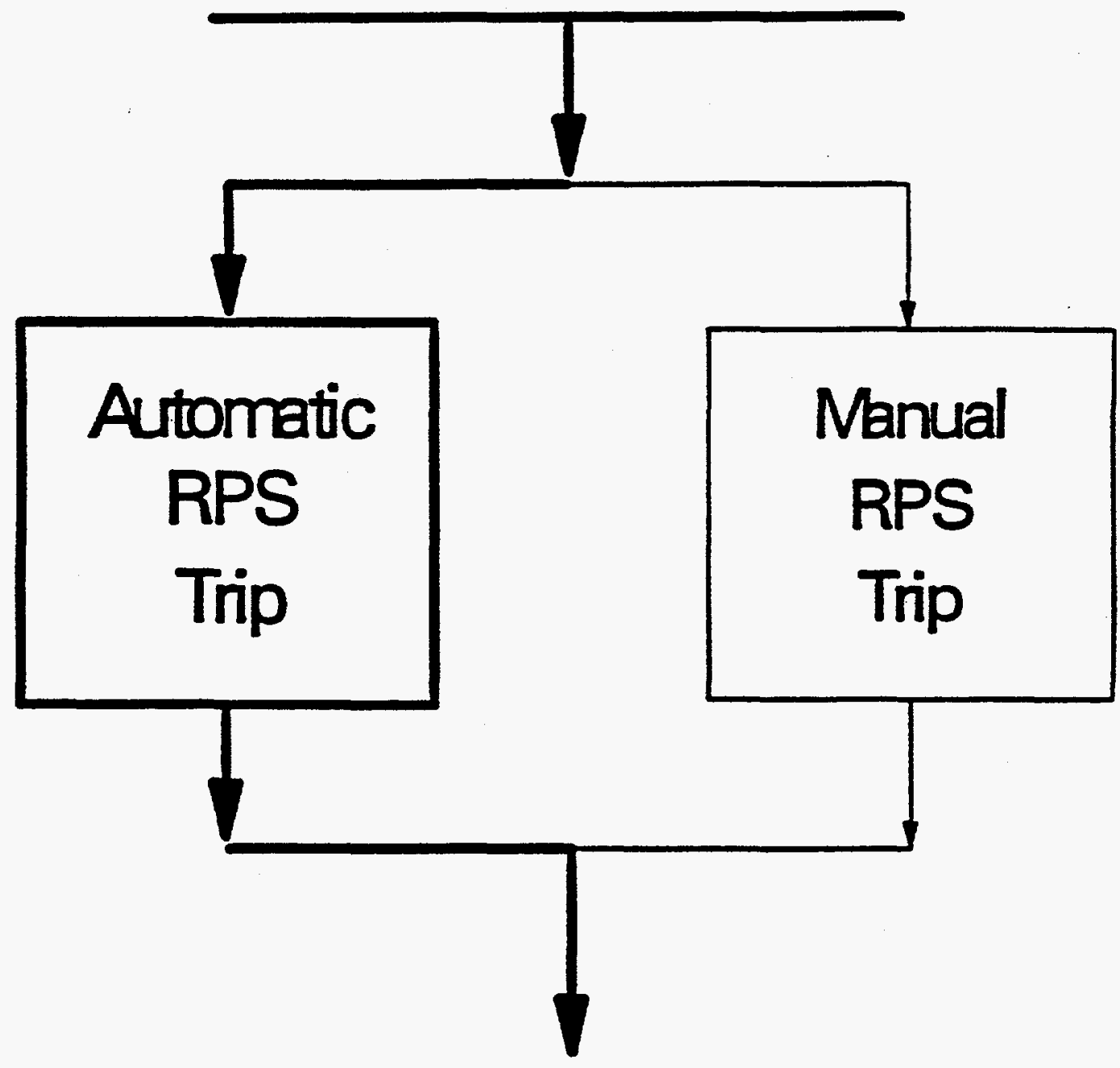

Figure 5 - 5

Plant X, Safe Shutdown for Reactor Reactivity Control 


\section{Reactor Coolant Pressure Control}

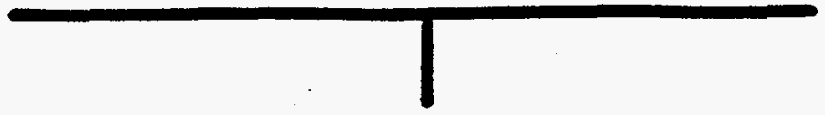

Control Pressure

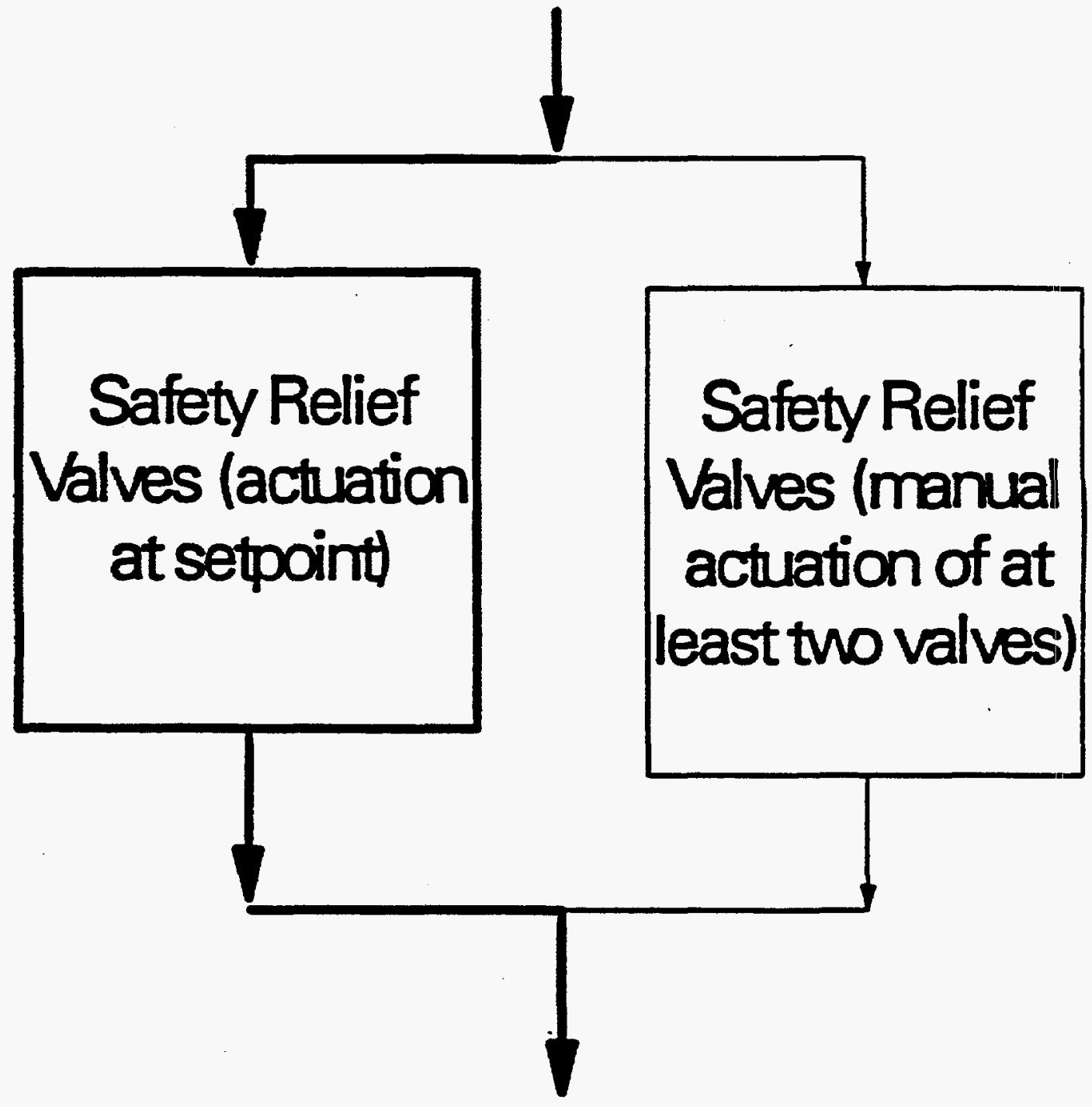

Figure 5 - 6

Plant X, Safe Shutdown for Reactor Coolant Pressure Control 


\section{Reactor Coolant Inventory Control}

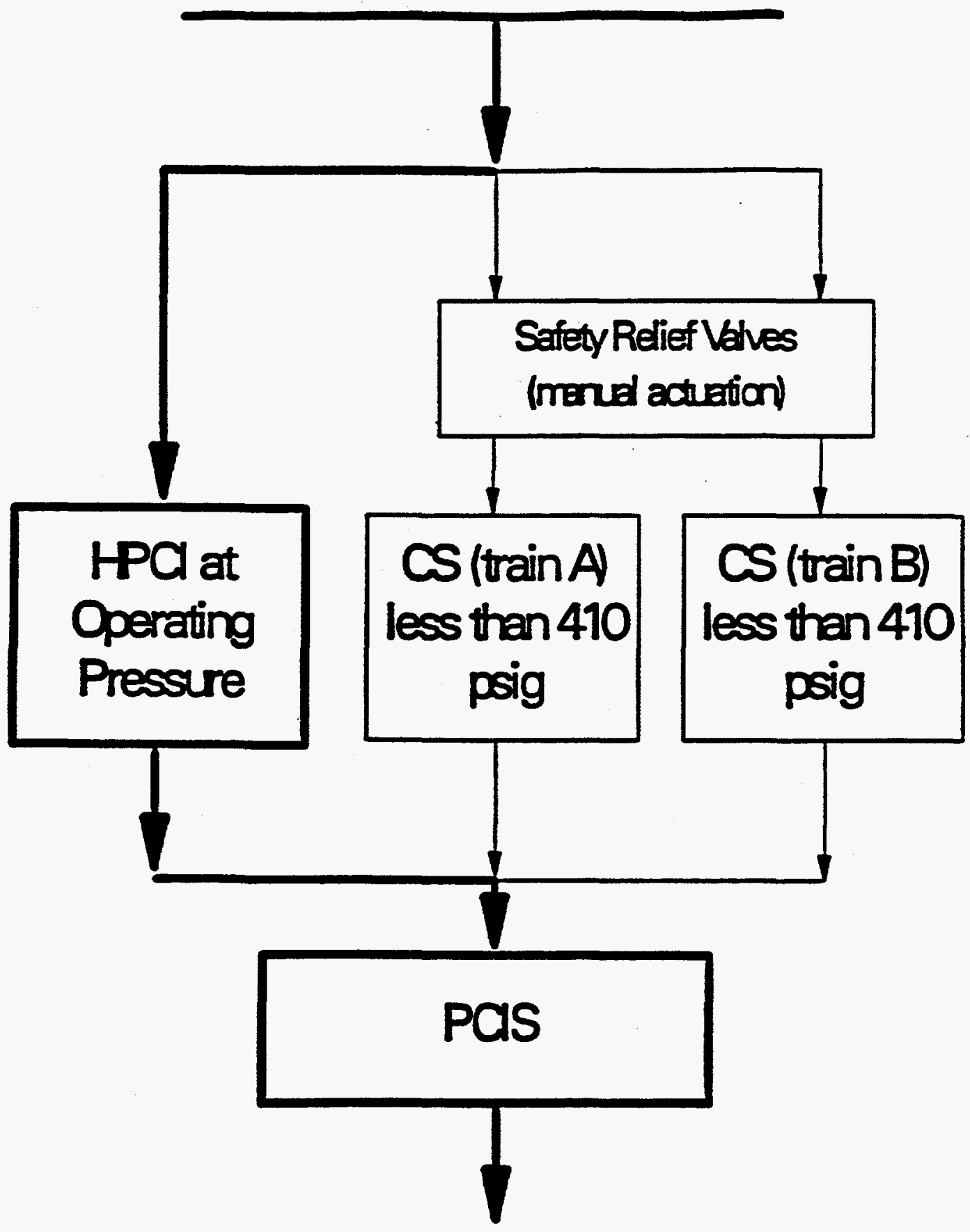

Figure 5 - 7

Plant X, Safe Shutdown for Reactor Coolant Inventory Control 
Decay Heat Rernoval

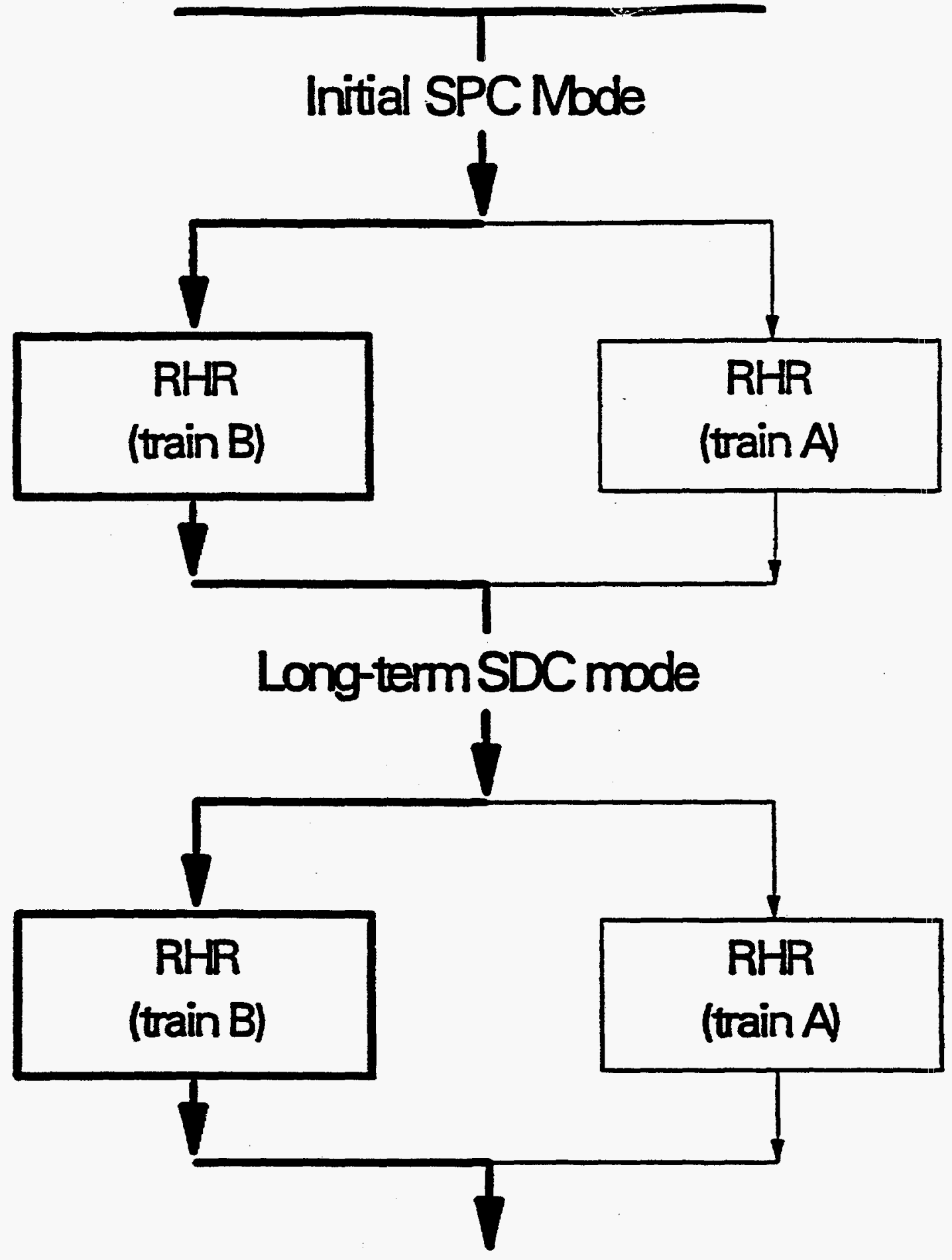

Figure 5 - 8

Plant X, Safe Shutdown for Decay Heat Removal 


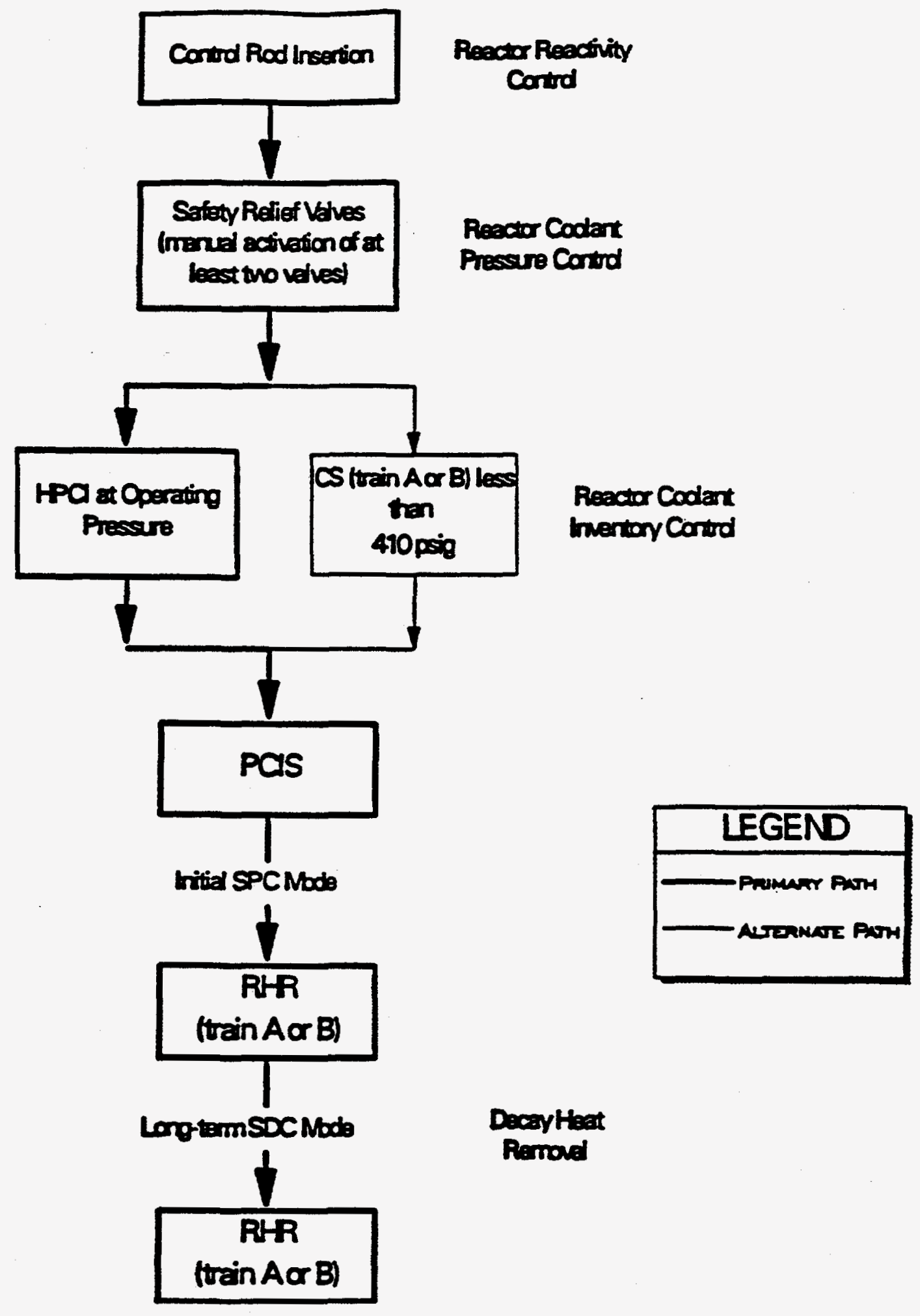

Figure 5 - 9

Plant X, Success Path Diagram 


\section{GENERIC SEISMIC FRAGILITIES}

\subsection{Background}

Seismic fragility of a structure or equipment is the conditional probability of its failure for a given level or greater of seismic input parameter, for example " $0.4 \mathrm{~g}$ spectral acceleration" or " $0.3 \mathrm{~g}$ peak ground acceleration". The concept of seismic fragility was first introduced in nuclear plant seismic risk assessment studies. Seismic fragilities have been estimated for structures and equipment in over 50 nuclear power plants in the last 15 years. The methodology is described in a number of papers and reports (Kennedy et al., 1980; Ravindra and Kennedy 1983; Kennedy and Ravindra 1984; NRC, 1983; Brookhaven, 1985; Casciati and Faravelli 1991; Reed and Kennedy, 1994) and the results of applications to nuclear power plant seismic PRAs and margin studies are discussed in several places (Kennedy et al., 1988 and 1989a; Kipp, Wesley and Nakaki, 1988; Ravindra et al., 1987; Ravindra, 1988).

Seismic fragilities are needed to estimate the frequency of occurrence of initiating events and to quantify the fault trees for obtaining the seismically-induced accident sequence frequencies. Seismic fragility is described by means of a family of fragility curves reflecting the uncertainty in the parameter values and in the models. A subjective probability is assigned to each curve representing the degree of belief in the set of parameter values and the model that yielded that curve. It is customary to show the median fragility curve, the $95 \%$ confidence fragility curve, and the 5\% conf idence curve (Figure 6-1). Using the double lognormal model, the fragility family is concisely described by means of three parameters: $A_{m}$, the median capacity of the component, the logarithmic standard deviation $B_{R}$ reflecting the aleatory randomness in the capacity, and the logarithmic standard deviation $B_{u}$ reflecting the epistemic uncertainty in the median capacity. These parameters are evaluated for each component for all critical failure modes using the design information, earthquake experience database, and qualification and fragility test data. In many applications, it is sufficient to use the mean fragility curve whose parameters are $A_{m}$ and $B_{c}$ where $B_{c}$ is the composite variability given by $\left(B_{R}^{2}+B_{U}{ }^{2}\right)^{1 / 2}$. Figure 6-1 also shows this mean curve.

In this study, seismic fragility has been developed in terms of the peak ground acceleration at the site. Therefore, the median capacity $A_{m}$ is the median ground acceleration capacity. From Figure 6-1, it can be seen that at each peak ground acceleration value, the probability of failure of the component is a variable reflecting the uncertainty in the probability estimate; this is very similar to the failure rate distribution given a demand (the demand in this case is the earthquake of a specified pga). Based on the double lognormal model for fragility and the parameters $A_{m}, B_{R}$ and $B_{y}$ the probability (uncertainty) distribution of the failure probability (also called "failure fraction") could be developed for each peak ground acceleration value.

Another important parameter in the seismic fragility and margin assessment is the High Confidence of Low Probability of Failure (HCLPF) capacity of the component. In the seismicmargin literature (NRC, 1985b; NRC, 1986; EPRI, 1988), this parameter is defined as the acceleration level at which the component has a probability of failure of less than 5 percent corresponding to a confidence level of 95 percent, which turns out to be:

$$
H C L P F=A_{m} \exp \left[-1.64\left(B_{R}+B_{U}\right)\right]
$$

When the variabilities due to randomness in capacity and uncertainty in the median capacity

$$
6-1
$$


are combined, the resulting HCLPF capacity is of ten expressed as the acceleration value at which the component has a probability of failure of less than 1 percent., i.e.,

$$
\mathrm{HCLPF}=\mathrm{A}_{\mathrm{m}} \exp \left[-2.33 \mathrm{~B}_{\mathrm{c}}\right]
$$

In the EPRI Seismic Margin Assessment Methodology (EPRI, 1988), the component HCLPF capacity is calculated using a set of deterministic rules, called the Conservative Deterministic Failure Margin (CDFM) method. A discussion of this method and comparisons of various calculations using it are in (Kennedy et al., 1989b).

\subsection{Application in ASP Analysis}

In the ASP analysis, it is recommended that the seismic fragilities and HCLPF capacities of components (other than those adversely impacted by the LER) as reported in the plant-specif ic PRA or IPEEE be used. For the components affected by the LER, if it is practical, new fragilities should be calculated using plant-specif ic information and the procedures described in the references cited above. However, as explained in Chapter 3, the ASP Step-3 analysis will sometimes incorporate entire new fault-tree and/or event-tree branches. Sometimes, these branches will involve some seismic failures of equipment or structures that have not been reported as weakened by the LER, but are nevertheless not otherwise modeled in the base-case seismic PRA. In this case, it is appropriate to use generic fragilities for these structures or equipment items as a means of perf orming the ASP seismic analysis readily without performing seismic-f ragility analysis on each such item. Therefore, this project has developed from the literature a set of generic fragility curves for numerous classes of equipment that can be used for this purpose.

For the plants which only have a seismic margin study, seismic HCLPF capacities of components affected by the LER should be calculated using the Conservative Deterministic Failure Margin (CDFM) method described in the EPRI margins methodology guidance (EPRI, 1988). The actual configuration of the components in the degraded condition should be used for this calculation.

\subsection{Generic Fragilities}

Table 6-1 lists the seismic fragilities of structures and equipment items typically encountered in nuclear power plants. This list has been compiled based on the seismic PRAs and margin studies performed for over 40 nuclear power plants by the US nuclear industry. Such a compilation of fragility estimates was made some years ago by Campbell, Ravindra and Murray (1988). That compilation has been reviewed and updated to produce Table 6-1. Although it is more appropriate to describe the seismic fragilities of equipment items in terms of floor spectral acceleration, information on the median floor response and its variability may not be available to the ASP analyst and may not be obtainable without inordinate effort. Therefore, the reference parameter used herein to describe the seismic fragility of structures and equipment is the peak ground acceleration. Since the seismic hazard curves for almost all US nuclear power plants are also presented in terms of the peak ground acceleration, the description of the seismic fragility in peak ground acceleration terms is considered appropriate.

The generic fragility parameters are also considered appropriate for the ASP analysis since these plants have already undergone seismic IPEEE, reviews (NRC, 1991) and obvious seismic vulnerabilities have been fixed. 
Table 6 - 1

Generic Component Seismic Fragilities

\begin{tabular}{|c|c|c|c|c|c|}
\hline Component & $\begin{array}{c}\text { Median } \\
\text { Capacity, g }\end{array}$ & $\widehat{\boldsymbol{\beta}_{R}}$ & $\overline{\boldsymbol{\beta}_{U}}$ & $\begin{array}{c}\text { HCLPF } \\
\text { Capacity, } \mathrm{g}\end{array}$ & Fallure Mode \\
\hline Accumulators & 2.5 & 0.30 & 0.35 & 0.85 & Structural failure \\
\hline Air handling units & 2.5 & 0.30 & 0.40 & 0.75 & Structural failure \\
\hline Air-operated valves & 3.8 & 0.35 & 0.50 & 0.93 & Loss of function \\
\hline $\begin{array}{l}\text { Batteries and Battery } \\
\text { Racks }\end{array}$ & 3.8 & 0.30 & 0.35 & 1.30 & $\begin{array}{l}\text { Structural failure of } \\
\text { supports }\end{array}$ \\
\hline Battery Chargers & 1.6 & 0.30 & 0.35 & 0.54 & Functional failure \\
\hline $\begin{array}{l}\text { Buried welded steel } \\
\text { piping }\end{array}$ & 2.0 & 0.25 & 0.30 & 0.80 & Buckling \\
\hline Cable Trays & 2.5 & 0.35 & 0.50 & 0.61 & Support Failure \\
\hline $\begin{array}{l}\text { Control rod drive and } \\
\text { hydraulic drive units }\end{array}$ & 2.5 & 0.30 & 0.40 & 0.76 & Functional failure \\
\hline $\begin{array}{l}\text { Diesel Generator and } \\
\text { support systems }\end{array}$ & 3.1 & 0.30 & 0.35 & 1.06 & Functional failure \\
\hline $\begin{array}{l}\text { Electrical Equipment } \\
\text { - Function during } \\
\text { - Function after }\end{array}$ & $\begin{array}{l}1.0 \\
2.5\end{array}$ & $\begin{array}{l}0.30 \\
0.30\end{array}$ & $\begin{array}{l}0.35 \\
0.40\end{array}$ & $\begin{array}{l}0.34 \\
0.77 \\
\end{array}$ & $\begin{array}{l}\text { Chatter } \\
\text { Functional failure }\end{array}$ \\
\hline $\begin{array}{l}\text { Heat exchangers and } \\
\text { small tanks }\end{array}$ & 1.9 & 0.30 & 0.35 & 065 & Rupture \\
\hline HVAC ducts & 2.5 & 0.35 & 0.50 & 0.61 & Support failure \\
\hline Inverters & 1.6 & 0.30 & 0.35 & 0.54 & Functional fallure \\
\hline $\begin{array}{l}\text { Large flat-bottom } \\
\text { storage tanks }\end{array}$ & 9.1 & 0.30 & 0.35 & 0.37 & $\begin{array}{l}\text { Buckling or wall } \\
\text { failure }\end{array}$ \\
\hline Motor-driven pumps & 2.0 & 0.30 & 0.35 & 0.68 & Support failure \\
\hline Motor-operated valves & 3.8 & 0.35 & 0.50 & 0.93 & Loss of function \\
\hline Offsite Power & 0.3 & 0.30 & 0.45 & 0.10 & $\begin{array}{l}\text { Failure of Ceramic } \\
\text { Insulators }\end{array}$ \\
\hline $\begin{array}{l}\text { Panelboards and } \\
\text { instrumentation panel }\end{array}$ & 3.8 & 0.30 & 0.35 & 1.30 & Functional Failure \\
\hline Piping & 3.8 & 0.35 & 0.50 & 0.93 & Loss of support \\
\hline Pressurizer & 2.5 & 0.30 & 0.40 & 0.75 & $\begin{array}{l}\text { Structural failure of } \\
\text { support }\end{array}$ \\
\hline Reactor Coolant Pump & 2.5 & 0.30 & 0.40 & 0.75 & $\begin{array}{l}\text { Structural failure of } \\
\text { support }\end{array}$ \\
\hline $\begin{array}{l}\text { Reactor Internals and } \\
\text { Core Assembly }\end{array}$ & 1.8 & 0.30 & 0.40 & 0.55 & Structural failure \\
\hline $\begin{array}{l}\text { Reactor Pressure } \\
\text { Vessel }\end{array}$ & 2.0 & 0.30 & 0.35 & 0.68 & Support failure \\
\hline Recirculation Pumps & 1.9 & 0.30 & 0.35 & 0.65 & Support failure \\
\hline $\begin{array}{l}\text { Safety relief, manual } \\
\text { and check valves }\end{array}$ & 3.8 & 0.35 & 0.50 & 0.93 & Loss of function \\
\hline Steam generators & 2.5 & 0.30 & 0.40 & 0.75 & $\begin{array}{l}\text { Structural tailure of } \\
\text { support }\end{array}$ \\
\hline $\begin{array}{l}\text { Switchgear and motor } \\
\text { control centers }\end{array}$ & 3.1 & 0.30 & 0.35 & 1.06 & Functional Failure \\
\hline Transformers & 1.9 & 0.30 & 0.35 & 0.65 & $\begin{array}{l}\text { Loss of Function/ } \\
\text { structural failure }\end{array}$ \\
\hline Turbine-driven pumps & 2.5 & 0.30 & 0.35 & 0.85 & Support failure \\
\hline
\end{tabular}




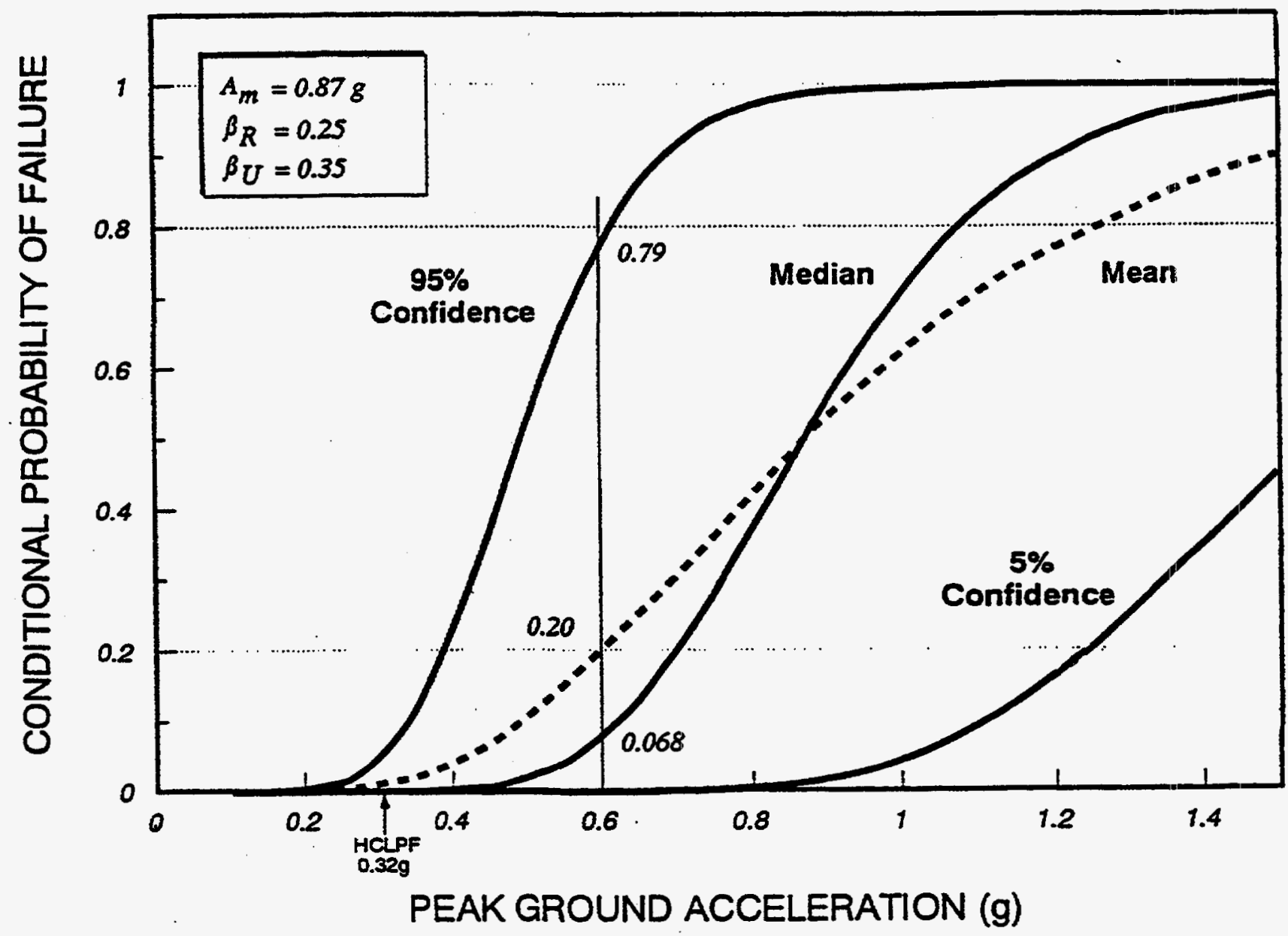

Figure 6 - 1

Median, 5\%-Non-Exceedence, and 95\%-Non-Exceedence Fragility Curves for a Component 


\section{RECOMMENDATIONS CONCERNING NEEDED INFORMATION}

\subsection{ASP Fire-Precursor Methodology: Needed Information}

- Risk Analysis Compilation

The first task required in the development of a working methodology for the evaluation of fire-related accident sequence precursors is the compilation of all the relevant fire risk-analysis documentation for each plant. This documentation is to include the plant PRA or IPEEE and the plant Final Safety Analysis Report (FSAR). This documentation will serve as the basis for all fire accident sequence precursors to be evaluated.

\section{- Fire Accident Sequence Database}

To aid in the determination as to whether a non-fire-related failure has significant implications as a fire accident sequence precursor, a plant-specific database should be developed that catalogues each of the top fire accident sequences. This database would form a basis for evaluating the conditional probability of core damage.

- Fire Location Database with Safety Function Mapping

A fire-location database should be developed to be used as a screening device and a functional tool. Incorporating the corresponding mapping of safe-shutdown equipment and cable routing, along with detection and suppression equipment, will allow for quick determination of whether or not a fire location is of consequence, and whether a PRA model exists or needs to be developed or altered. It will also provide a basis for a real-time fire-initiating-event-frequency database. The database can be accomplished by cross-referencing the FSAR, PRA or IPEEE information, and other relevant information. While it is recognized that cable-routing information may be difficult to obtain, and that it does not remain as current as other configuration information, the detailed fire-LER analysis, if required, will of ten require need type of information.

\section{- Fire Initiating-Event Database}

The usefulness of the fire initiating-event precursor data can be greatly enhanced by linking a fire initiating-event database to the fire location database. By cataloguing the fire events as they occur along with mapping of the locations where they occur, a consistent and convenient method for evaluating the fire-frequency distributions can be developed.

\subsection{ASP Seismic Precursor Methodology: Needed Information}

- Risk Analysis Compilation

The first task required in the development of a working methodology for the evaluation of seismic-related accident sequence precursors is the compilation of all

$$
7-1
$$


relevant seismic risk-analysis documentation for each plant. This documentation should include the plant seismic PRA or IPEEE and the plant FSAR. This documentation will serve as a basis for all seismic accident sequence precursors to be evaluated.

\section{- Plant-Specific Seismic Hazard Information}

Another key task required to implement this methodology is the compilation of a site-specific seismic hazard curve for each plant. This should not be difficult to do because the NRC has already been working on this issue for some time, and NRC recently published new hazard curves for all of the sites in the eastern U.S. (Sobel, 1993; Savy, 1993). However, it will be necessary to have these put into a standard format for easy access and use by seismic-ASP analysts.

\section{- Compilation of Systems-Analysis Aspects}

The NRC should compile, on a plant-specific basis, the systems-analysis aspects (cut sets, event trees, failure probabilities for non-seismic failures, etc.) of each seismic PRA or seismic-margins-IPEEE analysis. This compilation can then form the basis for the seismic-ASP analysis. This is necessary for both the seismic-configurationcompromise type of seismic precursor and the non-seismic-failure type. 


\section{REFERENCES}

Apostolakis. 1993: G. E. Apostolakis, "Fire Risk Assessment and Management in Nuclear Power Plants", Fire Science and Technology, Vol. 13, Suppl., pp. 12-39, 1993

ASP. 1994: L. Vanden Heuvel et al., "Precursors to Potential Core Damage Accidents: 1993, A Status Report", NUREG/CR-4674, Volume 19 (1994), and earlier annual editions of this report

ASP Plan, 1994: U.S. Nuclear Regulatory Commission, Office for Analysis and Evaluation of Operational Data, "Integrated Accident Sequence Precursor Program Plan", draft dated March 2, 1994, included as Enclosure 1 to NRC SECY-94-076, "Status Report on Accident Sequence Precursor Program and Related Initiatives", March 22, 1994

Brookhaven, 1985: M. McCann, J. Reed, C. Ruger, K. Shiu, T. Teichmann, A. Unione, and R. Youngblood, "Probabilistic Safety Analysis Procedures Guide", Report

NUREG/CR-2815, Brookhaven National Laboratory for the U.S. Nuclear Regulatory Commission, August 1985

Budnitz, 1984: R.J. Budnitz, "External Initiators in Probabilistic Reactor Analysis-Earthquakes, Fires, Floods, Winds", Risk Analvsis, Vol. 4, 323, 1984

Budnitz and Lambert, 1989: R.J. Budnitz and H.E. Lambert, "An Evaluation of the Reliability and Usef ulness of External-Initiator PRA Methodologies", Future Resources Associates, Inc. for the U.S. Nuclear Regulatory Commission, Berkeley, California, Report NUREG/CR-5477, 1989

Campbell, Ravindra, and Murray, 1988: R.D. Campbell, M.K. Ravindra, and R.C. Murray, "Compilation of Fragility Information from Available Probabilistic Assessments", Lawrence Livermore National Laboratory, Report UCID-20571, Revision 1, 1988

Casciati and Faravelli, 1991: F. Casciati and L. Faravelli, Fragility Analysis of Complex Structural Systems, John Wiley \& Sons Inc., New York, 1991

EPRI, 1988: NTS Engineering, RPK Structural and Mechanics Consulting, Pickard Lowe \& Garrick, Woodward Clyde Consultants, and Duke Power Company, "A Methodology for Assessment of Nuclear Power Plant Seismic Margin", Electric Power Research Institute, Report EPRI NP-6041, 1988

FIVE, 1993: "Fire Vulnerability Evaluation Methodology (FIVE), Plant Screening Guide", Professional Loss Control, Inc., EPRI Contract No. RP 3000-41, Electric Power Research Institute, Palo Alto, CA, 1993 
FRA. 1995: R.J. Budnitz, G. Apostolakis, and S.T. Jones, "Development of a Methodology for Analyzing Precursors to Earthquake-Initiated and Fire-Initiated Accident Sequences, Phase-I Report", Future Resources Associates, Inc., Berkeley, California, for the U.S. Nuclear Regulatory Commission, 1995

Ho. Chien, and Apostolakis, 1990: V. Ho, S. Chien and G.E. Apostolakis, "COMPBRN IIIe: An interactive computer code for fire risk analysis", University of California at Los Angeles, School of Engineering, Report UCLA-ENG-9016, 1990

IRRAS, 1995: Idaho National Engineering Laboratory, "Systems Analysis Programs For Hands-On Integrated Reliability Evaluations (SAPHIRE) Version 5.0, IRRAS", for the U.S. Nuclear Regulatory Commission, Report NUREG/CR-6116, 1995

Kennedy 1980: R.P. Kennedy et al., "Probabilistic Seismic Safety Study of an Existing Nuclear Power Plant", Nuclear Engineering and Design, Vol. 59, No. 2, pp. 315-338, August 1980

Kennedy and Ravindra, 1984: R.P. Kennedy and M.K. Ravindra "Seismic Fragilities for Nuclear Power Plant Risk Studies", Nuclear Engineering and Design, Vol. 79, No. 1 pp. $47-68$, May 1984

Kennedy et al. 1988: R.P. Kennedy, D.A. Wesley and W.H. Tong, "Probabilistic Evaluation of the Diablo Canyon Turbine Building Seismic Capacity Using Nonlinear Time-History Analysis", NTS Engineering Report No. 1643-01, Prepared for Pacific Gas \& Electric Company, December 1988

Kennedy et al.. 1989a: R.P. Kennedy, B.E. Sarkar and L.S. Cluff, "On Some Aspects of Seismic Fragility Evaluation for Diablo Canyon Seismic PRA", in "Proceedings of Second Symposium on Current Issues Related to Nuclear Power Plant Structures, Equipment, and Piping With Emphasis on Resolution of Seismic Issues in LowSeismicity Regions", EPRI Report NP-6437-D, Electric Power Research Institute, Palo Alto, CA, pp. 3-27 to 3-54, May 1989

Kennedy et al. 1989b: R.P. Kennedy, R.C. Murray, M.K. Ravindra, J.W. Reed, and J.D. Stevenson, "Assessment of Seismic Margin Calculation Methods", Lawrence Livermore National Laboratory for the U.S. Nuclear Regulatory Commission, Report NUREG/CR-5270, 1989

Kipp, Wesley, and Nakaki, 1988: T.R. Kipp, D.A. Wesley and D.K. Nakaki, "Seismic Fragilities of Civil Structures and Equipment Components at the Diablo Canyon Power Plant", NTS Engineering Report No. 1643-02, Prepared for Pacific Gas \& Electric Company, September 1988

LaSalle, 1993: Sandia National Laboratories, "Analysis of the LaSalle Unit 2 Nuclear Power Plant: Risk Methods Integration and Evaluation Program (RMIEP), Internal. Fire Analysis", Report NUREG/CR-4832, for the U.S. Nuclear Regulatory Commission, 1993

Minarick, 1990: J. W. Minarick, "The US NRC Accident Sequence Precursor Program: Present Methods and Findings", Reliability Engineering and Systems Safety, Vol. 27, pp. 23-51, 1990 
Nitzel et al. 1992: M.E. Nitzel, A.G. Ware, and J.D. Page, "Technical Evaluation of Generic Issue 113: Dynamic Qualification and Testing of Large Bore Hydraulic Snubbers", U.S. Nuclear Regulatory Commission, Report NUREG/CR-5416, 1992

NRC, 1975: U.S. Núclear Regulatory Commission, "Reactor Safety Study. An Assessment of Accident Risks in U.S. Commercial Nuclear Power Plants", Report WASH-1400, 1975

NRC, 1982: U.S. Nuclear Regulatory Commission, IE Information Notice No. 82-12, "Surveillance of Hydraulic Snubbers", April 21, 1982

NRC, 1983: U.S. Nuclear Regulatory Commission, "PRA Procedures Guide", Report NUREG/CR-2300, 1983

NRC, 1984a: U.S. Nuclear Regulatory Commission, "PRA Reference Document", Report NUREG-1050, 1984

NRC, 1984b: U.S. Nuclear Regulatory Commission, IE Information Notice No. 84-67, "Recent Snubber Inservice Testing with High Failure Rates", August 17, 1984

NRC, 1985a: U.S. Nuclear Regulatory Commission, "Policy Statement on Severe Accidents", Federal Register, Vol. $\underline{50}$, p. 32138, August 8, 1985

NRC, 1985b: R.J. Budnitz, P.J. Amico, C.A. Cornell, W.J. Hall, R.P. Kennedy, J.W. Reed, and $M$. Shinozuka, "An Approach to the Quantification of Seismic Margins in Nuclear Power Plants", Lawrence Livermore National Laboratory for the U.S. Nuclear Regulatory Commission, Report NUREG/CR-4334, 1985

NRC, 1986: P.G. Prassinos, M.K. Ravindra, and J.B. Savy, "Recommendations to the Nuclear Regulatory Commission on Trial Guidelines for Seismic Margin Reviews of Nuclear Power Plants", Lawrence Livermore National Laboratory for the U.S. Nuclear Regulatory Commission, draft report NUREG/CR-4482, published for comment, 1986

NRC, 1988: U.S. Nuclear Regulatory Commission, Generic Letter 88-20, "Individual Plant Examination for Severe Accident Vulnerabilities", 1988. This Generic Letter is supplemented with additional guidance in Report NUREG-1335, "Individual Plant Examination: Submittal Guidance", 1989

NRC. 1990: U.S. Nuclear Regulatory Commission, "Severe Accident Risks: An Assessment for Five U.S. Nuclear Power Plants", Report NUREG-1150, 1990

NRC, 1991: U.S. Nuclear Regulatory Commission, Generic Letter 88-20, Supplement 4, "Individual Plant Examination for Severe Accident Vulnerabilities Due to External Events", 1991. This Generic Letter is supplemented with additional guidance in Report NUREG-1407, "Procedural and Submittal Guidance for the Individual Plant Examination of External Events (IPEEE) for Severe Accident Vulnerabilities", 1991

NRC, 1992: U.S. Nuclear Regulatory Commission, "Proceedings of an NRC Workshop on the Use of PRA Methodology for the Analysis of Reactor Events and Operational Data", NUREG/CP-0124, 1992 
NRC, 1994: U.S. Nuclear Regulatory Commission, "Event Reporting Guidelines, 10 CFR 50.72 and 50.73", Report NUREG-1022, Revision 1, Second Draft, February 1994

Ravindra et al. 1987: M.K. Ravindra, G.S. Hardy, P.S. Hashimoto, and M.J. Griffin, "Seismic Margin Review of the Maine Yankee Atomic Power Station", Report NUREG/CR-4826, Vol 3, Prepared for U.S. Nuclear Regulatory Commission by EQE Engineering, Costa Mesa, CA, 1987

Ravindra, 1988: M.K. Ravindra, "Seismic Probabilistic Risk Assessment and Its Impact on Margin Studies", Nuclear Engineering and Design, 107, 51-59, 1988

Ravindra and Kennedy. 1983: M.K. Ravindra and R.P. Kennedy, "Lessons Learned from Seismic PRA Studies", Paper M6/4, in Proceedings of the Seventh Conference on Structural Mechanics in Reactor Technology, Chicago, Illinois, 1983

Reed and Kennedy, 1994: J.W. Reed and R.P. Kennedy, "Methodology for Developing Seismic Fragilities," EPRI TR-103959, Project 2722-23, prepared for Electric Power Research Institute, Palo Alto, California, 1994

Sattison et al. 1995: M.B. Sattison, T.A. Thatcher, J.K. Knudsen, J.A. Schroeder, and N.O. Siu, Lockheed Martin Idaho Technologies, Idaho National Engineering Laboratory, "Advanced Accident Sequence Precursor Analysis, Level 1 Models", paper presented at Twenty-Third U.S. NRC Water Reactor Safety Information Meeting, Bethesda, Maryland, October 1995

Savy et al. 1993: J. B. Savy, A. C. Boissonnade, R.W. Mensing, and C.M. Short, "Eastern U.S. Seismic Characterization Update", Report UCID-115111, Lawrence Livermore National Laboratory for the U.S. Nuclear Regulatory Commission, June 1993

Sobel, 1993: P. Sobel, "Revised Livermore Seismic Hazard Estimates for 69 Nuclear Power Plant Sites East of the Rocky Mountains" (draft), NUREG-1488, U.S. Nuclear Regulatory Commission, 1993

VEPCO, 1984: Virginia Electric Power Company, Surry Power Station Unit 1, Licensee Event Report LER-84-006, April 16, 1984

Wheelis, 1986: W. T. Wheelis, "Users' Guide for a Personal-Computer-Based Nuclear Power Plant Fire Data Base", NUREG/CR-4586, Sandia National Laboratories for the U.S. Nuclear Regulatory Commission, Albuquerque, NM, 1986 


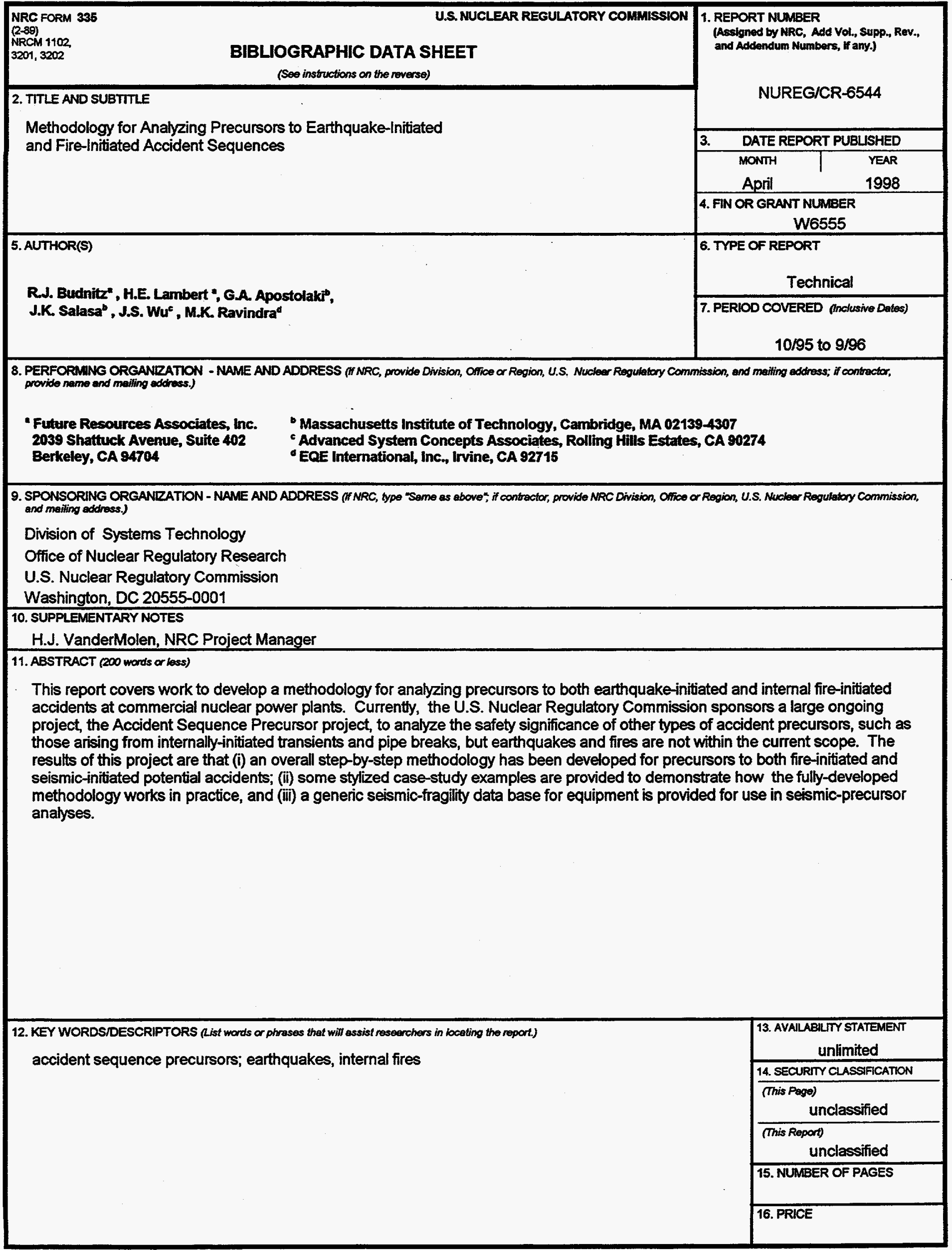

